\title{
A CUSTOMER VALUE ASSESSMENT PROCESS FOR BALLISTIC MISSILE DEFENSE
}

\author{
A Thesis \\ presented to \\ the Faculty of California Polytechnic State University, \\ San Luis Obispo
}

\author{
In Partial Fulfillment \\ Of the Requirements for the Degree \\ Master of Science in Aerospace Engineering
}

By

Alex Hernandez

June 2015 
(C) 2015

Alex Hernandez

ALL RIGHTS RESERVED 
TITLE:

AUTHOR:

DATE SUBMITTED: June 2015

COMMITTEE CHAIR: $\quad$ Dr. Dianne J. DeTurris, Ph.D., Professor Aerospace Engineering Department California Polytechnic State University, San Luis Obispo

COMMITTEE MEMBER: $\quad$ Dr. Kurt Colvin, Ph.D., Professor Aerospace Engineering Department California Polytechnic State University, San Luis Obispo

COMMITTEE MEMBER: Dr. Ahmed M. Deif, Ph.D., Assistant Professor Industrial Technology Department California Polytechnic State University, San Luis Obispo

COMMITTEE MEMBER: Arthur T. Stevens, MBA, Industry Advisor Lockheed Martin Space Systems Company Sunnyvale, CA 


\begin{abstract}
A Customer Value Assessment Process for Ballistic Missile Defense
\end{abstract}

Alex Hernandez

A systematic customer value assessment process (CVAP) was developed to give system engineering teams the capability to qualitatively and quantitatively assess customer values. It also provides processes and techniques used to create and identify alternatives, evaluate alternatives in terms of effectiveness, cost, and risk. The ultimate goal is to provide customers (or decision makers) with objective and traceable procurement recommendations. The creation of CVAP was driven by an industry need to provide ballistic missile defense (BMD) customers with a value proposition of contractors' BMD systems. The information that outputs from CVAP can be used to guide BMD contractors in formulating a value proposition, which is used to steer customers to procure their BMD system(s) instead of competing system(s). The outputs from CVAP also illuminate areas where systems can be improved to stay relevant with customer values by identifying capability gaps. CVAP incorporates proven approaches and techniques appropriate for military applications. However, CVAP is adaptable and may be applied to business, engineering, and even personal every-day decision problems and opportunities.

CVAP is based on the systems decision process (SDP) developed by Gregory S. Parnell and other systems engineering faculty at the Unites States Military Academy (USMA). SDP combines Value-Focused Thinking (VFT) decision analysis philosophy with Multi-Objective Decision Analysis (MODA) quantitative analysis of alternatives. CVAP improves SDP's qualitative value model by implementing Quality Function Deployment (QFD), solution design implements creative problem solving techniques, and the qualitative value model by adding cost analysis and risk assessment processes practiced by the U.S DoD and industry. CVAP and SDP fundamentally differ from other decision making approaches, like the Analytic Hierarchy Process (AHP) and the Technique for Order of Preference by Similarity to Ideal Solution (TOPSIS), by distinctly separating the value/utility function assessment process with the ranking of alternatives. This explicit value assessment allows for straightforward traceability of the specific factors that influence decisions, which illuminates the tradeoffs involved in making decisions with multiple objectives. CVAP is intended to be a decision support tool with the ultimate purpose of helping decision makers attain the best solution and understanding the differences between the alternatives. CVAP does not include any processes for implementation of the alternative that the customer selects.

CVAP is applied to ballistic missile defense (BMD) to give contractors ideas on how to use it. An introduction of BMD, unique BMD challenges, and how CVAP can improve the BMD decision making process is presented. Each phase of CVAP is applied to the BMD decision environment. CVAP is applied to a fictitious BMD example. 


\section{TABLE OF CONTENTS}

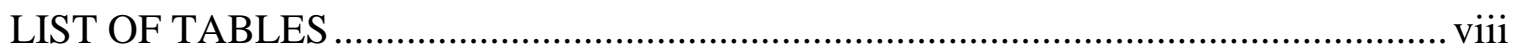

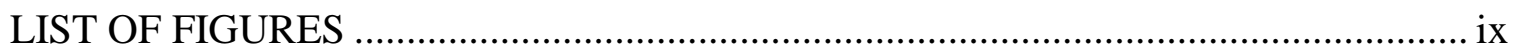

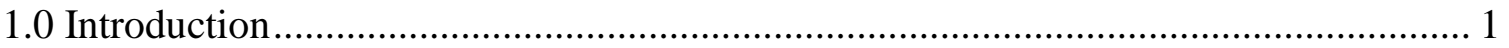

1.1 Motivation for a New Approach ……………….............................................. 1

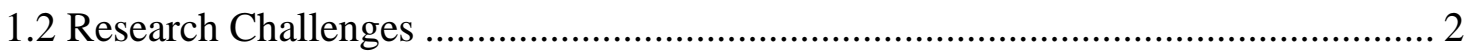

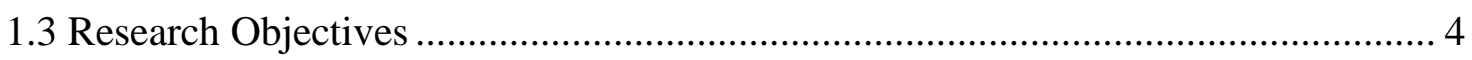

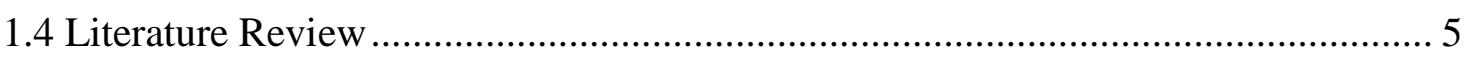

2.0 Survey and Comparisons of Decision Analysis Processes ........................................ 13

2.1 Decision Analysis from a Systems Engineering Perspective ................................... 13

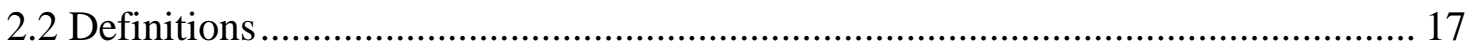

2.3 Survey of Decision Analysis Processes ........................................................... 18

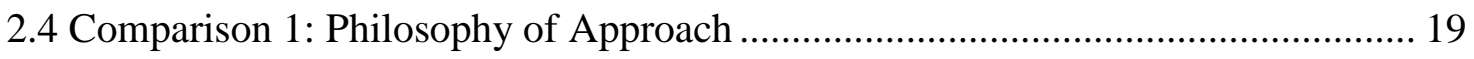

2.5 Comparison 2: Quantitative Prioritization Methods …………………………..... 22

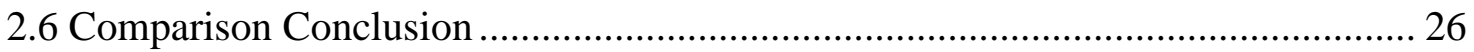

3.0 The Customer Value Assessment Process (CVAP) Methodology .............................. 27

3.1 Use of Analysis of Alternatives (AoA) and Systems Decision Process (SDP) ...... 27

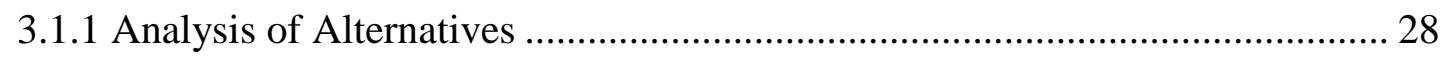

3.1.2 Systems Decision Process (SDP) ................................................................. 35

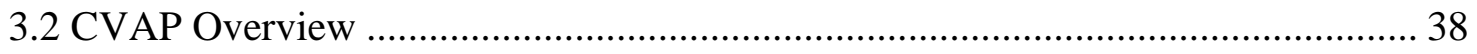

3.3 CVAP Phase 1: Qualitative Value Model ............................................................... 41

3.3.1 Problem Definition ..................................................................................... 44

3.3.1.1 Stakeholder Analysis ............................................................................. 45

3.3.1.2 Problem Definition Techniques ........................................................... 50

3.3.2 Quality Function Deployment (QFD)............................................................ 53

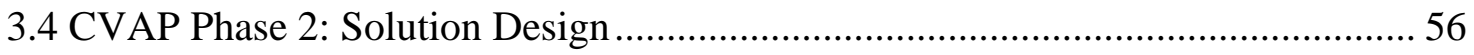

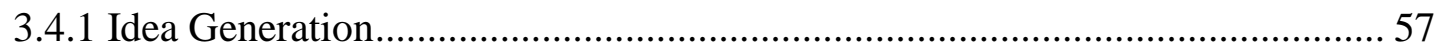

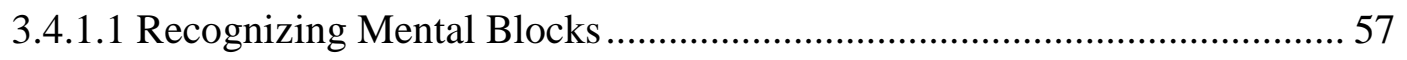

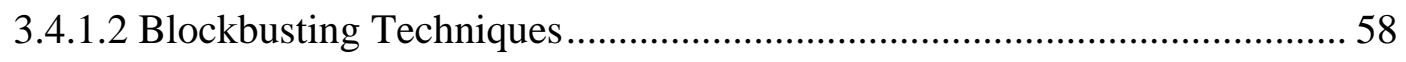

3.4.1.2.1 Emotional Blockbusting: Fear of Taking Risks................................. 59

3.4.1.2.2 Perceptual Blockbusting: Brainstorming …………………………..... 61

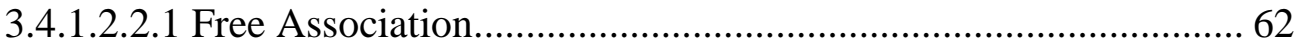




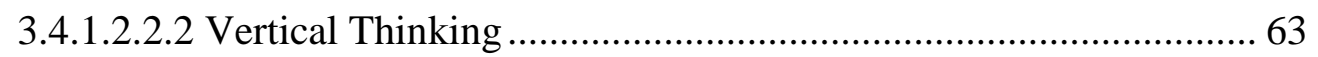

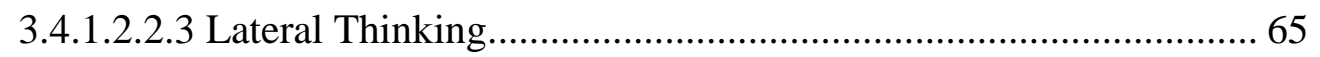

3.4.1.2.3 Perceptual Blockbusting: Cross-Disciplinary Solutions ..................... 66

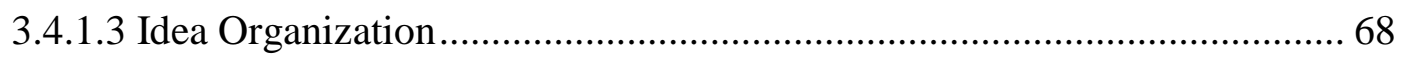

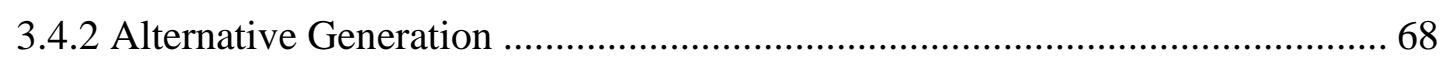

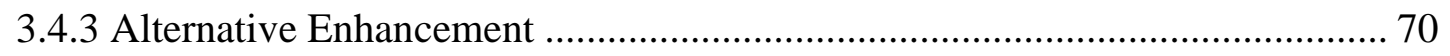

3.5 CVAP Phase 3: Quantitative Value Model ...................................................... 72

3.5.1 Effectiveness Analysis .................................................................................. 72

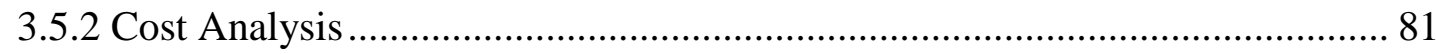

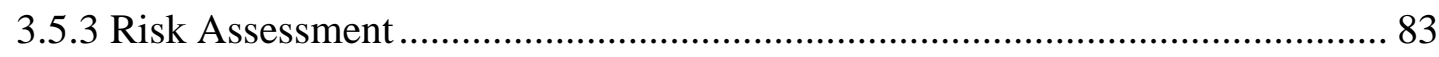

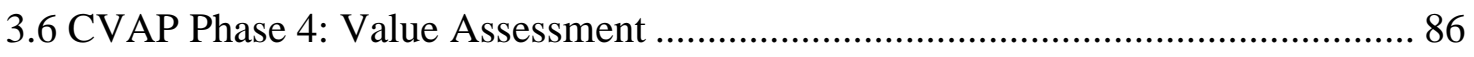

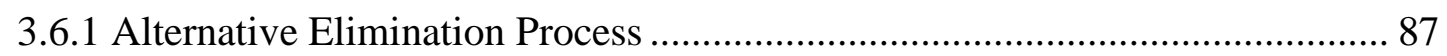

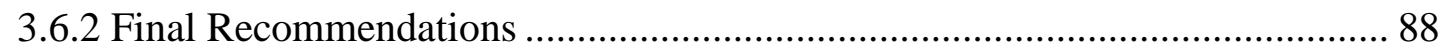

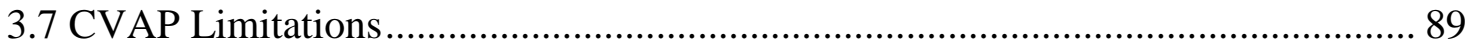

4.0 Ballistic Missile Defense (BMD) Customization ..................................................... 91

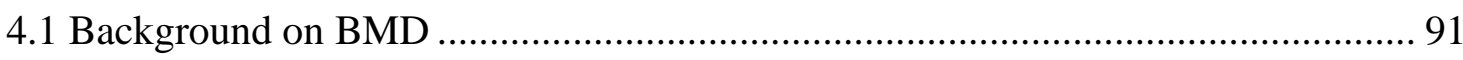

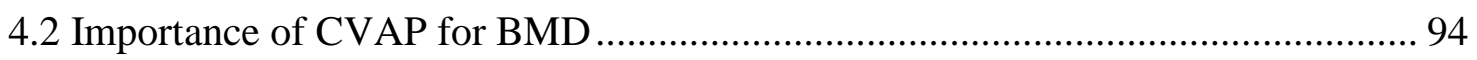

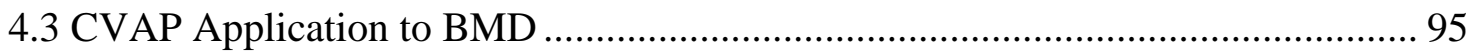

4.3.1 CVAP Phase 1: BMD Qualitative Value Model .............................................. 95

4.3.2 CVAP Phase 2: BMD Solution Design ........................................................ 100

4.3.3 CVAP Phase 3: BMD Quantitative Value Model ............................................ 104

4.3.4 CVAP Phase 4: BMD Value Assessment........................................................ 106

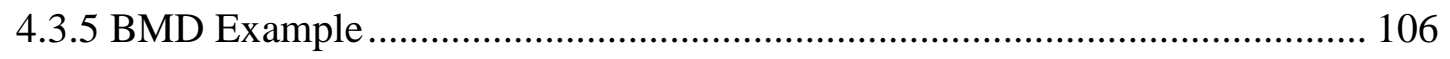

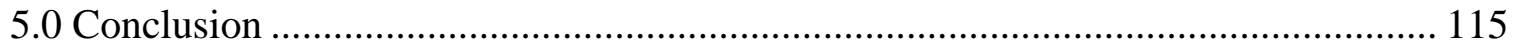

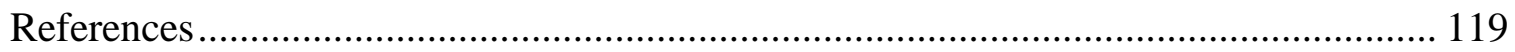

APPENDICES

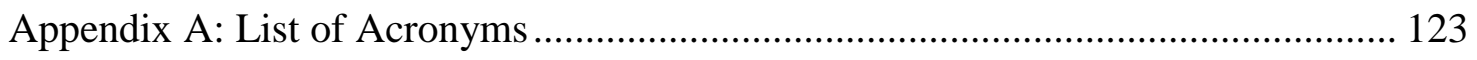

Appendix B: AHP Methodology and Example...................................................... 125

Appendix C: TOPSIS Methodology and Example ………...................................... 132

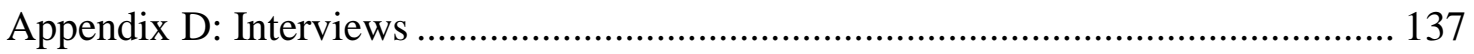

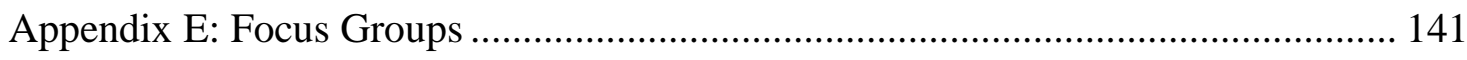

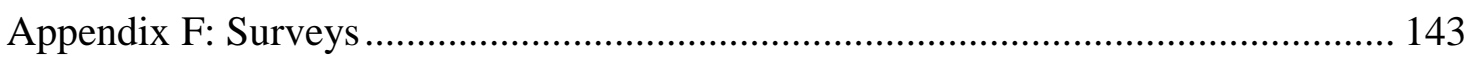




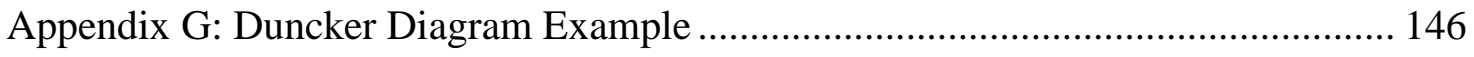

Appendix H: Statement-Restatement Example....................................................... 147

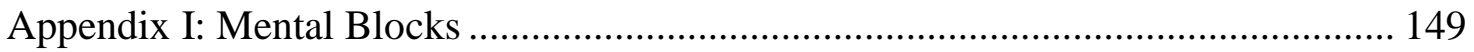

Appendix J: 77 Design Heuristic Cards ............................................................... 153

Appendix K: TRIZ Tables and Example............................................................ 155

Appendix L: Fish Diagram Example ............................................................... 159

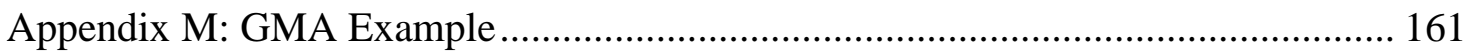

Appendix N: Exponential Constant Methodology ....................................................... 162

Appendix O: Swing Weights Method ................................................................... 165

Appendix P: Cost Analysis Tasks and LCC Estimation Process .................................. 167

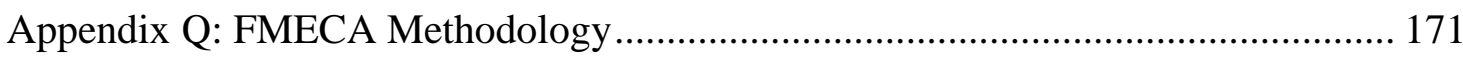

Appendix R: AoA Report Template................................................................... 173 


\section{LIST OF TABLES}

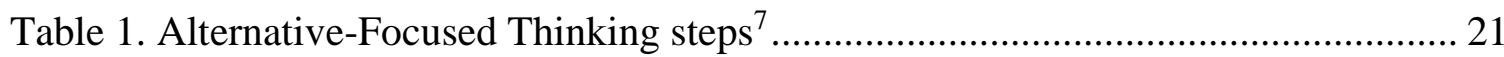

Table 2. Value-Focused Thinking steps ${ }^{7}$.................................................................... 21

Table 3. Comparison of Problem-Solving Processes ${ }^{3}$................................................ 38

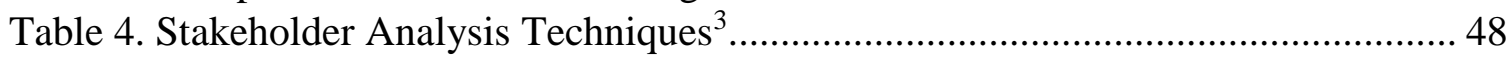

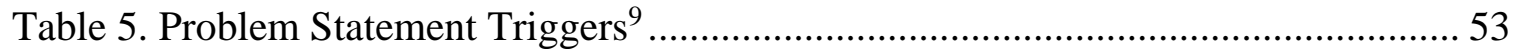

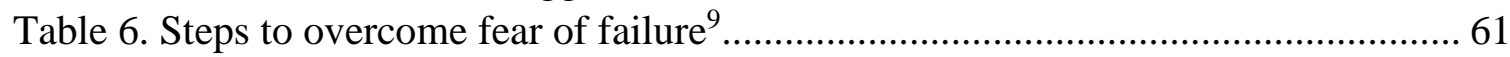

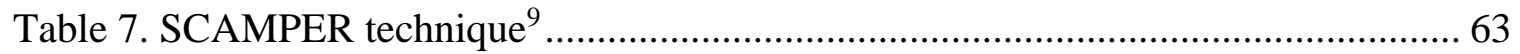

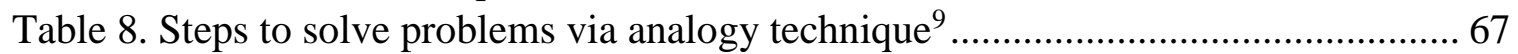

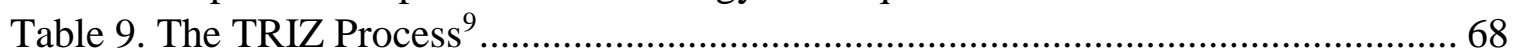

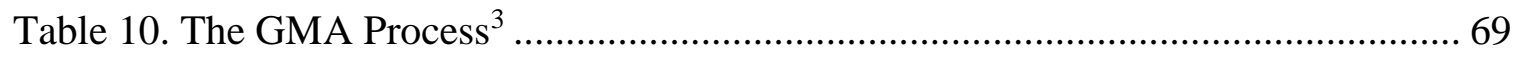

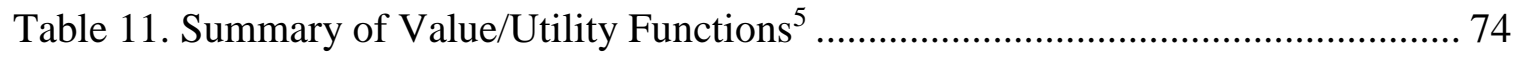

Table 12. Value/Utility Model Assumptions ${ }^{5}$................................................................. 75

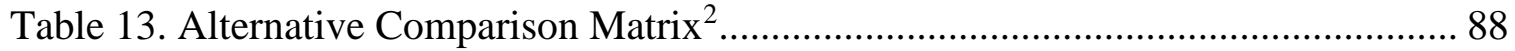

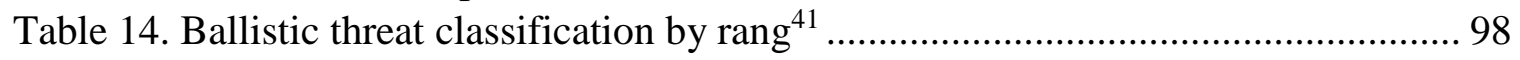

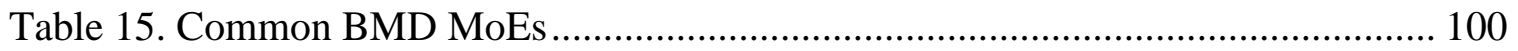

Table 16. Examples of U.S. BMD weapon systems ................................................ 103

Table 17. Examples of U.S. off-board sensors ........................................................... 103

Table 18. Probability of kill scores and respective single-dimensional values .............. 112

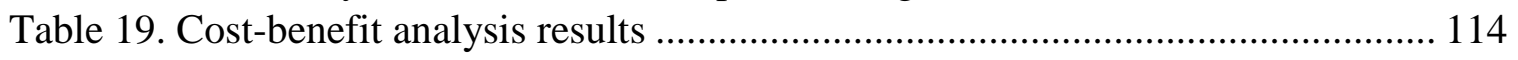

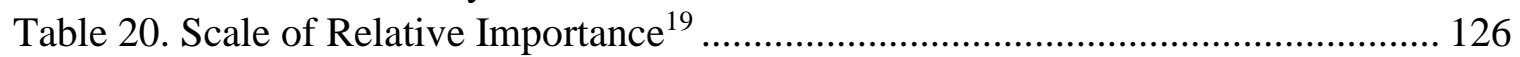

Table 21. RI values for different values of $\mathrm{N}$ (number of alternatives) ${ }^{19}$...................... 129

Table 22. Advantages and Disadvantages of Common Survey Methods ${ }^{3}$..................... 143

Table 23. Complied list of Design Heuristics ${ }^{28}$........................................................... 153

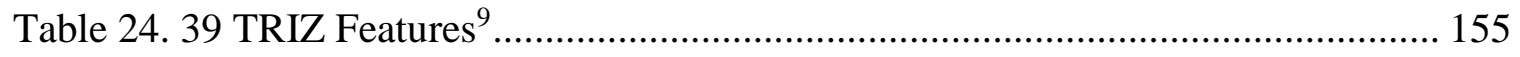

Table 25. Altshuller's 40 Principles of TRIZ ${ }^{9}$............................................................. 155

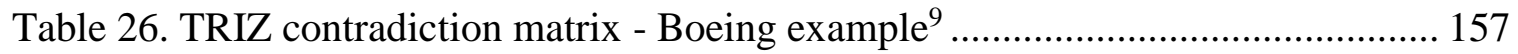

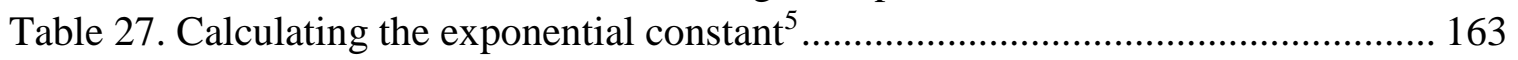

Table 28. The Twelve Steps of a High-Quality Cost Estimating Process ${ }^{24}$................... 168 


\section{LIST OF FIGURES}

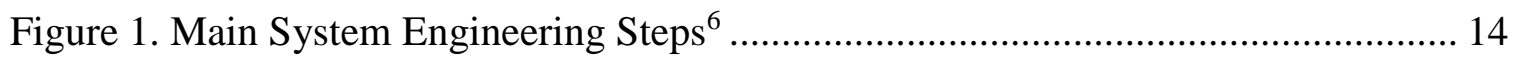

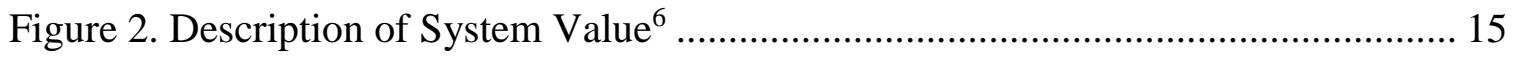

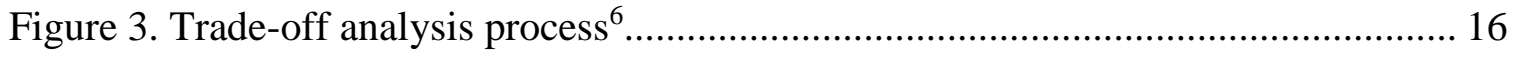

Figure 4. Philosophy of approach and quantitative models ........................................... 19

Figure 5. Benefits of Value-Focused Thinking ${ }^{7}$......................................................... 22

Figure 6. DoD Acquisition System framework ${ }^{23}$.......................................................... 29

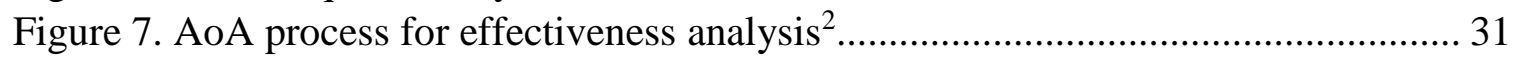

Figure 8. General Life Cycle Cost Summary ${ }^{2}$.............................................................. 33

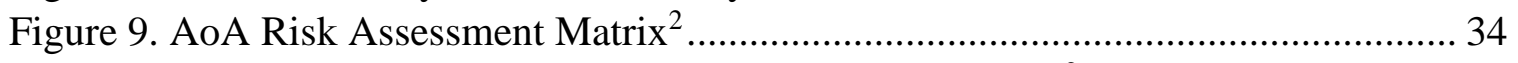

Figure 10. Notional Matrix for Alternative Comparison Results ${ }^{2}$.................................. 35

Figure 11. A simplified version of the Systems Decision Process ${ }^{3}$............................... 37

Figure 12. The Customer Value Assessment Process (CVAP) ....................................... 40

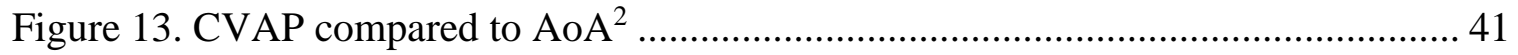

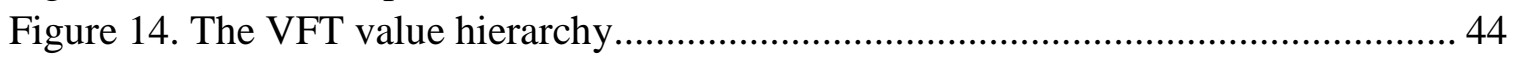

Figure 15. CVAP steps to define the VFT value hierarchy .......................................... 44

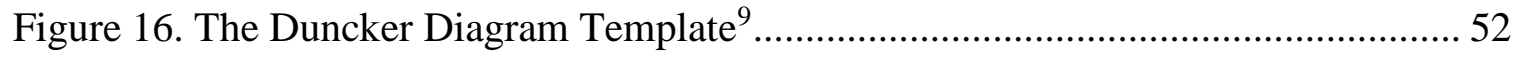

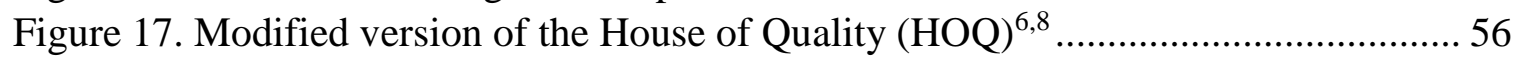

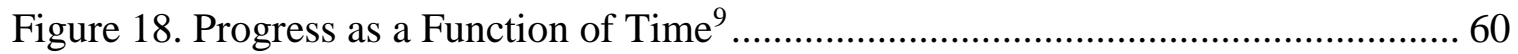

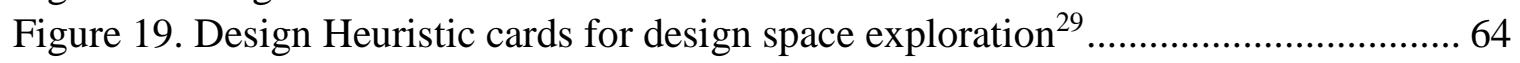

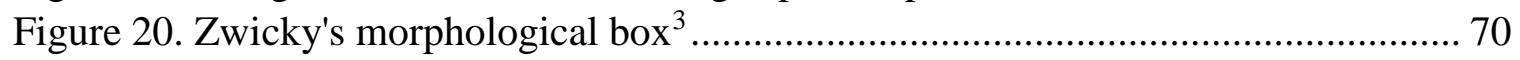

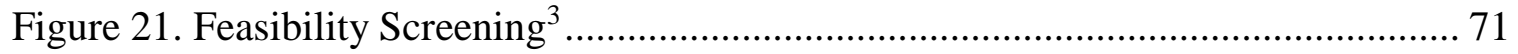

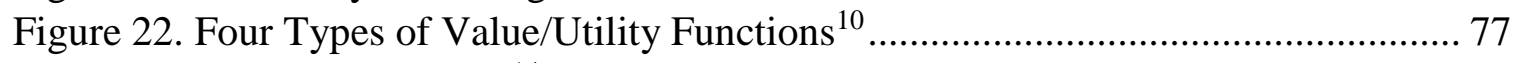

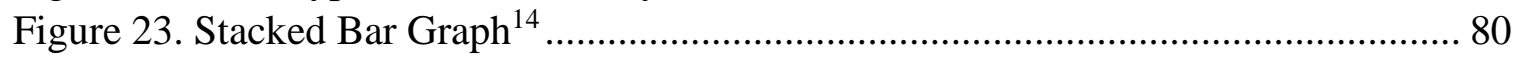

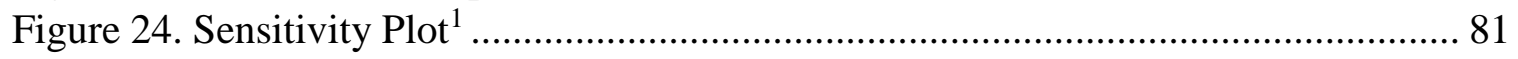

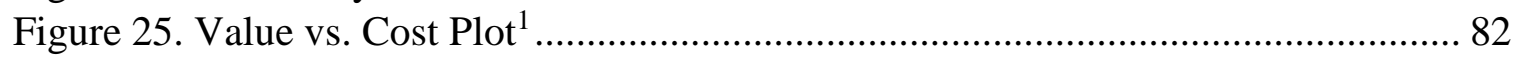

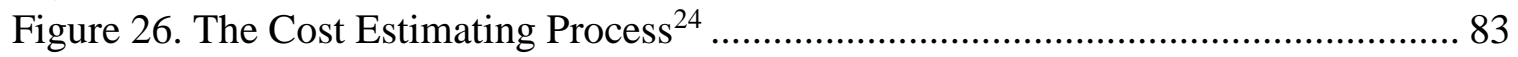

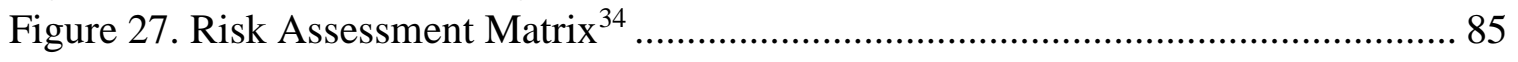

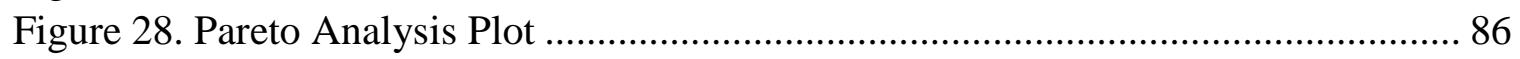

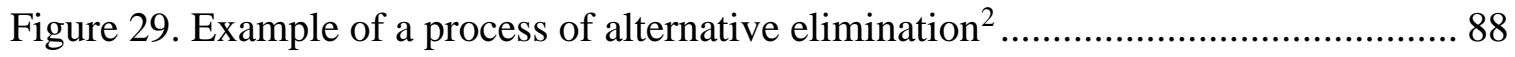

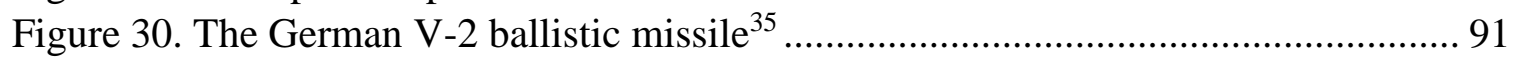

Figure 31. Missile proliferation outside the U.S. in 1972 (source: MDA $^{38}$ ) ................... 92

Figure 32. Missile Proliferation outside the U.S. in 2004 (source: MDA $^{38}$ ) .................... 93

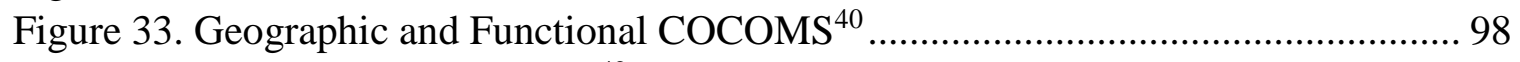

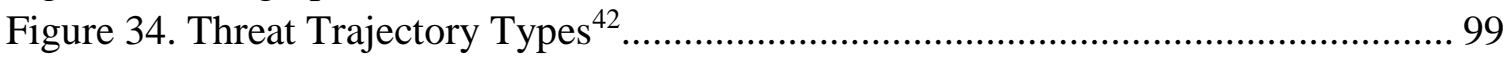

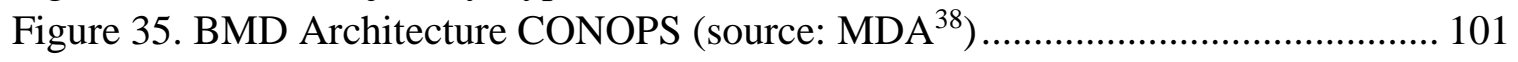

Figure 36. BMD element categorization by phase of interception ............................... 102

Figure 37. Example of Architecture Solution ${ }^{45}$.......................................................... 104

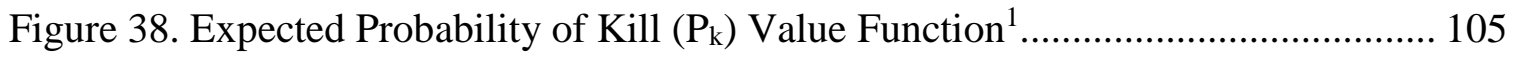

Figure 39. Fictitious scenario geography ................................................................ 108

Figure 40. Probability of kill contour plot for Alternative 1 and Alternative 2 ............. 110

Figure 41. Single-dimensional value function for probability of kill ........................... 111 
Figure 42. Stacked bar graph illustrating ranking of alternatives ............................... 113

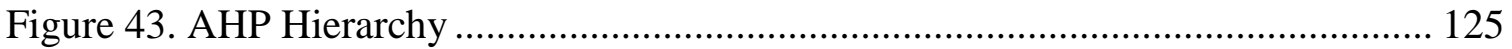

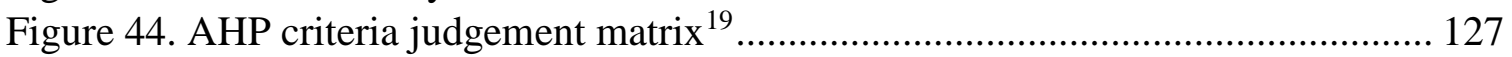

Figure 45. AHP alternative judgement matrices ${ }^{19}$.................................................... 128

Figure 46. Image of the table used to display the final priority of alternatives ${ }^{16} \ldots \ldots \ldots . . .130$

Figure 47. AHP numerical example of criteria judgement matrix ${ }^{20} \ldots \ldots \ldots \ldots \ldots \ldots \ldots \ldots \ldots . . . . . . . . . . . . . . . .130$

Figure 48. AHP Numerical example of alternatives' score matrice ${ }^{20}$......................... 131

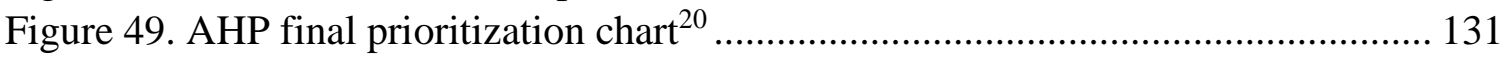

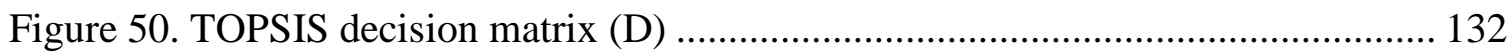

Figure 51. Decision matrix for TOPSIS numerical example....................................... 134

Figure 52. Normalized decision matrix for TOPSIS numerical example...................... 134

Figure 53. Weighted normalized decision matrix for TOPSIS numerical example ....... 135

Figure 54. Positive and negative ideal solutions for TOPSIS numerical example ........ 135

Figure 55. Separation measures for TOPSIS numerical example................................ 135

Figure 56. Relative closeness of alternatives for TOPSIS numerical example ............. 135

Figure 57. Final priority vector for TOPSIS numerical example ................................ 135

Figure 58. Duncker Diagram of detergent example ${ }^{9}$................................................... 146

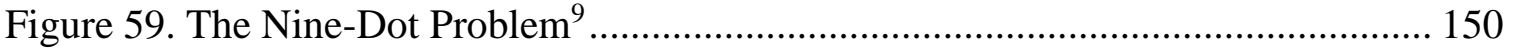

Figure 60. Nine-Dot Problem: four-line solution ${ }^{9}$........................................................ 150

Figure 61. Nine-Dot Problem: three-line solution ${ }^{9}$..................................................... 150

Figure 62. Playground Equipment Fishbone Diagram ${ }^{9}$................................................ 160

Figure 63. Morphological box and alternative generation table for rocket example ${ }^{3} \ldots 161$

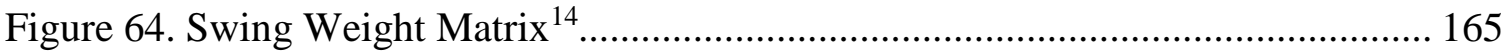




\subsection{Introduction}

Ballistic Missile Defense (BMD) contractors have sales opportunities in domestic and international markets. Therefore, they compete to develop and sell systems. In order to be successful, they need to identify their customer's values and how their weapon systems are relevant to those values. A discussion of the motivation behind this research, the major challenges that decision support tools need to overcome, and the objectives of this research are provided. A literature review of the most applicable sources to the creation of the Customer Value Assessment Process (CVAP) is also included.

\subsection{Motivation for a New Approach}

The creation of the Customer Value Assessment Process (CVAP) was motivated by a U.S. BMD industry need. A major goal of BMD contractors is to sell their systems in domestic and international markets. In order to be successful in sales, contractors need to define their systems' "value proposition" and use it to formulate a business strategy. However, every customer has different values (i.e., needs, wants, and desires), resulting in a completely different business strategy. Following a process to define value propositions will benefit contractors in explaining to customers why they should buy systems from them in an organized and credible manner. Following a process also allows for an efficient use of resources allocated for defining value propositions. Research was conducted to identify potential processes that may be used to derive customer value proposition, however, all were either inadequate for complex military decision making or do not provide enough guidance on how to apply them. Therefore, a new approach was taken with CVAP to provide a more detailed process adequate for complex military decision making. 


\subsection{Research Challenges}

In order for the process to be adequate for military applications like BMD, it needs to overcome various challenges. These challenges are summarized by the following:

\section{Challenge \#1: The process is objective $\mathrm{e}^{1}$}

Objective means that the process needs to (1) provide recommendations to customers (or decision makers) based on values (needs, wants, and desires) while minimizing sources of bias and (2) be capable of using raw technical data obtained from experiments and/or modeling and simulations. ${ }^{2}$

Final recommendations to the decision makers need to be based off of objective tradeoffs that differentiate the potential solutions (alternatives). Hence, evaluating alternatives should be based on effectiveness, cost, and risk criteria and assessed via tradeoffs that are relevant to decision makers' and stakeholders' values. However, there are many types of stakeholders involved in military decisions, each of which care about different factors. In order to minimize bias from values, all influential factors should to be addressed. These factors include: technologic, economic, political, legal, social, security, natural environment, cultural, historical, moral/ethical, organizational, and emotional. ${ }^{3}$

In order to be objective in military applications, the process needs to quantitatively evaluate alternatives based on criteria derived directly from the decision makers. For military applications, the evaluation criteria often emphasizes effectiveness/performance, thus, the measures (or metrics) in the criteria should represent raw quantities obtained by credible methods (e.g., experiments and/or modeling and simulation) when feasible. ${ }^{2}$ Obtaining these quantities from mathematical transformations (e.g., normalization) reduce the information content. The same goes for measures defined as ratios. ${ }^{2}$ (e.g., cost/kill). 
The United States Government (USG) uses the DoD 5000.02 process to make objective military decisions. In particular, the process within the DoD 5000.02 process that recommends a system to be acquired is the Analysis of Alternatives (AoA). "An AoA is an analytical comparison of the effectiveness, cost, and risks of proposed solutions to gaps and shortfalls in operational capability. AoAs document the rationale for identifying and recommending a preferred solution or solutions to the identified shortfall(s)." 2 The USG is not constrained to the DoD 5000.02 process and can move outside the process when deemed appropriate for business needs. ${ }^{4}$ However, it is noticeable to BMD contractor employees that the Missile Defense Agency (MDA) opts to try and follow the 5000.02 process as much as possible.

It is important to note that customers will not always choose the best solution that output from objective processes. This is due to psychological factors that are described by prospect theory. However, it is still important to know the objective solution when making decisions. The objective solution can point the customer in the direction of the better alternatives. This thesis does not take into account psychological factors in decision making and only researches expected utility theory.

\section{Challenge \#2: The process is traceable ${ }^{1}$}

Traceable means that all analysis performed within the process (e.g., ranking alternatives) can be traced back to decision maker values in a straightforward manner. This can be achieved by separating decision maker values from the scoring of alternatives, making it easy to determine whether inconsistencies are due to decision maker and stakeholder values or the estimated effectiveness, cost, or risk of the alternatives. This separation aids in tracing the reasoning behind a particular ranking of alternatives and also provides a clear audit trail in the case that final recommendations get questioned. "The 
more straightforward and clearly told the story, the easier it becomes to understand the differences among the alternatives."2

Challenge \#3: The process output minimizes sensitivity to change in inputs ${ }^{1}$

The outputs of the process should withstand changes from adverse conditions in the

inputs. In order for recommendations made from the outputs of the process to hold significance, they should not change significantly if there are small changes to the alternative scores or amount of inputs. For example, the ranking of alternatives (prioritization) and their values to the customer should not change significantly if the count of alternatives or Measures of Effectiveness (MoEs) that are analyzed change. There are many quantitative prioritization models that are convenient and relatively easy to use, however, they are sensitive to changes in input.

\subsection{Research Objectives}

The objectives of this thesis are to develop an expected utility theory process adequate for military applications (e.g., BMD) and to overcome the challenges involved:

Objective 1: Qualitatively and quantitatively model customer value proposition

The main objective of this thesis is to formulate a general systematic customer value assessment process (CVAP) that qualitatively obtains customer (or decision maker) values and uses them to quantitatively evaluate potential solutions (alternatives). Since the motivation for a new approach arose from a BMD industry need, CVAP was designed to overcome the military application challenges discussed in section 1.2.

CVAP can help BMD contractors understand their customers' perceptions of system alternatives and their inclination to procure them. The output from CVAP can be used by BMD contractors to gain insight on what a particular customer really values. When alternatives are quantitatively evaluated, the output illuminates advantages and 
disadvantages of the alternatives under consideration in terms of effectiveness, cost, and risk. If a contractor knows the values of their customer and where their product lies in comparison to the other alternatives, the contractor can formulate a business plan that may steer the customer to procure their weapon system instead of a competing system.

The output data of the model may also be used to identify capability gaps in a contractor's weapon system, highlighting areas that can be improved to stay relevant with the needs of the customer. For example, if the contractor's system doesn't meet customer values for interceptor range, the contractor will know that they need to improve their weapon system's interceptor range capability if they want to stay relevant and sell systems.

Objective 2: Provide general BMD value proposition guidelines

Another objective of this thesis is to provide a section that discusses the general BMD decision environment. Currently, there isn't a publically available source that discusses the process by which BMD systems are procured and the unique challenges that are involved). BMD decision environment considerations, key stakeholders, identification of the main weapon system measures of effectiveness, and BMD solutions of value to general BMD customers will be investigated.

\subsection{Literature Review}

The formulation of CVAP referenced sources in systems engineering, decision analysis, Quality Function Deployment, and creative problem solving. The literature review begins with reviews of chapters in two systems engineering textbooks that combine general systems engineering knowledge, Value-Focused Thinking (VFT), and MultiObjective Decision Analysis (MODA). The four reviews that follow are specific sources used for VFT, MODA, QFD, and creative problem-solving techniques. A survey of journal 
articles is presented at the end to show that MODA and VFT have successfully been applied to real applications.

\section{Decision Making in Systems Engineering Management ${ }^{3}$}

Decision Making in Systems Engineering Management is a general systems engineering textbook that focuses on decision analysis. Gregory S. Parnell, Ph.D. and Paul D. West, Ph.D. wrote the sections on the Systems Decision Process, which can be applied to any systems engineering decision problem at any point in the life-cycle. Chapter 9 discusses and overview of SDP, which includes the problem definition phase, solution design phase, the decision making phase, and the implementation phase. Chapter 9 also includes discussions on the use of value-focused thinking (VFT) compared to alternativefocused thinking (AFT), alternative generation techniques, and mathematical models used to objectively assess the value of alternatives (MODA). Parnell combined the VFT approach to decision making with MODA quantitative models to evaluate alternatives. The core of CVAP is based on SDP, which combines VFT with MODA.

\section{Systems Engineering and Analysis ${ }^{6}$}

Benjamin S. Blanchard is a professor of Industrial and Systems Engineering at Virginia Polytechnic Institute and State University. Blanchard wrote Systems Engineering and Analysis to be a general systems engineering textbook that emphasizes the overall classical process of bringing systems into being. He marches through a system life-cycle by beginning with the identification of a need and extending through determination of requirements, functional analysis, synthesis and evaluation, validation, operation and support, and ending with disposal. Chapter 7 of this book was used to follow a high-level systems engineering approach in the development of CVAP, following the iterative process 
of analysis, synthesis, and evaluation. This chapter focuses on alternatives, models, decision theory, multiple criteria, and risk and uncertainty. This book also includes discussions on the use of Decision Making, Quality Function Deployment (QFD), Lifecycle Cost Analysis, and Risk and Uncertainty Analysis.

Value-Focused Thinking: A Pathway to Creative Decision Making ${ }^{7}$

Ralph L. Keeney is a private consultant and professor of System Management at University of Southern California. Keeney wrote Value-Focused Thinking to argue that emphasis should be on the bottom-line objectives that gives decision making its meaning, for it is through recognizing and articulating fundamental values that create better decision alternatives. This book shows how one should think about decision situations. Most literature on decision making focuses on what should be done after the crucial steps of defining the actual decision problem, creating alternatives, and specifying objectives. This book describes and illustrates the creative processes that should be followed to identify decision problems, create alternatives, and articulate objectives. This is the philosophical approach to decision making that CVAP is based on.

\section{Strategic Decision Making: Multi-objective Decision Analysis with Spreadsheets ${ }^{5}$}

Craig Kirkwood presents methods for quantitatively evaluating alternatives and strategically making decisions using multi-objective decision analysis (MODA). Kirkwood also discusses the mathematical theory behind MODA models, Multi-Attribute Utility Theory (MAUT). The focus is on decisions where there are multiple competing objectives that require consideration of tradeoffs among these objectives. The techniques presented in this book have been successfully used in a number of military studies for over forty years and have demonstrated the capability to improve decision making. 


\section{Quality Function Deployment: How to Make QFD Work for You ${ }^{8}$}

Lou Cohen is a recognized expert in the field and has plenty of experience in QFD applications. This easy-to-read book does an excellent job at explaining on how to go about doing QFD. Over the past 40 years, companies in the United States have changed their style of conducting business due to overseas competitive pressures, the needs of global economics, and the advances in technology. QFD was adopted as a result of this change in paradigm. Cohen provides motivation for the use of QFD and puts it in a global business environment perspective. It explains in detail a main component of the QFD technique, the House of Quality (HOQ). Cohen also discusses how QFD can help organizations become more competitive by developing better products and services. A handbook is included inside that shows how to start using QFD, what to anticipate, and how to finish successfully. CVAP uses QFD as a process to define and organize my qualitative value model.

\section{$\underline{\text { Strategies for Creative Problem Solving }}{ }^{9}$}

This book provides a framework that was developed with the aid of a major grant from the National Science Foundation that improves creative problem-solving skills. It was awarded the Distinguished Author Award by the American Society for Engineering Education (ASEE). The techniques presented in the book were developed by researching and studying how experienced engineers and managers in industry approached solving problems. It does this by providing ways to combine the knowledge needed to understand the problem and develop technical solutions with creativity that generates new and innovative solutions. The book highlights on the skills necessary for effective problem solving, how to gather information, how to properly define the real problem, how to 
generate creative and innovative solutions, and methods for solution evaluation. I use the methods presented in this book to develop my problem definition step and solution design step in CVAP.

\section{Applications of VFT and MODA}

The following articles describe validated applications of MODA and VFT, some of which are military and some not. Only the Multi-Objective Decision Analysis of Theater Missile Defense (TMD) Architecture ${ }^{l}$ article refers specifically to BMD.

\section{A Methodology to Assess the Utility of Future Space Systems ${ }^{10}$}

USAF Captain Bruce Rayno, a student of Gregory Parnell, wrote a thesis on a modified methodology that assess the utility of future space systems. His research identifies the assumptions and simplifications in the SPACECAST 2020 value model and assesses modifications. The model determines and prioritizes future space systems' utility toward controlling and exploiting space. This study shows that the assumptions of using a multiobjective decision analysis (MODA) additive utility function is valid. Rayno does this by comparing the results of the additive utility function to the multiplicative and multi-linear utility functions. Rayno also made modifications to the 98 SPACECAST 2020 measures of merit scoring functions by replacing most of the initial functions with either a concave, convex, linear, or "S" scoring function. The modified scoring functions and alternate utility functions did not alter the SPACECAST 2020 results, but did improve upon the model. When making his modifications to the SPACECAST model, Rayno applied concepts from Kirkwood's book “Strategic Decision Making”. 
Multi-Objective Decision Analysis of Theater Missile Defense (TMD) Architecture ${ }^{I}$

Parnell, Metzger, Merrick, and Eilers developed an architecture analysis methodology that uses Multi-objective Decision Analysis (MODA) to maximize the value of the TMD architecture subject to life cycle budget constraints. They used the Joint Doctrine, the Mission Need Statement, and the Operational Requirements Document to qualitatively define the value of each potential TMD architecture. They used decision trees to determine the best TMD targeting strategies. Finally, they used optimization to determine optimal architectures and missile procurement levels for given life cycle (R\&D and procurement) budget constraints. They then developed a demonstration model that illustrates the methodology to TMD architecture decision makers. It served as a starting point for the research conducted because it is the most relevant application of decision analysis to BMD. The research intends to expand and extend this demonstration model into a better defined process that is customized to BMD.

A Multiple-Objective Decision Analysis of Stakeholder Values to Identify Watershed Improvement Needs ${ }^{11}$

Merrick, Parnell, Barnett, and Garcia demonstrated the use of VFT and MODA to guide future watershed quality improvement projects. They developed a qualitative value model of stakeholder values and a quantitative value model with single-dimensional value functions of the Measures of Effectiveness (MoEs) of greatest importance. After weightings for the MoEs and single-dimensional values were determined, they were applied to the additive value model. The results were used to rank alternatives based on their MoE performance and to identify value gaps of each alternative. The value gaps were used to leverage areas that watershed improvement projects can focus on. The results of the analysis were used to guide restoration efforts. 
Alternative Resource Allocation Techniques ${ }^{12}$

Stokes, Parnell, Klimack, and McGinnis performed a survey of resource allocation techniques appropriate for the United States Army: Relative Benefit Technique, Partial Funding Relative Benefit Technique, Multiple Objective - Additive Value Technique (MODA), Partial Funding Relative Pain Technique, and Partial Funding Measure Pain Technique. Based on interviews with U.S. Army clients, the techniques were evaluated based on how well they performed in providing the optimal solution, how responsive they were to preference changes, and how defensible they were. They concluded that VFT allowed MODA to output the optimal solution, the additive value model allowed for quick changes in preference, and that MODA allowed the most credible, objective, and traceable rationale for resource allocation.

\section{Mission Oriented Risk and Design Analysis of Critical Information Systems ${ }^{13}$}

Buckshaw, Parnell, Unkenholz, Parks, Wallner, and Saydjari wrote this paper that describes a value-based information assurance methodology for Mission Oriented Risk and Design Analysis (MORDA), a quantitative risk assessment and risk management process that uses MODA and VFT to evaluate information system design alternatives. MODA and VFT were applied particularly in the SOCRATES optimization tool within the MORDA process. VFT and MODA are used to develop value hierarchies and models, mathematically determine the best alternatives facing conflicting objectives, and determine benefits of alternatives used in cost-benefit analysis.

Journal articles that investigate MODA and VFT in military applications are shown in the following list as compiled by Parnell: ${ }^{14}$ 
1. Bassham, C. B., W. K. Klimack, and K. W. Bauer, Jr. 2002. ATR Evaluation Through the Synthesis of Multiple Performance Measures. Signal Processing, Sensor Fusion, and Target Recognition, No. XI, edited by Ivan Kadar, in Proceedings of SPIE, Vol. 4729, 112-121.

2. Beauregard, J. E., D. F. Deckro, and S. P.Chambal. 2002. Modeling Information Assurance: An Application. Military Operations Research, Vol. 7, No. 4: 35-55.

3. Buede, D. M., and R. W. Choisser. 1992. Providing an Analytic Structure for Key System Design Choices. Journal of Multi-Criteria Decision Analysis. Vol. 1, No. 1: 17-27.

4. Burk, R. C., C. Deschapelles, K. Doty, J. E. Gayek, and T. Gurlitz. 2002. Performance Analysis in the Selection of Imagery Intelligence Satellites. Military Operations Research. Vol. 7, No. 2: 45-60.

5. Chambal, S., M. Shoviak, and A. Thal. 2003. Decision Analysis Methodology to Evaluate Integrated Solid Waste Management Alternatives. Environmental Modeling and Assessment, Vol. 8, No. 1: 25-34.

6. Davis, C. C., R. F. Deckro, and J. A.Jackson. 1999. A Methodology for Evaluating and Enhancing C4 Networks. Military Operations Research, Vol. 4, No. 2: 45-60.

7. Doyle, M. P., R. F. Deckro, J. M. Kloeber, Jr., and J.A.Jackson. 2000. Measures of Merit for Offensive Information Operations Courses of Action. Military Operations Research, Vol. 5, No. 2: 5-18.

8. Hale, G., J. A. Jackson, and G. S. Parnell. 1997. Assessing Communications Systems for the Australian Defense Force. Asia-Pacific Journal of Operational Research, Vol. 14, No. 2: 45-67.

9. Kerchner, P. M., R. F. Deckro, and J. M. Kloeber. 2001. Valuing Psychological Operations. Military Operations Research, Vol. 6, No. 2: 41-62.

10. Lehmkuhl, L., D. Lucia, and J. K. Feldman. 2001. Signals from Space: The NextGeneration Global Positioning System. Military Operations Research, Vol. 6, No. 4: 5-18. 


\subsection{Survey and Comparisons of Decision Analysis Processes}

In this section we introduce the purpose of decision analysis as a systems engineering decision support tool and survey processes that have been applied to military decisions. A comparison of these methods is performed resulting in a justification of why particular methods are preferred and used to develop CVAP.

\subsection{Decision Analysis from a Systems Engineering Perspective}

The efficient use of limited resources is the main concern of most engineers, whether they are part of the design phase near the start of a program or part of the production phase near the end of the program. When known solutions fail to efficiently utilize limited resources, there is a need for better solutions. This leads to exploring better ways of efficiently utilizing limited resources and evaluating them to see if they are better than the current solutions. This exploration of better solutions is what leads to decision analysis, where customer requirements are analyzed, alternatives are identified and/or created, and the alternatives are quantitatively evaluated. This invokes a process that coordinates the foundational cycle of systems engineering: Analysis, Synthesis, and Evaluation, as described in Systems Engineering and Analysis ${ }^{6}$ in Figure 1.

In the analysis step, the system engineering team determines what the customer needs. Requirements and constraints are determined, functions are allocated to the components of the system, and customer objectives and measures of effectiveness are developed. In the synthesis step, alternatives are generated using engineering methods or identified through research. In the evaluation step, alternatives are evaluated to see if they meet the requirements. Tradeoffs are investigated between alternatives and requirements and decisions are made. Decision analysis methodologies follow this three step systems 
engineering process, where they first start off by qualitatively defining customer requirements, then generating possible solutions that meet the requirements, and then quantitatively evaluating them to pick the best solution.

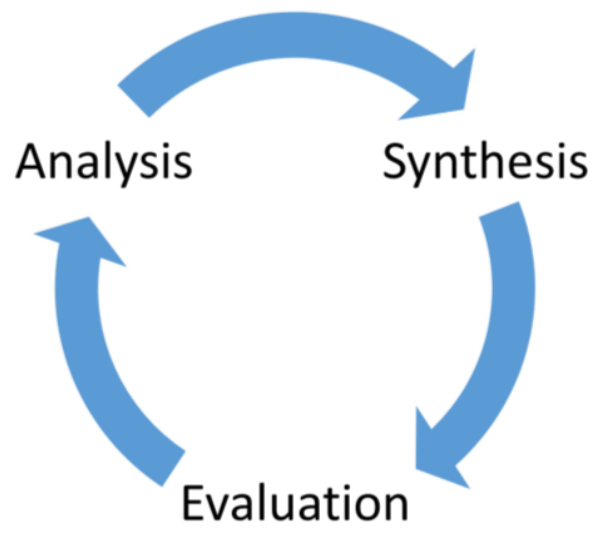

Figure 1. Main System Engineering Steps ${ }^{6}$

Alternatives are evaluated by assessing them in terms of the value they bring to the customer. As Blanchard discusses in his book, system value is defined by two factors: economic and technical. Technical factors may be expressed in terms of system effectiveness, which encompasses function of performance, operational availability, dependability, etc. economic factors are expressed in life-cycle cost, which includes research and development cost, production cost, procurement cost, operation cost, maintenance cost, and disposal cost. Figure 2 shows a flow chart that was derived from a similar figure in Blanchard's book. It shows the different factors that collectively express system value. 


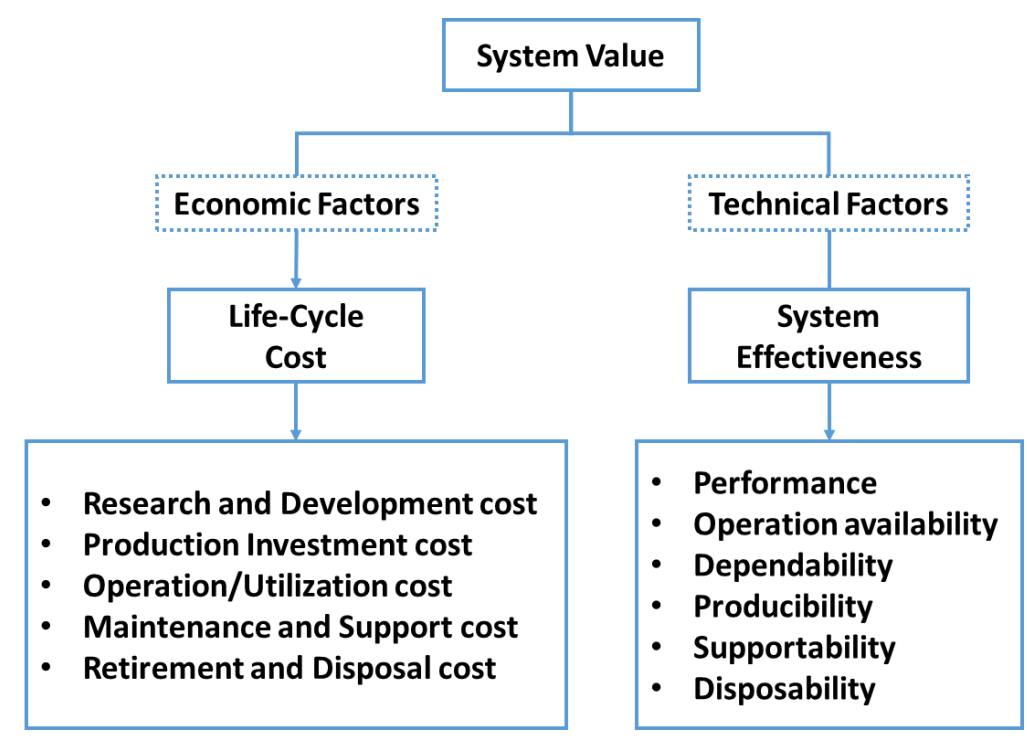

Figure 2. Description of System Value 6

Some of these factors may be considered to be more important than others by the customer, which will consequently influence the ultimate decision by placing different levels of importance on the evaluation criteria. Alternatives are generated from design synthesis and become the appropriate targets for evaluation. Evaluation is the determination of how well an alternative satisfies the evaluation criteria (customer values). Applicable criteria regarding the system should be expressed in terms of measures of effectiveness (MoEs) and should be prioritized at the system level. The prioritized MoEs reflect the overall performance characteristics of the system as it accomplishes objectives in response to the needs of the customer. These MoEs must be specified in terms of some level of importance, as determined by the customer, and the criticality of the functions to be performed. For example, Customer A might have a mission scenario where system reliability is less important since maintainability considerations are built into the systems that allow for easy repair. However, Customer B might face a mission scenario where maintenance is not feasible, which means that reliability becomes much more important. Therefore, the criticality of the objective(s) that the customer needs to accomplish will 
result to the identification of key requirements and the relative levels of importance of the applicable MoEs. ${ }^{6}$

Overall, the systems engineering approach suggests that one must first define the problem and identify the evaluation criteria and MoEs against which the various alternatives will be evaluated. One must then select the appropriate evaluation techniques, select or develop a model to facilitate the evaluation process, acquire the necessary input data, and evaluate each of the candidates under consideration. In order to make final recommendations one

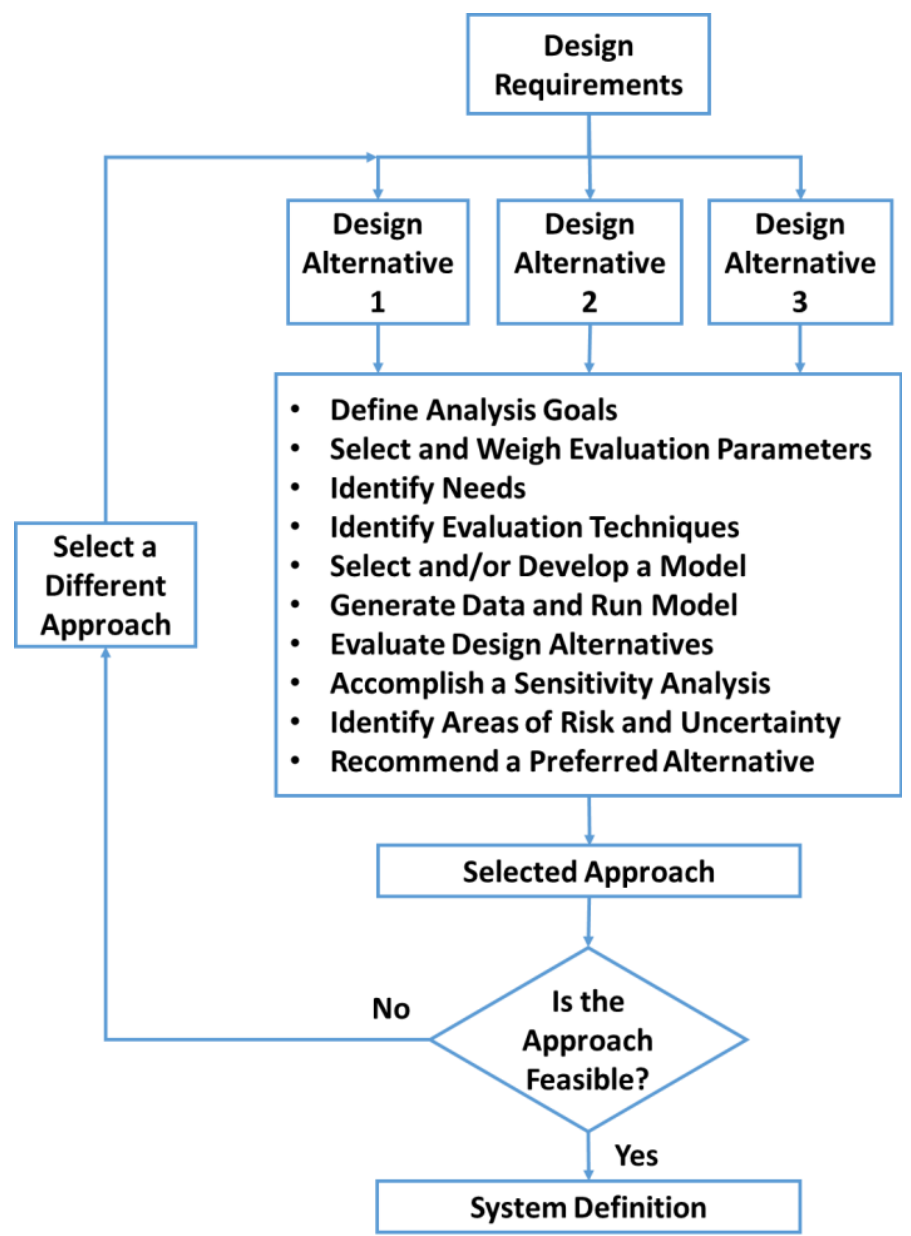

Figure 3. Trade-off analysis process 6 must perform a sensitivity analysis to identify potential areas of risk. This general systems engineering process is illustrated in Figure 3, and can be tailored and applied at any point in the life cycle. ${ }^{6}$ 


\subsection{Definitions}

Now that we have discussed how systems engineering books recommend making systems decisions, we will now investigate developed processes that follow these guidelines. These processes use distinct terminology as defined in Ch. 19 Value-Focused Thinking ${ }^{14}$ :

Evaluation consideration: A factor to compare the worth of alternatives, such as target destruction. An alternative term is evaluation "criteria".

Functions: When multiple decisions are involved, you'll want to identify functions before identifying the objectives. An alternative term is "missions" or "tasks".

Fundamental objective: The most basic objective we're trying to achieve. Example: select the best course of action to achieve the commander's intent. An alternative term is "problem statement".

Objective: A preference statement about an evaluation consideration. Example: maximize target destruction or minimize collateral damage.

Qualitative value model: The complete description of our qualitative values, including the fundamental objective, functions, objectives, and value measures (MoEs).

Quantitative value model: The value functions, weights, and mathematical equation (such as the additive value model) to evaluate the alternatives.

Range of a value measure: The possible variation of the scores of a value measure, such as probability of kill (Pk), may range from 0.0 to 1.0 .

Score (level): A specific numerical rating of the value measure, such as a $\mathrm{P}_{\mathrm{k}}$ of 0.95 . A score may be on a natural or a constructed scale. (We avoid using the term value for scores because the value function defines that term)

Tier (layer): Levels in the value hierarchy (Fundamental Objective, Functions, Objectives, and MoEs).

Utility: Utility is different from value. It includes returns to scale and risk preference.

Utility function: A function that assigns utility to a value measure score. We assess utility functions using lotteries.

Value function: A function that assigns value to a value measure's (MoE's) score. Quantitatively, value is defined as returns to scale on the value measure.

Value hierarchy (value tree): Pictorial representation of the qualitative value model. An alternative term is "objective hierarchy". 
Value measure: Scale to assess how much we attain an objective. For example, we may measure target destruction with a single shot probability of kill $\left(\mathrm{P}_{\mathrm{k}}\right)$. Alternative terms are evaluation measures, Measures of Effectiveness (MoEs), measures of merit, and metrics.

Value model: Contains both qualitative and quantitative assessment process.

Weights: The weight assigned a value measure depends on the measure's range. Weights are our relative preference for value measures. They must sum to one.

\subsection{Survey of Decision Analysis Processes}

There are many decision analysis processes that have been developed and applied to various disciplines. However, the representative processes with military applications can be compared in two aspects: (1) The philosophy of approach and the (2) quantitative prioritization methods. We have identified four representative decision analysis processes applied to military-type decisions: Multi-Objective Decision Analysis of TMD Architectures $^{1}$, Applications of Decision Analysis to Military Systems Acquisition Process ${ }^{15}$, Technique for Interactive Probabilistic Multiple Attribute Decision Making ${ }^{16}$, and A Hybrid, Interactive, Multiple-Attribute, Exploratory Approach (HIMAX). ${ }^{17}$ Each process was evaluated and it was found that all have factors in common as seen in Figure 4. The processes either used a Value-Focused Thinking (VFT) or Alternative-Focused Thinking (AFT) philosophy or Multi-objective decision analysis (MODA) or MultiAttribute Decision Making (MADM) prioritization method. MADM is also known as Multi-Criteria Decision Making (MCDM). These aspects will be investigated further in the following two sections. 

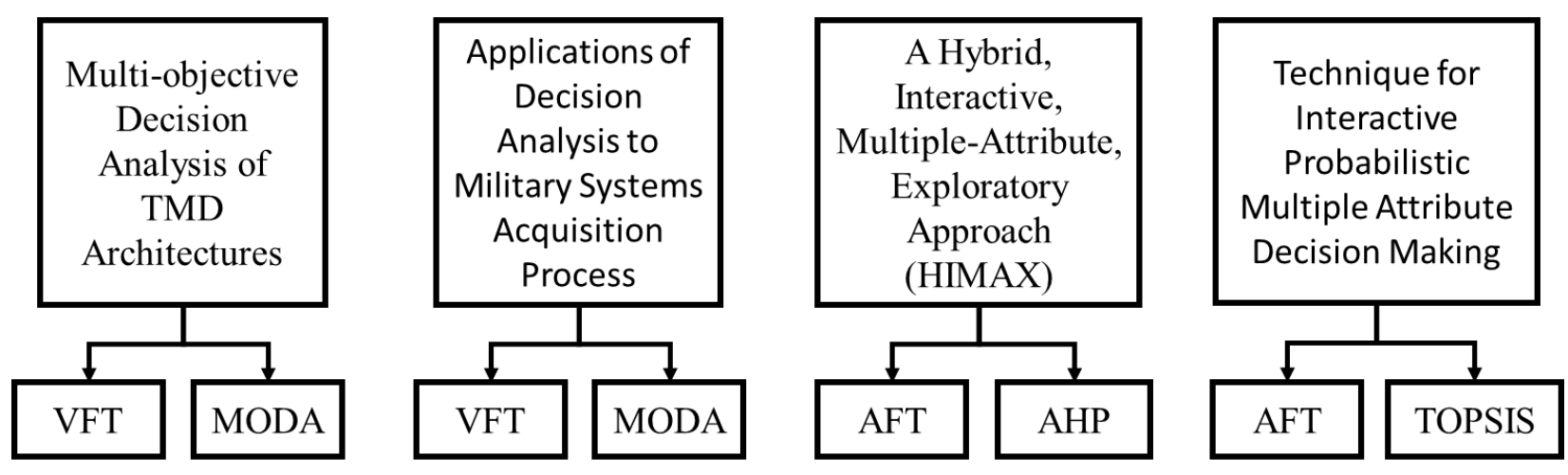

Figure 4. Philosophy of approach and quantitative models

\subsection{Comparison 1: Philosophy of Approach}

All decision analysis methods are addressed as either Alternative-Focused Thinking (AFT) or Value-Focused Thinking (VFT) as described by Ralph L. Keeney in Value-Focused Thinking: A Path to Creative Decisionmaking. ${ }^{7}$ Keeney states that the fundamental difference between AFT and VFT is that AFT focuses more on the analysis of alternatives while VFT focuses more on the assessment of values. AFT is merely a reactive decision problem approach while VFT is much broader. Besides being capable of solving decision problems, VFT is also capable of solving decision opportunities. A decision problem is defined when the decision situation occurs as a result of actions that are not controlled by the decision maker, thus, there is a need to find a solution. For example, a division of a company may be losing money or the company is losing market share to a competitor, or a government defense system may be evaluated as ineffective. In cases like these, there is a need to find an alternative solution. On the other hand, decision opportunities are identified and controlled by the decision maker rather than being caused by external events. Decision opportunities are discovered out of a desire to do something better, thus, VFT is a proactive approach. There is an old American saying, "If it ain't broke, don't fix it". Dr. Edward de Bono, regarded as the father of lateral thinking and "one of the foremost expects in the fields of creativity", claims that this saying reflected the 
attitude that lead to the decline of the U.S industry within the last couple of decades. ${ }^{9}$ This saying reflects a purely reactive (AFT) attitude instead of a proactive VFT attitude. The following quotes signify VFT as a preferred approach.

"To survive in today's business culture, proactive thinking-as opposed to reactive thinking - is required. This shift in thinking patterns requires creativity."

- Fogler and LeBlanc ${ }^{9}$

"The formulation of a problem is often more essential than its solutions, which may be merely a matter of mathematical or experimental skill. To raise new questions, new possibilities, to regard old problems from a new angle requires creative imagination and marks real advances in science."

- Albert Einstein ${ }^{18}$

The steps for AFT and VFT are listed on Tables 1 and 2. Table 1 shows that AFT is only capable of evaluating decision problems. Table 2 shows that VFT is capable of both decision problems and decision opportunities. Both AFT and VFT follow the same steps, but are performed in a different order and emphasize different steps. Keeney argues that values are more fundamental to a decision problem than are alternatives. "Values are what we care about [, thus,] values should be the driving force for making decisions". The purpose of making decisions is to achieve desirable consequences while avoiding the undesirable ones. The concept of "desirability of consequences" is based on values. Therefore, the fundamental driving force in making decisions should be values, not alternatives. "Alternatives are the means to achieve the more fundamental values." Keeney states that focusing early and deeply on values when facing difficult problems leads to more desirable consequences and that more time should be spent concentrating on what is important: defining and understanding values and using them to create better alternatives than those already identified. ${ }^{7}$ 
Table 1. Alternative-Focused Thinking steps ${ }^{7}$

\begin{tabular}{|l|}
\hline \multicolumn{1}{|c|}{ Decision Problems } \\
\hline 1. Recognize a decision problem \\
\hline 2. Identify alternatives \\
\hline 3. Specify values \\
\hline 4. Evaluate alternatives \\
\hline 5. Select an alternative \\
\hline
\end{tabular}

Table 2. Value-Focused Thinking steps ${ }^{7}$

\begin{tabular}{|l|l|l|}
\hline Decision Problems & \multicolumn{2}{|c|}{ Decision Opportunities } \\
\hline & $\begin{array}{l}\text { Before specifying strategic } \\
\text { objectives }\end{array}$ & $\begin{array}{l}\text { After } \text { specifying strategic } \\
\text { objectives }\end{array}$ \\
\hline $\begin{array}{l}\text { 1. Recognize a } \\
\text { decision problem }\end{array}$ & $\begin{array}{l}\text { 1. Identify a decision } \\
\text { opportunity }\end{array}$ & 1. Specify values \\
\hline 2. Specify values & 2. Specify Values & $\begin{array}{l}\text { 2. Create a decision } \\
\text { opportunity }\end{array}$ \\
\hline 3. Create alternatives & 3. Create alternatives & 3. Create alternatives \\
\hline $\begin{array}{l}\text { 4. Evaluate } \\
\text { alternatives }\end{array}$ & 4. Evaluate alternatives & 4. Evaluate alternatives \\
\hline $\begin{array}{l}\text { 5. Select an } \\
\text { alternative }\end{array}$ & 5. Select an alternative & 5. Select an alternative \\
\hline
\end{tabular}

Keeney identifies nine benefits of VFT as shown in Figure 5. Parnell ${ }^{14}$ states that three of these benefits are especially relevant to military applications of decision analysis:

- Guiding strategic thinking: value-focused thinking can capture the commander's intent for courses of action.

- Evaluating alternatives: multiple objective decision analysis (MODA) can evaluate alternative courses of action.

- Creating alternatives: once alternatives are evaluated, we can assess the value gaps (the difference between the ideal value and the best alternative) and focus our effort to develop better alternatives. 


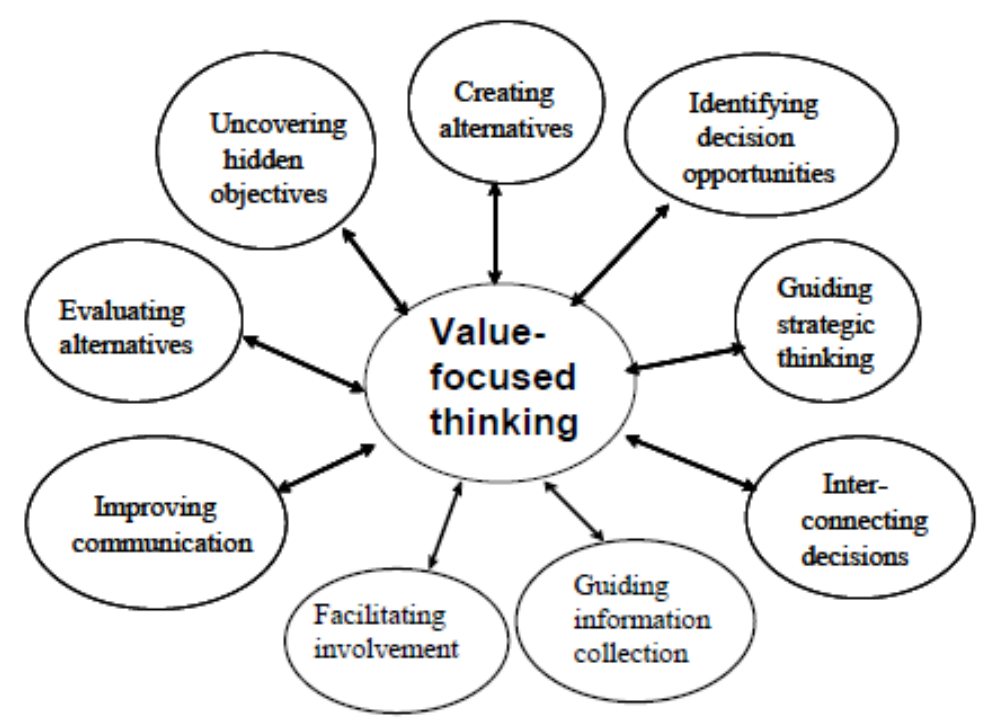

Figure 5. Benefits of Value-Focused Thinking ${ }^{7}$

\subsection{Comparison 2: Quantitative Prioritization Methods}

Two representative decision making methods that aim to prioritize alternatives are compared with Multi-Objective Decision Analysis (MODA). These methods are the Analytical Hierarchy Process (AHP) and Technique for Order of Preference by Similarity to Ideal Solution (TOPSIS). Both AHP and TOPSIS are considered Multi-Criteria Decision Making (MCDM) or Multi-Attribute Decision Making (MADM) methods. Although MCDM methods are convenient to use, they are not as accurate as MODA.

The AHP was developed by Thomas Saaty ${ }^{19}$ in the early 1970 's and is a MCDM method that helps decision makers make the best decision by selecting the best alternative in a set of alternatives. It determines the best alternative to be the one that achieves the most suitable trade-off among the criteria. AHP does this by reducing complex decisions to a series of pairwise comparisons that capture both subjective and objective aspects of a decision. The AHP starts by generating a weight for each evaluation criterion according to criteria pairwise comparisons made by the decision maker. The more important criterion is the one with the largest weight value. Next the AHP assigns a score to each alternative per 
criterion according to the decision maker's pairwise comparisons of the alternatives. The better performing alternative will get the higher score. Finally, the AHP combines the criteria weights and the alternatives' scores and determines a global weighted score for each option that is used for final ranking of the alternatives. The global score for a particular alternative is a weighted sum of the scores it obtained for each criterion. AHP also incorporates a technique that checks for consistency of the decision maker's evaluations that aims to reduce the bias in the decision making process. ${ }^{19}$ According to Triantaphyllou and Mann, ${ }^{20}$ AHP has been criticized, leading to revised versions. Most criticism is due to the way pairwise comparisons are used and the way AHP evaluates alternatives. The revised version that was accepted by Saaty is now called the Ideal Mode AHP, but only the original AHP is discussed in this section since both versions are fundamentally the same. ${ }^{20}$ The steps taken to use AHP are included in Appendix B.

TOPSIS, known as one of the most classical MCDM methods, was developed by Hwang and Yoon. ${ }^{21}$ TOPSIS typically relies on other MCDM techniques to qualitatively assess inputs like the evaluation criteria and the alternatives to be evaluated. TOPSIS prioritizes alternatives by determining their scores using qualitative measures (e.g., Good, Very Good, and Extremely Good) that are then quantified to a scale (e.g., 5, 7, and 9). TOPSIS is merely a mathematical algorithm that prioritizes scores subject to multiple criteria by comparing them to a Positive Ideal Solution, (PIS) and a Negative Ideal Solution (NIS). The best alternative is the one closest to the PIS and furthest away from the NIS. ${ }^{21}$ This is how TOPSIS differs from AHP. AHP ranks alternatives by the relative performance to each other while TOPSIS ranks alternatives by the alternatives' performance relative to the best possible solution out of the set, where the best possible solution out of the set is 
composed of the highest alternative score per criterion. Therefore, TOPSIS is capable of making conclusions based on the performance gaps of each alternative when compared to the best possible solution. These performance gaps can be used to recommend to customers/decision makers how alternatives can be improved and by how much. For example, let's say a particular alternative receives a ranking score $\left(\mathrm{C}_{\mathrm{i}}^{+}\right)$of 0.90 . This means that this alternative is $90 \%$ of an ideal solution, where the ideal solution is a fictitious alternative defined by the highest score in each criterion. A more detailed explanation of the steps taken to use TOPSIS is include in Appendix C.

Although MCDM methods (e.g., AHP and TOPSIS) have many method-particular differences, they fundamentally differ from MODA in that a value (or utility) function is not explicitly assessed. MCDM methods argue that explicitly assessing values is too difficult, undesirable, and should be avoided ${ }^{5}$. However, assessing values is useful given the fact that decisions are made to meet values. This extra effort might not be justified for relatively low-risk decision situations like "choosing the best car" or "picking the best job offer", but it is certainly worth the extra effort for high-risk military and political decisions, where the lives of people and the well-being of society face the frightening consequences of a wrong decision.

MODA explicitly assesses value functions and separates it from the prioritization of alternatives, which provides a "straightforward [way] to determine whether disagreements among stakeholders to a decision are with regard to values or the estimated performance of the alternatives." This separation allows for traceability of the factors that result in a particular ranking of alternatives, making it easy to audit the decision process if it is questioned ${ }^{5}$. On the other hand, MCDM methods merge decision maker preferences 
with the ranking of alternatives, which leads to a loss of control and a "black-box" feeling of the reasoning behind recommendations.

Furthermore, MCDM approaches are not capable of using raw Measures of Effectiveness (MoE) quantities obtained from experiments or Modeling and Simulation (M\&S) to rank alternatives. Instead, MCDM approaches use qualitative scales and/or normalization techniques to rank alternatives. According to the DoD, MoEs should be raw quantities when feasible. "Attempts to disguise these quantities through a mathematical transformation (e.g., through normalization), no matter how well meaning, reduce the information content and may be regarded as "tampering with the data."” Use of raw quantities allow for the investigation of performance sensitivities of alternatives, whose defining parameters are subject to significant uncertainty ${ }^{2}$. MODA is capable of using raw MoEs, providing objective and traceable recommendations.

The goal of MCDM methods is to identify the best alternative in a set of candidate solutions, narrowing down to a single solution and leaving no room for tradeoffs. According to the DoD, "the goal of the [decision making processes] is to identify the most promising candidates for consideration by decision makers. In some cases this may mean a single alternative. In other cases, there will be several alternatives, each with different cost, effectiveness, and/or risk pluses and minuses." ${ }^{2}$ MCDM methods blend effectiveness, cost, and risk criterion into a mathematical algorithm that obscures the contribution of each category. This results in insufficient information for making tradeoffs on the alternatives. On the other hand, MODA separates the evaluation of cost and risk from effectiveness, allowing the decision maker to make clear tradeoffs in each category. 


\subsection{Comparison Conclusion}

We conclude that VFT is the preferred philosophy and MODA is the preferred way to evaluate and prioritize alternatives for military applications. Based on the teachings of Keeney, VFT is preferred because it allows for the creation of better alternatives that lead to more desirable consequences than AFT. AFT is restricted to the alternatives that are preselected and picks the better one, which may not be the best possible solution for the decision maker. Since VFT is the preferred approach, MODA is the most appropriate quantitative method to use for ranking alternatives. MODA separates value function assessment from the ranking of alternatives, which allows decision analysis teams to provide recommendations that are traceable to customer values, while MCDM methods like AHP and TOPSIS do not. Unlike MCDM methods, MODA allows for solution tradeoffs between effectiveness, cost, and risk categories. MODA is also capable of using raw MoE quantities gathered from experiments and/or modeling and simulation and does not alter the data like AHP and TOPSIS. This further contributes to traceability and objectivity in the prioritization of alternatives. 


\subsection{The Customer Value Assessment Process (CVAP) Methodology}

We conducted research to see if a general process that uses both VFT and MODA exists and found a model called the Systems Decision Process (SDP) developed by Gregory S. Parnell and other systems engineering faculty at the United States Military Academy (USMA) in West Point, NY. CVAP uses SDP as its foundation and extends and expands on it.

CVAP is a systematic decision analysis methodology that includes a structured approach guided by the U.S. Department of Defense (DoD) Analysis of Alternatives (AoA). CVAP improves SDP's qualitative value model by implementing Quality Function Deployment (QFD), the solution design step by implementing creative problem solving techniques, and the quantitative value model by adding cost analysis and risk assessment techniques practiced by the U.S DoD. An outline of the approaches used to develop CVAP and steps to implementing it are presented.

\subsection{Use of Analysis of Alternatives (AoA) and Systems Decision Process (SDP)}

Since the motivation for the formulation of CVAP was from a ballistic missile defense (BMD) industry need, the U.S. DoD approach to decision making was investigated. What was found was that the DoD uses a process called the Analysis of Alternatives (AoA) when it faces a decision problem involving multiple alternatives. "An AoA is an analytical comparison of the effectiveness, cost, and risks of proposed solutions to gaps and shortfalls in operational capability. AoAs document the rationale for identifying and recommending a preferred solution or solutions to the identified shortfall(s)." The Air Force Material Command's Office of Aerospace Studies (OAS), designated the Air Force Center of Expertise (CoE) for AoAs, created the AoA Handbook ${ }^{2}$. The AoA Handbook provides a framework and guidelines for the AoA process, but it does 
not recommend specific techniques used to perform the analysis. SDP also does not provide much detail on the steps and techniques used to apply it. CVAP incorporates the steps presented in the AoA Handbook and SDP and implements specific techniques for each step. The following two sections are brief descriptions of the AoA and SDP processes.

\subsubsection{Analysis of Alternatives}

When the DoD is faced with a decision problem, they apply their Acquisition System framework, which is composed of three interconnected processes: Joint Capabilities Integration Development System (JCIDS), Acquisition Process, and the Planning, Program, Budget, and Execution Process (PPBE) shown in Figure 6. JCIDS is the requirements development process that outputs the Initial Capabilities Document (ICD) and the Capabilities Development Document (CDD). These documents are inputs to the AoA. The Acquisition Process marches through the acquisition phases, milestones, and decision points in the development of a program. The PPBE is essentially the process that allocates the DoD budget for the program of interest. The AoA is incorporated in all three processes, but it is most important and significant in the JCIDS and Acquisition Processes. ${ }^{22}$ 


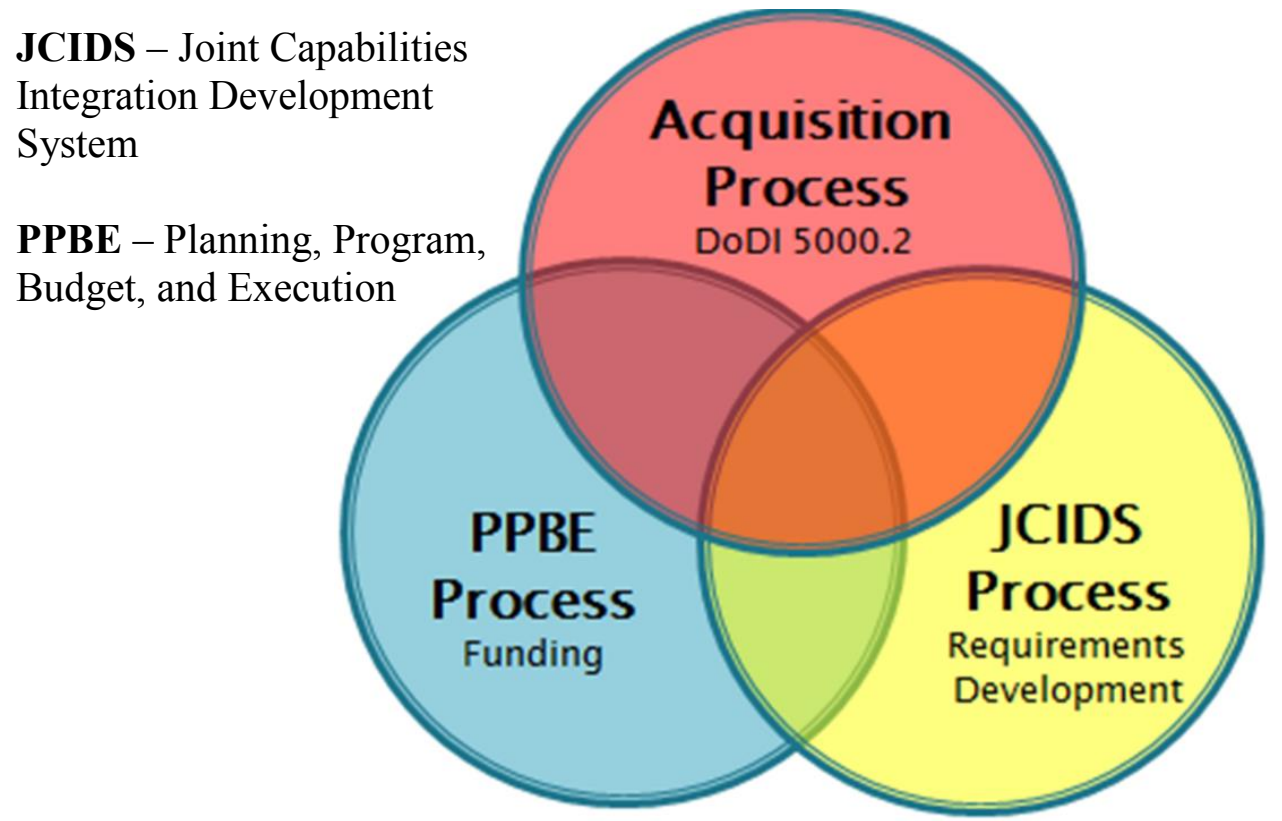

Figure 6. DoD Acquisition System framework ${ }^{23}$

The DoD uses the AoA when it is faced with a decision problem involving multiple alternatives. "An AoA is an analytical comparison of the effectiveness, cost, and risks of proposed solutions to gaps and shortfalls in operational capability. AoAs document the rationale for identifying and recommending a preferred solution or solutions to the identified shortfall(s)."2 The DoD performs an AoA whenever they need justification for starting, stopping, or continuing an acquisition program. The AoA process provides decision makers with reliable, objective assessments of the alternatives. AoAs identify potentially viable solutions and provide comparable cost, effectiveness, and risk assessments of each solution to a baseline, which can be the current operating solution or an ideal solution. Although AoAs are a big factor in selecting a final solution, they aren't the only factor. "The final decision must consider not only cost-effectiveness, risk, and military worth, but also domestic policy, foreign policy, technological maturity of the solution, the environment, the budget, treaties, and a host of additional factors." 2 


\section{Effectiveness Analysis}

Once the ICD and CDD are obtained from the JCIDS process, they are used in the first step of the AoA, performing an effectiveness analysis. Effectiveness analysis is normally the most complex element of the AoA and consumes a significant fraction of AoA resources to assess the technical complexity of military systems. The goal of the effectiveness analysis is to determine the military worth of the alternatives in performing Mission Tasks (MTs), which can be thought of as functions/objectives that systems need/should satisfy. The MTs are derived directly from the capability requirements identified in the ICD and CDD. The ability to satisfy the MTs is determined from estimates of alternatives' performance with respect to Measures of Effectiveness (MoEs) and their supporting Measures of Performance (MoPs). The difference between MoEs and MoPs is that MoEs can either be qualitative or quantitative measures of operational success related to an objective of the MT being evaluated while MoPs are strictly quantitative measures (like range, velocity, mass, fire rate, etc.). An alternative term for MoP that is commonly used in engineering is Technical Performance Measure (TPM). MoPs/TPMs usually have a threshold value specified in the ICD/CDD that is used to determine how well an alternative needs to perform. Since MTs are functions and objectives that the system(s) need to perform, cost is never an MT or MoE. "Cost is never considered in the effectiveness analysis". MoEs should represent raw quantities obtained from scientific methods like Modeling and Simulation $(M \& S)$ and/or experimental data. Any attempt to disguise raw quantities through mathematical algorithms, like normalization (e.g., AHP and TOPSIS) "reduce the information content and may be regarded as "tampering with the data." The same reasoning applies to MoEs defined as ratios (like final priorities from AHP or MoEs 
like cost/kill); a ratio essentially "hides" both quantities." The AoA effectiveness analysis process is shown in Figure 7.
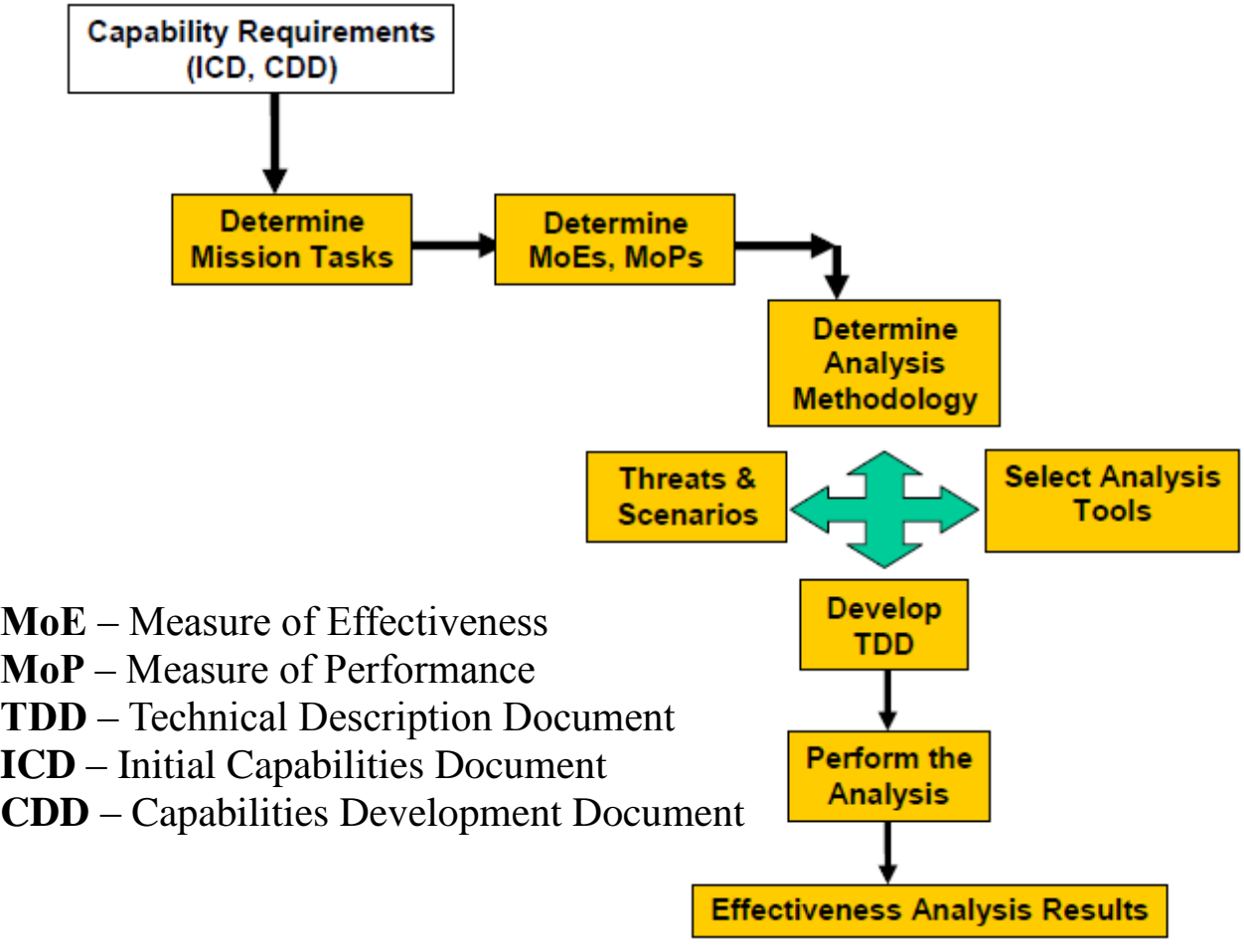

Figure 7. AoA process for effectiveness analysis ${ }^{2}$

Cost Analysis

A cost analysis is performed in parallel with the operational effectiveness analysis.

It is equal in importance in the overall AoA decision process. The cost analysis estimates the total Life-Cycle Cost (LCC) of each alternative and combines it with the effectiveness analysis results to identify the alternative(s) that represent the best joint value. Figure 8 is a template that AoA uses to summarize LCC element estimates. The LCC approach captures the total cost of each alternative over its entire life cycle composed of the following elements as described in the AoA Handbook ${ }^{2}$ :

- $\quad$ Research and Development $(R \& D)$ Cost

R\&D costs include concept and technology development, and system development and demonstration. There are many types of $R \& D$ costs: prototypes, engineering development, equipment, test hardware, contractor 
system test and evaluation, and government support to the test program. Engineering costs for environmental safety, supportability, reliability, and maintainability efforts are also included, as are support equipment, training, and data supporting R\&D efforts

\section{- $\quad$ Procurement and Investment Cost}

The cost of investment (low rate initial production, production, and deployment) includes the cost of procuring the prime mission equipment and its support. This includes training, data, initial spares, war reserve spares, pre-planned product improvement (P3I) program items, and military construction (MILCON). MILCON cost is the cost of acquisition, construction, or modification of facilities necessary to accommodate an alternative. The cost of all related procurement, such as modifications to existing equipment, is also included.

\section{- $\quad$ Operating and Support $(O \& S)$ Cost}

O\&S costs are those program costs necessary to operate, maintain, and support system capability. This cost element includes all direct and indirect elements of a defense program and encompasses costs for personnel, consumable and repairable materiel, and all appropriate levels of maintenance, facilities, and sustaining investment. Manpower estimates should be consistent with the Manpower Estimate Report (MER), which is produced by the operating command's manpower office.

\section{- Disposal Cost}

Disposal cost is the cost of getting rid of excess or surplus property or materiel from the inventory. It may include costs of demilitarization, detoxification, redistribution, transfer, donation, sales, salvage, or destruction. It may also reflect the costs of hazardous waste disposition (including long-term storage) and environmental cleanup. Disposal costs may occur during any phase of the acquisition cycle.

Note: "Sunk costs (money already spent or obligated) are not included in the LCC estimates; however, they may be of interest to decision makers and should be identified separately. Those alternatives failing to meet minimum effectiveness analysis are normally not considered in the cost analysis" 


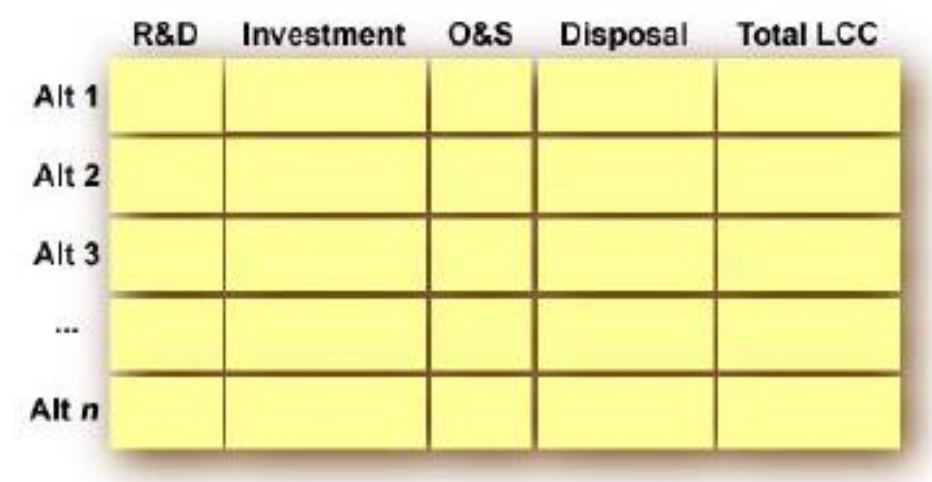

Figure 8. General Life Cycle Cost Summary²

\section{Risk Assessment}

The AoA Handbook identifies three categories of risks that should be assessed for each alternative in the AoA: Technological, Programmatic, and Operational. The handbook defines risk to be the probability of an adverse event occurring and the severity of the consequences should that event occur. The first step in the risk assessment process is to determine what factors are relevant to each alternative. The following shows the three risk categories and potential factors that may be appropriate to assess under each category as listed in the AoA Handbook ${ }^{2}$ :

- Technological Risks

○ Technology maturity

- Modularity

- Open architecture

- Extensibility

- Programmatic Risks

- Efficacy of doctrine, organization, training, materiel, leadership and education, personnel and facilities (DOTLMPF) characteristics

- Cost and schedule drivers

- Overarching dependencies

- Identify political issues

- Operational Risks

- Special basing requirements or fly-over issues

- Unique maintenance requirements

- Technology sensitivities (e.g., keeping info from some of our allies) 
Once all risks factors associated with each alternative have been identified, the decision analysis team will need to develop a methodology for assigning a measure of probability of the adverse events occurring (e.g., high (H), medium (M), low (L), or 1-10). The decision analysis team must then determine the severity of the impact if the adverse event occurs (e.g., high (H), medium (M), low (L), or 1-10). The AoA uses a risk assessment matrix to display the risk of each alternative as shown in Figure 9. The left axis represents the probability of the adverse event occurring with lowest probability on the bottom and highest probability at the top. The bottom axis represents the impact of the adverse event starting with lowest impact on the right and highest impact on the left. The highest risk alternatives are those that are at the top right corner of the matrix (i.e., high probability and severity) and the lowest risk alternatives are those at the bottom left corner (i.e., low probability and severity). As you go up this diagonal, the alternatives increase in risk.

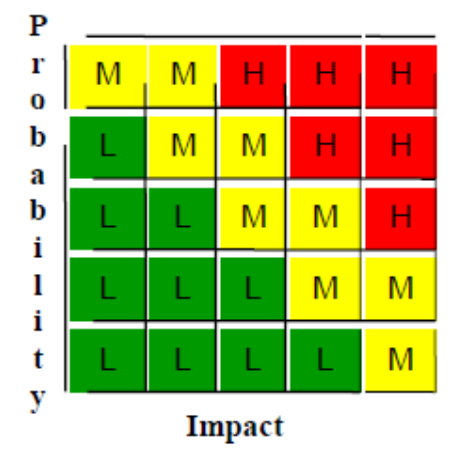

Figure 9. AoA Risk Assessment Matrix ${ }^{2}$

\section{Comparative Analysis}

Once the effectiveness analysis, cost analysis, and risk assessment has been completed, the next step is to combine all the information and perform a comparative analysis. A comparative analysis aims to assess dilemmas between alternatives in terms of effectiveness, cost, and risk and then eliminate alternatives with critical flaws. The 
remaining alternatives can be compared by using a matrix like the one shown in Figure 10 $(\mathrm{G}=$ green, $\mathrm{Y}=$ yellow, and $\mathrm{R}=$ red $)$. Finally, recommendations are made based on tradeoffs between advantages and disadvantages of the alternatives and how each alternative address the ICD/CDD requirements. The overall purpose of the comparative analysis is to help decision makers understand the differences between the alternatives and there is generally no requirement to recommend a single solution.

\begin{tabular}{|c|c|c|c|c|c|c|c|c|c|c|c|}
\hline & \multicolumn{6}{|c|}{ Critical } & \multirow{2}{*}{\multicolumn{3}{|c|}{$\begin{array}{l}\text { Non-Critical } \\
\text { Mission Task } 3\end{array}$}} & \multirow{3}{*}{ Risk } & \multirow{3}{*}{$\begin{array}{l}\text { Total } \\
\text { LCC } \\
\mathbf{S ( M )}\end{array}$} \\
\hline & \multicolumn{3}{|c|}{ Mission Task 1} & \multicolumn{3}{|c|}{ Mission Task 2} & & & & & \\
\hline & $\begin{array}{l}\text { MoE } \\
1-1\end{array}$ & \begin{tabular}{|l|} 
MoE \\
$1-2$
\end{tabular} & $\begin{array}{l}\text { MoE } \\
1-3\end{array}$ & $\begin{array}{l}\text { MoE } \\
2-1\end{array}$ & $\begin{array}{l}\text { MoE } \\
2-2\end{array}$ & $\begin{array}{l}\text { MoEE } \\
2-3\end{array}$ & $\begin{array}{l}\text { MoE } \\
3-1\end{array}$ & \begin{tabular}{|l|} 
MoE \\
3-2
\end{tabular} & \begin{tabular}{|l|} 
MoE \\
3-3
\end{tabular} & & \\
\hline $\begin{array}{l}\text { Alt } 1 \\
\text { (baseline) }\end{array}$ & G & $\mathrm{Y}$ & $\mathrm{R}$ & G & G & Y/G & G & $\mathrm{R}$ & G & $\mathrm{R}$ & $\$ 1,200$ \\
\hline Alt 2 & $\mathbf{R}$ & Y/G & G & $R / Y$ & $\mathrm{R}$ & G & G & Y/G & $\mathrm{Y}$ & G & $\$ 1,450$ \\
\hline Alt 3 & Y/G & G & $\mathbf{R}$ & G & $Y$ & Y/G & $\mathrm{Y}$ & G & G & $\mathbf{R}$ & $\$ 1,457$ \\
\hline Alt 4 & G & $\mathbf{R}$ & G & $R / Y$ & G & $\mathrm{Y}$ & $\mathrm{R} Y$ & G & $\mathbf{R}$ & G & \\
\hline
\end{tabular}

Figure 10. Notional Matrix for Alternative Comparison Results ${ }^{2}$

\subsubsection{Systems Decision Process (SDP)}

The Systems Decision Process (SDP) was developed by Gregory S. Parnell along with other faculty members of the Systems Engineering Department at United States Military Academy in West Point, New York. It is a general problem solving process that is applicable to problems in all stages of a system life cycle. It has been applied to many military decision problems and capstone research projects. SDP approaches problem solving with the VFT approach; first qualitatively defining values and then using them to generate alternatives. SDP then quantitatively asses the generated alternatives using MODA, which allows for the separation of value function assessment from the ranking of alternatives. This separation is key to traceability since conclusions from the process can 
be traced back to customer/stakeholder values and/or scoring of alternatives. SDP has the following characteristics as found in Decision Making in Systems Engineering and Management: ${ }^{3}$

- Starts with a description of the current system. The current system, or baseline, is the foundation for assessment of future needs and comparison with candidate solutions to meet those needs.

- Focuses on the decision maker and stakeholder value. Stakeholders and decision makers identify important functions, objectives, requirements, constraints, and screening criteria. They key stakeholders are the consumers of the system products and services, the system owners; and the client responsible for the system acquisition.

- Focuses on the value creation and defines the desired end state that we are trying to achieve. The value modeling task of the problem definition phase plays an important role in defining the ideal solution for comparison with alternative solutions. The solution enhancement task improves the alternative design solutions. Finally, we use value focused thinking to improve the non-dominated solutions.

- Has four phases (problem definition, solution design, decision making, and solution implementation) and is highly iterative based on the information and feedback from stakeholders and decision makers.

- Explicitly considers the environment that systems will operate within (i.e., historical, legal, social, cultural, technological, security, environmental, and economic) and the political, organizational, moral/ethical, and emotional issues that arise with stakeholder and decision makers in the environment.

The SDP is composed of four phases, each with three tasks as can be seen in Figure 11. The first phase, problem definition, is the most important phase since it defines the actual problem that needs to be solved. If the actual problem is not identified or understood, we could be wasting time and energy developing solutions for the wrong problem. Once the problem has been defined, the next phase is solution design, where ideas are generated to create alternatives and then enhanced to a set of high quality feasible alternatives. After 
the set of high-quality alternatives has been created, the next step is to quantitatively evaluate them using MODA in the decision making phase. The output from this phase are used to make recommendations to decision makers. If the decision makers approve the recommendations and secure a decision, the next phase is to allocate resources and plan the implementation of the solution in the solution implementation phase.

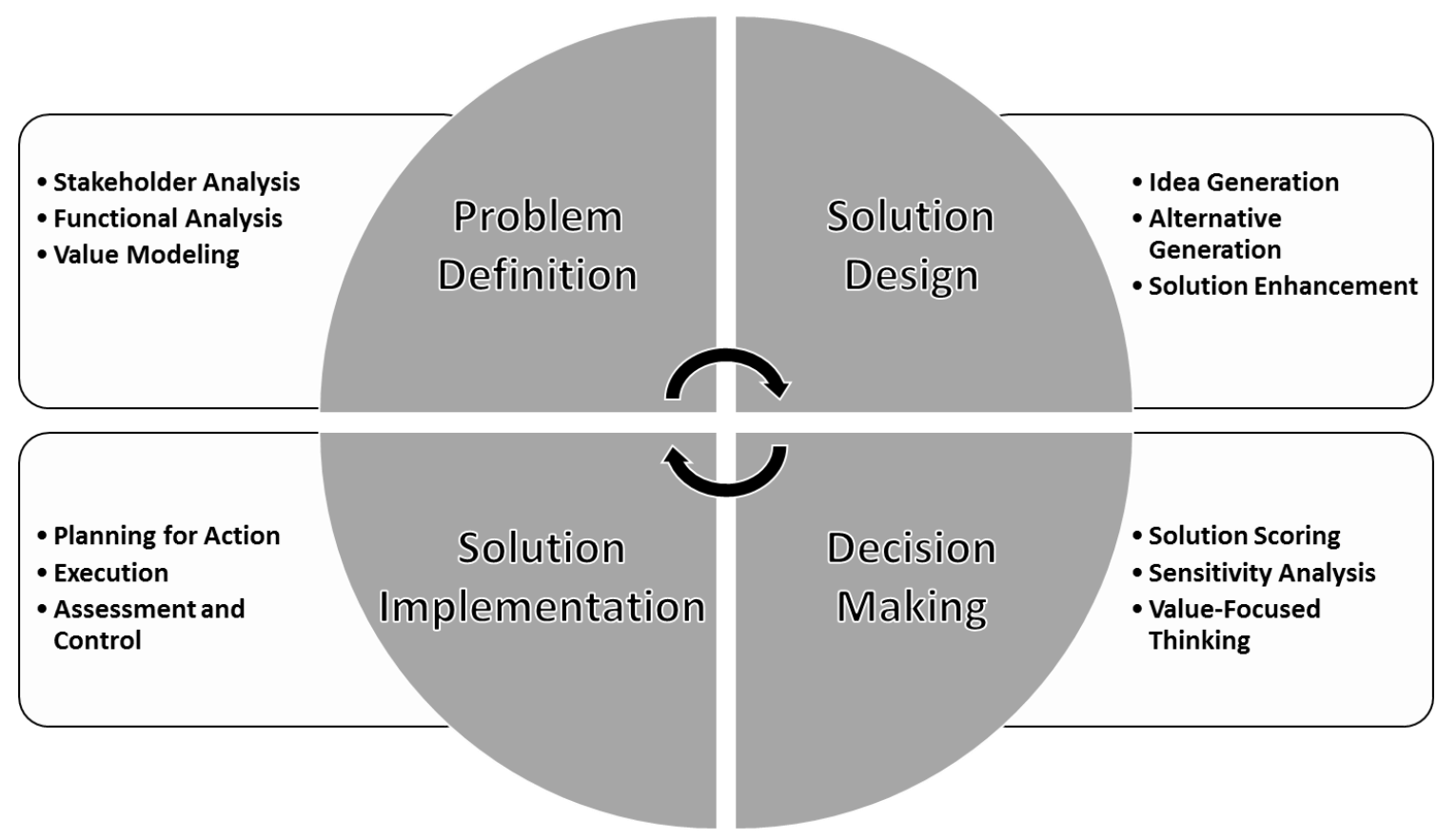

Figure 11. A simplified version of the Systems Decision Process ${ }^{3}$

SDP is similar to other problem solving processes, namely Athey's Systematic Systems Approach and the Military Decision Making Process. Athey's systematic systems approach is much more general and the military decisions process focuses more on a course of action instead of a system. SDP provides more detail on the steps needed for a systems decision that Athey's systematic systems approach. Table 3 displays the three processes for comparison. SDP is an elaborate process that can be applied to many systems engineering decision problems and opportunities, however, the level of detail makes it difficult to follow based on just the literature provided. SDP briefly describes the 
techniques that can be used in each phase, but lacks a guide on how to apply these techniques.

Table 3. Comparison of Problem-Solving Processes ${ }^{3}$

\begin{tabular}{|c|c|c|}
\hline Systems Decision Process & $\begin{array}{l}\text { Athey's Systematic } \\
\text { Systems Approach }\end{array}$ & $\begin{array}{l}\text { Military Decision Making } \\
\text { Process }\end{array}$ \\
\hline $\begin{array}{l}\text { 1) Problem Definition } \\
\text { a. Stakeholder } \\
\text { analysis } \\
\text { b. Functional } \\
\text { analysis } \\
\text { c. } \text { Value modeling } \\
\text { 2) Design Solution } \\
\text { a. Idea generation } \\
\text { b. Alternative } \\
\text { generation } \\
\text { c. Solution } \\
\text { enhancement } \\
\text { 3) Decision Making } \\
\text { a. Solution scoring } \\
\text { b. Sensitivity } \\
\text { analysis } \\
\text { c. Value-focused } \\
\text { thinking } \\
\text { Solution Implementation } \\
\text { a. Planning for } \\
\text { action } \\
\text { b. Execution } \\
\text { c. Assessment and } \\
\text { control }\end{array}$ & $\begin{array}{l}\text { 1) Formulate the problem } \\
\text { 2) Gather and evaluate } \\
\text { information } \\
\text { 3) Develop potential } \\
\text { solutions } \\
\text { 4) Evaluate workable } \\
\text { solutions } \\
\text { 5) Decide the best } \\
\text { solution } \\
\text { 6) Communicate system } \\
\text { 7) Implement solution } \\
\text { 8) Establish performance } \\
\text { standards }\end{array}$ & $\begin{array}{l}\text { 1) Receipt of mission } \\
\text { 2) Mission analysis } \\
\text { 3) Course of action } \\
\text { (COA) development } \\
\text { 4) COA analysis } \\
\text { 5) COA comparison } \\
\text { 6) COA approval } \\
\text { 7) Order production } \\
\text { 8) Rehearsal } \\
\text { 9) Execution and } \\
\text { assessment }\end{array}$ \\
\hline
\end{tabular}

\subsection{CVAP Overview}

We concluded in Section 2.0 that VFT and MODA have desirable characteristics that overcome the challenges of formulating an objective, traceable process and recommendations. We identified the $\mathrm{SDP}^{3}$ as a general systems engineering process that applies VFT and MODA, however, it does not provide much detail on how to apply the tasks within the phases of the process. Namely, it only provides a brief description of the 
techniques involved for some of the tasks that need to be completed. The following are areas where SDP can be improved:

- Problem Definition phase $^{3}$

In this phase, SDP discusses why it is important to define the tiers of the value hierarchy (i.e., fundamental objective, functions, objectives, and measures of effectiveness), however, it does not clearly define a process to do this. SDP states that the value hierarchy can be defined via stakeholder and functional analyses, but these are merely examples of how the tiers can be defined. This phase lacks a structured approach to defining each tier of the value hierarchy.

\section{- $\quad$ Solution Design phase ${ }^{3}$}

VFT is very influential in the Solution Design phase since one of the main goals is to allow the generation of creative and innovative solutions, thus resulting in desirable consequences. However, SDP briefly summarizes creative problem solving concepts and techniques. More depth and structure is needed in this section to maximize the benefits of VFT.

\section{- Decision Making phase ${ }^{3}$}

This phase includes a great explanation of how to apply MODA to assess the effectiveness of the alternatives. However, after examining the DoD's AoA process, it was evident that SDP lacks depth in the cost analysis and risk assessment tasks. SDP only discusses why these tasks are important and shows examples of the type of knowledge gained by completing them, but it does not provide a discussion on specific processes used to complete them.

CVAP improves on these SDP areas by formulating a process for each of these phases. CVAP combines the "Voice of the Customer" with the "Voice of the Engineer" with Quality Function Deployment (QFD) to completely define the tiers of the value hierarchy (Fundamental Objective(s), Functions, Objectives, and Measures of Effectiveness). QFD further contributes to the traceability of the overall process since it is a structured approach to deriving the tiers of the value hierarchy. The values that are defined by QFD and industry-proven creative problem solving techniques are used to generate and/or identify creative and innovative alternatives. CVAP then uses MODA to 
quantitatively score and rank alternatives in terms of effectiveness. With the guidance from government sources, ${ }^{2,24} \mathrm{CVAP}$ also incorporates processes to complete cost analysis and risk assessment. Since CVAP uses SDP as a foundation, it has similar phases and tasks. Each of these phases will be discussed in detail in the next four sections $(3.3-3.6)$. The CVAP process is illustrated in Figure 12.

CVAP is also based on the DoD's AoA process since it is intended to be used in military applications. Figure 13 shows an overlay of the CVAP phases onto the AoA process to illustrate that CVAP includes all steps taken by the AoA. CVAP is capable of qualitatively and quantitatively assessing customer value for decisions and utilizing detailed technical analysis in order to provide objective and traceable recommendations to the customer.

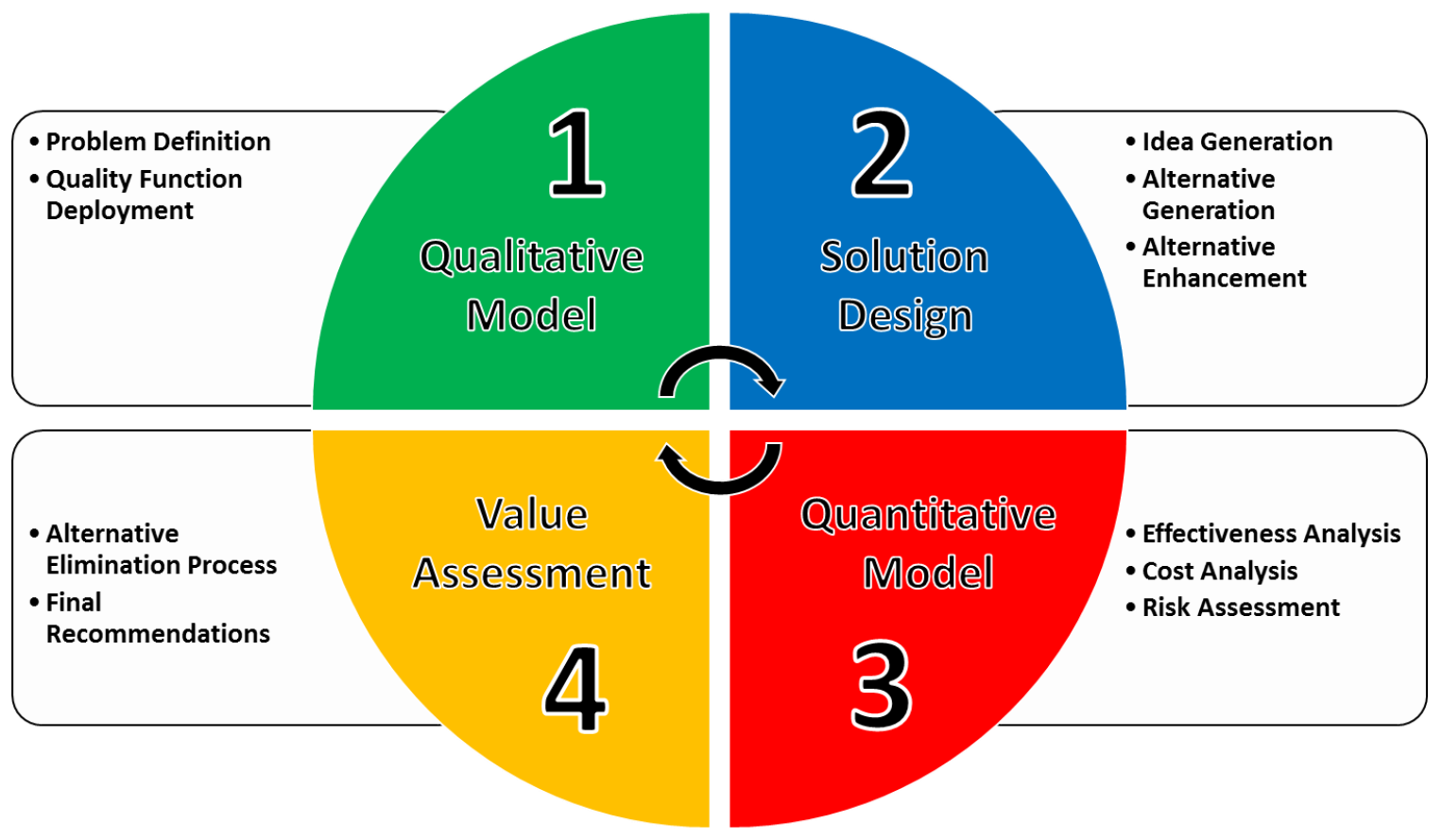

Figure 12. The Customer Value Assessment Process (CVAP) 


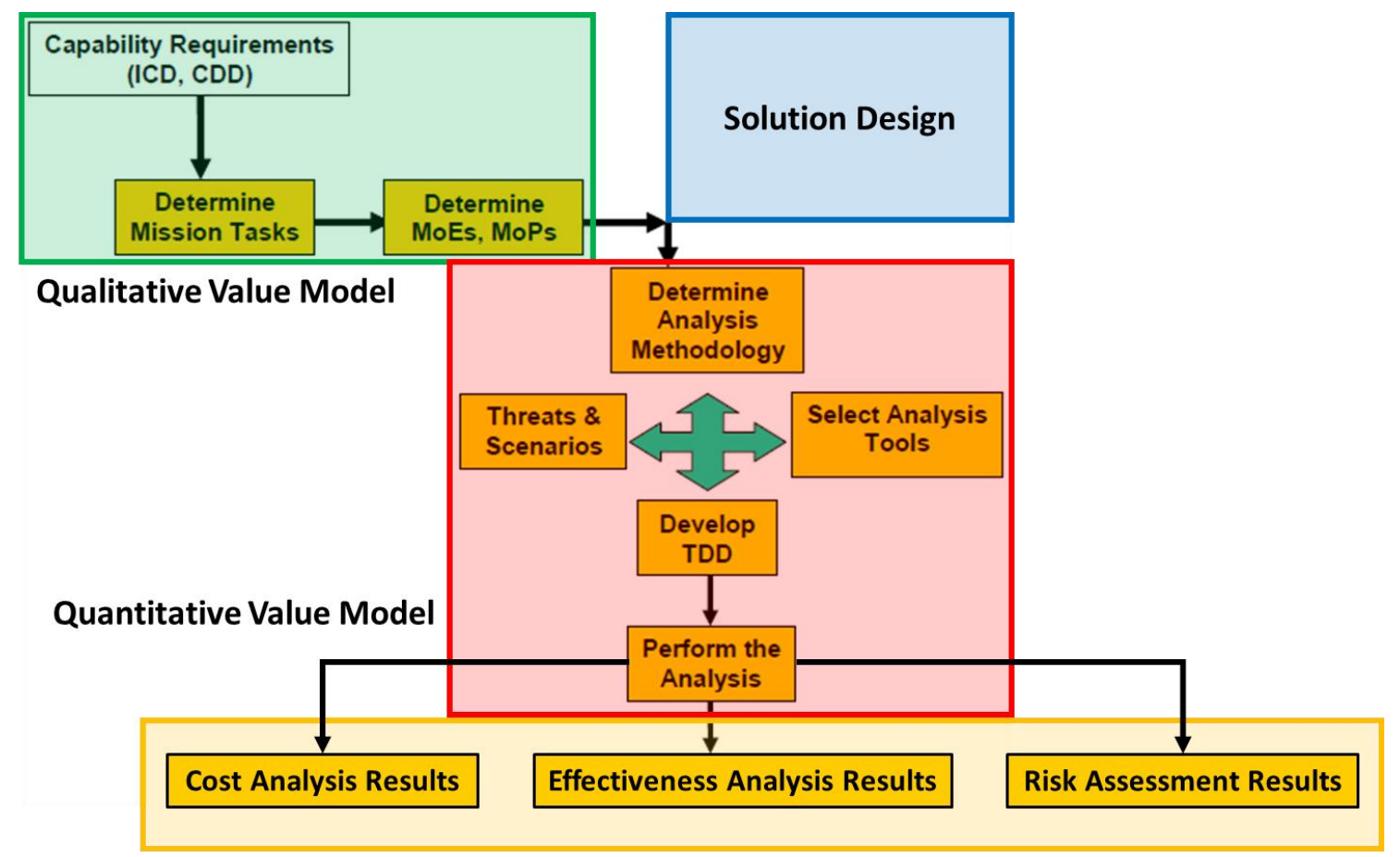

Value Assessment

Figure 13. CVAP compared to AoA ${ }^{2}$

\subsection{CVAP Phase 1: Qualitative Value Model}

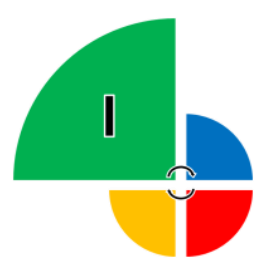

Phase 1 of CVAP is to develop a well-structured qualitative value model that accurately derives the problem statement and stakeholder values. These values are collectively defined by the fundamental objective, functions, objectives, and measures of effectiveness (definition in section 2.2.1). The qualitative value model provides the foundation for the entire analysis, thus, should be accurate and traceable if it is ever questioned. The information gathered in this phase is used in Phase 2 to generate solutions (alternatives), in Phase 3 to evaluate alternatives, and Phase 4 to make recommendations to the customer. If the problem and values are not defined right in Phase 1, the customer 
and stakeholders will not and should not care about the analysis performed in the following phases ${ }^{10}$. Therefore, it is critical that sufficient time is dedicated to properly defining the problem and values of the customer and stakeholders. The steps taken to complete the VFT qualitative value model are shown below as defined by Parnell ${ }^{14}$ :

Step 1: Identify the fundamental objective ${ }^{14}$

Identifying the fundamental objective is the essential first step that guides how we'll develop the value model. It must be a clear, concise statement of the most basic reason for the decision. In practice, we take time and thought to properly specify the fundamental objective. Once we understand it, we can determine if we have single or multiple functions. If we have a single function, we can skip step 2 and start to identify the objectives.

Step 2: Identify functions that provide value ${ }^{14}$

We can get functions from requirements documents or derive them from information gathered from stakeholder analysis.

Step 3: Identify the objectives that define value ${ }^{14}$

For each function, we need to identify the objectives that define value. Objectives can come from requirements documents, interviews with senior leaders, or workshops with stakeholders (or stakeholders' representatives).

Step 4: Identify the value measures ${ }^{14}$ (Measures of Effectiveness)

We can identify measures of effectiveness by research and interviews with decision makers, stakeholders, and subject-matter experts. Access to stakeholders and experts is the key to developing good Measures of Effectiveness (MoEs).

Step 5: Vet the qualitative value model with key decision makers and stakeholders ${ }^{14}$

We must ensure our model has captured the values of the decision makers and stakeholders. Vetting the qualitative value model and incorporating their comments is critical to ensuring they will "buy" the analysis results.

Parnell states that qualitative values models must satisfy four criteria: collectively exhaustive, mutually exclusive, operable, and as small as possible. Collectively exhaustive means that the value models must consider all essential types of evaluation. Mutually exclusive means that the criteria don't overlap. Value measures must be operable, meaning 
customers and stakeholders involved in the decision situation must interpret them the same way. Finally, as few value measures as possible should be used to limit the model's size. ${ }^{14}$

Once these steps 1-5 have been completed, VFT organizes the values in a hierarchical structure called the value hierarchy shown in Figure 14. Defining the tiers of the value hierarchy is the primary goal of Phase 1 in CVAP. The nature of a hierarchical structure allows the lower tiers to be traced back to the higher tiers and customer values. The tiers are defined in two CVAP steps that encompass the five steps previously mentioned: Problem Definition and Quality Function Deployment (QFD) as shown in Figure 15. Problem Definition is composed of two tasks: stakeholder analysis and problem definition techniques. Stakeholder analysis identifies stakeholders relevant to the decision situation and gathers needs, wants, and desires from them. CVAP then applies problem definition techniques to accurately define the first tier of the value hierarchy, the fundamental objective. After the problem definition step is complete, QFD uses the stakeholder information gathered from stakeholder analysis and uses it to derive the remaining tiers of the value hierarchy (i.e., functions, objectives, and Measures of Effectiveness). QFD can be thought of as a transfer function that converts the customer values into measureable technical parameters. ${ }^{16}$ QFD further contributes to traceability since it also uses a hierarchical structure to derive functions, objectives, and MoEs. After the QFD step is complete, all the tiers of the value hierarchy are defined and can be used to generate solutions (alternatives) in Phase 2. 


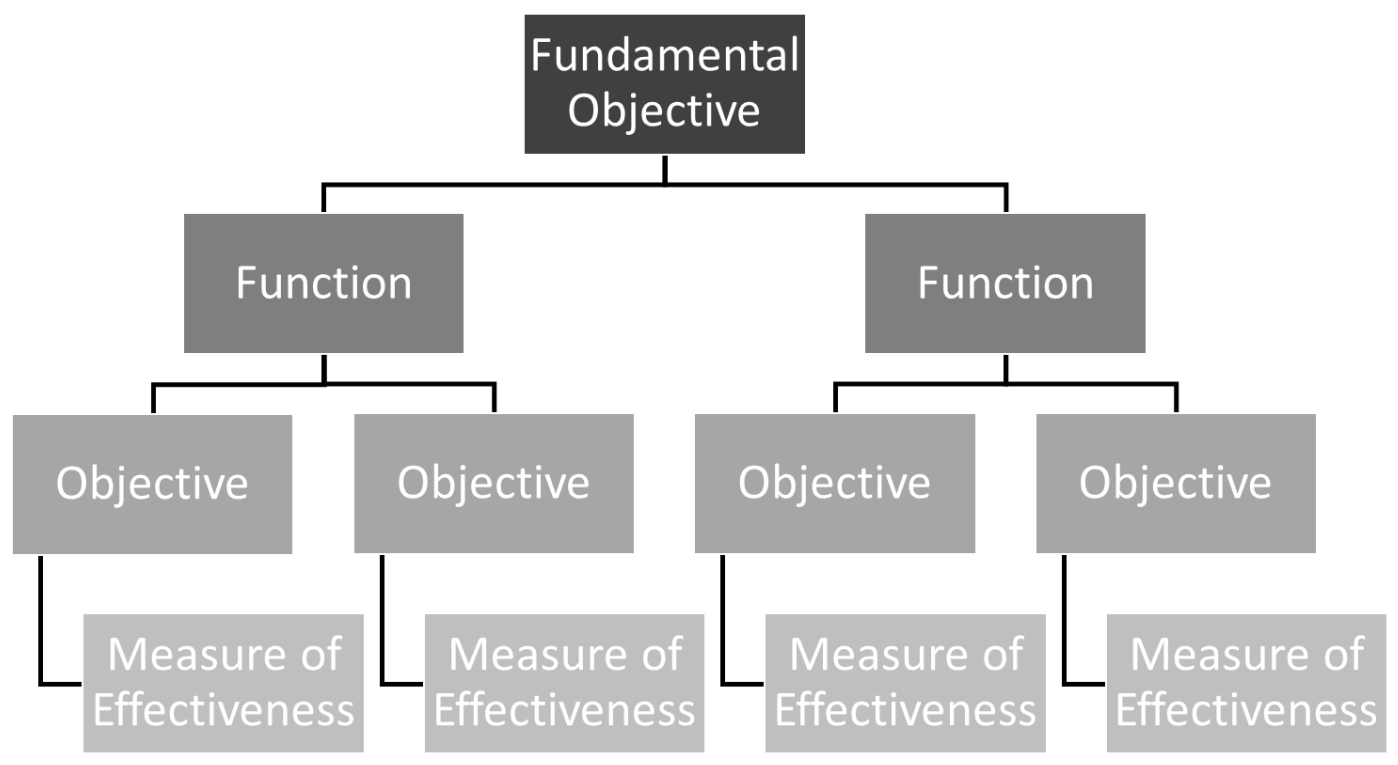

Figure 14. The VFT value hierarchy

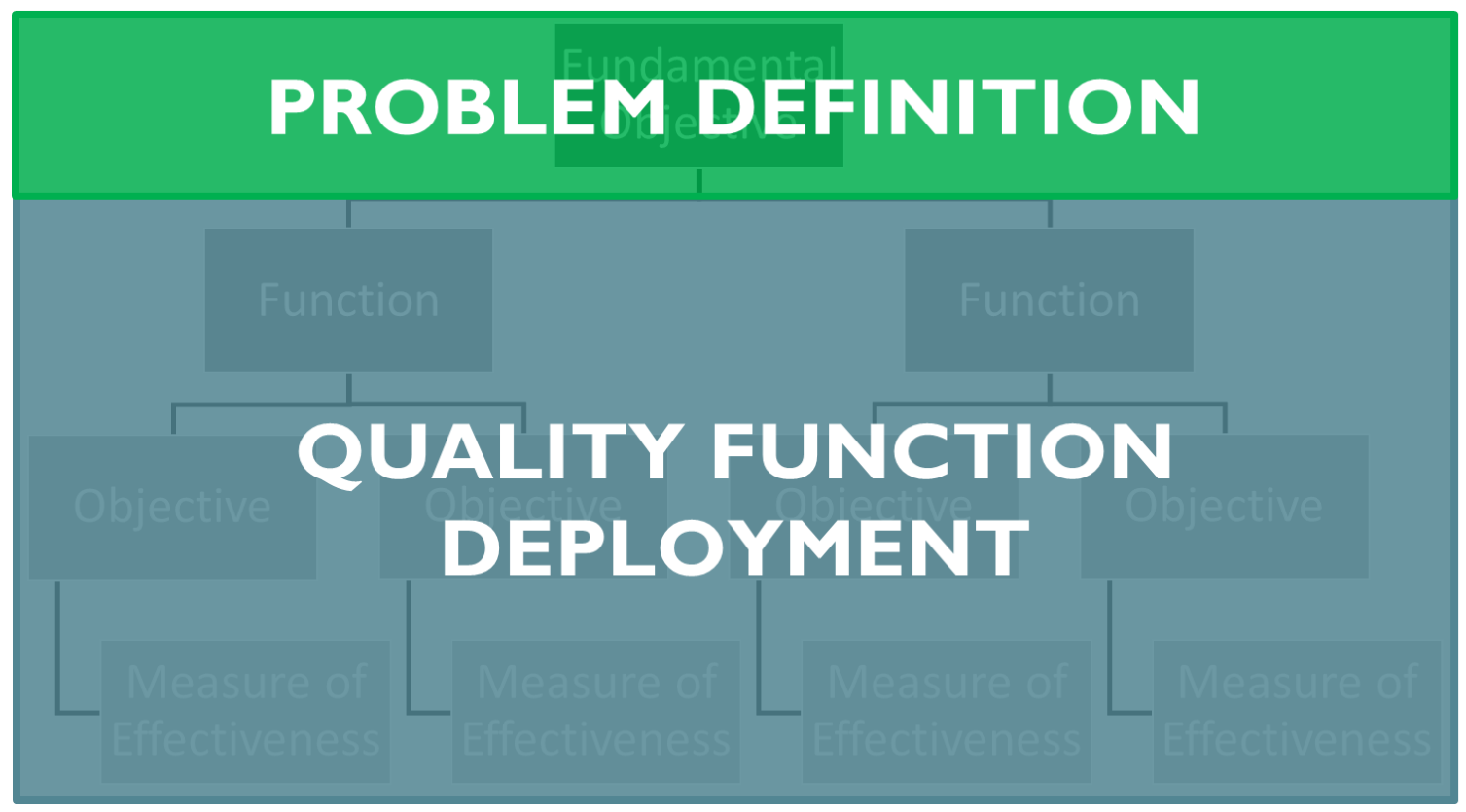

Figure 15. CVAP steps to define the VFT value hierarchy

\subsubsection{Problem Definition}

Most decision situations (problems and opportunities) have several acceptable solutions and the goal is to find, select, and implement the best one. However, all the time, money, and energy used to find the best solution would be a waste if the solution is for the perceived problem and not the real problem. This is the main objective of the problem 
definition step, to define the real problem. By defining the real problem, a statement of the most basic reason for a decision can be accurately written. This statement is known as the fundamental objective. It is possible for a decision situation to have multiple fundamental objectives. The fundamental objective is the basis of all the solutions that get generated/identified and the recommendations that are made at the end, so it is very important that sufficient time is dedicated to properly defining it.

The fundamental objective gets derived from information gathered from stakeholders through user needs documents that explicitly state values (needs, wants, and desires) and/or stakeholder analysis. In many business cases, user needs documents are not available either because the customer has not developed them or the customer does not know that they have a need for a particular product and/or service. In cases like the latter, contractors instead formulate a value proposition to customers based on values that were derived from stakeholder analysis. Value propositions show the benefits that products and/or services bring to the customer. Once stakeholder data has been gathered, the next step is to identify the real problem so the fundamental objective can be accurately defined. CVAP uses stakeholder analysis techniques used in SDP to gather stakeholder data and adds industry-proven problem definition techniques to define the fundamental objective. These problem definition techniques are the Duncker Diagram, ${ }^{9}$ Statement-Restatement, ${ }^{9}$ and Kepner-Tregoe (K.T.) Problem Analysis. ${ }^{9}$

\subsubsection{Stakeholder Analysis}

Stakeholders are the set of influential individuals and organizations that are interested in the problem and its solution. Stakeholder analysis is used to identify these individuals and organizations that are relevant to the decision situation. Stakeholders can be the customer, system users, system owners, system maintainers, regulatory agencies, 
contractors, and subcontractors among others. ${ }^{3}$ Stakeholder analysis includes a thorough study of the decision environment factors impacting the decision situation. By considering these factors, we can identify all the stakeholders. Parnell briefly describes these factors in his book as follows: ${ }^{3}$

\section{- Technological}

System elements use technologies to perform functions for consumers and users. Some techniques are developed and available. New technologies may involve technical, cost, and schedule risks for the system. In addition, the consequences of technologies are not always understood; for example, the health consequences of asbestos or the environmental impact of gasoline. A major system failure can delay a system for many years, as witnessed in the Challenger spacecraft failure.

- Economic

Economic factors are almost always a major systems decision issue. Most program managers have a budget to manage. Stakeholders are concerned about the economic impact of the new system on their budgets. For example, design changes to the airline security system have dramatically impacted many government and commercial organizations.

- Political

Political factors come into play for many systems decisions. Many stakeholder groups (e.g., lobby groups) exist to impact systems decisions by private or public organizations. Many public decisions require approval by U.S. government agencies and/or Congress. Press coverage can make any system a major political issue, for example, the space shuttle after the Challenger disaster.

- $\underline{\text { Legal }}$

Systems must comply with federal, state, and community legal requirements. For example, automobiles must meet federal safety and emissions standards and also state regulations.

- $\underline{\text { Social }}$

Systems can have social implications. For example, IT systems have significantly changed how we work and how we interact with our family, friends, and associates.

- $\underline{\text { Security }}$ 
Systems must be secure. System owners, users, and consumers want to be sure that their system and their products and services are secure against potential threats. There are several security dimensions: physical security and information security are very important issues for systems designers.

- Natural Environment

Systems can have significant consequences on our natural environment. For example, the nuclear weapons and nuclear power industries have generated a significant amount of radioactive waste that must be properly processed and safeguarded.

- Cultural

Many systems and products are designed for national cultural groups and international customers. Systems designers must consider cultural factors in their design and marketing, especially if they develop products and services for international markets with diverse customers. Cultural considerations also arise when an organization is faced with adapting to meet new challenges and desires to retain a set of cultural characteristics that define who they are or how they operate.

- Historical

Some systems impact historical issues. Most states have historical preservation societies that are interested in changes that impact historical landmarks and facilities. These organizations can impact system designs and can delay solution implementation.

- Moral/Ethical

Many times moral or ethical issues arise in systems decisions. For example, there are privacy issues associated with Integrated Technology (IT) solutions. Also, the use of certain weapons systems (e.g., chemical, biological, or nuclear) is a moral issue to many stakeholders.

\section{- Organizational}

Decisions are made within organizations. They key formal and informal organizational leaders can be important stakeholders in the decision process. Stakeholder analysis is the key to identifying and resolving organizational issues.

\section{- Emotional}

Sometimes decision makers or key stakeholders have personal preferences or emotional issues about some systems or potential system solutions. For example, nuclear power is an emotional issue for some stakeholders. Systems engineers must identify and deal with these issues. 
The primary purpose of stakeholder analysis is to obtain diverse stakeholder perspectives resulting in a broader definition of the problem. The initial problem statement is rarely the real and/or complete problem statement from the perspective of all stakeholders. The foundation of developing a complete problem definition is to understand which stakeholders are affected by the system or solution in a decision situation. ${ }^{3}$

Once the stakeholders are identified, stakeholder analysis continues by gathering data/information that includes stakeholder values (needs, wants, and desires). The stakeholder data is used to derive the fundamental objectives, functions, objectives, and Measures of Effectiveness (MoEs) that make up the value hierarchy. CVAP incorporates the same three stakeholder analysis techniques as SDP to gather stakeholder data: interviews, surveys, and focus groups. Table 4 summarizes the three techniques. ${ }^{3}$

Table 4. Stakeholder Analysis Techniques ${ }^{3}$

\begin{tabular}{|l|l|l|l|l|l|}
\cline { 2 - 6 } \multicolumn{1}{c|}{} & $\begin{array}{l}\text { Time } \\
\text { commitment of } \\
\text { participants }\end{array}$ & $\begin{array}{l}\text { Ideal } \\
\text { stakeholder } \\
\text { group }\end{array}$ & Preparation & Execution & Analysis \\
\hline Interviews & $30-60 \mathrm{~min}$ & $\begin{array}{l}\text { Senior leaders } \\
\text { and key } \\
\text { stakeholder } \\
\text { representatives }\end{array}$ & $\begin{array}{l}\text { Develop } \\
\text { interview } \\
\text { questionnaire(s) } \\
\text { and schedule or } \\
\text { reschedule } \\
\text { interviews }\end{array}$ & $\begin{array}{l}\text { Interviewer } \\
\text { has } \\
\text { conversations } \\
\text { with senior } \\
\text { leader using } \\
\text { questionnaire } \\
\text { as a guide. } \\
\text { Separate note } \\
\text { taker. }\end{array}$ & $\begin{array}{l}\text { Note taker types } \\
\text { interview notes. } \\
\text { Interviewer } \\
\text { reviews typed } \\
\text { notes. Team } \\
\text { analyzes notes to } \\
\text { determine } \\
\text { findings, } \\
\text { conclusions, and } \\
\text { recommendations }\end{array}$ \\
\hline $\begin{array}{l}\text { Focus } \\
\text { Groups }\end{array}$ & $\begin{array}{l}\text { Shortest }-60 \\
\text { min } \\
\text { Typical }-4-8 \\
\text { hrs }\end{array}$ & $\begin{array}{l}\text { Mid-level to } \\
\text { senior } \\
\text { stakeholder } \\
\text { representatives }\end{array}$ & $\begin{array}{l}\text { Develop } \\
\text { meeting plan } \\
\text { for recording } \\
\text { input. }\end{array}$ & $\begin{array}{l}\text { At least one } \\
\text { facilitator and } \\
\text { one recorder. } \\
\text { Larger groups } \\
\text { may require } \\
\text { breakout } \\
\text { groups and } \\
\text { multiple } \\
\text { facilitators }\end{array}$ & $\begin{array}{l}\text { Observations } \\
\text { must be } \\
\text { documented. } \\
\text { Analysis } \\
\text { determines } \\
\text { findings, } \\
\text { conclusions, and } \\
\text { recommendations }\end{array}$ \\
\hline & & & & & \\
\hline
\end{tabular}




\begin{tabular}{|l|l|l|l|l|l|}
\hline Surveys & $5-20$ min & $\begin{array}{l}\text { Junior to mid- } \\
\text { level } \\
\text { stakeholder } \\
\text { representatives }\end{array}$ & $\begin{array}{l}\text { Develop survey } \\
\text { questions, } \\
\text { identify survey } \\
\text { software, and } \\
\text { develop } \\
\text { analysis plan. } \\
\text { Online surveys } \\
\text { are useful. }\end{array}$ & $\begin{array}{l}\text { Complete } \\
\text { survey } \\
\text { questionnaire, } \\
\text { solicit } \\
\text { surveys, and } \\
\text { monitor } \\
\text { completion } \\
\text { status }\end{array}$ & $\begin{array}{l}\text { Depends on } \\
\text { number of } \\
\text { questions and } \\
\text { capability of } \\
\text { statistical } \\
\text { analysis package. } \\
\text { Conclusions } \\
\text { must be } \\
\text { developed from } \\
\text { the data }\end{array}$ \\
\hline
\end{tabular}

Interviews $^{3}$

If we wish to obtain information from each individual stakeholder, interviews are one of the best techniques. Interviews are particularly better for senior leaders/managers who have do not have enough time to attend longer focus group sessions or are not interested in filling out questions in a survey. It is very important to take time to prepare for the interview so that the best possible information is gathered. Appendix D provides an elaborate outline of the best practices for each step of the interviewing process as defined by Parnell. ${ }^{3}$

\section{$\underline{\text { Focus Groups }}{ }^{3}$}

A stakeholder analysis technique that is useful for determining the values and perspectives of a group of stakeholders is focus groups. The process involved gathering a group of stakeholders in a room and facilitating a discussion of the topics of interest. An advantage of facilitating a focus group is that since group members are listening to each other's responses, it may bring up topics that would have not otherwise been thought of. Another advantage is that gathering of information is much more efficient due to the fact that multiple stakeholders are interviewed instead of interviewing individually. (QFD) This saves time and money. However, focus groups may lead to biased information. If the group is not large enough, the perspective of the stakeholders will be too narrow. If the group is too large, some individuals might be reluctant to share their thoughts or provide meaningful input $^{3}$. Parnell recommends that the focus group includes 6-12 individuals. Like the 
interview technique, focus groups also need time dedicated to prepare, execute, and analyze data obtained from the focus group. Appendix E provides the best practices for focus groups as outlined by Parnell ${ }^{3}$.

\section{$\underline{\text { Surveys }}^{3}$}

Surveys are a stakeholder analysis technique that is good for gathering data from large groups of stakeholders, especially when they are geographically dispersed. Surveys are particularly appropriate for junior to mid-level stakeholders and also for gathering quantitative data that can be statistically analyzed in order to support conclusions and recommendations. Surveys are very convenient since they can be distributed via mail, email, and the Internet. Appendix $\mathrm{F}$ includes a summary of the advantages and disadvantages of each survey method and best practices. Besides these common methods, there are also several online programs that help design surveys, collect responses, and analyze the results. Some websites include surveymonkey.com, InsitefulSurveys.com, and SurveySystem.com.

\subsubsection{Problem Definition Techniques}

Now that customer data has been gathered via stakeholder analysis, the next step is to analyze the data with problem definition techniques in order to identify the real problem (i.e., fundamental objective).

The following example ${ }^{9}$ illustrates the difference between the perceived and real problem and why it is important to define the real problem. In 1990, the Bureau of Engraving and Printing (BEP) decided to improve the quality of paper dollars by purchasing a new type of paper and new machines. The BEP faced a problem when the ink used to print the paper dollars would smear when touched. The BEP initiated research programs at several universities to develop better printing inks. After a year and half of 
funding these research programs, the BEP withdrew the funds because they found that the real problem was not the ink, it was the printing machines. The machines did not print at a high enough pressure to force the ink deeper into the new type of paper. Since the BEP had initially defined the perceived problem, they wasted thousands of hours of effort by government officials and college faculty. The real problem should have been "Find out why the ink is smearing" not "Develop better printing inks". This example ${ }^{9}$ illustrates that if we don't properly define the problem, time, money, and energy are wasted finding the best solution to the wrong problem.

CVAP incorporates three techniques that "greatly enhance your chances of defining the real problem" when combined with information gathered from stakeholders ${ }^{9}$ : The Duncker Diagram, Statement-Restatement, and K.T. Problem Analysis.

Duncker Diagram $^{9}$

The Duncker Diagram aims to define the real problem by looking at two states of a perceived problem: the present state and the desired state. The present state is "where you are" and the desired state is "where you want to go". For example, let's say you are unhappy at your current job and you want a new job. The present state is that you are unhappy at your current job and the desired state is to have a new job. It is important to not be vague when describing the desired state and to be quantitative when possible. Words and phrases like "best", "maximize", "fastest", or "reasonable cost" should be avoided because these words can be taken to mean different things depending on who is reading them. For example, it is better to say "The car needs to travel $150 \mathrm{mph}$ at a cost less than $\$ 100,000$ " instead of saying "The car should maximize speed and minimize cost". The Duncker Diagram has two major pathways of general solutions as described in Fogler and LeBlanc: ${ }^{9}$ 
- Side 1: General solutions on the left side of the diagram show us how to move from the present state to achieve the desired state

- $\quad$ Side 2: General solutions on the right side of the diagram show us how to make it okay not to achieve the desired state

In each pathway, there are two types of solutions: functional solutions and specific solutions. Functional solutions are those that describe "what you need to do" while specific solutions describe "how to do it" (how to implement functional solution). Specific solutions are generated for each functional solution. Figure 16 shows the Ducker Diagram template.

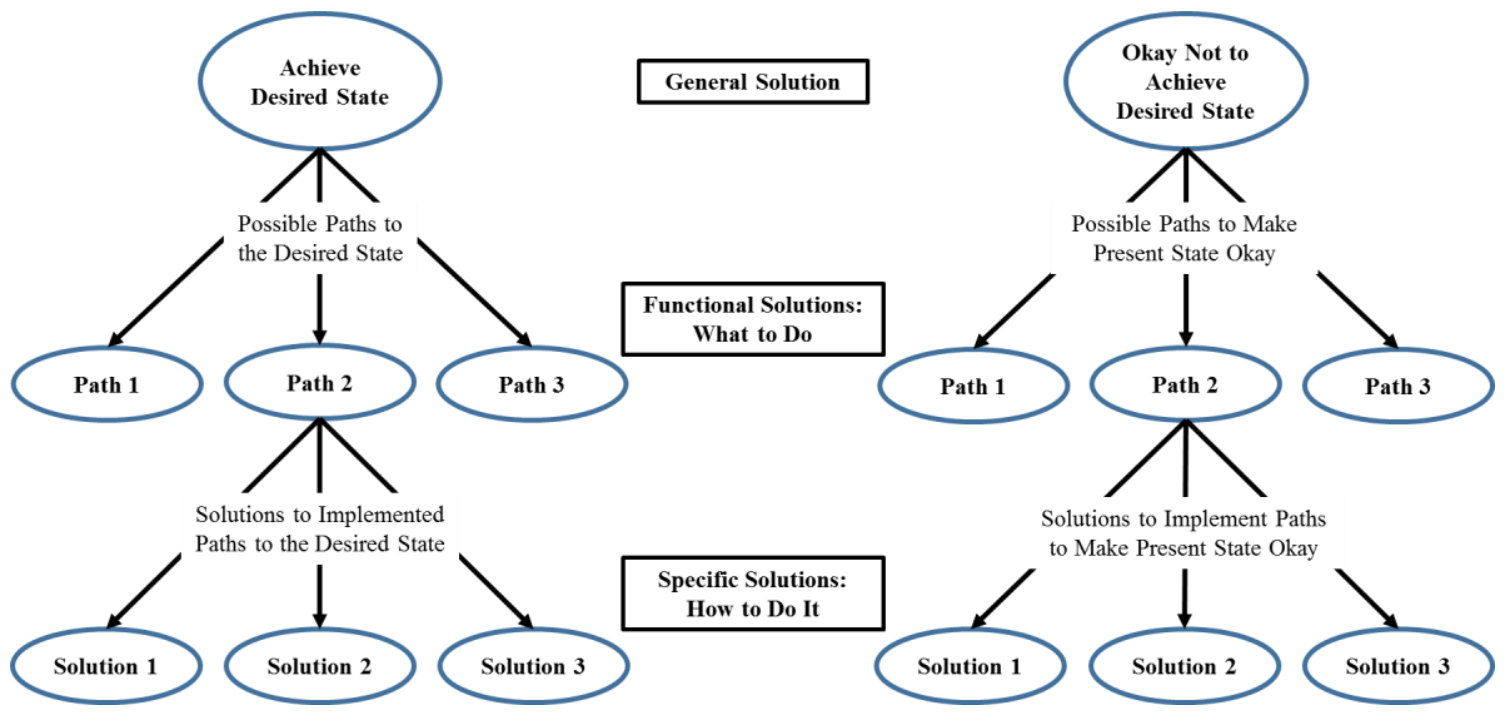

Figure 16. The Duncker Diagram Template 9

After completing the Duncker Diagram, a new problem statement should be written. This new refined problem statement compromises between present and desired states to achieve an acceptable solution. Appendix G includes an example of how the Duncker Diagram works.

$\underline{\text { Statement-Restatement }^{9}}$

The Statement-Restatement technique is a method to "evolve" the problem statement to the most accurate representation. It is similar to the Duncker Diagram in that it also requires the rephrasing of the problem statement. This technique starts off by 
assessing an unclear problem to write an initial problem statement. The problem is then repeatedly restated by applying "triggers" that change the form of the statement to generalize it. These triggers inject new ideas in the problem statement which helps in attaining the broadest problem statement. "The triggers help us find the "sensitivity" of the system variables in the problem statement and to focus on the variables that dominate the problem." "The six triggers are shown in Table 5. An example is included in Appendix H.

Table 5. Problem Statement Triggers ${ }^{9}$

\section{Problem Statement Triggers}

1) Vary the stress pattern - try placing emphasis on different words and phrases.

2) Choose a term that has an explicit definition and substitute the explicit definition in each place that the term appears.

3) Make an opposite statement, change positives to negatives, and vice versa.

4) Change "every" to "some", "always" to "sometimes", and "sometimes" to "never" and vice versa.

5) Replace "persuasive words" in the problem statement such as "obviously", "clearly", and "certainly" with the argument it is supposed to replacing.

6) Express words in the form of an equation or picture, and vice versa.

\subsubsection{Quality Function Deployment (QFD)}

Once the Problem Definition step is completed, the fundamental objective and customer and stakeholder values are defined. However, this only defines the first tier of the value hierarchy. The next step is to define the remaining tiers (i.e. functions, objectives, and Measures of Effectiveness) using the Quality Function Deployment (QFD) process. QFD is a systematic model with the purpose of establishing prioritized requirements and translating them into technical measures (MoEs) that are used in developing technical 
solutions. It ensures that customer values are reflected in the final decision ${ }^{6}$ by acting as a transfer function between the "Voice of the Customer" and the "Voice of the Engineer"16. The prioritized MoEs that are derived are then used to generate solutions in Phase 2 and evaluate them in Phase 3.

The QFD process involves creating one or more interdependent matrices, the first of which is known as the House of Quality ${ }^{8}$ (HOQ). A version of the HOQ is shown in Figure 17. The first step is to qualitatively identify what the customer needs are and then prioritize them based on weight of importance given by the stakeholders. The needs are derived from "actual words from the customer" interviews, focus groups, and surveys). The qualitative needs are then categorized in a hierarchy structure using the Affinity Diagram ${ }^{8}$ and Tree Diagram $^{8}$ processes. The Affinity Diagram and Tree Diagram processes work together to define functions, objectives, and MoEs. The derived functions, objectives, and their weights of importance populate the Customer Needs in Section A of the HOQ is Figure 17. The MoEs and a Preference Direction populate the Technical Response in Section B. For example, if the MoEs for a car were top speed and weight, the Preference Direction could be "up" (higher values are better) and "down" (lower values are better) respectively. The Technical Correlations in Section C illuminate how the MoEs impact each other. For example, if weight is increased in a car, it would reduce top speed and greatly reduce fuel consumption. At the same time, it could probably increase safety since the car would absorb more energy. It is important to understand these correlations so that effectiveness evaluations can be traced back to the MoEs. The degrees of impact can either be Strong Positive, Moderate Positive, No Impact, Moderate Negative, and Strong Negative. Section D is similar to Section C, except that the 
correlations are between Customer Needs (functions and objectives) and Technical Response (MoEs). The degrees of linkage are Not Linked, Possibly Linked, Moderately Linked, and Strongly Linked. The degree of linkage also receives a score (e.g., 0, 1, 3, and 9) that is multiplied to receive a weighted score. The scores of each MoE are added up and are used to prioritize them in Section E. The Target Values represent the MoEs that are most importance for meeting customer needs. The prioritized MoEs can then be used to generate better solutions in Phase 3.

Besides providing a structured and visual approach to deriving exactly what the customer values and how to achieve it, QFD also provides other benefits. QFD contributes to traceability because it visually correlates MoEs to the needs of the customer. The HOQ is also a great communication tool since the left side of the house is business oriented and the top is engineering oriented, allowing both disciplines to work together. Working together results in better communication and better organization. 


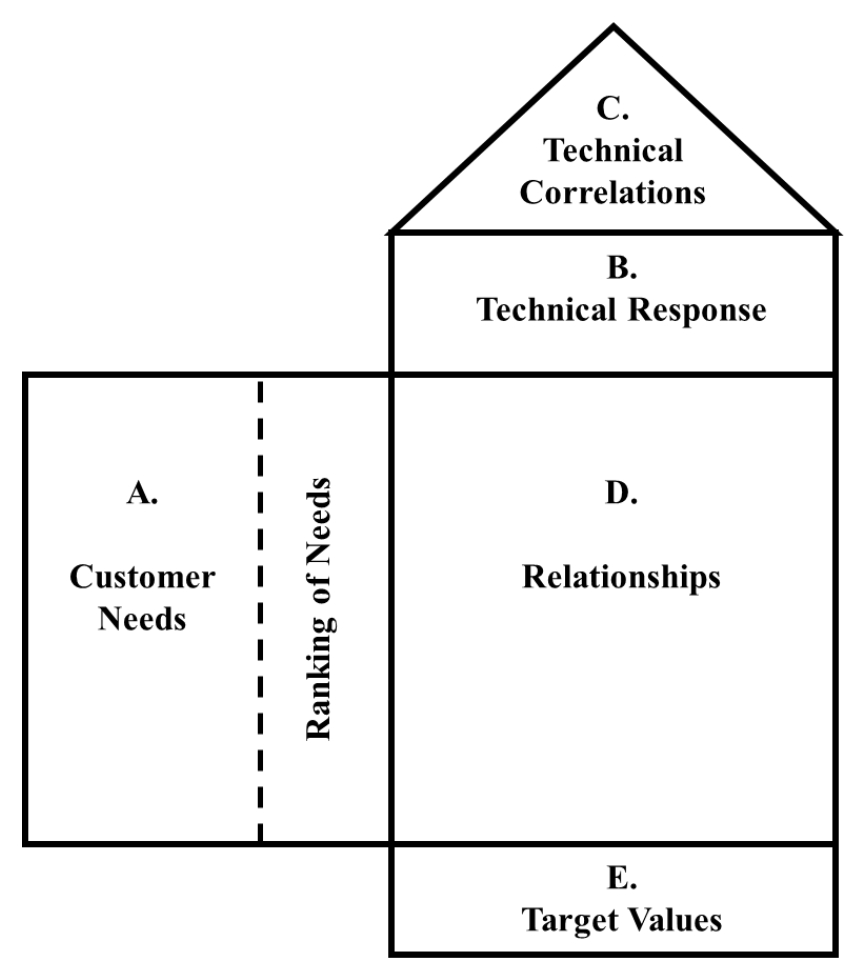

Figure 17. Modified version of the House of Quality $(H O Q)^{6,8}$

\subsection{CVAP Phase 2: Solution Design}

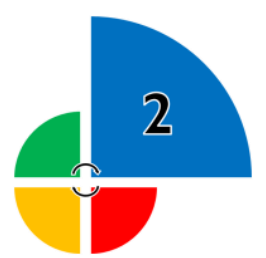

Once the tiers of the value hierarchy (i.e., fundamental objective, functions, objectives, and Measures of Effectiveness) have been defined in Phase 1, they are used in Phase 2 to identify and create alternatives (i.e., VFT). Phase 2 starts with the Idea Generation step, where industry proven creativity techniques ${ }^{9}$ are used to come up with "out of the box" innovative solutions. Once all ideas are generated, they are then combined to generate plausible alternatives in the Alternative Generation step. These plausible solutions are then screened in the Alternatives Enhancement step to filter out low-quality 
alternatives, leaving only the feasible high-quality alternatives that will be quantitatively evaluated in Phase 3.

\subsubsection{Idea Generation}

A big advantage of VFT is that it uses customer values displayed in the value hierarchy to create creative and innovative solutions, broadening the design space of possible solutions instead of limiting the solutions to those that are known (i.e., AFT). Creativity thrives in the Idea Generation step because ideas of possible solutions are suggested without judgement of feasibility. ${ }^{3,9}$ However, in order to maximize creativity, we must first be aware of the mental blocks that hinder creativity. Then, we may overcome particular mental blocks by applying the appropriate blockbusting idea generation techniques.

\subsubsection{Recognizing Mental Blocks}

There are many mental blocks that hinder the progress to a unique solution. "The first step in overcoming these blocks is to recognize them". 9 After they are recognized, appropriate blockbusting techniques can be used to move past them and work towards the best solution. Fogler and LeBlanc identified the following to be common causes of mental blocks: 9

- Defining the problem too narrowly

- Assuming there is only one right answer

- Getting "hooked" on the first solution that comes to mind

- Trying to get by with a solution that almost works (but really doesn't)

- Being distracted by irrelevant information

- Being too anxious to finish

The types of mental blocks that prevent the problem solver from correctly perceiving a problem or coming up with a solution are called conceptual blocks. Some conceptual blocks are: perceptual blocks, emotional blocks, cultural blocks, environmental 
blocks intellectual blocks, and expressive blocks. ${ }^{9}$ A description of each mental block is included in Appendix I. The most common types of mental blocks are perceptual and emotional as described by Fogler and LeBlanc: ${ }^{9}$

- A perceptual block are obstacles that prevents the problem solver from clearly perceiving either the problem itself or the information needed to solve it.

- An emotional block interferes with your ability to solve problems in many ways. They decrease the amount of freedom with which you explore and manipulate ideas, and they interfere with your ability to conceptualize fluently and flexibly. Emotional blocks also prevent you from communicating your ideas to others in a manner that will gain their approval.

\subsubsection{Blockbusting Techniques}

Now that we have recognized the two most common conceptual mental blocks (i.e., perceptual and emotional), we can now go ahead and apply appropriate blockbusting techniques to overcome them. A common emotional block is the fear of risk-taking due to the fear of failing. Overcoming this fear results in adopting a positive risk-taking attitude, which leads to confidently pursuing innovative ideas. Perceptual blocks consciously and subconsciously affect how problems are perceived. These are usually the first type of mental blocks that are experienced by individuals and groups, hence, the blockbusting techniques are most commonly applied and researched. Brainstorming is a popular perceptual blockbusting technique that overcomes stereotyping of solutions. Some perceptual blockbusting techniques that prevent the unnecessary limitation of possible solutions are cross-fertilization, analogy, and Teoriya Resheniya Izobreatatelskikh Zadatch (TRIZ). Each technique is briefly discussed. Detailed examples can be found in Fogler and LeBlanc. $^{9}$ 


\subsection{Emotional Blockbusting: Fear of Taking Risks}

The most common emotional block is the fear of taking risks. Individuals and companies are afraid of taking risks because they are afraid of making mistakes and thus, are afraid of exploring areas that have uncertainty in success. However, finding those truly unique and innovative solutions are almost never found without some risk-taking.

"Anyone who has never made a mistake has never tried anything new." - Albert Einstein ${ }^{25}$

The following is an example that illustrates a type of consequence for not taking risks. In 1973, Xerox, an American multinational document management corporation that is known for producing photocopiers, ${ }^{26}$ missed an opportunity to make billions of dollars because management was afraid of taking a risk. ${ }^{9}$ Xerox had developed the first personal computer (PC), the innovative Alto System. It contained the first handheld mouse and the first word processing system. Xerox performed a market survey that implied there was no demand for PCs. Consequently, they did not want to take the risk of losing money so they did not market the Alto System. By 1981, Apple's and IBM's revenues from PCs measured in the billions of dollars. If Xerox management would have taken the risk and marketed the Alto System, they would have made billions of dollars and would have been publically known as the company to make the first PC. To this day, Xerox is known as a "copier company" even though it was the first to develop the PC. ${ }^{9}$

The main reason why individuals and companies are afraid of taking risks is the fear of failure. Most people and companies believe that the journey to success is an upward smooth curve like the one shown on the left in Figure 18. However, the journey to success is actually like the curve shown on the right in Figure 18. The numbers on this curve refer 
to those setbacks or negative events. "These are not failures; they are events on the learning curve." ${ }^{9}$ Knowledge gained from these events should be used constructively, increasing the chances of success on the next try. The only time that these setbacks are failure is when nothing is learned.

"I have not failed. I've just found 10,000 ways that won't work."

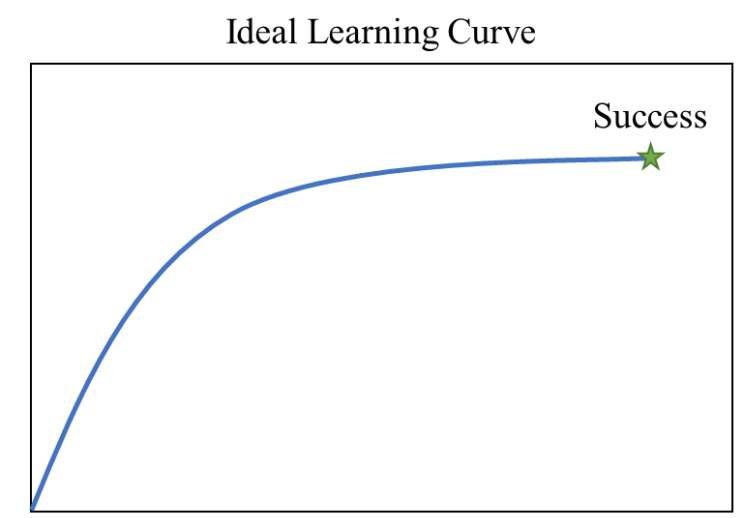

Time
- Thomas Edison ${ }^{25}$

Actual Learning Curve

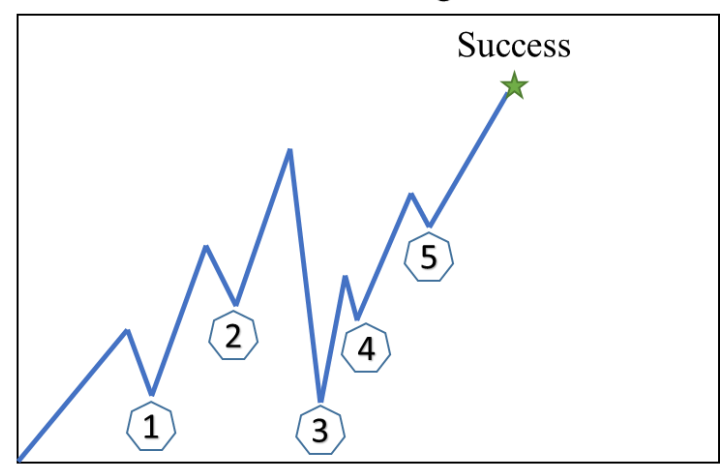

Time

Figure 18. Progress as a Function of Time ${ }^{9}$

The following is an example ${ }^{9}$ of when learning from a mistake led to success. Tom Monaghan opened a pizza store in Ypsilanti, Michigan in 1958 and closed in 1959. Instead of giving up and taking this as failure, Tom researched why the store had closed and then opened another store in 1960. This store was the first in the worldwide pizza chain known as Domino's. Monaghan did not take the closing of his first store as failure. Instead, he learned from his mistakes and continued onward to success.

"Failure shows you how to do something right."

Risks must be taken if major breakthroughs are to be made. The knowledge gained from mistakes should be used constructively in order to increase chances of success on the 
next attempt. Fogler and LeBlanc created the steps displayed in Table 6 to overcome the fear of failure: ${ }^{9}$

Table 6. Steps to overcome fear of failure ${ }^{9}$

\section{Steps to Overcome Fear of Failure}

1) Outline what the risk is and explain why the risk is important for you to take

2) Describe the worst possible outcome if you take the risk and fail

3) Describe your options when given the worst possible outcome

4) Describe what you could learn from the worst possible outcome

These steps allow the user to view the best and worst case scenario. In most cases, individuals and companies are afraid of failure so much that they only look at the worst case scenario. However, if the worst case scenario is compared to the best case scenario, many times it isn't as bad as individuals and companies make it to be. Following these steps puts the risk-taking situation in a neutral perspective, thus, allowing the user to weigh the negatives and positives instead of just looking at the negatives.

\subsection{Perceptual Blockbusting: Brainstorming}

A common way and one of the oldest techniques for overcoming perceptual mental blocks and generating ideas is brainstorming. Many books, however, only describe what brainstorming is and do not provide a detailed explanation on how to make it effective. Fogler and LeBlanc present a step-by-step brainstorming process ${ }^{9}$ and discuss the industryproven techniques that are involved. The process starts with free association, where all solution suggestions are written down without judgement of the feasibility. Usually, ideas are generated at a high rate in the beginning and then start to slow down due to perceptual mental blocks. At this point, vertical thinking and lateral thinking techniques are applied to build upon initial ideas and to continue generating new ones. 


\subsection{Free Association}

The first step of the brainstorming process is to generate solution ideas via unstructured free association. During this stage, the team should create a list of all solutions that come to mind, including all those that are viewed as wild, crazy, and unusual. ${ }^{9}$ Feasibility of solutions should not be questioned because they could spark another idea that is a logical solution. "This triggering of ideas in others is key to a successful group brainstorming." 9 In order to allow a flow of ideas, it is critical that the group maintains a positive environment for all members. Negative comments and judgements discourages individuals to suggest all their ideas, possibly resulting in not finding the best solution. "As more ideas are generated, the group stands a better chance of devising an innovative, workable solution". 9 If the brainstorming session leader fails to maintain a positive environment for all members, the brainstorming session may turn into a "brain drizzle" session. The following is a list of comments that may reduce the brainstorming session to a "braindrizzling" as written by Fogler and LeBlanc: 9

- That won't work

- It's against our policy

- It's not our job

- We haven't done it that way before

- We don't have enough time

- That's too expensive

- That's too much hassle

- That's not practical

- That's too radical

- We can't solve this problem

Typically, ideas are generated at a fast rate in the beginning, but the rate soon slows down and brainstorming hits a perceptual "road block", hindering the generation of all creative ideas. The following are blockbusting techniques that help overcome the perceptual mental blocks that lead to a "road block": vertical thinking and lateral thinking. 


\subsection{Vertical Thinking}

The first type of perceptual blockbusting technique is vertical thinking. It builds on the ideas that have already been generated and/or illuminates different parts of the problem that may trigger the flow of ideas. Fogler and LeBlanc present two vertical thinking techniques ${ }^{9}:$ SCAMPER and 77 Cards: Design Heuristics.

\section{SCAMPER}

SCAMPER is an acronym defined by Robert Eberle that is composed of verbs that stimulate the brain to think about a problem in a different perspective. The list of the verbs that make up SCAMPER are in Table 7.

\section{Table 7. SCAMPER technique ${ }^{9}$}

\begin{tabular}{|c|c|}
\hline & SCAMPER \\
\hline Substitute: & $\begin{array}{l}\text { Who else, where else, or what else could be substituted for? } \\
\text { Substitute another ingredient, material, or approach? }\end{array}$ \\
\hline Combine: & $\begin{array}{l}\text { Combine parts, units, ideas? Blend? Compromise? Combine } \\
\text { from different categories? }\end{array}$ \\
\hline Adapt: & $\begin{array}{l}\text { How can this (product, idea, plan, etc.) be used as is? What are } \\
\text { other purposes it could be adapted to? }\end{array}$ \\
\hline Modify: & Magnify? Minify? Change the meaning, material, size, etc.? \\
\hline Put to other use: & $\begin{array}{l}\text { Who else, where else, or what else could be substituted for? } \\
\text { Substitute another ingredient, material, or approach? }\end{array}$ \\
\hline Eliminate: & Remove something? Eliminate waste? Reduce something? \\
\hline Rearrange: & $\begin{array}{l}\text { Interchange components? Change pattern, pace, schedule, or } \\
\text { layout? }\end{array}$ \\
\hline
\end{tabular}

\section{Cards: Design Heuristics}

A more extensive technique than SCAMPER that has recently become more popular is using Design Heuristics to stimulate idea generation. This technique uses a lists of prompts that "help designers move through a "space" of possible solutions and also to support designers in becoming "unstuck" when they are struggling to generate more, and 
different ideas". ${ }^{9}$ Figure 19 shows how these cards can be used to come up with new ideas as well as further develop concepts. These design heuristic cards were "systematically derived from engineering designers and empirically validated in scientific studies. ${ }^{28}$ They were developed through protocol studies with expert industrial designers and engineers, and through analyses of award winning innovative product designs". ${ }^{28}$

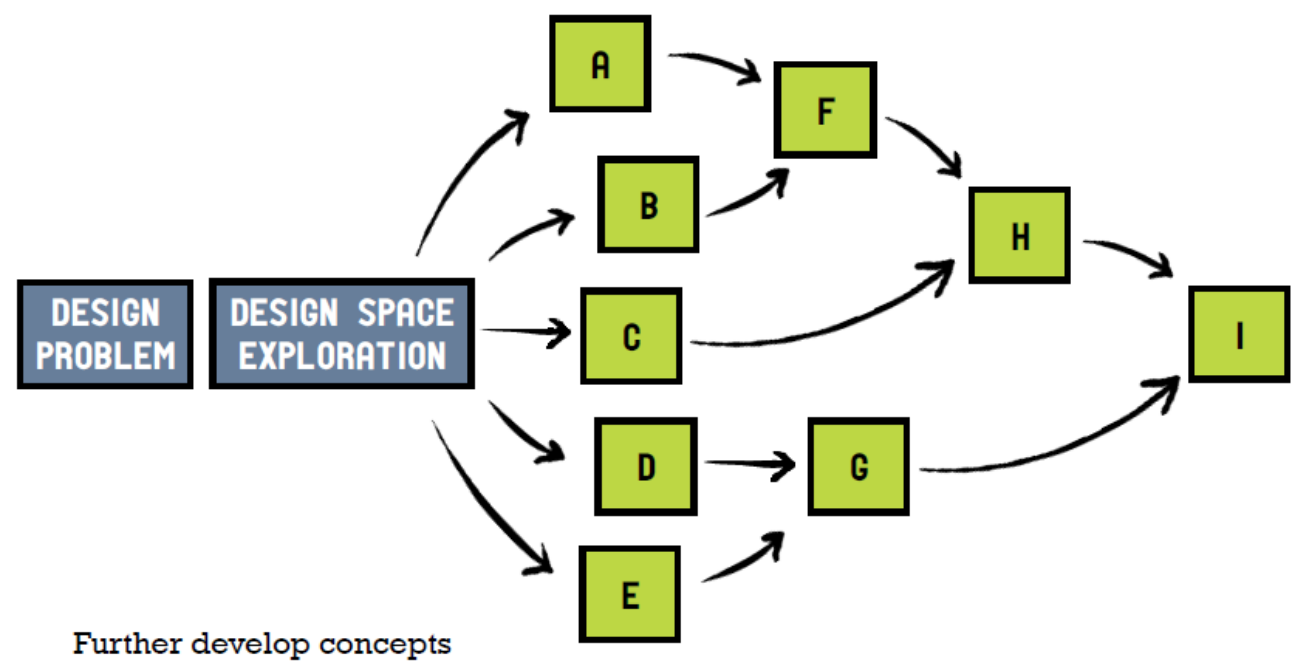

Figure 19. Design Heuristic cards for design space exploration ${ }^{29}$

A research article was published in the International Journal of Design Creativity and Innovation by Seda Yilmaz, Shanna R. Daly, James L. Christian, Colleen M. Seifert, and Richard Gonzalez titled Can experienced designers learn from new tools? A case study of idea generation in a professional engineering team. ${ }^{30}$ This research article investigated if Design Heuristics cards can help experienced engineers who are familiar with a specific product line. Their study found empirical evidence that the use of Design Heuristics for idea generation are "sufficient to stimulate novel and diverse concepts during idea generation", even for experienced professional engineers. The authors performed another study to compare the Design Heuristics approach with other design approaches taken by engineers and industrial designers and published their results in Comparison of Design 
Approaches between Engineers and Industrial Designers. ${ }^{31}$ The study performed an experiment with engineering and industrial design students to identify the utility of Design Heuristics in two different classroom settings. They concluded from this experiment that "designers in both domains can use the Design Heuristics effectively with minimal training as a tool for creating new concepts." ${ }^{31}$

\subsection{Lateral Thinking}

Vertical thinking is used to extend preexisting ideas into better concepts. On the other hand, lateral thinking produces ideas that are not related to other ideas. Two lateral thinking techniques presented in Fogler and LeBlanc ${ }^{9}$ are random stimulation and Other Points of View (OPV).

Random Stimulation

When faced with a perceptual mental block, another way to stimulate the brain into generating completely different ideas from those already listed is to use a lateral thinking technique called random stimulation. Random stimulation uses a set of random words to stimulate a multitude of different patterns of thought and feelings that may result in ideas that are totally different. One way to perform this technique is to obtain a list of random words. ${ }^{9}$

Other Points of View (OPV)

A lateral thinking technique called Others Points of View (OPV) is helpful when multiple stakeholders are involved in the decision problem. In many cases, the type of people that design the product are not the type of people that end up using or buying the product, so it is important to put yourself "in their shoes" in order to obtain the best solution for them. That is, it is important to view the problem in the perspective of the stakeholders in order to understand their thoughts and feelings. Imagining the role of the stakeholder takes into consideration what they will hear, smell, think, feel, etc. Engineers must consider 
the views of customers, management, marketing, sales, and regulatory agencies when developing a system. ${ }^{9}$

\subsection{Perceptual Blockbusting: Cross-Disciplinary Solutions}

Brainstorming primarily focuses on overcoming the perceptual mental blocks that consciously and/or subconsciously stereotype solutions. The following three techniques focus more on overcoming the perceptual mental blocks that unnecessarily limit the solutions. The techniques accomplish this by applying solutions from other disciplines and/or solutions to problems that have already been solved. The blockbusting techniques are cross-fertilization, analogy, and TRIZ.

\section{Cross-Fertilization}

The application of solutions to other cross-disciplinary problems is called crossfertilization. "Cross-fertilization utilizes unique knowledge and skill sets of individuals and groups with different backgrounds by applying expertise in new disciplines. The main advantage to solutions generated from cross-fertilization is that, in many cases, adaption is much quicker and more cost-effective than invention. For example, it would be much quicker and cost-effective to design a car around a chassis from another design than to design a new chassis.

Many creative and innovative solutions to problems have risen from solutions in another disciplines. For example, Sir Richard Branson, founder and owner of Virgin Records, applied his knowledge of the entertainment industry with knowledge from airline industry experts to start a new airline, Virgin Atlantic Airlines. The result was an unparalleled concept that provided passengers with extensive in-flight entertainment services and options. Branson's solutions to entertainment applied to the airline industry resulted in Virgin Atlantic to lead the industry. ${ }^{9}$ 
$\underline{\text { Analogy }}$

Another cross-disciplinary technique is analogy, which identifies analogous situations and problems in related and unrelated areas. In order for this technique to be most effective, it is important that we become familiar with things outside our area of expertise by taking the time to reading and learning. The steps in Table 8 guide how to solve problems via analogy as listed in Fogler and LeBlanc. ${ }^{9}$

Table 8. Steps to solve problems via analogy technique ${ }^{9}$

\section{Solving Problems by Analogy}

1) State the problem

2) Generate analogies (this is problem is like...).

3) Solve the analogy

4) Transfer the solution to the problem.

$\underline{\text { TRIZ }}$

Teoriya Resheniya Izobreatatelskikh Zadatch (TRIZ), Russian for "Theory of Inventive Problem Solving" (TIPS), is a creative problem solving technique developed by Russian engineer Genrich Altshuller that that looks at the problem at the system level, imagines the ideal solution, and resolves contradictions. Altshuller developed TRIZ after investigating tens of thousands of patents and found the common causes of innovation. What he found was that resolving contradictions while minimizing introduction of resources led to ideality in solutions. TRIZ is based on two principles as described in Fogler and LeBlanc:

- $\quad$ Principle \#1: Someone, someplace, has already solved your problems or one similar to it. Creativity means finding that solution and adapting it to the current problem.

- Principle \#2: Don't accept contradictions. Resolve them. 
The first principle states that we should not to waste time creating a solution since it has probably been created. Essentially, stating that we shouldn't waste time "reinventing the wheel". The second principle tells us that we should focus on resolving contradictions, where contradictions are defined as opposing requirements or negative correlations in performance between two or more components of a system. An example of a contradiction is making a laptop more portable results in decreasing functionality due to limited space for configuration items. Another example is driving a car at a higher speed results in reduced fuel efficiency. Table 9 shows the steps of the TRIZ process. ${ }^{9}$ Appendix K includes a more detailed outline of TRIZ.

Table 9. The TRIZ Process ${ }^{9}$

\section{The TRIZ Process}

1) Determine who else has solved the problem.

2) Identify the ideal solution. TRIZ calls it the ideal final result (IFR).

3) Identify resources that are currently available to solve problem.

4) State the problem and the contradictions that are to be solved.

\subsubsection{Idea Organization}

After ideas have been generated using blockbusting techniques, the fishbone diagram is used to graphically organize them. Appendix L has an example of how to apply the fishbone diagram in organizing ideas. ${ }^{9}$

\subsubsection{Alternative Generation}

In the previous section we identified mental blocks that hinder the generation of creative and innovative ideas and provided blockbusting techniques that overcome them. The application of these techniques, however, generate ideas that may or may not be plausible solutions. CVAP, like SDP, uses the General Morphological Analysis (GMA) method to produce all possible combinations of ideas and identifies the plausible 
alternatives. GMA has been applied to hundreds of projects in diverse fields like the development of jet and rocket propulsion systems to legal aspects of space travel. ${ }^{32}$ GMA was developed by Swiss astrophysicist and aerospace scientist Fritz Zwicky ${ }^{32}$ to provide a structured process on exploring the complete set of interrelationships between ideas and creating possible solutions to multi-dimensional problems. It allows us to discover new relationships or configurations which may be overlooked by other less structured methods. GMA is useful and trusted since it is based on the "fundamental scientific method of alternating between analysis and synthesis." GMA uses a cross-consistent matrix to analyze solutions, leaving a clear reproducible "audit trail". The steps to GMA are shown Table 10 as found in SDP. ${ }^{3}$ Appendix M includes an example of GMA.

\section{Table 10. The GMA Process ${ }^{3}$}

\section{The GMA Process}

1) Concisely formulate the problem to be solved.

2) Localize all parameters that might be important for the solution.

3) Construct a multidimensional matrix containing all possible solutions.

4) Assess all solutions against the purposes to be achieved.

5) Select suitable solutions for application or iterative morphological study.

Steps 1 and 2 are defined by the CVAP Phase 1, thus, the next step is to construct a multi-dimensional matrix that contains all possible solutions. This matrix is referred to as Zwicky's morphological box, which can be a 2-D (e.g. 5 x 5) or 3-D matrix (e.g. 5 x 5 $x$ 3). Figure 20 shows a morphological box of size $5 \times 5 \times 3$. Each cell in the matrix contains a possible solution, so for a $5 \times 5 \times 3$ box, there is total of 75 possible solutions. 


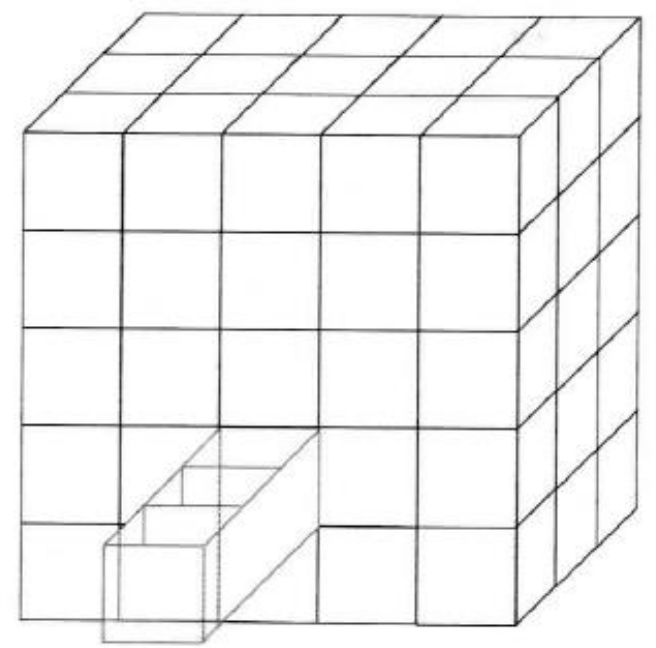

Figure 20. Zwicky's morphological box ${ }^{3}$

GMA outputs all combinations of solutions from the morphological box, however, not all are possible due to inconsistencies. GMA recognizes three types of inconsistencies: Logical, Empirical, and Normative. A logically inconsistent alternative is one that is not reasonable or rational. For example, an alternative that performs a low earth orbit in an underwater environment is logically inconsistent because orbiting earth underwater is irrational. An empirically inconsistent alternative is one that is improbable or implausible, such as "build an aircraft carrier using personal savings". A normatively inconsistent alternative is one that is not possible due to moral, ethical, or political factors. For example, a country might not be allowed to obtain certain technology due to political restrictions. The alternatives that are logically, empirically, and/or normatively inconsistent are eliminated.

\subsubsection{Alternative Enhancement}

The remaining alternatives from the Alternative Generation step are plausible, but may or may not be consistent with stakeholder needs, wants, and desires. In the Alternative Enhancement step, the plausible solutions are screened to filter out low-quality alternatives, leaving only the feasible high-quality alternatives that will be quantitatively evaluated in 
Phase 3. High-quality alternatives are those that meet the stakeholders' criteria in terms of needs, wants, and desires. Parnell ${ }^{3}$ defines needs, wants, and desires as:

- Needs are those essential criteria that must exist for the alternative to be considered

- Wants are additional features or specifications that significantly enhance the alternative, but do not cause an alternative to be rejected if missing

- Desires are features that provide a margin of excellence

Alternative Enhancement can be thought of as a "series of increasingly fine screens that filter out alternatives"3 that do not meet stakeholders' criteria as seen in Figure 21.

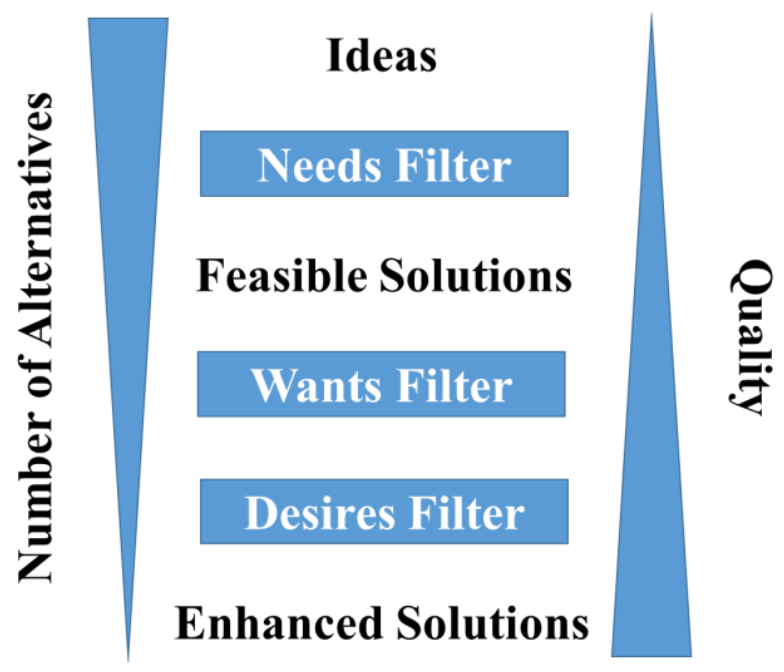

Figure 21. Feasibility Screening ${ }^{3}$

Screening through this series of filters occurs on a go or no-go basis, which means that alternatives are either passed or rejected. Those that are rejected, however, should not be eliminated until there is an attempt to modify or delete the feature(s) that caused the rejection. The screening process starts with all ideas from Idea Generation and Alternative Generation and are passed through the "needs filter". At this filter, alternatives are evaluated to see if they satisfy the requirements that must be met. Alternatives that are not capable of meeting requirements are eliminated, leaving only those that are feasible. The feasible solutions are all acceptable solutions to the decision problem. However, we want 
those of highest quality, thus, evaluated against the wants and desires of the stakeholders. The feasible solutions that satisfy the wants and desires are the highest quality solutions from the initial set of ideas and are also the set of alternatives that will be quantitatively evaluated in Phase 3 in terms of effectiveness, cost, and risk.

\subsection{CVAP Phase 3: Quantitative Value Model}

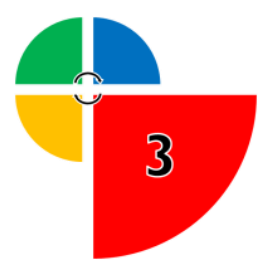

After the set of feasible high-quality alternatives have been identified and/or generated in Phase 2, the next step is to quantitatively evaluate them in Phase 3. According to the DoD, alternatives should be evaluated based on their effectiveness, cost, and risk. ${ }^{2}$ The output from these evaluations is assessed in Phase 4 to make final recommendations. At this point, CVAP only provides methods that evaluate alternatives without uncertainty in their effectiveness, cost, and risk. However, CVAP would accommodate uncertain variables with the addition of probabilistic methods. A brief description on how uncertainty is accommodated by MODA mathematical modeling is included.

\subsubsection{Effectiveness Analysis}

The first task is to evaluate alternatives based on effectiveness using MODA. MODA derives the value/utility functions for the Measures of Effectiveness (MoEs) of interest, determines the weights for the MoEs (or attributes), and then applies a mathematical model to calculate the effectiveness of each alternative. However, before applying MODA, we must remember that in order for the output to be clear, we must only evaluate alternatives against attributes that mark differences between the alternatives. "Only true differences are important in decision making." $"$ Before applying MODA, the 
attributes that are identical or have the same significance across all the alternatives should be canceled out. This results in a smaller model, reduces work and effort for the analysis team, and outputs clear results that are traceable.

Once we identify the attributes of importance (i.e., those that mark differences) we then apply MODA, which allows for two analyses: (1) ranking of alternatives based on effectiveness and (2) assessing value gaps. Value gaps illuminate areas where alternatives can be improved. The following are steps taken to perform MODA: ${ }^{14}$

\section{Step 1: Determine value/utility model}

Value (or utility) models are mathematical equations that assess the value (or utility) of a score on a MoE (or attribute) and their respective relative weight. Utility models are those with uncertainty in the outcome of selecting a particular alternative while value functions are those without uncertainty. CVAP only considers cases without uncertainty (deterministic) at this point as uses the additive value function shown in Equation 1. Cases with uncertainty will need to be addressed in future work. When assuming certainty in the outcome of selecting a particular alternative, the most simple and most common is the additive value model: ${ }^{14}$

$$
v(x)=\sum_{i=1}^{n} w_{i} v_{i}\left(x_{i}\right)
$$

where,

$v(x)$ is the alternative's value

$i=1$ to $\mathrm{n}$ is the number of the attribute $(\mathrm{MoE})$

$x_{i}$ is the alternative's score on the $\mathrm{i}^{\text {th }}$ attribute

$v_{i}\left(x_{i}\right)$ is the single dimensional value of a score of $x_{i}$

$w_{i}$ is the weight of the $\mathrm{i}^{\text {th }}$ measure of attribute

and $\sum_{i=1}^{n} w_{i}=1$ (all weights sum to one) 
However, there are many other mathematical models that may be applied, each with their own simplifications and assumptions. In order to define which mathematical model to use for analysis, we must first define if there is uncertainty or not in the consequence of picking a particular alternative. When there is uncertainty MODA uses either multiplicative, multilinear, or an additive utility model. Under uncertainty, utility models are denoted as $u(x)$ and weights as $k$. When there is certainty, MODA uses the additive value model. Under certainty, utility models are denoted as $v(x)$ and weights as $w$. Each math model has assumptions that need to be met in order to be used. Table 11 summarizes each math model and Table 12 includes a description of each assumption (Suppose that $\mathrm{Y}$ and $Z$ are a partition of the set of attributes $X$, where $X=\left\{X_{1}, X_{2}, \ldots, X_{n}\right\}$ and $X_{i}$ is a single attribute). Again, CVAP assumes certainty (deterministic values) in the outcome of selecting a particular alternative, so it uses the additive value model.

Table 11. Summary of Value/Utility Functions ${ }^{5}$

\begin{tabular}{|c|c|c|}
\hline $\begin{array}{c}\text { Value/Utility } \\
\text { Model }\end{array}$ & Equation & Assumption \\
\hline $\begin{array}{c}\text { Additive } \\
\text { Value } \\
\text { Model }\end{array}$ & $v(x)=\sum_{i=1}^{n} w_{i} v_{i}\left(x_{i}\right)$ & $\begin{array}{c}\text { Preferential } \\
\text { Independence }\end{array}$ \\
\hline $\begin{array}{c}\text { Additive } \\
\text { Utility } \\
\text { Model }\end{array}$ & $u(x)=\sum_{i=1}^{n} k_{i} u_{i}\left(x_{i}\right)$ & $\begin{array}{c}\text { Additive } \\
\text { Independence }\end{array}$ \\
\hline & & \\
\hline
\end{tabular}




\begin{tabular}{|c|c|c|}
\hline $\begin{array}{l}\text { Multilinear } \\
\text { Utility } \\
\text { Model }\end{array}$ & $\begin{aligned} u(x)=\sum_{i=1}^{n} k_{i} & u_{i}\left(x_{i}\right) \\
& +\sum_{i=1}^{n} \sum_{j>1} k_{i j} u_{i}\left(x_{i}\right) u_{j}\left(x_{j}\right) \\
& +\sum_{i=1}^{n} \sum_{j>i} \sum_{l>j} k_{i j l} u_{i}\left(x_{i}\right) u_{j}\left(x_{j}\right) u_{l}\left(x_{l}\right) \\
& +\cdots+k_{123 \ldots n} u_{1}\left(x_{1}\right) u_{2}\left(x_{2}\right) \ldots u_{n}\left(x_{n}\right)\end{aligned}$ & $\begin{array}{c}\text { Utility } \\
\text { Independence }\end{array}$ \\
\hline $\begin{array}{l}\text { Multiplicative } \\
\text { Utility } \\
\text { Model }\end{array}$ & $\begin{array}{l}u(x) \\
=\left\{\begin{array}{l}\left\{\prod_{i=1}^{n}\left[k k_{i} u_{i}\left(x_{i}\right)+1\right]-1\right\} / k, \quad-1<k \neq 0 \\
u(x)=\sum_{i=1}^{n} k_{i} u_{i}\left(x_{i}\right), \quad \text { otherwise }\end{array}\right. \\
\text { where, } \\
\qquad 1+k=\sum_{i=1}^{n}\left(k k_{i}+1\right)\end{array}$ & $\begin{array}{c}\text { Mutual } \\
\text { Utility } \\
\text { Independence }\end{array}$ \\
\hline
\end{tabular}

Table 12. Value/Utility Model Assumptions ${ }^{5}$

\begin{tabular}{|c|l|}
\hline Assumption & \multicolumn{1}{c|}{ Description } \\
\hline Additive \\
Independence & $\begin{array}{l}\text { Preferences over } \mathrm{X} \text { (Where } \mathrm{X}=\left\{\mathrm{X}_{1}, \mathrm{X}_{2}, \ldots, \mathrm{X}_{\mathrm{n}}\right\} \text { and } \mathrm{X}_{\mathrm{i}} \text { is a single } \\
\text { attribute) are additive independent if the rank ordering for any set of } \\
\text { alternatives depends only on the marginal probability distributions } \\
\text { over the attributes (MoEs) for each alternative. }\end{array}$ \\
\hline $\begin{array}{c}\text { Preferential } \\
\text { Independence }\end{array}$ & $\begin{array}{l}\text { Suppose that } \mathrm{Y} \text { and } \mathrm{Z} \text { are a partition of the set of attributes } \mathrm{X} \text { (Where } \\
\mathrm{X}=\left\{\mathrm{X}_{1}, \mathrm{X}_{2}, \ldots, \mathrm{X}_{\mathrm{n}}\right\} \text { and } \mathrm{X}_{\mathrm{i}} \text { is a single attribute). Then partition } \mathrm{Y} \text { is } \\
\text { preferentially independent of partition } \mathrm{Z} \text { if the rank ordering of } \\
\text { alternatives that have common levels for all attributes in } \mathrm{Z} \text { does not } \\
\text { depend on these common levels. }\end{array}$ \\
\hline Utility & $\begin{array}{l}\text { Suppose } \mathrm{Y} \text { and } \mathrm{Z} \text { are a partition of attribute } \mathrm{X} \text {. Then } \mathrm{Y} \text { is utility } \\
\text { independent of } \mathrm{Z} \text { if the rank ordering of any set of alternatives with } \\
\text { uncertainty about the outcomes for the attributes in } \mathrm{Y} \text { and common } \\
\text { specified levels for the attributes in } \mathrm{Z} \text { does not depend on the } \\
\text { specified levels of the attributes in } \mathrm{Z} \text {. (The common levels do not } \\
\text { have to be the same for different attributes, but the level of each } \mathrm{X}_{\mathrm{i}} \\
\text { in } \mathrm{Z} \text { is that same for all alternatives, and there in no uncertainty about } \\
\text { this level.) }\end{array}$ \\
\hline
\end{tabular}


Mutual Utility Independence
The attributes $\left\{\mathrm{X}_{1}, \mathrm{X}_{2}, \ldots, \mathrm{X}_{\mathrm{n}}\right\}$ are mutually utility independent if every subset of the attributes is utility independent of the remaining attributes.

Multiplicative and multilinear utility models are not as restrictive as the additive utility model and allow for cross terms, thus, may be more accurate. However, they are more complicated and require further judgment in assessing cross term weights. So the questions is, "which one should be used?" Rayno applied all three utility models to a military problem to see if one math model was more accurate than the others in terms of prioritizing alternatives and final value scores. He found that as long as the assumptions were valid for each model in the particular application, the multilinear and multiplicative models are "sufficiently explained by the additive model"10. He concluded that there is no gain in using the more complicated models. As long as additive independence is assumed, there is no loss of accuracy when using the simpler additive model.

Step 2: Determine value/utility functions

Once we have selected the mathematical model that is appropriate for the intended application, the next step is to determine the value/utility functions of the measures of effectiveness. Value functions determine the single dimensional value of a score of $x_{i}$ and the returns to scale on the measures of effectiveness. Value (or utility) functions convert an alternative's score to a relative value (or utility). These relative values (or utilities) are between 0 and 1, where 0 indicates no value (or utility) and 1 indicates highest value (or utility). The functions have four basic shapes: linear, concave, convex, and an S-curve as seen in Figure 22. These shapes are determined with the help of subject-matter experts (SMEs). The following is each type of value function as described by Parnell: ${ }^{14}$

- Linear: constant returns to scale which means that each increment of the measure of effectiveness is equally valuable 
- Concave: decreasing returns to scale which means that each increment is worth less than the preceding increment

- Convex: increasing returns to scale: each increment of the measure is worth more than the preceding increment

- S-curve: increasing, then decreasing, returns to scale on the measure of effectiveness

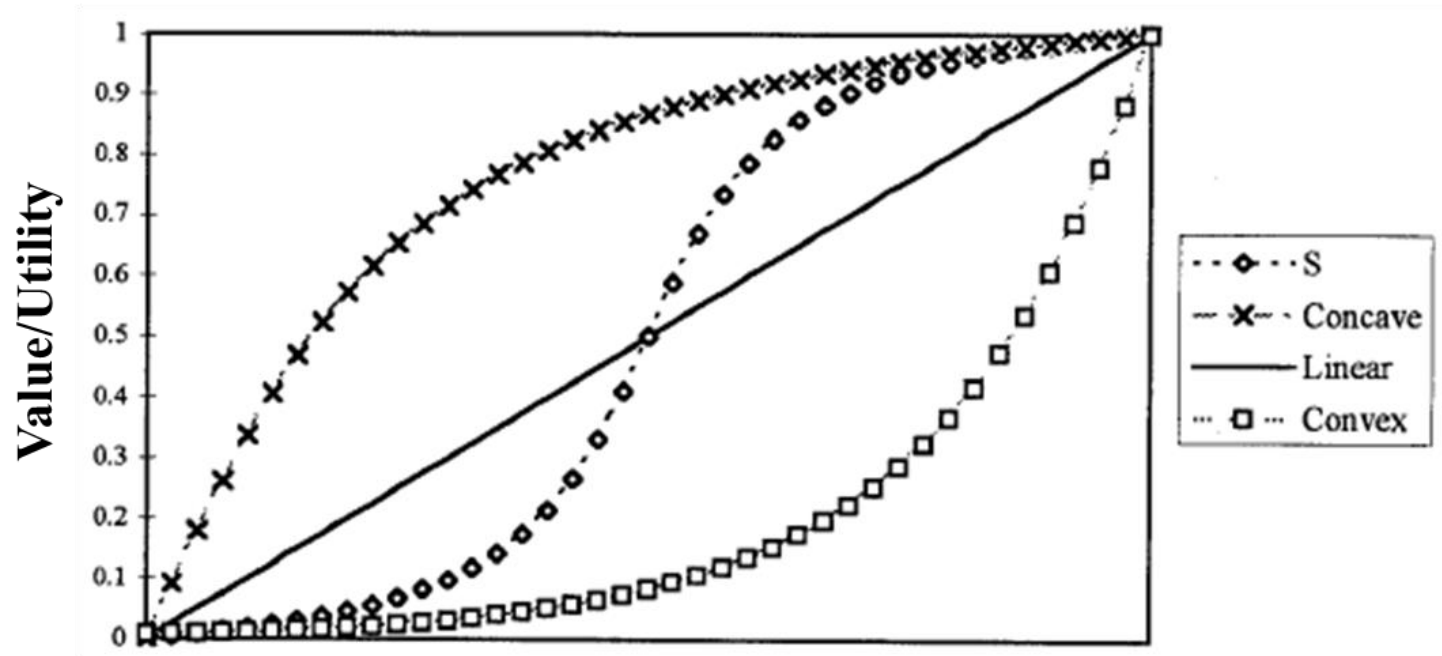

Measure of Effectiveness

Figure 22. Four Types of Value/Utility Functions ${ }^{10}$

There are several techniques to develop value curves from subject-matter experts.

The first step is to have the experts determine whether the shapes of the curves are linear, concave, convex, or S-curve. Next, we can use either (1) piecewise linear value/utility functions or (2) exponential value/utility functions. If using piecewise functions, subjectmatter experts determine the value increments to identify several points on the curve along with the relative value of the increments in the measure of effectiveness scale. If using exponential functions, the subject-matter expert must first determine if preferences over a measure of effectiveness are monotonically increasing or monotonically decreasing. If the measure of effectiveness is increasing, then Equation 2 is used, if it is decreasing, Equation 3 is used. $^{5}$ 
The specific shapes of the exponential curves depend on Rho ( $\rho)$, which is called the exponential constant. For smaller values of $\rho$, the functions are more curved while for larger values of $\rho$, the functions are less curved. When rho gets infinitely large, the curve becomes linear. The value of the exponential constant $(\rho)$ is found using a table included in Appendix N.

$$
\begin{aligned}
& v(x)= \begin{cases}\frac{1-e^{-(x-L o w) / \rho}}{1-e^{-(\text {High }- \text { Low }) / \rho}}, & \rho \neq \infty \\
\frac{x-\text { Low }}{\text { High-Low }}, & \text { otherwise }\end{cases} \\
& v(x)= \begin{cases}\frac{1-e^{-(\text {High }-x) / \rho}}{1-e^{-(\text {High-Low }) / \rho},} & \rho \neq \infty \\
\frac{\text { High }-x}{\text { High }- \text { Low }}, & \text { otherwise }\end{cases}
\end{aligned}
$$

Step 3: Determine weights

MODA quantitatively assesses the trade-offs between conflicting objectives by evaluating the alternative's contribution to the MoEs and the importance of each measure of effectiveness (weight). The weights depend on the MoE's importance and range. Most methods only take into account the importance when producing weights. However, this is inadequate to accurately determine weights because they also depend on the variation of the MoE's scale. ${ }^{33}$ For example, if we hold constant all other MoE ranges and reduce the range of one of the measure scales, the measure's relative weight will decrease and the weight assigned to the others increases since the weights add to $1.0 .^{33}$ Therefore, it is important to consider both importance and variation of each attribute when determining the weight. The swing weight matrix method explicitly defines these two factors when 
determining weights. Appendix $\mathrm{O}$ has the steps to determine the swing weights. The swing weight matrix method has four advantages over traditional weighting methods: ${ }^{14}$

- Develops an explicit definition of importance

- Forces explicit consideration of the variation of scores

- Provides a framework for consistent swing weight assessments

- Provides a simple yet effective framework to present and justify the weighting decisions

\section{Step 4: Score alternatives on measures of effectiveness}

Now that we have determined the shape of the value (or utility) functions and determined MoE weights, we must then score the alternatives on the MoEs. Parnell identifies three scoring approaches that have been successful in his military applications: alternative champions, a scoring panel, and alternative champions reviewed by a scoring panel: ${ }^{14}$

- $\quad$ Scoring by alternative champions

This approach is useful because it sends information about values from the value model directly to "champions" as they do the scoring. A disadvantage is the perception that a champion of an alternative may bias a score to unduly favor it or that scores from different champions will be inconsistent.

- Scoring by a scoring panel

To avoid the perception of scoring bias and potential scoring inconsistencies, subject-matter experts can convene as a panel to assign scores and improve the alternatives. Champions of alternatives can present scoring recommendations to the panel, but the panel assigns the score.

- $\quad$ Scoring by alternative champions reviewed by a scoring panel

Having the idea champion score the alternative and modify it to create more value is the essence of value-focused thinking. A scoring review panel can then ensure the scores are unbiased and consistent.

Step 5: Illustrate results with Stacked Bar Graph

Once we have scores and weights, we can plug them into the mathematical model and rank the alternatives. If we assume no uncertainty, we can rank alternatives via 
deterministic analysis. Therefore, stacked bar graphs are used to compare alternatives in terms of effectiveness. However, this may not be applicable to all applications. In the case where uncertainty is significant, a probabilistic analysis is more appropriate. CVAP only considers deterministic analysis at this point.

Each stack of the bar graph is the weighted value score that a particular alternative receives for a particular MoE. The summation of all the weighted value scores is the global score that is used for ranking. The global scores in Figure 23 are 7.5, 6.5, and 6.3 for Alternative 1, Alternative 2, and Alternative 3, respectively.

A major goal of VFT is to generate better alternatives. When we score the alternatives, we can identify value gaps. Value gaps illuminate the opportunities to improve the alternatives so they can achieve a higher value. They are calculated by subtracting the alternatives' "stacks" with the stacks from the ideal alternative (one that scores a value of 1 for all MoEs). Figure 23 shows an example of a stacked bar graph.

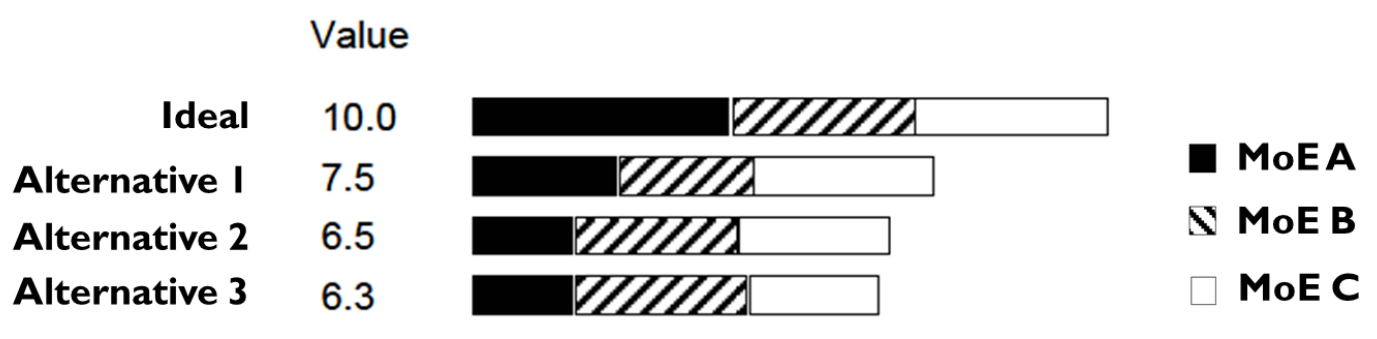

Figure 23. Stacked Bar Graph ${ }^{14}$

\section{Step 6: Perform Uncertainty Analysis}

The additive value model has three sources of uncertainty: alternative scores, value functions, and weights.

Uncertainty about alternative scores can be assessed using probability distributions, giving the analysis team the probability distribution of value (or utility) from which 
customers (or decision makers) can directly assess the alternative's risk of it not being effective. Two of the most common approaches are decision trees and Monte Carlo simulations. ${ }^{14}$

Uncertainty on weights and alternative scores are assessed with sensitivity analysis. A common approach is to vary the weights or alternative scores and show how it impacts the alternatives' value (utility). Varying the weights is more useful for models with high quantity of alternatives because they affect the scores of all alternatives. Varying the individual MoE scores for each alternative would be extremely time-consuming and may have little impact on the overall value (utility). Figure 24 shows a typical plot from a sensitivity analysis. Lines with higher slope are those more sensitive to changes in weight or score.

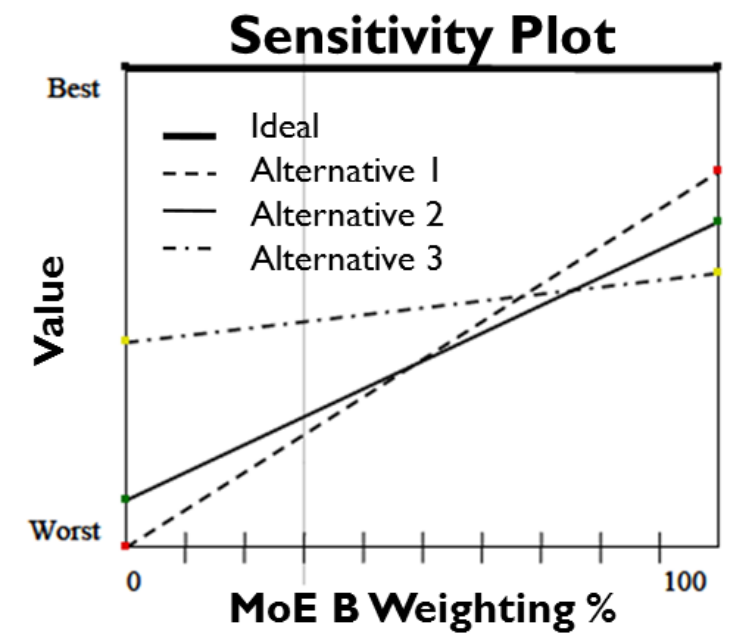

Figure 24. Sensitivity Plot ${ }^{1}$

\subsubsection{Cost Analysis}

Cost analysis uses estimates of total life cycle cost (LCC) of each alternative and combines it with the effectiveness analysis results to identify the alternative(s) that represent the best joint value. The DoD recognizes four elements of LCC: Research and Development (R\&D) cost, Procurement and Investment cost, Operations and Support 
(O\&S) cost, and Disposal cost (described in section 3.1.1). It is important to take into account all of these elements when performing a cost analysis because each element may be more dominant depending on the type of system. For example, space systems must invest heavily in R\&D because the system cannot be maintained once it is launched into space. $^{24}$

Once alternatives are evaluated in terms of cost and effectiveness, a value versus cost plot like the one shown in Figure 25 can be made. The plot helps to quickly identify the dominant alternatives and enables decision makers to see the increase in cost for the value that may be added. Assessing cost allows the analysis team to present tradeoffs when making recommendations to the customer. For example, a particular alternative may be the most effective but it may also be the most expensive. Depending on the flexibility of the customer's budget, this may or may not be feasible.

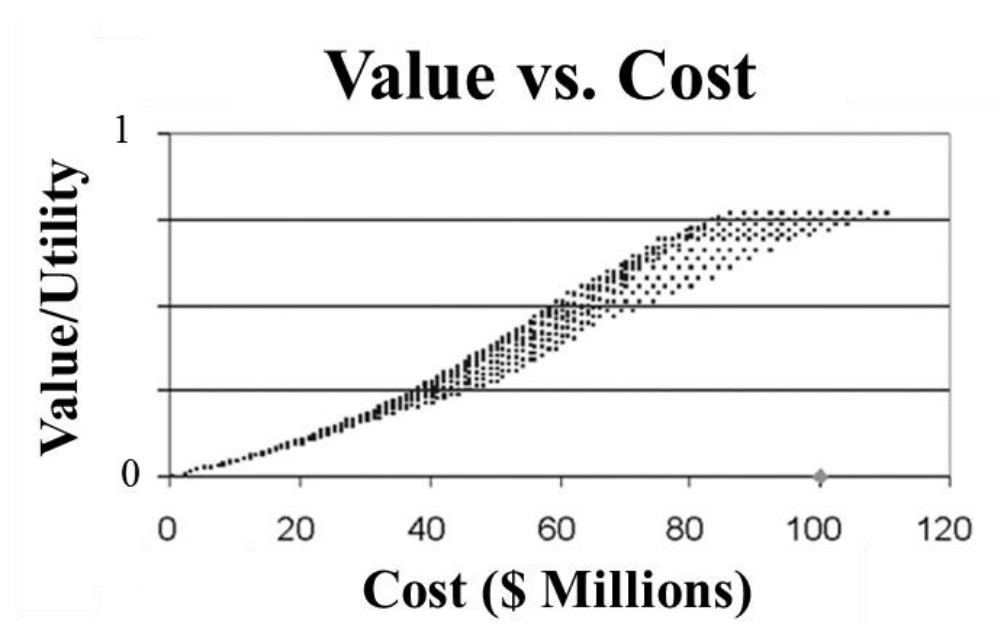

Figure 25. Value vs. Cost Plot ${ }^{1}$

In order for a cost analysis to be useful, the LCC must be estimated properly. However, estimating LCC is a very complicated task since it involves collecting and analyzing historical data and applying quantitative tools to predict it. The United States 
Government Accountability Office (GAO) published a cost estimating and assessment guide $^{24}$ that discusses a 12 -step process and best practices that accurately and reliably estimate cost. The 12-step process is shown in Figure 26. An explanation of each step is included in Appendix P.

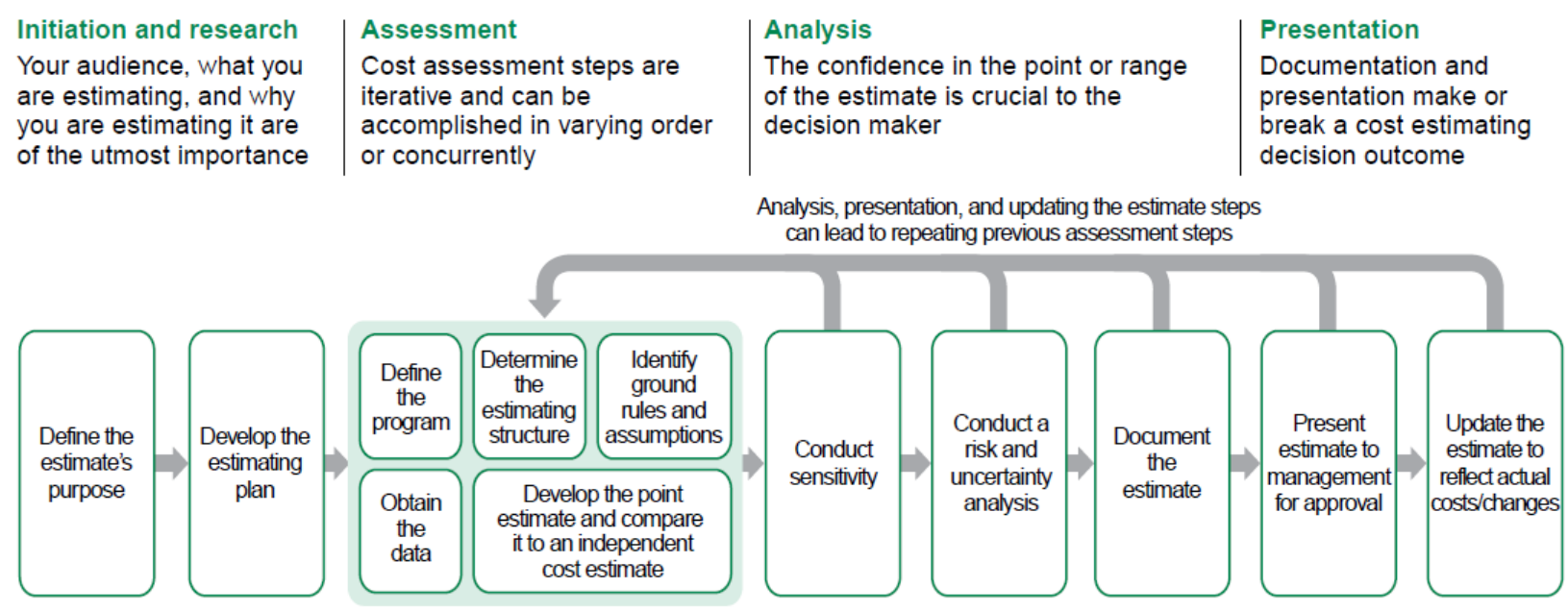

Figure 26. The Cost Estimating Process ${ }^{24}$

\subsubsection{Risk Assessment}

Risk is defined to be the probability of an adverse event (undesirable consequences) occurring and the severity of it occurring. It is important to consider it when comparing alternatives because the driving force of making a decision is to attain desirable consequences. Alternatives with low risk are more likely to attain desirable consequences while alternatives with high risk are more likely to attain the undesirable ones. Assessing risk allows the analysis team to present tradeoffs when making recommendations to the customer. For example, a particular alternative may be the most effective but it may also be the riskiest. Depending on how risk averse the customer (or decision maker) is, this may or may not be the best alternative.

CVAP uses a technique called Failure Modes Effects and Criticality Analysis (FMECA) to assess technologic and operational risks. FMECA is a systematic process that 
quantitatively and objectively analyzes possible system failure modes (FMs). FMECA first identifies failure modes and then estimates the probability of them occurring (denoted by the variable "P"), the severity of their effect (denoted by the variable "S"), and the probability of detecting the failure (denoted by the variable "D"). ${ }^{6}$ FMECA quantifies "P", "S", and "D" with a scale (usually 1-10) that is developed by the analysis team with the help of subject matter experts. The scale should also include the ranges of scores that are considered to be low, medium, and high risk. Once failure modes are scored on each scale, the analysis team can perform two types if analyses: (1) establish a risk assessment matrix to identify the low, medium, and high risk failure modes per alternative and (2) rank the alternatives based on risk.

To establish a risk assessment matrix, the scores of the "P" and " $\mathrm{S}$ " of the failure modes (FM) of each alternative populate a matrix as shown in Figure 27. The maximum score considered to be low probability and low severity are used to create the low-risk boundary line. Any failure mode below this line is considered to be low risk. The minimum score considered to be high probability and high severity are used to create the high-risk boundary line. Anything below the high-risk boundary line and above the low-risk boundary line is considered medium risk. Anything above the high-risk boundary line is considered to be high risk. 


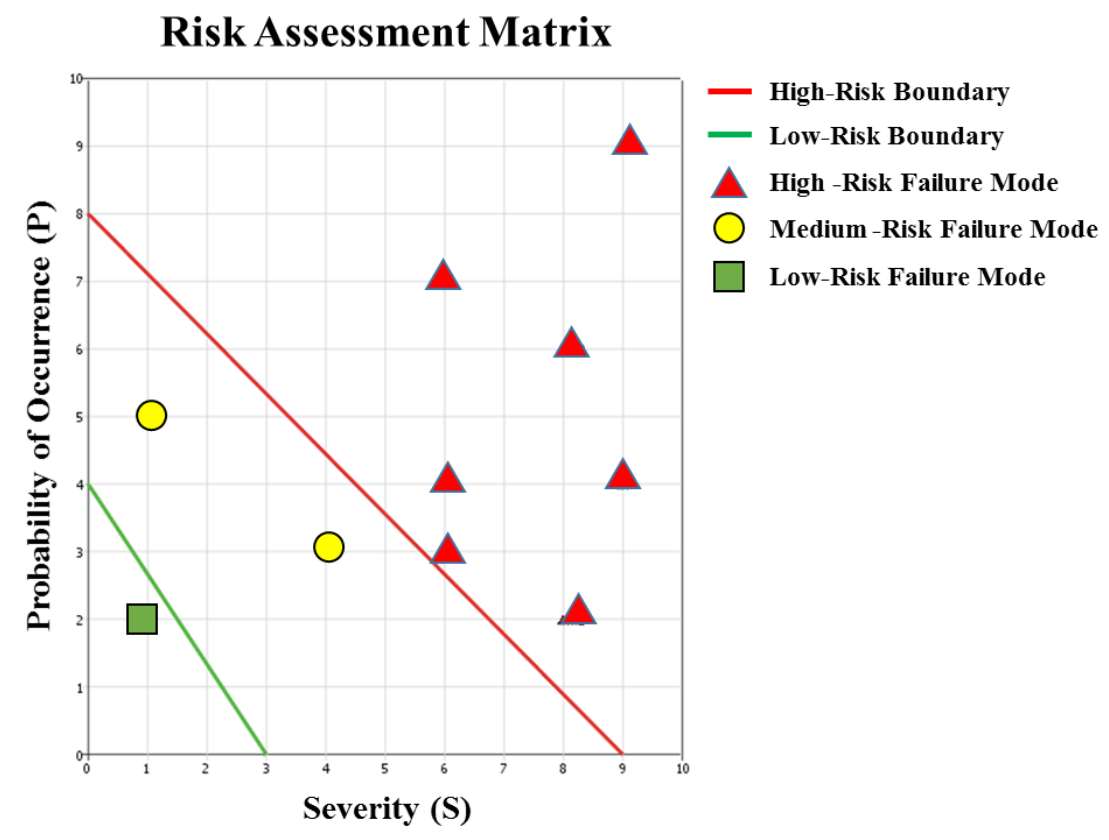

Figure 27. Risk Assessment Matrix ${ }^{34}$

FMECA can also be used to rank alternatives based on risk by multiplying "P", "S", and "D" together to get a risk priority number (RPN) per failure mode (Equation 4) and adding them up to make up a total RPN per alternative (Equation 5). The total RPNs are displayed from largest to lowest in a Pareto analysis plot as seen in Figure 28. Alternatives with a higher RPN face a higher threat of not achieving desirable consequences than alternatives with a lower RPN. Like the boundary lines of the risk assessment matrix, scale intervals of low, medium, and high risk can also be assigned to total RPNs.

$$
\begin{gathered}
R P N_{F M i}=(P)(S)(D) \\
R P N_{\text {Alternative } i}=R P N_{F M 1}+R P N_{F M 2}+\cdots+R P N_{F M n}
\end{gathered}
$$




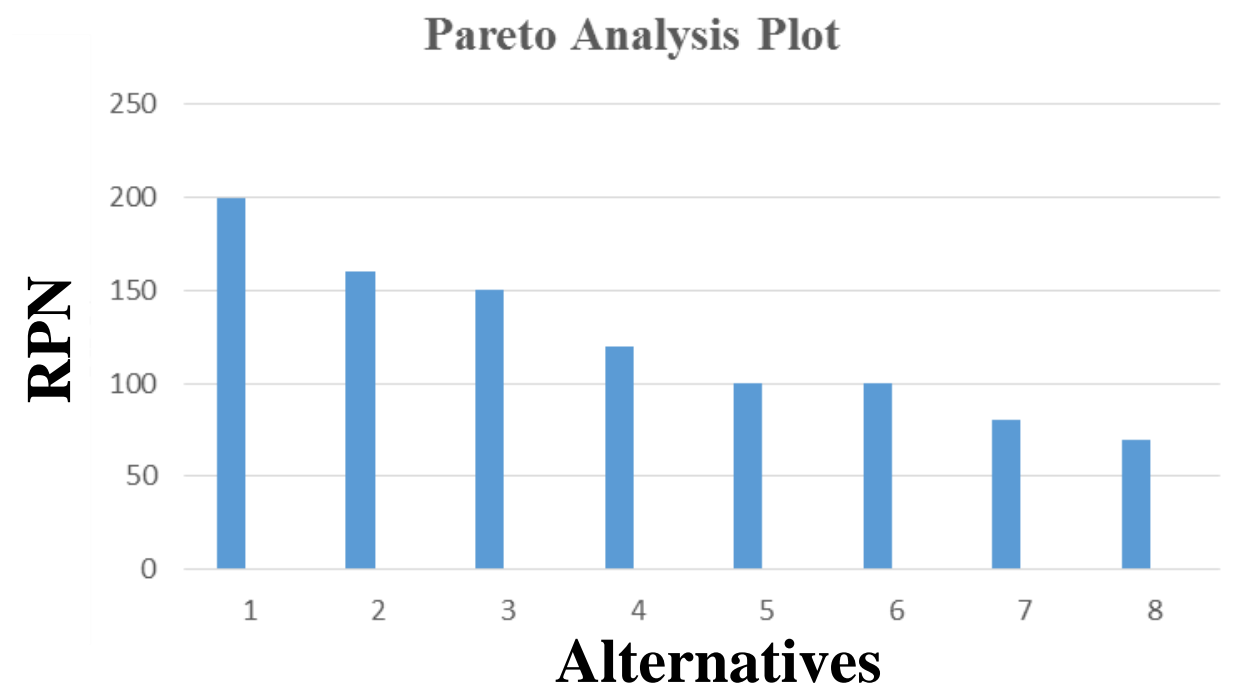

Figure 28. Pareto Analysis Plot

\subsection{CVAP Phase 4: Value Assessment}

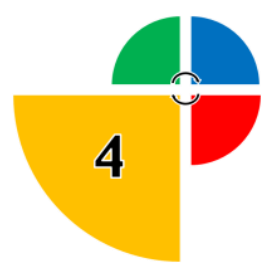

Phase 4 of CVAP brings all the information gathered from Phase 3 (effectiveness, cost, and risk) and uses it to: (1) eliminate alternatives with critical flaws in costeffectiveness or risk and (2) conduct a comparative analysis of the surviving alternatives to make final recommendations that are consistent with the values of the customer attained in Phase 1. According to the AoA Handbook, there is generally no requirement to narrow down to one alternative. ${ }^{2}$ The ultimate goal is to help the customer (or decision makers) understand the differences between the alternatives and their tradeoffs among effectiveness, cost, and risk. ${ }^{2}$ 


\subsubsection{Alternative Elimination Process}

First, alternatives that have critical flaws in respect to cost-effectiveness and risk are eliminated (non-viable). The alternatives that were generated in Phase 2 are all feasible in terms of effectiveness since they are created/identified to meet customer functional needs, wants, and desires. However, since every customer has a different priority between cost and risk when compared to effectiveness, the alternatives may or may not be reasonable. For example, an alternative may be the most effective and have relatively reasonable risks associated with it, but if its cost does not meet budgetary constraints, the alternative is eliminated as an option for that particular decision. However, that alternative may be feasible for a future decision situation (or another customer) if budgetary constraints permit. If alternatives are eliminated, it is important that the reasoning that lead to the elimination is documented to provide traceability in the event that the results are questions. $^{2}$ Figure 29 shows a general process of elimination.

If there is an obvious winner within the remaining alternatives, then that one gets recommended to the customer, however, this is unlikely. In most cases, the remaining alternatives may seem equivalent. These alternatives should then be further assessed by looking more closely at the dilemmas among them and identifying discriminating factors. Some examples of dilemmas as seen in the $A o A H$ Hadbook $^{2}$ are: (1) is the increase in effectiveness worth the increase in cost/risk? (2) Do the remaining alternatives really have significant differences in overall effectiveness/cost/risk? If these dilemmas can be resolved by the analysis team, then the remaining alternative is the one recommended to the customer. If the dilemmas cannot be resolved, then the analysis team should present tradeoffs between the final set of alternatives and have the customer help resolve the dilemmas. 
Possible Alternatives

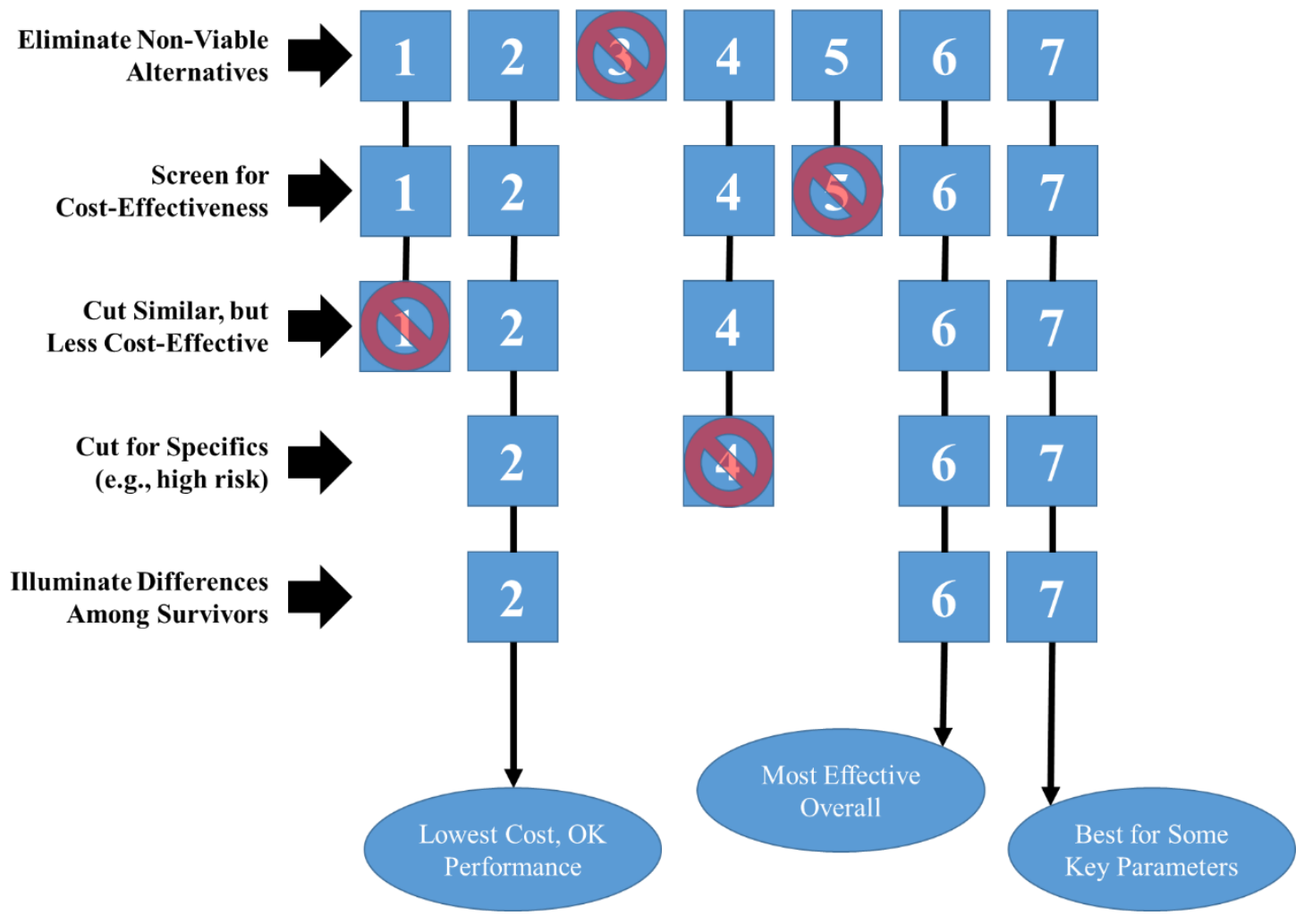

Figure 29. Example of a process of alternative elimination ${ }^{2}$

\subsubsection{Final Recommendations}

The final set of alternatives can be presented in a comparison matrix like the one shown in Table 13. The cells can either be scores or colors that represent scale intervals of scores. For example, green can represent alternatives with high effectiveness or low risk/cost, yellow can represent medium effectiveness/risk/cost, and red can represent low effectiveness or high risk/cost. Once the analysis is complete, it will need to be documented in a report. Appendix Q includes the template used by the DoD.

Table 13. Alternative Comparison Matrix ${ }^{2}$

\begin{tabular}{|c|c|c|c|c|c|c|c|c|c|c|c|}
\cline { 2 - 11 } \multicolumn{1}{c|}{} & \multicolumn{3}{c|}{ Function 1 } & \multicolumn{3}{c|}{ Function 2 } & \multicolumn{3}{c|}{ Function 3 } & & Total \\
\cline { 2 - 12 } \multicolumn{1}{c|}{} & MoE & MoE & MoE & MoE & MoE & MoE & MoE & MoE & MoE & Risk & LCC \\
& 1 & 2 & 3 & 1 & 2 & 3 & 1 & 2 & 3 & $($ RPN) & \$(M) \\
\hline Alt 1 & & & & & & & & & & & \\
(Ideal) & & & & & & & & & & & \\
\hline Alt 2 & & & & & & & & & & & \\
\hline
\end{tabular}




\begin{tabular}{|l|l|l|l|l|l|l|l|l|l|l|l|}
\hline Alt 3 & & & & & & & & & & & \\
\hline Alt 4 & & & & & & & & & & & \\
\hline
\end{tabular}

\subsection{CVAP Limitations}

CVAP provides a decision support framework for military applications. However, there are some limitations to it that should be addressed in future work. CVAP does not take into account schedule and cost risks. These factors are significant in military applications. For example, some customers might need a system within the next year in order to defend their country. If the schedule risks associated with an alternative imply that they will not get it in time, the customer will eliminate the alternative and go with something more effective and/or costly. Since effectiveness, cost, and schedule risks are interrelated, all three must be taken into account. CVAP only takes into account effectiveness risks (i.e. technology and operations) at this point.

Thus far, CVAP doesn't provide a process that takes into account uncertainty in the scores of alternatives. CVAP assumes certainty in the scores, therefore, it only includes deterministic analysis (stacked bar graphs). However, this can be improved by including probabilistic analysis in the quantitative value model. Probabilistic analysis assumes a distribution of scores (e.g. uniform, normal, binomial, etc.) instead of a single score. This would decrease subjectivity and sensitivity in the recommendations made.

Another limitation of CVAP is that it does not take into account psychological factors in decision making as described by prospect theory. It is known that humans are significantly influenced by psychological factors and as a result do not make objective decisions. However, it is still important to know the objective solution when making 
decisions because it points the customer in the direction of the better alternatives. CVAP can be improved by incorporating psychological factor modeling and it will not change the overall process, but it will no longer be an expected utility theory process. 


\subsection{Ballistic Missile Defense (BMD) Customization}

Now that the formulation of CVAP has been presented, we will investigate how it can be applied to ballistic missile defense (BMD). An introduction of BMD, unique BMD challenges, and how CVAP can improve the BMD decision making process is presented. Each phase of CVAP is applied to the BMD decision environment to give BMD contractors an idea of how to use CVAP.

\subsection{Background on BMD}

The dawn of the Missile Age was on September 8, 1944 (WWII) when the German V2 (shown in Figure 30), the world's first ballistic missile, was launched at London. It was not very sophisticated since it was inaccurate and was limited by the payload it was able to carry. However over 1,000 of them had fallen on Great Britain by the end of the war. Germany also launched V-2s to hit Belgium, France, Luxemburg, and the Netherlands. There was no

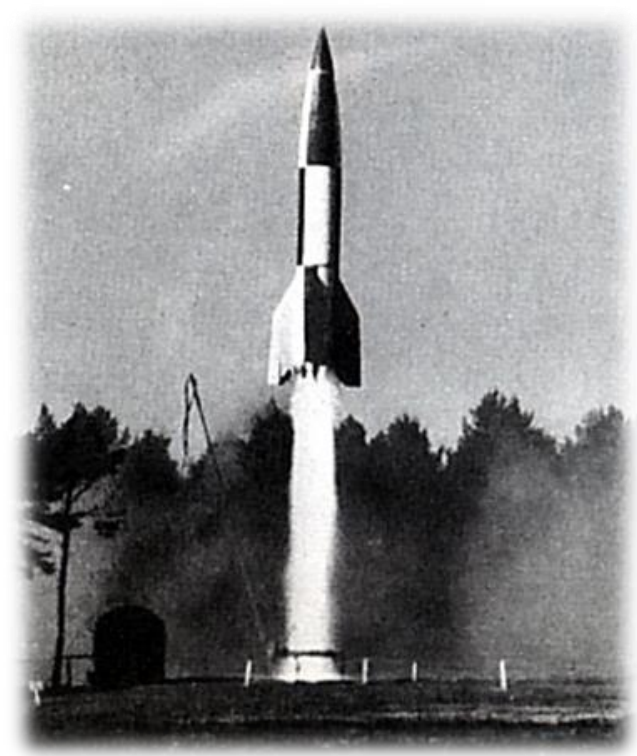

Figure 30. The German V-2 ballistic missile 35 active defense against them. The only solution was to bomb or overrun launch sites to disable launches. The United States Army recognized the need to develop a capability to counter this new type of threat. They sent officers to investigate how allies attempted to counter the new threat. They found that Great Britain was able to destroy a small percentage of the incoming missiles. They used radar to detect launches, triangulated track data to predict the missile trajectory, and at the right time, concentrated antiaircraft artillery fire to shoot it down. This defense strategy was not very efficient. It was estimated that it would 
have taken 12,000 antiaircraft rounds to destroy one V-2. However, this strategy was an innovative approach to the development of ballistic missile defense (BMD) systems. ${ }^{36}$

The end of WWII was the beginning of a new era. It was defined by the decline of old world powers and the rise of two new superpowers: The United States and the Soviet Union (USSR). These two nations lead the nuclear arms race that lead to the Cold War. In addition, Great Britain, France, and China also developed their own indigenous nuclear capability, but much smaller in quantity compared to the United States or the Soviet Union. ${ }^{37}$ By 1972, the Soviet Union had deployed their Scud-B, a short range ballistic missile (SRBM) with nuclear capability, in Poland, Bulgaria, East Germany, and Czechoslovakia as can be seen in Figure 31 below. Even though the amount of nations with nuclear capability increased during the Cold War, there weren't as many as there are in the present day. Figure 32 shows the significant increase in missile proliferation by the year 2004.

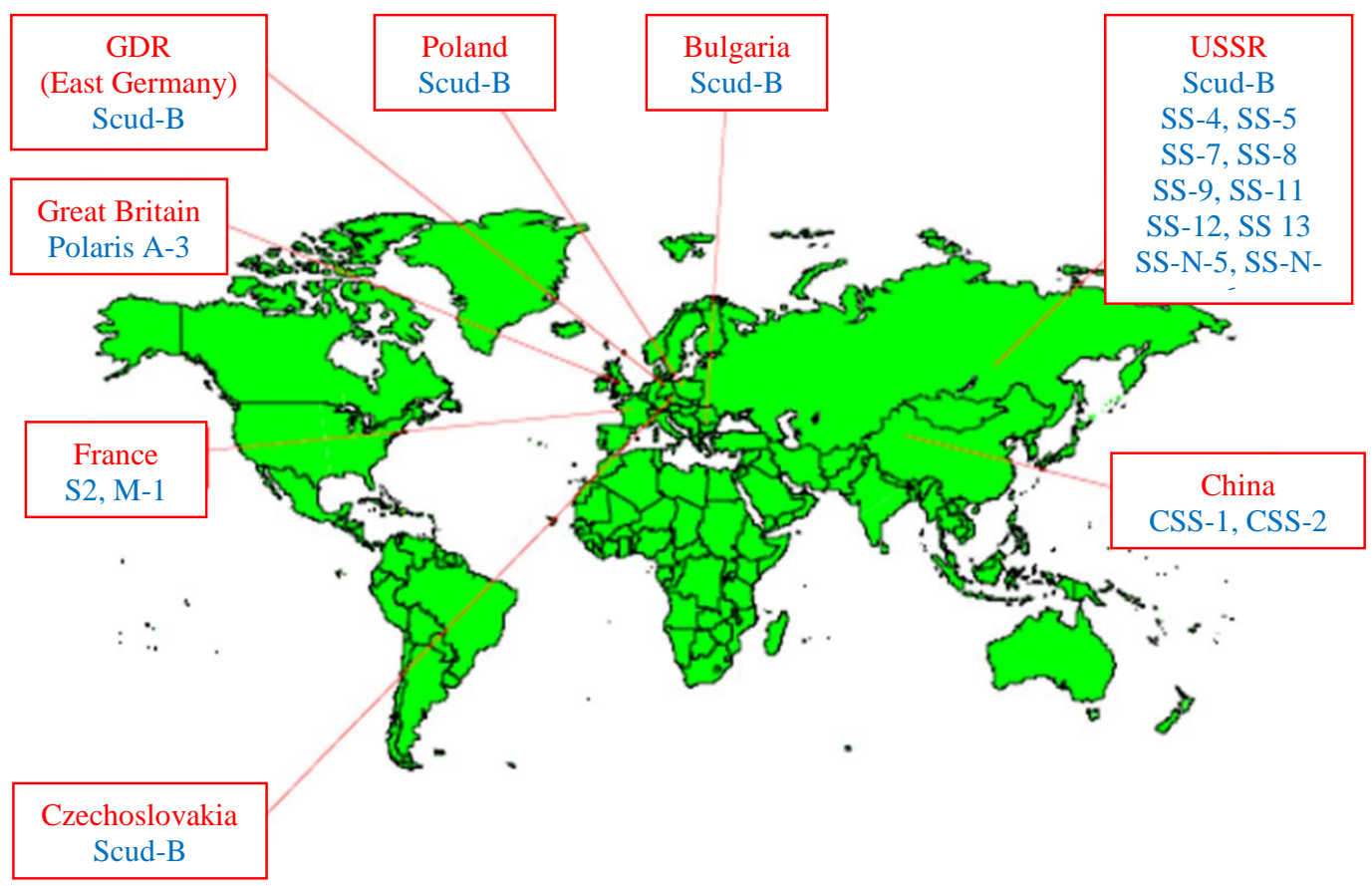

Figure 31. Missile proliferation outside the U.S. in 1972 (source: MDA ${ }^{38}$ ) 


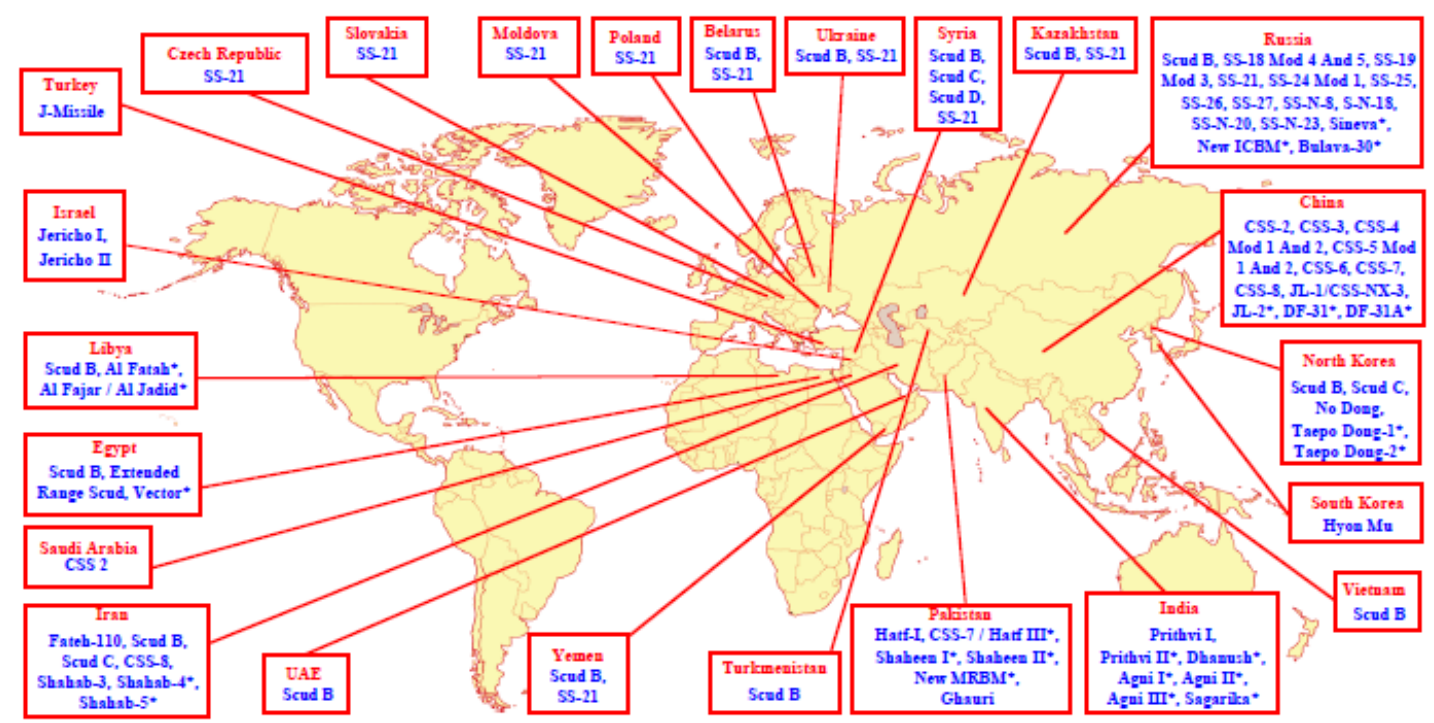

Figure 32. Missile Proliferation outside the U.S. in 2004 (source: MDA ${ }^{38}$ )

Over 30 countries are developing or already possess operational ballistic missile systems, mostly developing countries in the Middle East and Asia. ${ }^{37}$ Even more threatening is the fact that many of these same countries are also seeking to acquire nuclear, biological, or chemical capability. ${ }^{1}$

The main reasons why we should be concerned are that ballistic missile technology is available on a wider scale to hostile countries, the threats are becoming more mobile, reliable, accurate, and longer range, and missile arsenals in hostile countries are growing every year. What makes this frightening is that some countries shown in Figure 32 have unstable governments and are hostile to the United States and its allies. Therefore, they are more likely to use Weapons of Mass Destruction (WMD) in a conflict. "In fact, since 1980, ballistic missiles have been used in more than six regional conflicts". ${ }^{1}$

The future of a nation can be profoundly affected by which weapon systems are procured to defend the nation. The United States has defense cooperation ties with many allies and partners and is committed to working with them in two categories: ${ }^{39}$ 
- Developing and fielding robust, pragmatic, and cost-effective capabilities

- Engaging in international cooperation on a broad range of missile defenserelated activities, including technological and industrial cooperation.

The United States seeks to deter the development, acquisition, deployment, and use of ballistic missiles by hostile countries by eliminating their confidence in the effectiveness of such attacks. "By working with allies and partners to promote effective missile defense capabilities, the United States builds closer defense cooperation ties as it accomplishes its direct purpose of making U.S. partners less vulnerable to coercion and ballistic missile attack." 39

\subsection{Importance of CVAP for BMD}

BMD contractors compete to develop and sell systems. Besides domestic sales, BMD contractors have opportunities for international sales. In order to be successful in sales, contractors need to define their systems" "value proposition" and use it to formulate a business strategy. However, every customer has different values (i.e., needs, wants, and desires), resulting in a completely different business strategy. Following CVAP to define value propositions will benefit contractors in explaining to customers why they should buy systems from them in an objective and traceable manner. Following CVAP also allows for an efficient use of resources allocated for defining value propositions. CVAP can help contractors gain competitive advantage by guiding them to properly define customer values and evaluating how alternative weapon system(s) are relevant to those values. CVAP answers customer questions like: ${ }^{2}$

- Which weapon systems provide validated capabilities?

- Can the weapon systems be supported by my current infrastructure?

- What are the risks associated to each weapon system?

- What are the life-cycle costs for each weapon system and is it worth the investment? 
- How do the weapon systems compare to one another?

Contractors need an objective and traceable way to answer these questions. CVAP provides a guide on how to do this.

\subsection{CVAP Application to BMD}

In order to illustrate how CVAP can be applied to BMD, a discussion on each phase of CVAP and how it relates to BMD is presented.

\subsubsection{CVAP Phase 1: BMD Qualitative Value Model}

The purpose of Phase 1 is to identify stakeholders and obtain their values to define the value hierarchy: fundamental objective, functions, objectives, and Measures of Effectiveness (MoEs). First, stakeholders that give information on the important factors (i.e. technological, economic, political, legal, social, security, natural environment, cultural, historical, moral/ethical, organizational, and emotional) in a BMD decision situation are identified. Their values are then gathered using stakeholder analysis techniques (e.g., interviews, focus groups, and surveys).

Once stakeholders are identified, information from their respective category is attained via analysis techniques (e.g., interviews, focus groups, and surveys). The following includes examples of the type of information that is gathered for each category in $\mathrm{BMD}:^{3}$

\section{$\underline{\text { Technological }}$}

- Identify current systems, if any, and why they are not adequate for needs, wants, and desires (e.g. weapon systems and radar)

- Define the degree of interoperability between current systems and future systems

- Mobility and deployment of future systems (e.g. land-fixed or sea-mobile)

\section{$\underline{\text { Economical }}$}

- Define the budget for system procurement

- Project future budget 


\section{$\underline{\text { Political }}$}

- Define industry politics that influence the decision

- Define political climate between countries

- Anticipation of manufacturing collaboration between parties involved in the decision (e.g., create jobs and improving indigenous technology)

- Active defense vs. Passive defense

- Better indigenous capability vs. better interoperability with allies

Legal

- Define export control laws

- Define treaties between countries

$\underline{\text { Social }}$

- Define customer's country social views of procurement and deployment of future systems

\section{$\underline{\text { Security }}$}

- Identify assets of value (e.g. population centers and/or military bases)

- Define timeline of current and emerging threats

- Define particular threats of interest

- Define threat intel

- Quantity of threat vs. Complexity of threat

Natural Environment

- Deployment constraints from natural environment (e.g., mountains)

- Deployment constraints due to preservation societies

\section{Cultural}

- Cultural biases that affect deployment of types of systems

\section{Organizational}

- Organizational challenges that affect deployment of systems

- Define if infrastructure is enough to support deployment

\section{Emotional}

- Public emotions about deployment of new systems

- Public emotions about threats

- Political emotions on particular weapon systems 
Information attained from these categories is used to influence more stakeholders. First, gaps or needs are identified. Once the gaps are identified, contractors needs to make sure that it is of high priority to the warfighter. The warfighter will request for more capability to fill the identified gaps and request it to the government. The government and warfighter will then become aware of the possible solutions that can address the known gaps. At the same time, political and budgeting communities also need to be aware of the known capabilities. Contractors then need to support studies like the AoA to validate their systems for the proposed capability to address the known gaps.

The key stakeholders in a BMD decision situation are the customers and the users/operators of the systems. The customer is the government of the country of interest and the users are the country's military branches. In the case of the U.S., the political customer in charge of missile defense is the Missile Defense Agency (MDA) and the users are the combatant commands (COCOMS). Figure 33 displays the geographic and functional COCOMS. Geographic commands operate in assigned areas of operation where they have distinct military focus. Function commands operate world-wide and provide support to the geographic commands.

Their main concern of key stakeholders is to ensure that critical assets are defended from particular threats. Therefore, the driving stakeholder values in BMD procurement revolve around how well systems perform in defending or deterring threats. In order to provide the customer with the best alternative, a clear definition of the threats is necessary. Threats are classified by range, trajectory type, and payload. Table 14 shows the classification of threats by their range. 


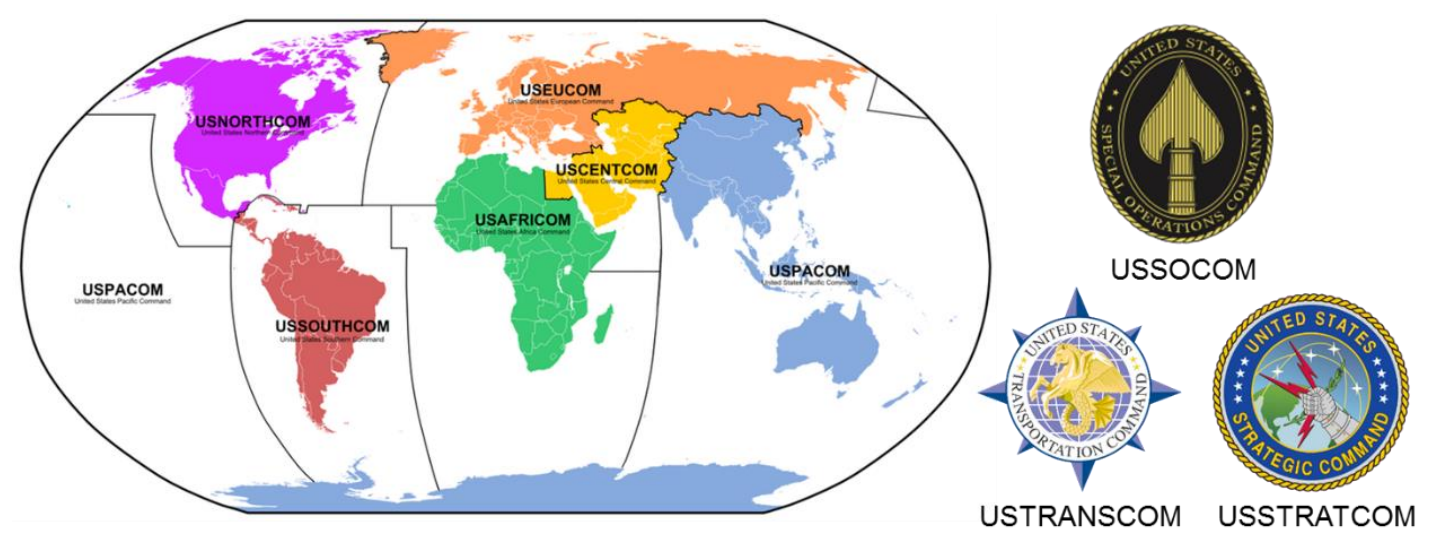

Figure 33. Geographic and Functional COCOMS ${ }^{40}$

Table 14. Ballistic threat classification by rang ${ }^{41}$

\begin{tabular}{|l|c|c|}
\hline \multicolumn{1}{|c|}{ Classification } & $\begin{array}{c}\text { Min. Range } \\
(\mathbf{k m})\end{array}$ & $\begin{array}{c}\text { Max. Range } \\
(\mathbf{k m})\end{array}$ \\
\hline Short Range Ballistic Missile (SRBM) & 0 & 1,000 \\
\hline Medium Range Ballistic Missile (MRBM) & 1,000 & 3,500 \\
\hline Intermediate Range Ballistic Missile (IRBM) & 3,500 & 5,500 \\
\hline Intercontinental Ballistic Missile (ICBM) & 5,500 & $>5,500$ \\
\hline Submarine-Launched Ballistic Missile (SLBM) & Varies & Varies \\
\hline
\end{tabular}

Ballistic threats can be launched in strategic angles in attempt to penetrate defenses.

Besides range, threats are also defined by the trajectory they fly called the trajectory type.

A default trajectory is one launched at 45 degrees and provides the maximum potential range. Any trajectory type with an apogee higher than a default trajectory is called a lofted trajectory. Although the maximum range is decreased, the lofted missile is aimed to fly over defense systems to reduce warning time for BMD command, control, and communication systems. Any trajectory type with an apogee lower than a default trajectory is called a depressed trajectory. It is similar to the lofted trajectory in strategy, except that it is aimed to fly under defenses instead of over. Notice in Figure 34, if assuming equal 
launch speeds and no drag, lofted and depressed trajectories can be aimed to land on the same location.

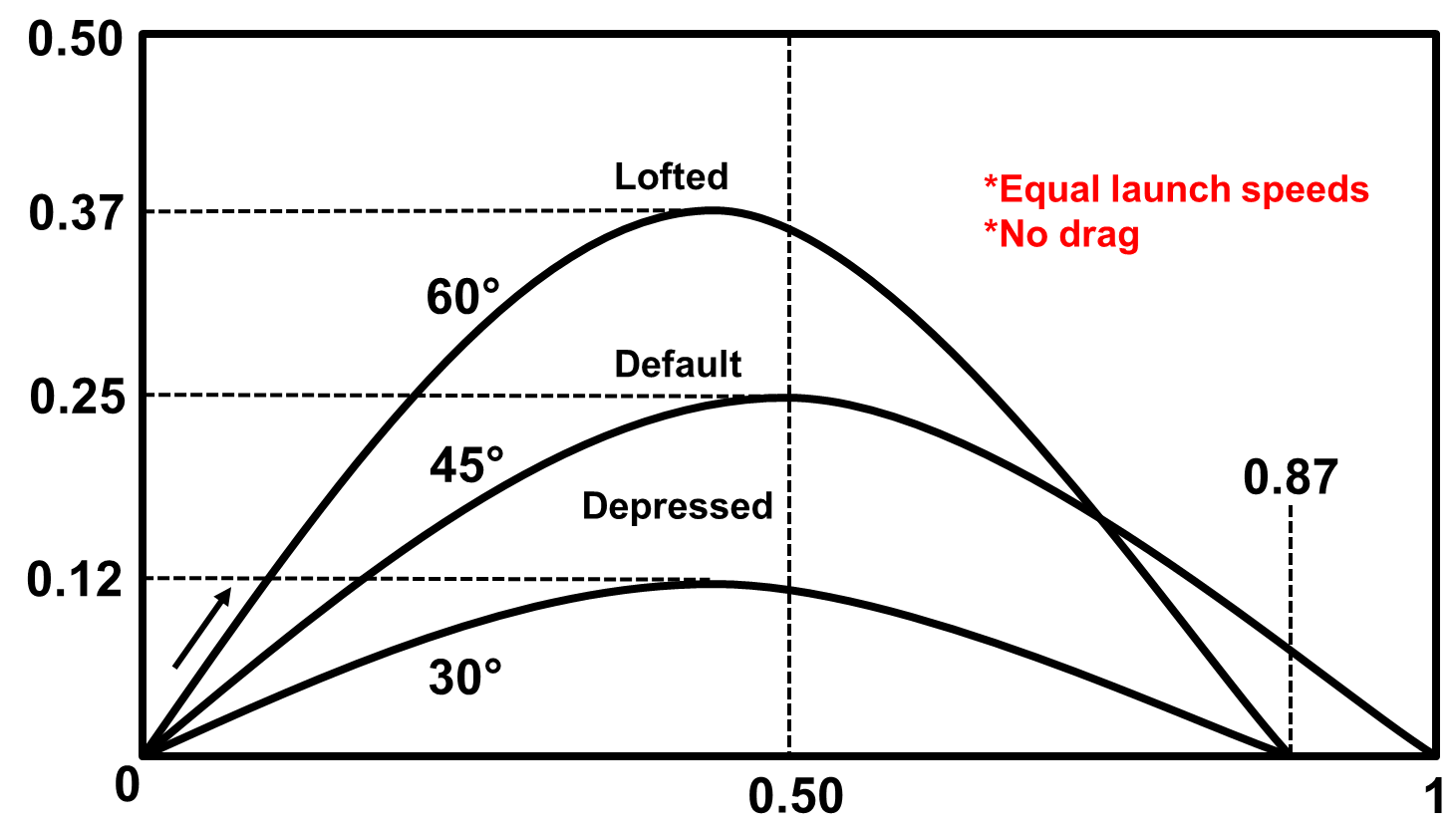

Figure 34. Threat Trajectory Types ${ }^{42}$

Ballistic threats are also defined by the payload (warhead) that they carry. All are referred to weapons of mass destruction (WMD) except conventional warheads. The types of payload carried by ballistic threats are: ${ }^{43}$

- Conventional: Use chemicals such as gunpowder and high explosives, which store significant energy within their molecular bonds

- Nuclear: Use a nuclear fission or nuclear fusion reaction to release immense energy

- $\quad$ Chemical: Use toxic chemicals, such as poison gas or nerve gas, designed to injure or kill human

- Biological: Use an infectious agent, such as anthrax spores, designed to sicken or kill humans 
- Radiological: Uses radioactive material, such as spent fuels from nuclear power plants or radioactive medical waste, designed to render a large area uninhabitable

Defense capabilities for a given threat profile define the values of the key stakeholders. This information is used to derive the tiers of the value hierarchy. Problem Definition techniques help develop the fundamental objective the represents the actual problem statement. Next, functions, objectives, and Measures of Effectiveness (MoEs) are derived using QFD. MoEs are the key output from QFD because they encompass all the upper tiers of the value hierarchy (since they are derived from them). For example, MoEs incorporate BMD functions relevant to the interceptor, radar, kill vehicle, threat, and system deployment. Some common BMD MoEs are shown in Table 15.

Table 15. Common BMD MoEs

\begin{tabular}{|l|c|l|}
\hline \multicolumn{1}{|c|}{ MoE } & Units & \multicolumn{1}{c|}{ Description } \\
\hline Defended Area (DA) & $\%$ & $\begin{array}{l}\text { Percentage of the area that is to be } \\
\text { defended is actually protected }\end{array}$ \\
\hline $\begin{array}{l}\text { Single-Shot Probability of Kill } \\
\left(\mathrm{P}_{\text {ssk }}\right)\end{array}$ & $\%$ & $\begin{array}{l}\text { Probability that a single threat is destroyed } \\
\text { by a single interceptor }\end{array}$ \\
\hline Expected Probability of Kill $\left(\mathrm{P}_{\mathrm{k}}\right)$ & $\%$ & $\begin{array}{l}\text { Percentage of incoming threats destroyed } \\
\text { by BMD architecture }\end{array}$ \\
\hline Time of Engagement $\left(\mathrm{T}_{\text {eng }}\right)$ & time & $\begin{array}{l}\text { Time it takes to achieve the first possible } \\
\text { intercept after default trajectory threat } \\
\text { burnout }\end{array}$ \\
\hline Battlespace & time & $\begin{array}{l}\text { Amount of time between first to last } \\
\text { engagement opportunity }\end{array}$ \\
\hline
\end{tabular}

\subsubsection{CVAP Phase 2: BMD Solution Design}

The completion of Phase 1 defined the values of the customer and stakeholders.

These values are then used to guide the generation solutions. Due to the multitude and complexity of threats, BMD elements (weapon systems and sensors) are not capable of individually defending or detecting everything. Therefore, BMD customers procure BMD elements with the intent of developing an architecture of integrated systems that form a layered defense. Layered meaning that each element is assigned to defend particular 
regions of Earth's atmosphere. Figure 35 illustrates the concept of operations (CONOPS) for a typical BMD architecture.

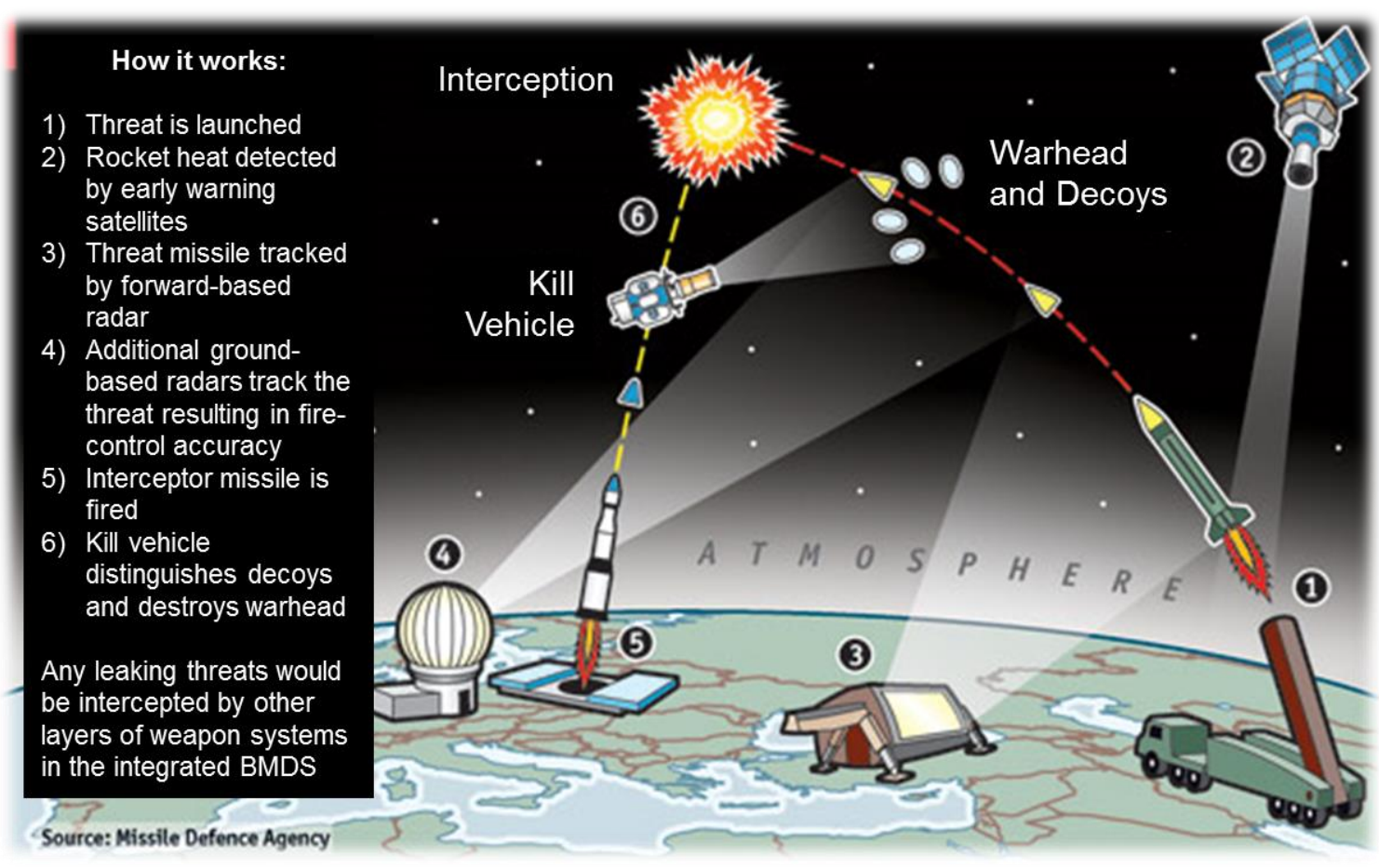

Figure 35. BMD Architecture CONOPS (source: $M D A^{38}$ )

One way to categorize BMD elements is where in the threat's trajectory they are able to intercept or detect, categorized as either the boost phase, midcourse phase, and/or terminal phase. The boost phase starts at launch of the threat until booster burnout. Between threat burnout and re-entry is the midcourse phase, the longest phase of the ballistic threat's trajectory. The terminal phase starts when the threat re-enters the atmosphere and ends at the target. Figure 36 illustrates these phases (Note: acronyms defined in Appendix A)

Another way to categorize BMD weapon systems is the altitude they are capable of intercepting threats, categorized as endoatmospheric and/or exoatmospheric. Endoatmospheric being within the Earth's atmosphere and exoatmospheric being outer 
space. This division is made by the Karman Line, which states that the boundary between Earth's atmosphere and outer space is at an altitude of $100 \mathrm{~km} \cdot{ }^{44}$ Figure 36 also illustrates this categorization. (Note: acronyms defined in Appendix A)

There are other characteristics that are commonly used to differentiate BMD elements besides where they are designed to intercept and/or detect threats. Table 18 and 19 summarizes these characteristics. The various differentiating characteristics results in a multitude of possible BMD architecture solutions. Figure 37 shows the current BMD architecture solution that is designed to defend the U.S. homeland from ballistic missile attacks.

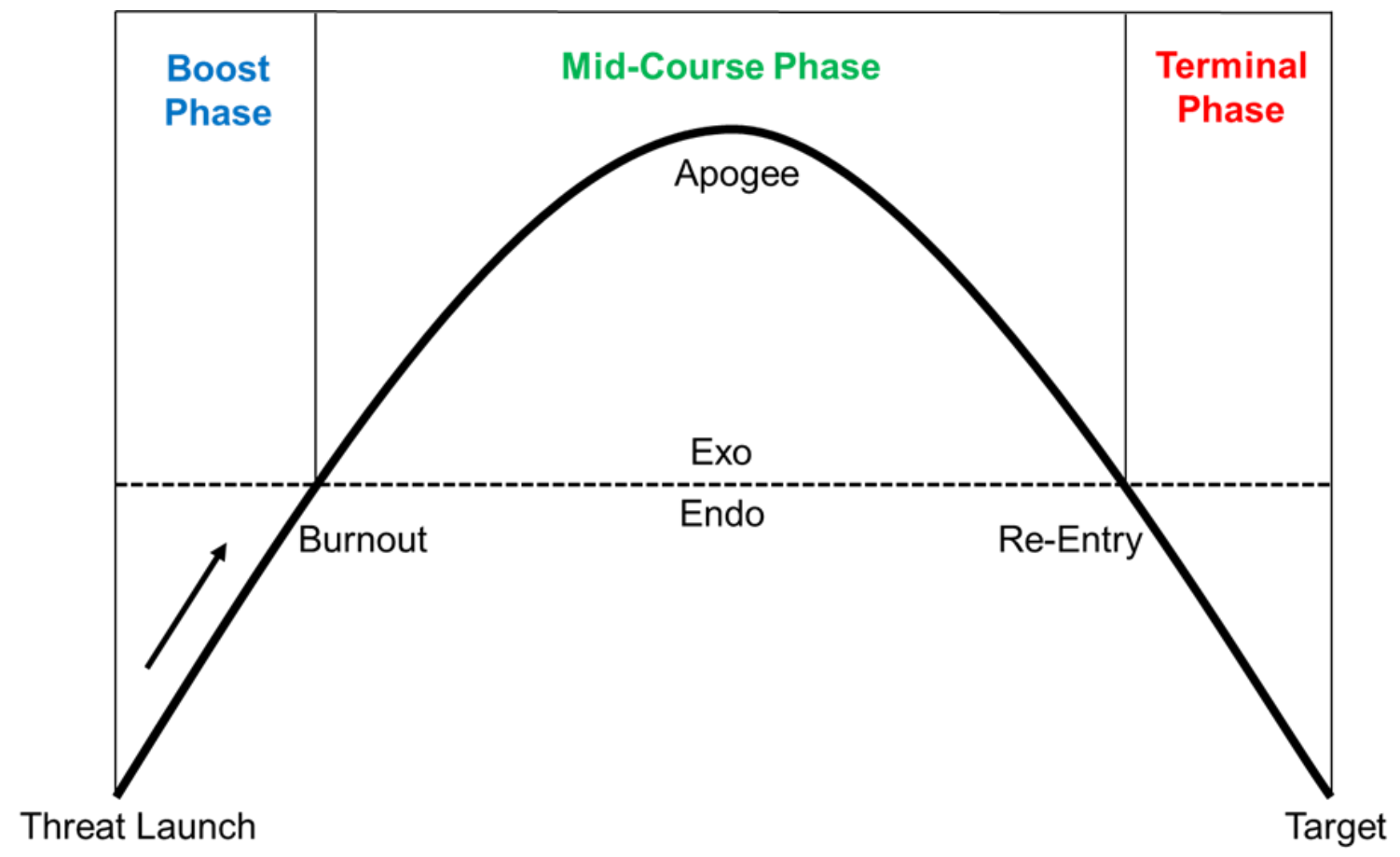

Figure 36. BMD element categorization by phase of interception 
Table 16. Examples of U.S. BMD weapon systems

\begin{tabular}{|c|c|c|c|c|c|c|}
\hline $\begin{array}{c}\text { Weapon } \\
\text { System }\end{array}$ & Deployment & Interceptor & $\begin{array}{c}\text { Organic } \\
\text { Radar }\end{array}$ & $\begin{array}{c}\text { Atmosphere } \\
\text { Engagement }\end{array}$ & $\begin{array}{c}\text { Trajector } \\
\mathbf{y} \\
\text { Engagem } \\
\text { ent }\end{array}$ & Capability \\
\hline $\begin{array}{c}\text { Aegis } \\
\text { BMD }\end{array}$ & Sea-mobile & $\begin{array}{c}\text { SM-2 } \\
\text { SM-3 } \\
\text { SM-6 }\end{array}$ & AN/SPY-1 & Exo (SM-3) & Midcourse & $\begin{array}{c}\text { SRBM } \\
\text { MRBM } \\
\text { IRBM }\end{array}$ \\
\hline GMD & Land-fixed & GBI & N/A & Exo & Midcourse & ICBM \\
\hline Patriot & Land-mobile & $\begin{array}{c}\text { PAC-3 } \\
\text { PAC-3 MSE }\end{array}$ & $\begin{array}{c}\text { AN/MPQ-53 } \\
\text { AN/MPQ-65 }\end{array}$ & Endo & Terminal & SRBM \\
\hline $\begin{array}{c}\text { THAAD } \\
\text { Land-mobile }\end{array}$ & $\begin{array}{c}\text { THAAD } \\
\text { missile }\end{array}$ & $\begin{array}{c}\text { AN/TPY-2 } \\
\text { (terminal } \\
\text { mode) }\end{array}$ & Endo & Terminal & $\begin{array}{c}\text { SRBM } \\
\text { MRBM }\end{array}$ \\
\hline $\begin{array}{c}\text { THAAD } \\
\text { ER }\end{array}$ & Land-mobile & $\begin{array}{c}\text { THAAD ER } \\
\text { missile }\end{array}$ & $\begin{array}{c}\text { AN/TPY-2 } \\
\text { (terminal } \\
\text { mode) }\end{array}$ & Endo & Terminal & $\begin{array}{c}\text { MRBM } \\
\text { IRBM }\end{array}$ \\
\hline
\end{tabular}

Table 17. Examples of U.S. off-board sensors

\begin{tabular}{|c|c|c|c|}
\hline Sensor & Deployment & Function & Sensor \\
\hline SBX-1 & Sea-mobile & Surveillance/Track & Radio Frequency \\
\hline AN/SPY-1 & Sea-mobile & Surveillance/Track & Radio Frequency \\
\hline EWR & Land-fixed & Early Warning & Radio Frequency \\
\hline $\begin{array}{c}\text { AN/TPY-2 } \\
\text { (forward mode) }\end{array}$ & Land-mobile & Surveillance/Track & Radio Frequency \\
\hline SBIRS & Space & Early Warning & Infrared \\
\hline DSP & Space & Early Warning & Infrared \\
\hline STSS & Space & Early Warning & Infrared \\
\hline
\end{tabular}




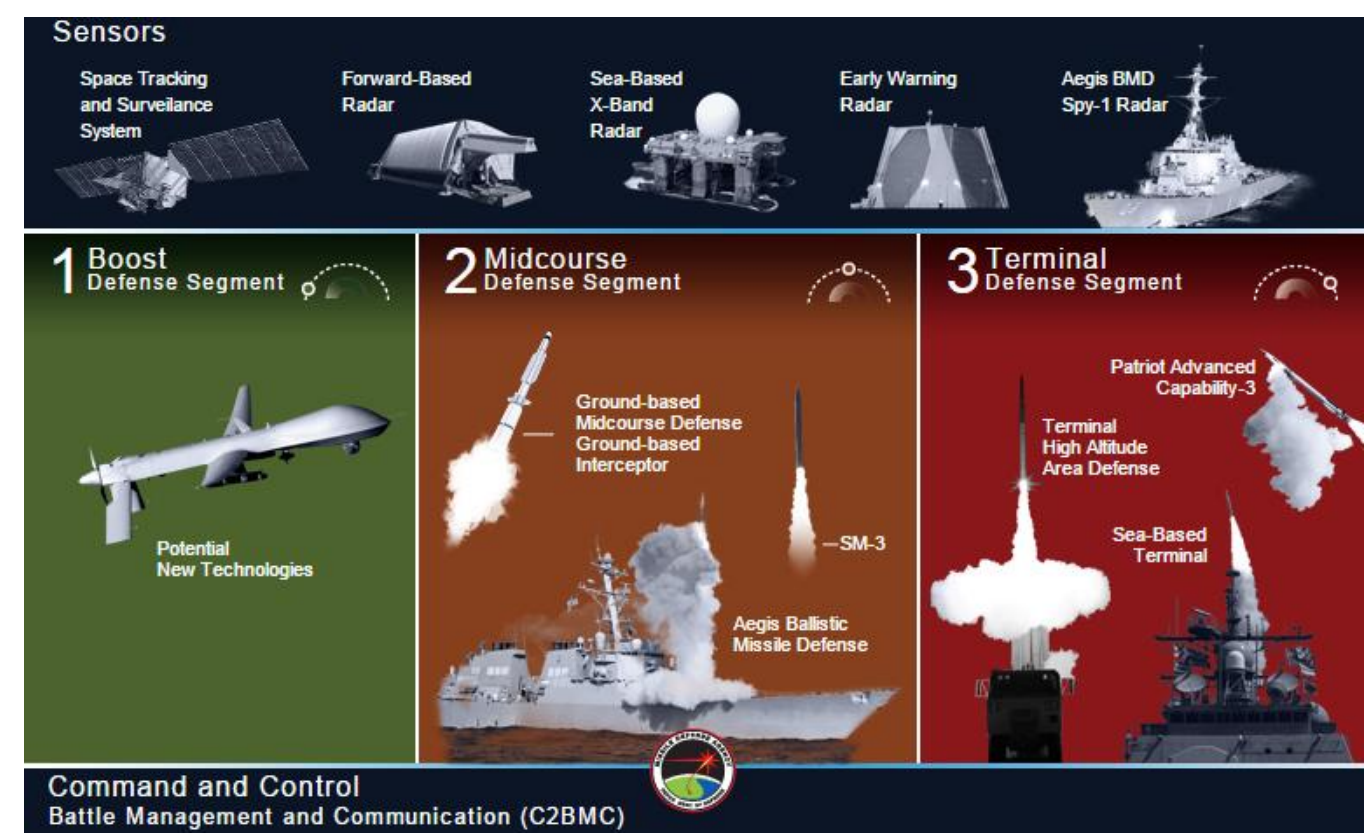

Figure 37. Example of Architecture Solution ${ }^{45}$

\subsubsection{CVAP Phase 3: BMD Quantitative Value Model}

Using the elements discussed in Phase 2, BMD architecture solutions may be generated. In this phase, those generated solutions are quantitatively assessed by first deriving MoE value functions, weight, and scores. These are then inputted into a MODA mathematical model that outputs effectiveness scores. We will use the expected probability of kill $\left(\mathrm{P}_{\mathrm{k}}\right) \mathrm{MoE}$ as an example to illustrate the process taken in Phase 3. $\mathrm{P}_{\mathrm{k}}$ depends on the threat, the targeting strategies, and the effectiveness $\left(\mathrm{P}_{\text {ssk }}\right)$ of the BMD weapon systems. ${ }^{1}$ Defense capabilities can be assessed by a single-dimensional value function that assigns value to an architecture's overall ability to kill incoming enemy missiles. In the Multiobjective Decision Analysis of Theater Missile Defense Architectures ${ }^{l}$ article, the authors discussed with BMD decision-makers which shape is appropriate for the $\mathrm{P}_{\mathrm{k}}$ value function. From this discussion, it was clear that each increment of $P_{k}$ is not equally valuable. Therefore, the authors concluded that a value function with increasing returns to scale as 
shown in Figure 38 was appropriate. This means that the decision makers placed a premium on high BMD architecture performance. ${ }^{1}$ Equation 6 is used to plot the value function. It was multiplied by 10 to make the ideal architecture have a value of 10 (instead of 1$)$.

$$
v\left(P_{k}\right)=10 \cdot \frac{1-e^{P_{k} / \rho}}{1-e^{\left(P_{k} \max ^{-P_{k} \min }\right) / \rho}}
$$

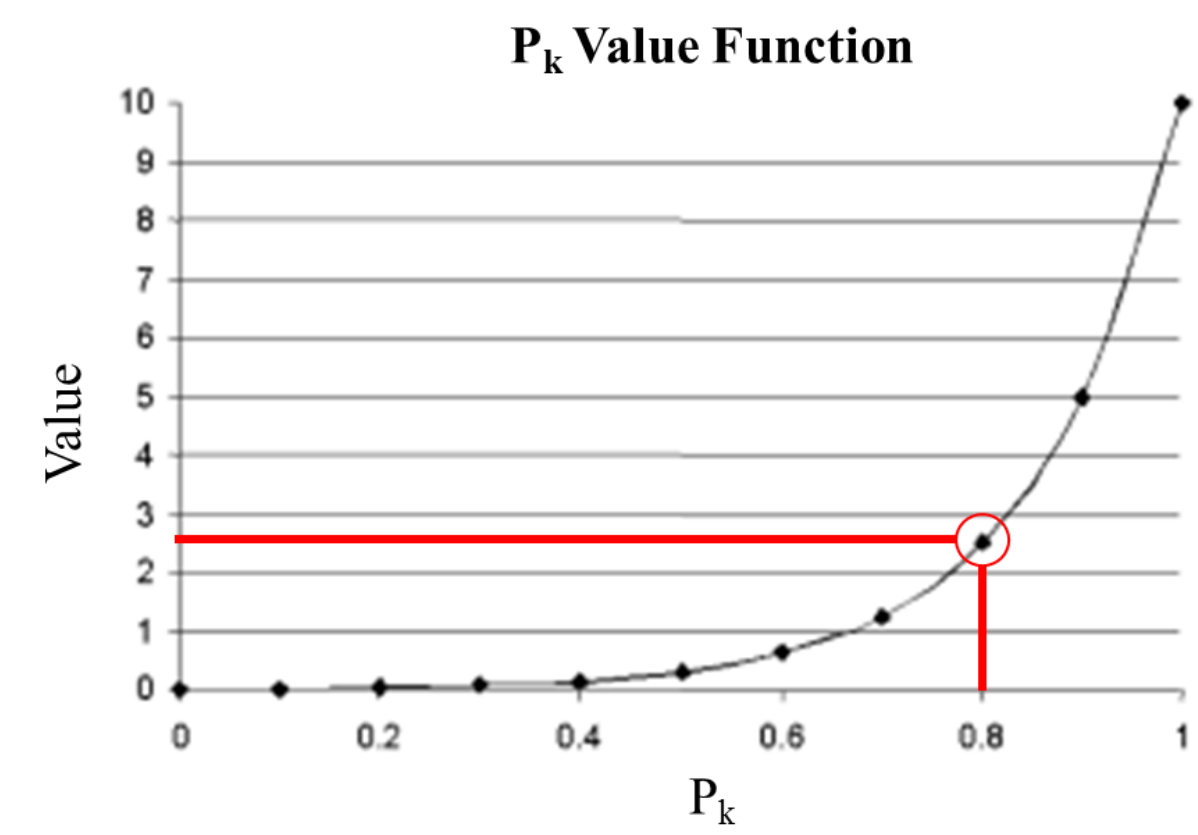

Figure 38. Expected Probability of Kill $\left(P_{k}\right)$ Value Function ${ }^{1}$

With this derived value function, we can now calculate the value of the $\mathrm{P}_{\mathrm{k}}$ score of a particular BMD architecture alternative. Let's say that after modeling and simulating the alternative, the $\mathrm{P}_{\mathrm{k}}$ score it received was 0.80 . This means that the particular architecture alternative defends against $80 \%$ of the incoming threats. Based on the derived value function for $\mathrm{P}_{\mathrm{k}}$ shown in Figure 38, this would result in a respective value of 2.5. The next step is to derive the weight from the customer and stakeholders using the swing weight method. Let's say that the weight that was derived for $P_{k}$ came out to be 0.25 out of 1 . This means that the maximum value that $\mathrm{P}_{\mathrm{k}}$ can have is 2.5 . Now that we have the weight and 
value of the alternative's $\mathrm{P}_{\mathrm{k}}$ score, we can get a weighted score for $\mathrm{P}_{\mathrm{k}}$ using the additive value model (preferential independence for $\mathrm{P}_{\mathrm{k}}$ is assumed). By multiplying the weight with the value of a $\mathrm{P}_{\mathrm{k}}$ score of 0.8 , we get a weighted value of 0.625 . This weighted score would be added to the weighted scores of other MoEs in the evaluation criteria (e.g. DA or $\mathrm{T}_{\text {eng }}$ ) to come up with the alternatives overall effectiveness score. Let's say that the designer of the architecture alternative wanted to know the value gap of their system's performance in terms of $\mathrm{P}_{\mathrm{k}}$. They would subtract their system's weighted score from the ideal score. In this case, the ideal score for $\mathrm{P}_{\mathrm{k}}$ was 2.5 and their system scored 0.625 . This means that if they want their system to be ideal for the customer in terms of $\mathrm{P}_{\mathrm{k}}$, the designer needs to increase their value by 1.875 (300\% increase in $\mathrm{P}_{\mathrm{k}}$ effectiveness)

\subsubsection{CVAP Phase 4: BMD Value Assessment}

After alternatives have been quantitatively assessed in terms of effectiveness, cost, and risk in Phase 3, the last phase is to gather this information to provide recommendations and trade-offs to the customer. In BMD, industry experts agree that every customer will have a different degree of preference between effectiveness, cost, and risk (i.e. cost, schedule, and performance). Each customer has distinct procurement habits which shift as geopolitical and economic forces weigh on acquisition leaders across the globe. It is important to know these value in order to make the best recommendations to the customer.

\subsubsection{BMD Example}

In order to illustrate how CVAP can be applied to a BMD decision situation, a fictitious example was created. Actual stakeholder data is either classified or proprietary, so the qualitative and quantitative models use fictitious data. However, this is enough to illustrate how the information gathered from CVAP can be used to make objective and traceable recommendations. 


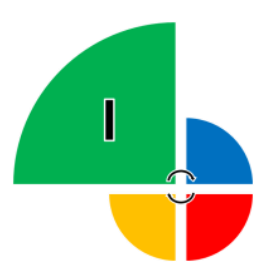

\section{Qualitative Value Model}

The first phase of CVAP is the qualitative value model. In this phase, stakeholder analysis is performed to gather raw customer values and then organized in a hierarchical structure (i.e., fundamental objective, functions, objectives, and MoEs). The first step is to define the top tier of the value hierarchy, the fundamental objective. Stakeholder values are gathered via techniques like interviews, focus groups, and surveys. This information is then used to derive the problem statement that describes the primary reason why the customer is making the decision. However, the first problem statement is usually the perceived problem statement. The Duncker Diagram and/or Statement-Restatement techniques can be applied to derive the real problem statement. For the fictitious example, the fundamental objective is: Procure a ballistic missile defense system to defend one asset that maximizes the quality of defense against a known threat. Figure 39 displays the scenario that the customer faces. The blue circle represents the area that the customer occupies and the blue star represents the particular asset that is to be defended and where the customer plans to deploy the weapon system. The red circle represents the area where threats can be launched from. 


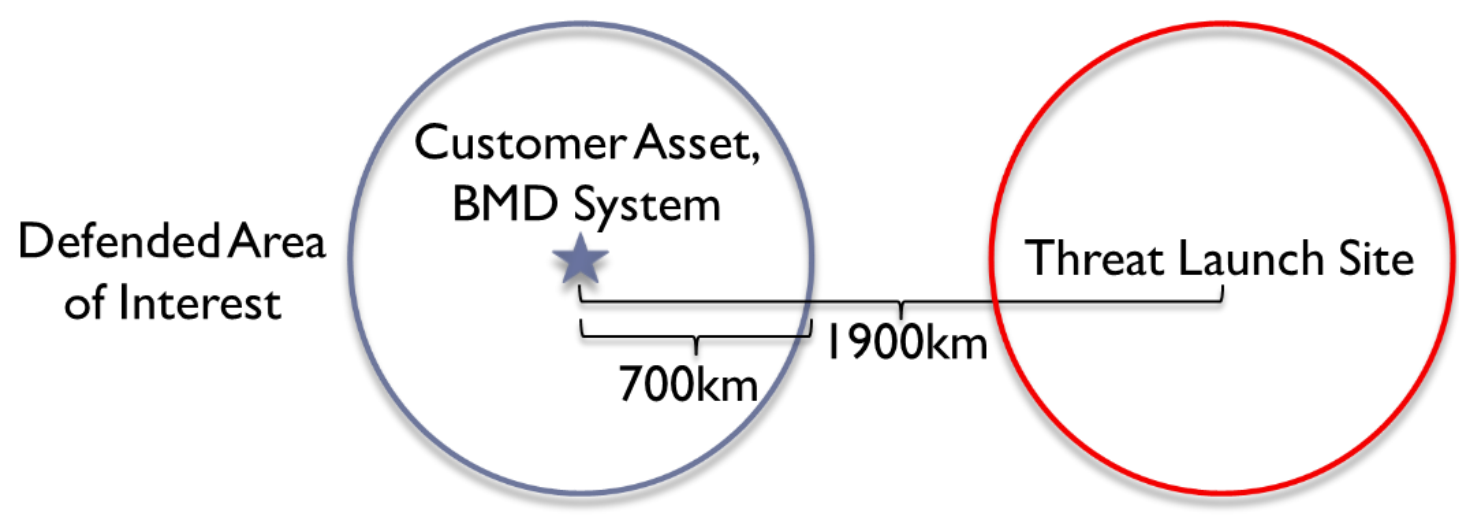

Figure 39. Fictitious scenario geography

The next step is to derive the remaining tiers (i.e. functions, objectives, and MoEs) with Quality Function Deployment (QFD). QFD uses the Affinity Diagram and Tree Diagram to hierarchically derive functions, objectives, and MoEs. QFD also prioritizes the MoEs that are of most importance to the customer in the decision situation. For the fictitious example, the customer prioritizes probability of kill $\left(\mathrm{P}_{\mathrm{k}}\right)$ as the driving MoE in their procurement decision.

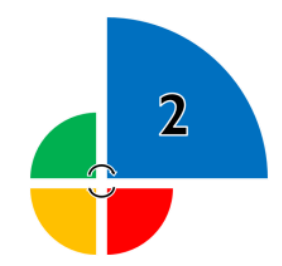

\section{$\underline{\text { Solution Design }}$}

Next is the solution design phase, where ideas of potential solutions are generated and the final set of alternatives is identified. Now that we know that the customer prioritizes solutions with higher probabilities of kill, we can focus our effort in generating ideas with high probabilities of kill. For the fictitious example, it was concluded that one weapon system, either land-based or sea-based, is sufficient to defend the customer asset of interest with high probability of kill. 


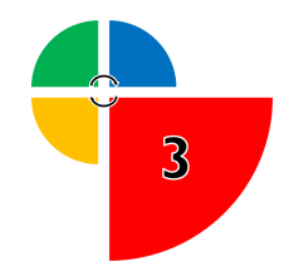

\section{Quantitative Value Model}

Now that the high-quality alternatives have been identified, we can quantitatively evaluate them. Multi-Objective Decision Analysis (MODA) evaluates the alternatives in terms of effectiveness and their average unit procurement cost (AUPC) is estimated in the cost analysis step. For this particular application, the risks associated with the alternatives are not significantly different, so it is safe to assume that risk is not an influential factor in the ultimate decision. Therefore, risk will not be assessed for this fictitious scenario.

The first step in the quantitative analysis is to determine the mathematical value model that is most appropriate to the application. The most appropriate model for the fictitious scenario is the additive value model as shown in Equation 7, which is a particular case of Equation 1 in section 3.5.1.

$$
v_{\text {alt }}=\boldsymbol{w}_{P_{k}} \cdot \boldsymbol{v}_{P_{k}}
$$

The additive value model requires both a (1) single-dimensional value score that represents the customer's value of the performance of each alternative in respect to the $\mathrm{MoE}\left(\mathrm{P}_{\mathrm{k}}\right)$ and the (2) weighting factor for the MoE. To determine the (1) performance of each alternative in respect to probability of kill, a simple physics modeling and simulation tool was used to create ballistic trajectories and simulates interceptor engagements. The outputs of the tool are shown in Figure 40. The circle represents the $700 \mathrm{~km}$ radius area that the customer occupies and the contour overlaid on the circle represents the performance of the alternatives in terms of probability of kill. 


\section{Alt I: Land-Based}

$P_{k}$ Over Defended Area

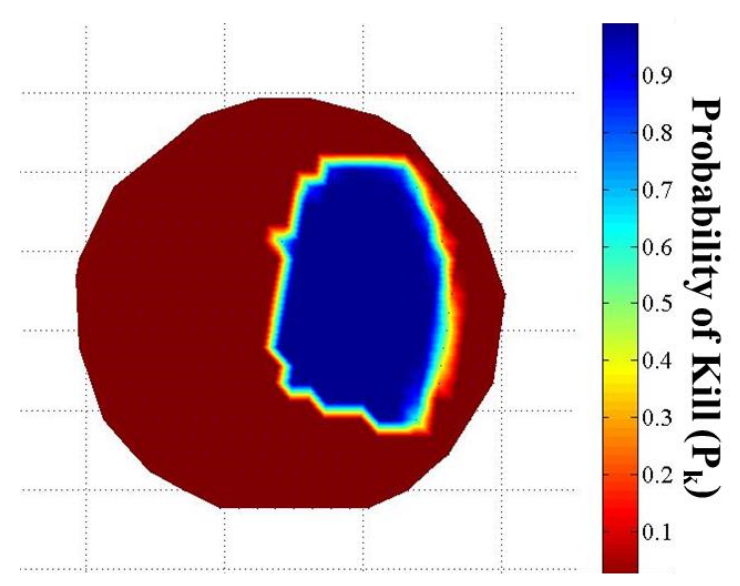

Alt 2: Sea-Based $P_{k}$ Over Defended Area

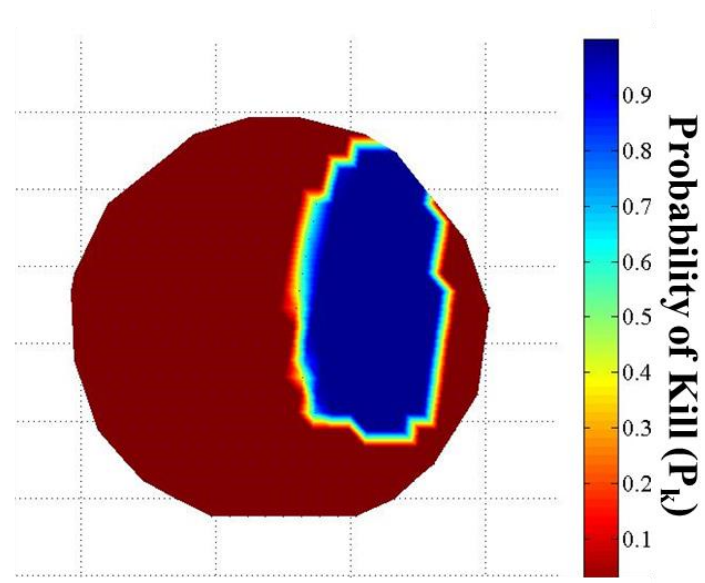

Figure 40. Probability of kill contour plot for Alternative 1 and Alternative 2

The outputs of the simulation tool shows that both alternatives have similar performance in probability of kill, but when an average of the probability of kill is taken for the circle, alternative 1 receives a probability of kill score of 0.91 and alternative 2 receives a probability of kill score of 0.96.

Now that we know the performance of each alternative in respect to probability of kill MoE, we can derive a function that describes the value that the customer has for the range of possible probability of kill scores. Parnell, Metzger, Merrick, and Eilers, authors of Multi-Objective Decision Analysis of Theater Missile Defense (TMD) Architecture ${ }^{1}$, developed a value function for probability of kill for their customer. They met with subjectmatter experts to define the proper shape of the function. A similar value function will be used for this fictitious example. The customer prefers higher scores of probability of kill, where every incremental increase in probability of kill exponentially adds value. The exponential constant $(\rho)$ is defined to be 0.1448 . Since probability of kill is a ratio, the minimum value in the range is 0 and the maximum is 1 . With this known information, we 
can now create a value function for probability of kill using Equation 8. It is multiplied by 10 to have the customer value range from 0 to 10 instead of 0 to 1.

$$
\begin{gathered}
v_{P_{k}}\left(P_{k}\right)=10 \cdot \frac{1-e^{P_{k} / \rho}}{1-e^{\left(P_{k \max }-P_{k \min }\right) / \rho}} \\
\rho=0.1448
\end{gathered}
$$

The plot that results from Equation 8 is shown in Figure 41. Figure 41 also shows the performance score of each alternative and their respective single-dimensional value. Table 18 summarizes the results taken from the probability of kill value function.

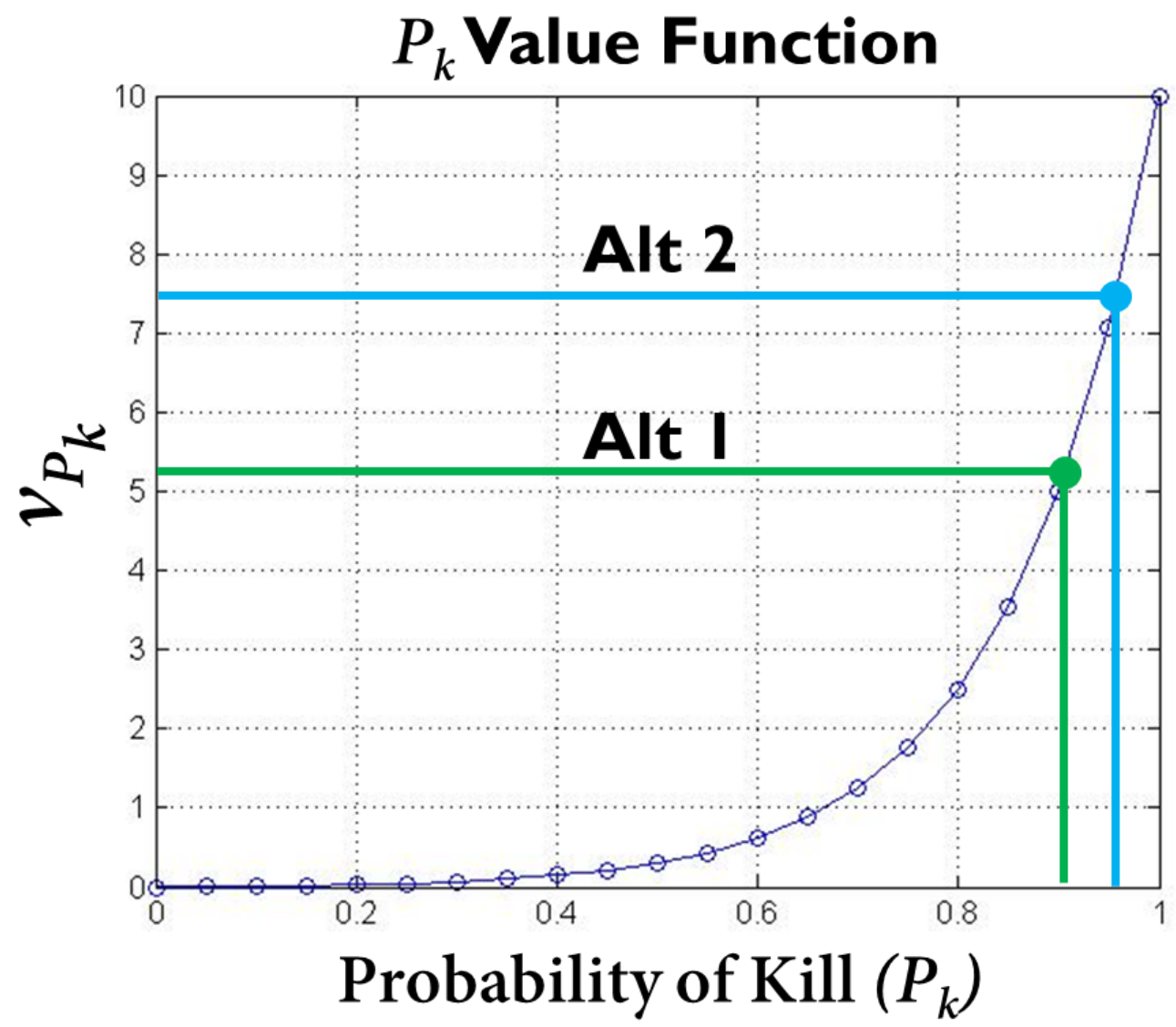

Figure 41. Single-dimensional value function for probability of kill 
Table 18. Probability of kill scores and respective single-dimensional values

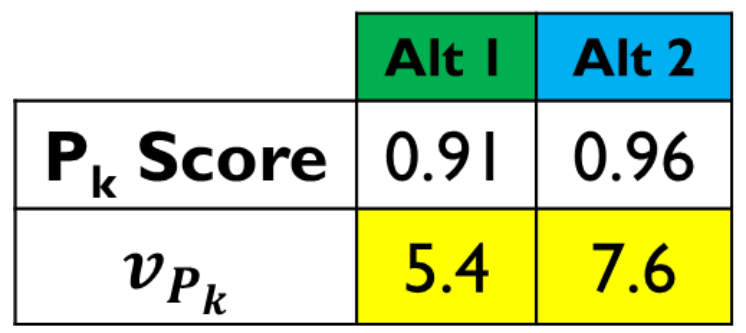

Since we are using the additive value model as shown in Equation 7, (1) MoE single-dimensional values and (2) weights need to be determined. We already calculated the MoE single-dimensional values using the value function, now we need to define the (2) weighting for the probability of kill MoE. After discussing with the customer for the fictitious example, the weighting factor for the probability of kill MoE is 0.25 . This means that the highest weighted value that can be attained by any alternative is 2.5 (i.e., an ideal alternative). Figure 42 shows the weighted value of the alternatives and ideal alternative. Since we are using probability of kill as the only MoE, it seems unnecessary to multiply the alternatives by the weighting factor. However, there are many MoEs that are used in real scenarios, so weighting factors need to be multiplied to each MoE. This action of multiplying the weighting factor in this fictitious example serves to illustrate the entire process. 


\section{Alternative Ranking \\ Stacked Bar Graph}

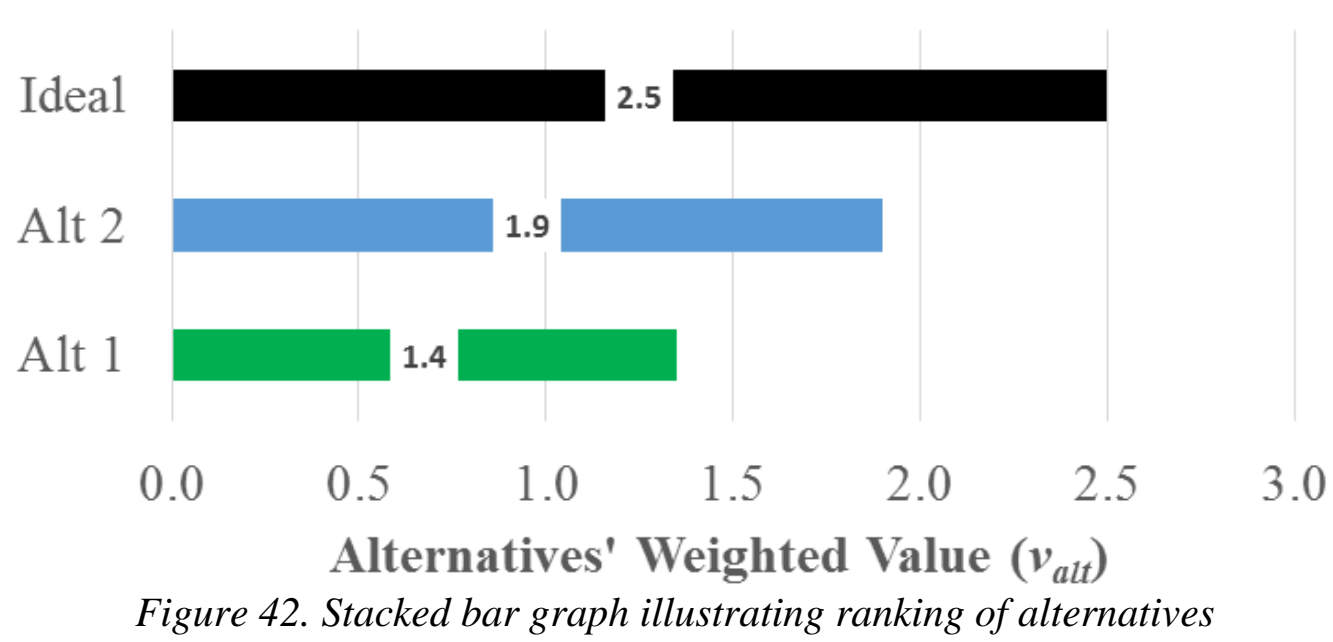

The conclusions that can be drawn from Figure 42 are that Alternative 2 is more effective than Alternative 1 in terms of the probability of kill MoE. Alternative 2 has $36 \%$ more weighted value than Alternative 1. Also, Alternative 2 would attain ideal value for this particular customer if its performance in probability of kill is increased by $32 \%$ (weighted value from 2.9 to 2.5 ). Alternative 1 will attain ideal value if its performance in probability of kill is increased by $79 \%$ (weighted value from 1.4 to 2.5 ).

We have now completed the effectiveness analysis and concluded that Alternative 2 is more valuable to the customer than Alternative 1 in terms of effectiveness. However, we cannot conclude that Alternative 2 is the best alternative until we perform a cost analysis. Since this is an illustrative example, Average Unit Procurement Cost (AUPC) will be used instead of Life-Cycle Cost to perform a cost-benefit analysis. The same idea applies for both, however, using Life-Cycle Cost is always better since it takes into account all costs of importance. Alternative 1 has an AUPC of $\$ 818,000,000$ and a weighted singledimensional value (i.e. benefit) of 1.4. Alternative 2 has an AUPC of $\$ 1,730,000,000$ and a weighted single-dimensional value of 1.9. The ratio of benefit to AUPC for each 
alternative represents the cost-effectiveness. In this scenario, the ratio is multiplied by $100,000,000$ to eliminate the multitude of zeros in the ratio. Table 19 shows the results from the cost-benefit analysis.

Table 19. Cost-benefit analysis results

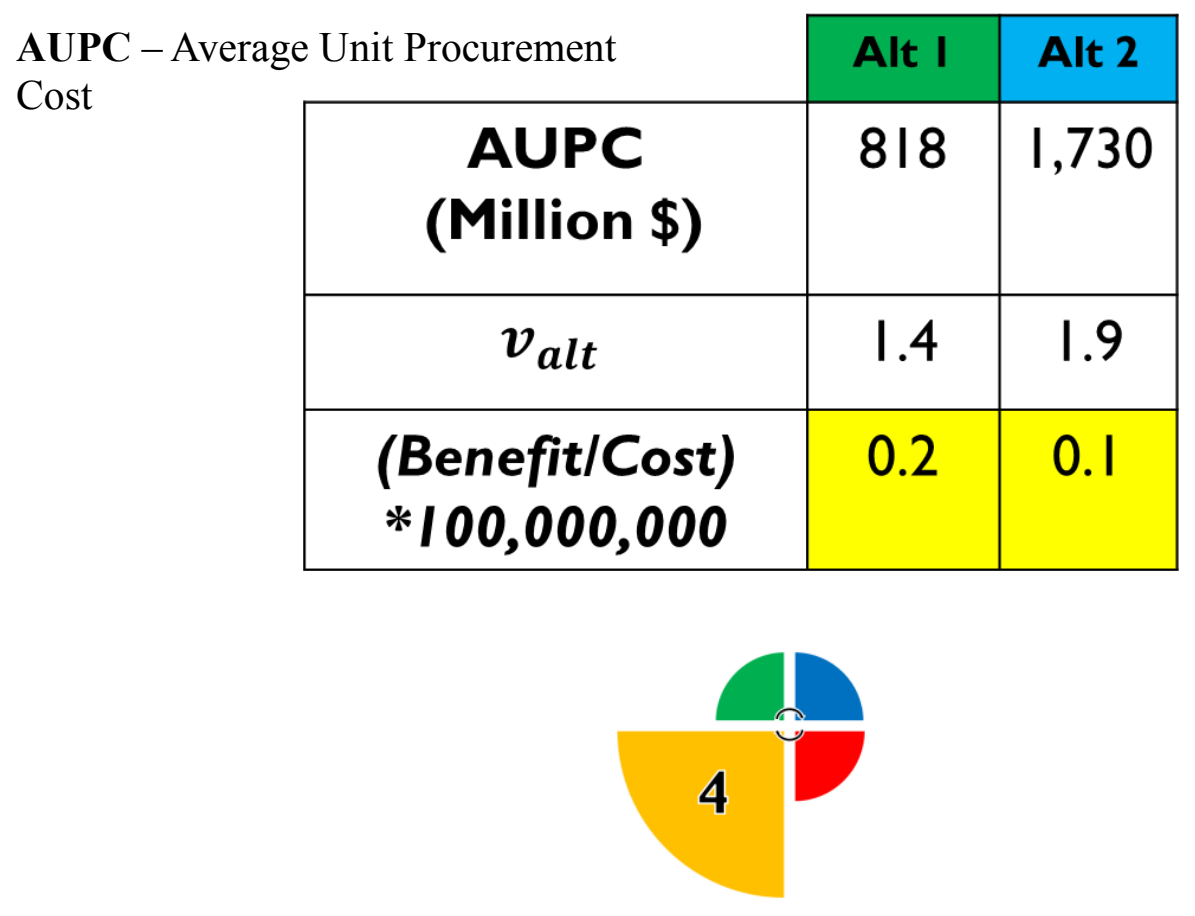

$\underline{\text { Value Assessment }}$

Now that we have complete the effectiveness and cost analysis, we gather the information and provide recommendations based on tradeoffs between cost and effectiveness. The key conclusions were that Alternative 2 is the most effective, but also the most expensive. Alternative 1 is less effective, but also the most affordable. However, Alternative 1 provides best joint-value for effectiveness and cost. If the customer needs the higher effectiveness and can afford either alternative, Alternative 2 would be best. If customer doesn't need the higher effectiveness provided by Alternative 2, Alternative 1 is best. 


\subsection{Conclusion}

The customer value assessment process (CVAP) was developed to give system engineering teams in military industries a decision support tool to qualitatively and quantitatively assess customer values. The assessment of values before alternatives results in objective and traceable solution recommendations that meet the customers' strategic goals. These recommendations are also less sensitive to changes in inputs when compared to Multi-Criteria Decision Making (MCDM) methods like the Analytical Hierarchy Process (AHP).

CVAP incorporates proven approaches and techniques appropriate for military applications. CVAP is based on the AoA, which is a decision making process that the DoD uses when faced with an acquisition decision situation ${ }^{2}$. The AoA states that recommendations are to be based on tradeoffs between effectiveness, cost, and risk. CVAP is also based on $\mathrm{SDP}^{3}$, a decision making process developed by the systems engineering faculty at United States Military Academy in West Point, NY. SDP incorporates a VFT philosophy of approach and MODA quantitative value modeling, which together provide objective and traceable recommendations based on customer values. AoA and SDP offer guidelines to the tasks that need to be accomplished overall, but lack depth on how to accomplish the tasks. CVAP extends and expands AoA and SDP by providing techniques that are consistent with their fundamental concepts as discussed.

CVAP provides problem definition techniques that identify the real problem versus the perceived problem ${ }^{9}$. Defining the real problem allows for customer strategic goals to be met while minimizing the waste of resources used for the decision analysis. CVAP combines the "Voice of the Customer" and the "Voice of the Engineer" with Quality 
Function Deployment (QFD) ${ }^{16}$, a structured and traceable process that develops and prioritizes customer values (i.e. functions, objectives, and MoEs). The prioritized MoEs that are derived from functions and objectives are used to generate and/or identify creative and innovative alternatives with industry-proven creative problem solving techniques. CVAP then applies MODA to rank alternatives based on effectiveness and performs a cost analysis and risk assessment as described by the AoA process. Recommendations are then made based on trade-offs between effectiveness, cost, and risk, allowing the customer to have objective and traceable options.

MODA uses the multiplicative, multilinear, and additive utility/value models when ranking alternatives in respect to effectiveness. Multiplicative and multilinear are not as restrictive as the additive model and may be more accurate. However, they are more complicated and require further judgment in assessing cross term weights. Rayno applied all three utility models to a military problem to see if one math model was more accurate than the others in terms of prioritizing alternatives and final value scores. He concluded that there is no gain in using the more complicated models. As long as additive independence is assumed, there is no loss of accuracy when using the simpler additive model. ${ }^{10}$

The creation of CVAP was driven by a ballistic missile defense (BMD) industry need to provide BMD customers with a value proposition of BMD systems. The outputs of CVAP can guide BMD contractors in formulating a value proposition, which is used to explain to customers why they should procure their systems instead of competing systems. CVAP does this by identifying customer values, creating and/or identifying the alternatives that meet those values, identifying the benefits of each alternative, and providing analysis 
that is objective and traceable. Besides making sales, contractors can also benefit by knowing how their systems can be improved to stay relevant with customer values. CVAP illuminates these areas by identifying the value gaps of each alternative when compared to an ideal solution. Although real decisions are affected by psychological factors, it is still helpful and important to know the objective solution derived with CVAP. The objective solution can point the customer in the direction of the better alternatives. It also allows the customer to trust the solutions recommended by the contractor since they are based on objective and traceable conclusions and not based on biased sales pitches.

CVAP provides a decision support framework for military applications. However, there are some limitations that should be addressed in future work. CVAP does not take into account schedule and cost risks, which can be significant influential factors in military decisions. CVAP only takes into account effectiveness risks (i.e. technology and operations) at this point. Thus far, CVAP does not provide a process that takes into account uncertainty in the scores of alternatives. CVAP assumes certainty in the scores, therefore, only includes deterministic analysis (stacked bar graphs). However, this can be improved by using probability distributions of the scores rather than a single score. CVAP also does not take into account psychological factors in decision making as described by prospect theory. Instead, the research included in this report follows concepts from expected utility theory. CVAP can be improved by incorporating behavioral factors in the outputted recommendations.

CVAP was demonstrated with a fictitious scenario to illustrate how customer values can be qualitatively and quantitatively assessed. Unclassified and non-proprietary conditions were simulated between two defense system alternatives (i.e. land-based and 
sea-based). The tradeoffs made from the value assessment are representative of real customer recommendations. 


\section{References}

[1] Parnell, G. S., R. E. Metzger, J. Merrick, and R. Eilers. 2000. Multiobjective Decision Analysis of Theater Missile Defense Architectures.PDF.

[2] Analysis if Alternatives (AoA) Handbook. N.p: Air Force Material Command OAS/A9, July 2008.PDF.

http://www.ndia.org/Divisions/Divisions/SystemsEngineering/Documents/Commi ttees/Mission\%20Analysis\%20Committee/Support\%20Documentation/AoA\%20 Handbook\%20Final.pdf

[3] Parnell, G. S. 2008. Decision Making in Systems Engineering and Management. Hoboken, NJ: Wiley.

[4] DoD Operation of Defense Acquisition System. 2015. N.p.PDF.

[5] Kirkwood, C. W. 1997. Strategic Decision Making, Multi-objective Decision Analysis with Spreadsheets, Duxbury Press, Belmont, CA.

[6] Blanchard, B. S. and Fabrycky, W.J. 2006. Systems Engineering and Analysis. Upper Saddle River, NJ: Prentice Hall.

[7] Keeney, R. L. 1992. Value-Focused Thinking: A Path to Creative Decisionmaking. Cambridge, MA: Harvard University Press.

[8] Cohen, L. 1995. Quality Function Deployment: How to Make QFD Work for You. University of Michigan: Addison-Wesley.

[9] Fogler, S.H., LeBlanc, S.E., and Rizzo, B. 2013. Strategies for Creative Problem Solving. Upper Saddle River, NJ: Prentice Hall

[10] Rayno, B. A. 1994. Methodology to Assess the Utility of Future Space Systems, M.S. Thesis, Department of Operational Sciences, Air Force Institute of Technology.

[11] Merrick, J.R.W, Parnell, G.S., Barnett, J., Garcia, M. 2005. A Multiple-Objective Decision Analysis of Stakeholder Values to Identify Watershed Improvement Needs. Informs.PDF

[12] Stokes, B.S., Parnell, G.S., Klimack, W.K., McGinnis, M.L. 2002. Alternative Resource Allocation Techniques. United States Military Academy. West Point, NY.PDF

[13] Buckshaw, D.L., Parnell, G.S., Unkenholz, W.L., Parks, D.L., Wallner, J.M., Saydjari, O.S. 2005. Mission Oriented Risk and Design Analysis of Critical Information Systems. Military Operations Research.PDF.

[14] Parnell, G. S., Chapter 19, Value-Focused Thinking Using Multiple Objective Decision Analysis, Methods for Conducting Military Operational Analysis: Best Practices in Use Throughout the Department of Defense, Military Operations 
Research Society, Editors Andrew Loerch and Larry Rainey, 2007. http://www.academia.edu/2817001/Value-Focused_Thinking

[15] Buede, D.M. and Bresnick, T.A. 1992. Applications of Decision Analysis to the Military Systems Acquisition Process.PDF. http://www.usc.edu/dept/create/assets/002/50866.pdf

[16] Biltgen, P.T. and Mavris, D.N. 2007. A Technique for Interactive Probabilistic Multiple Attribute Decision Making. AIAA.PDF. http://arc.aiaa.org/doi/pdf/10.2514/6.2007-1332

[17] Pinder, J.D. 2000. Evaluating Future Force Options for the U.S. Army: A Hybrid, Interactive, Multiple-Attribute, Exploratory Approach. RAND Graduate School.PDF. http://www.rand.org/content/dam/rand/pubs/rgs_dissertations/2006/RGSD153.pdf

[18] Einstein, A. and Leopold, I. 1967. The Evolution of Physics. Touchstone, NY.

[19] Saaty, T.L. 1980. The Analytic Hierarchy Process. McGraw-Hill, NY. http://www.dii.unisi.it/ mocenni/Note_AHP.pdf

[20] Triantaphyllou, E. and Mann, S.H. 1995. Using the Analytic Hierarchy Process for Decision Making in Engineering Applications: Some Challenges.PDF. http://bit.csc.lsu.edu/trianta/Journal_PAPERS1/AHPapls1.pdf

[21] Bhutia, P.W. and Phipon, R. 2012. Application of AHP and TOPSIS Methods for Supplier Selection Problem.PDF.

http://www.iosrjen.org/Papers/vol2_issue10\%20\%28part-3\%29/F021034350.pdf

[22] Defense Acquisition Guidebook. 2013. N.p.PDF. http://acqnotes.com/acqnote/references/reference-main-page

[23] AcqNotes.com. 2015. Web. http://acqnotes.com/acqnote/references/referencemain-page

[24] GAO Cost Estimating and Assessment Guide: Best Practices for Developing and Managing Capital Program Costs. 2009. N.p.PDF. http://acqnotes.com/acqnote/references/reference-main-page

[25] Brainy Quotes. 2015. Web. http://www.brainyquote.com/

[26] Xerox Wikipedia Page. 2015. Web. http://en.wikipedia.org/wiki/Xerox

[27] Quote Wise. 2015. Web. http://www.quoteswise.com/tom-monaghan-quotes.html

[28] Yilmaz, S., Daly, S. R., Seifert, C. M., \& Gonzalez, R. 2014. Design Heuristics as a tool to improve innovation. Annual Conference of American Society of Engineering Education (ASEE), June 16-18, Indianapolis, IN.PDF. 
https://www.designheuristics.com/wp-content/uploads/2014/06/DesignHeuristics-as-a-Tool-to-Improve-Innovation.pdf

[29] Design Heuristic Workshop. 2012.PDF. https://www.designheuristics.com/wpcontent/uploads/2012/08/Design-Heuristic-Workshop.pdf

[30] Yilmaz, S., Daly, S. R., Christian, J. L., Seifert, C. M., \& Gonzalez, R. 2013. Can experienced designers learn from new tools? A case study of idea generation in a professional engineering team. International Journal of Design Creativity and Innovation, 2(2), 82-96. PDF. https://www.designheuristics.com/wpcontent/uploads/2014/06/Can-Experienced-Designers-Learn-from-New-Tools-ACase-Study-of-Idea-Generation-in-a-Professional-Engineering-Team.pdf

[31] Yilmaz, S., Daly, S. R., Seifert, C. M., \& Gonzalez, R. 2013. Comparison of design approaches between engineers and industrial designers. International Conference of Engineering and Product Design Education (EPDE), September 56, Dublin, Ireland.PDF. https://www.designheuristics.com/wpcontent/uploads/2014/06/Comparison-of-Design-Approaches-Between-Engineersand-Industrial-Designers.pdf

[32] Ritchey, T. 2011. Wicked Problems - Social Messes: Decision Support Modelling with Morphological Analysis. Springer-Verlag Berlin Heidelberg.

[33] G.S. Parnell, and T.E Trainor. 2000. Using the Swing Weight Matrix to Weight Multiple Objectives, U.S. Military Academy, West Point, NY.

[34] Examining Risk Priority Numbers in FMEA. 2015. Web. http://www.reliasoft.com/newsletter/2q2003/rpns.htm

[35] Operation Backfire (WWII). http://en.wikipedia.org/wiki/Operation_Backfire_(WWII)

[36] Dabrowski, John R. 2013. Missile Defense: The First Seventy Years. N.p.: MDA. PDF. http://www.mda.mil/global/documents/pdf/first70.pdf

[37] Davenport, Kelsey. 2015. Worldwide Ballistic Missile Inventories. Arms Control Association. 05 January 2012. Web. https://www.armscontrol.org/factsheets/missiles\#1

[38] MDA Website. 2015. Web. http://www.mda.mil

[39] Ballistic Missile Defense Review Report. United States of America Department of Defense. 2010.PDF. http://www.defense.gov/bmdr/docs/BMDR\%20as\%20of\%2026JAN10\%200630_f or\%20web.pdf

[40] Unified Combatant Command Wikipedia Page. 2015. Web. http://en.wikipedia.org/wiki/Unified_Combatant_Command 
[41] Montague, D.L. 2012. Making Sense of Ballistic Missile Defense: An Assessment of Concepts and Systems for U.S. Boost-Phase Missile Defense in Comparison to Other Alternatives. The National Academic Press. Washington, D.C.

http://www.nap.edu/catalog/13189/making-sense-of-ballistic-missile-defense-anassessment-of-concepts

[42] Trajectory of a Projectile Wikipedia Page. 2015. Web. http://en.wikipedia.org/wiki/Trajectory_of_a_projectile

[43] Weapon of Mass Destruction Wikipedia Page. 2015. Web. http://en.wikipedia.org/wiki/Weapon_of_mass_destruction

[44] Missile Defense Wikipedia Page. 2015. Web. http://en.wikipedia.org/wiki/Missile_defense

[45] The Ballistic Missile Defense System (BMDS). 2015. Web. http://www.mda.mil/system/system.html 


\section{APPENDICES}

Appendix A: List of Acronyms

CVAP - Customer Value Assessment Process

BMD - Ballistic Missile Defense

SDP - Systems Decision Process

VFT - Value-Focused Thinking

MODA - Multi-Objective Decision Analysis

QFD - Quality Function Deployment

DoD - Department of Defense

USMA - United States Military Academy

AHP - Analytic Hierarchy Process

MAUT - Multi-Attribute Utility Theory

R\&D - Research and Development

HOQ - House of Quality

MoE - Measure of Effectiveness

HIMAX - A Hybrid, Interactive, Multiple-Attribute, Exploratory Approach

TMD - Theater Missile Defense

AFT - Alternative-Focused Thinking

MCDM - Multi-Criteria Decision Making

MADM - Multi-Attribute Decision Making

AoA - Analysis of Alternatives

OAS - Office of Aerospace Studies

CoE - Air Force Center of Expertise

JCIDS - Joint Capabilities Integration Development System

ICD - Initial Capabilities Document

CDD - Capabilities Development Document

PPBE - Planning, Program, Budget, and Execution

MT - Mission Task

TPM - Technical Performance Measure

MoP - Measure of Performance

M\&S - Modeling and Simulation

TDD - Technical Description Document

LCC - Life-Cycle Cost

MILCON - Military Construction

O\&S - Operation and Support

Alt - Alternative

COA - Course of Action

K.T. - Kepner-Tregoe

IT - Integrated Technology

BEP - Bureau of Engraving and Printing

TRIZ - Teoriya Resheniya Izobreatatelskikh Zadatch

SCAMPER - Substitute, Combine, Adapt, Modify, Put to other use, Eliminate, Rearrange 
OPV - Other Points of View

TIPS - Theory of Inventive Problem Solving

GMA - General Morphological Analysis

GAO - Government Accountability Office

FMECA - Failure Modes, Effects, and Criticality Analysis

FM -Failure Mode

RPN - Risk Priority Number

WWII - World War II

USSR - Soviet Union

SRBM - Short Range Ballistic Missile

MRBM - Medium Range Ballistic Missile

IRBM - Intermediate Range Ballistic Missile

ICBM - Intercontinental Ballistic Missile

SLBM - Submarine-Launched Ballistic Missile

MDA - Missile Defense Agency

FMS - Foreign Military Sale

COCOMS - Combatant Commands

DA - Defended Area

CONOPS - Concept of Operations

GMD - Ground-based Midcourse Defense

THAAD - Terminal High Altitude Area Defense

GBI - Ground-Based Interceptor

THAAD ER - Terminal High Altitude Area Defense Extended Range

SBIRS - Space-Based Infrared System

DSP - Defense Support System

STSS - Space Tracking Surveillance System

EWR - Early Warning Radar

TOPSIS - Technique for Order Preference by Similarity to Ideal Solution

UCC - Unified Combatant Commands

CR - Consistency Ratio

CI - Consistency Index

RI - Random Consistency Index 


\section{Appendix B: AHP Methodology and Example}

The AHP starts by generating a weight for each evaluation criterion according to criteria pairwise comparisons made by the decision maker. The more important criterion is the one with the largest weight value. Next the AHP assigns a score to each alternative per criterion according to the decision maker's pairwise comparisons of the alternatives. The better performing alternative will get the higher score. Finally, the AHP combines the criteria weights and the alternatives' scores and determines a global score for each option that is used for final ranking of the alternatives. The global score for a given option is a weighted sum of the scores it obtained with respect to all the criteria. ${ }^{19}$

The steps that are followed for the original AHP are:

Step 1: Define the problem and determine the kind of knowledge sought $\mathrm{t}^{20}$

The first step of AHP is to determine the goal for the decision. This statement is the main objective that is to be accomplished. It can be something as simple as "choose the best weapon system". This is usually determined by speaking with stakeholders and decision makers.

Step 2: Structure the decision hierarchy ${ }^{20}$

The decision hierarchy shown in Figure 43 is a qualitative assessment of what the customer values and identifies the alternatives of interest. The decision hierarchy starts from the top with the goal of the decision (objective), then the intermediate levels which are criteria and possibly sub-criteria, to the lowest level which is usually a set of the alternatives.

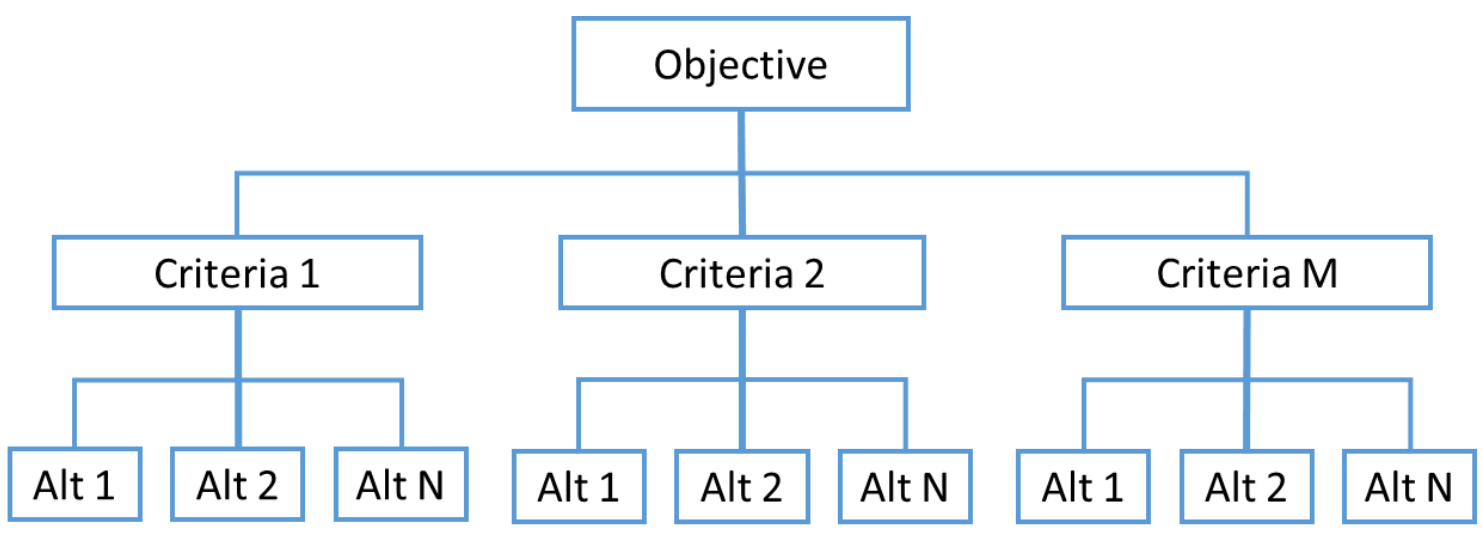

Figure 43. AHP Hierarchy

Step 3: Compute the vector if criteria weights using a set of pairwise comparison matrices ${ }^{19}$

The AHP depends on the use of pairwise comparisons of the criteria to develop the weights of each criteria. AHP uses pairwise comparisons using a relative importance scale because the quantification of qualitative data is either very difficult or impossible to do correctly. Therefore, AHP attempts to determine the relative importance of the criteria to develop weights. A commonly used scale is shown in Table 20. 
Table 20. Scale of Relative Importance ${ }^{19}$

\begin{tabular}{|c|c|c|}
\hline $\begin{array}{l}\text { Intensity of } \\
\text { Importance }\end{array}$ & Definition & Explanation \\
\hline 1 & Equal importance & $\begin{array}{l}\text { Two activities } \\
\text { contribute equally to } \\
\text { the objective }\end{array}$ \\
\hline 3 & $\begin{array}{l}\text { Weak importance of one over } \\
\text { another }\end{array}$ & $\begin{array}{l}\text { Experience and } \\
\text { judgement slightly } \\
\text { favor one activity over } \\
\text { another }\end{array}$ \\
\hline 5 & Essential or string importance & $\begin{array}{l}\text { Experience and } \\
\text { judgement strongly } \\
\text { favor one activity over } \\
\text { another }\end{array}$ \\
\hline 7 & Demonstrated importance & $\begin{array}{l}\text { An activity is strongly } \\
\text { favored and its } \\
\text { dominance } \\
\text { demonstrated in } \\
\text { practice }\end{array}$ \\
\hline 9 & Absolute importance & $\begin{array}{l}\text { The evidence favoring } \\
\text { one activity over } \\
\text { another is of the } \\
\text { highest possible order } \\
\text { of affirmation }\end{array}$ \\
\hline $2,4,6,8$ & $\begin{array}{l}\text { Intermediate values between the two } \\
\text { adjacent judgements }\end{array}$ & \\
\hline $\begin{array}{l}\text { Reciprocals of above } \\
\text { nonzero }\end{array}$ & $\begin{array}{c}\text { If activity } i \text { has one of the above } \\
\text { nonzero numbers assigned to it } \\
\text { when compared to activity } j \text {, the } j \\
\text { has the reciprocal value when } \\
\text { compared to } i\end{array}$ & \\
\hline
\end{tabular}

The values displayed on the scale in Table 20 are used to populate the criteria judgement matrix (there is also an alternative judgement matrix in Step 4) shown by the cells in color in Figure 44. The judgement matrix (J) is populated with the pairwise comparisons of the various criteria. If there are $\mathrm{M}$ criteria, then the judgement matrix is of size $\mathrm{Mx}$ M. The main diagonal of the matrix is set to " 1 " by default because those represent comparisons of a particular criteria to itself, which is of relative equal importance, therefore a vale of " 1 " according to the scale shown in Table 20. Although there is a lower and upper triangular that need scale values, only the upper triangular of the matrix needs to be determined (illustrated with the darker shades of color). The cells in the lower triangular (illustrated with the lighter shades of color) that correspond to the upper triangular are merely the reciprocal of the values in the corresponding cells in the upper triangular. In mathematical terms, $\mathrm{J}_{\mathrm{ij}} * \mathrm{~J}_{\mathrm{ji}}=1$. Once the judgement matrix is populated, the criteria 
weights are calculated by first taking the geometric mean of each row "That is, the cells in each row are multiplied with each other and then the $\mathbf{M}^{\text {th }}$ root is taken (where $\mathrm{m}$ is the number of cells in the row)". The numbers are then normalized by dividing them with their sum. ${ }^{15}$ Although this way of calculating the weights is common, another way to calculate them is by normalizing each column of the judgement matrix by dividing each cell in the column by the sum of the column. The average of the rows of the resulting matrix are the criteria weights. The criteria weights are as seen by the column bordered in red in Figure 44. The resulting vector is called the criteria weight priority vector (there is also an alternatives' scores priority vector in Step 4). One way that the user can use the criteria weights is to see how much decision maker value is contained within each of the criterion. For example, let's say there are three criterion, and criterion 1 received a weight of 0.60 and criterion 2 received a weight of 0.30 , and criterion 3 received a weight of 0.10 . One can conclude that $60 \%$ of the customer/decision maker value is contained within criterion $1,30 \%$ of the customer/decision maker value is contained within criterion 2 , and $10 \%$ of the customer/decision maker value is contained within criterion 3. One can also conclude that $90 \%$ of the customer/decision maker value is contained within criterion 1 and criterion $2(0.60+0.30=0.90)$. However, these conclusions can be made by any method that normalizes the criteria/attribute weights (weights sum to 1) and is not particular to AHP.

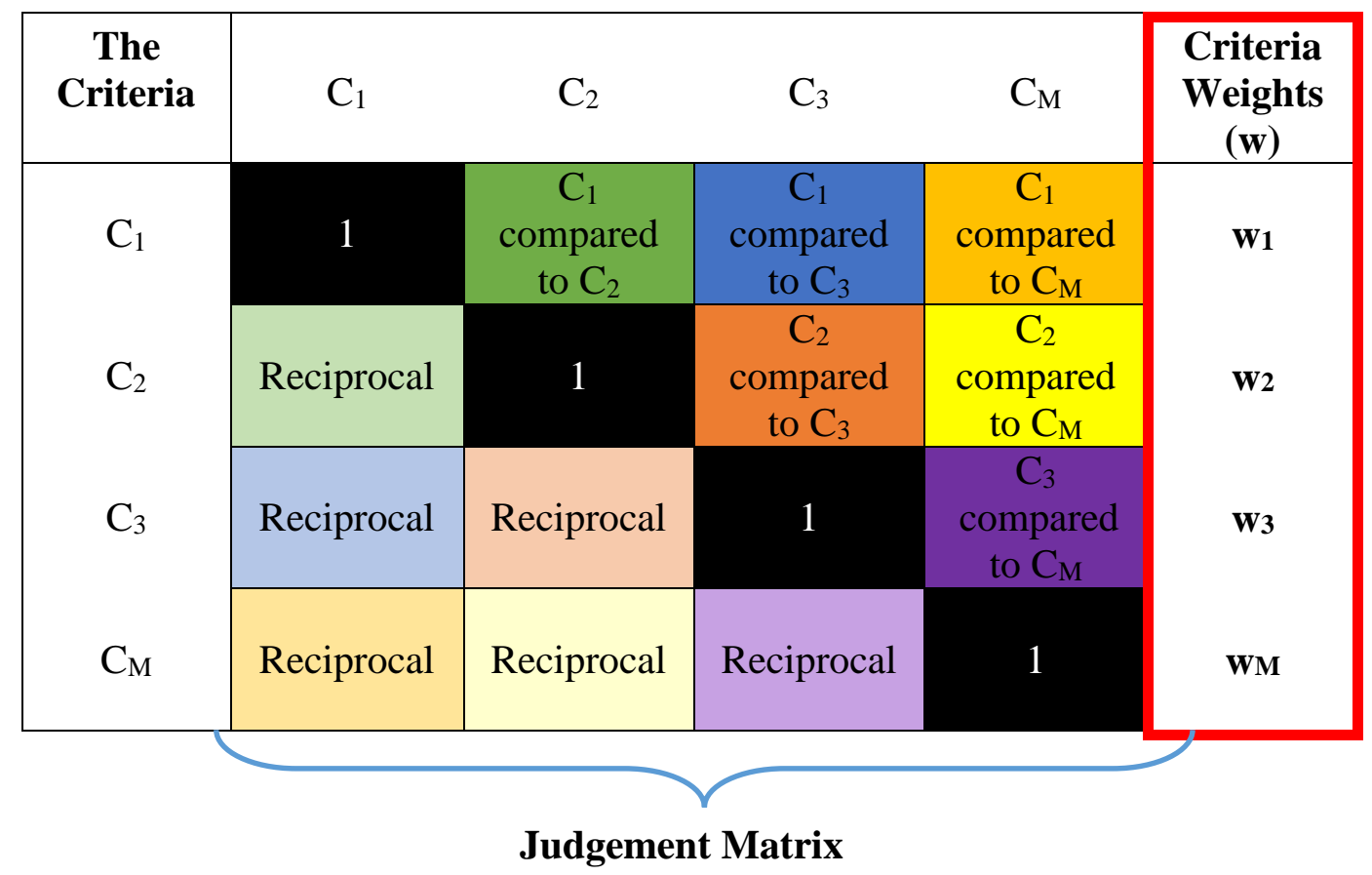

Figure 44. AHP criteria judgement matrix ${ }^{19}$

Step 4: Compute the vectors of alternative scores using a set of pairwise comparison $\underline{\text { matrices }^{19}}$ 
The alternatives are then compared to evaluate how well each alternative scores for every criteria. If there are $\mathrm{M}$ criteria, then there will be $\mathrm{M}$ separate matrices of alternative comparisons (one per criteria). If there are $\mathrm{N}$ alternatives, the size of the alternative score matrices are of size $\mathrm{N} \times \mathrm{N}$. The alternative score matrices are populated using the same pairwise comparison scale as displayed by Table 20, except instead of thinking of comparisons in terms of importance, one can think of the comparisons in terms of how well the alternatives score in each criteria. For example, Alternative $1\left(\mathrm{~A}_{1}\right)$ scores absolutely more than Alternative $2\left(\mathrm{~A}_{2}\right)$ in respect to Criteria $1\left(\mathrm{C}_{1}\right)$. The priority vector for the alternatives per criteria is obtained the same way as the criteria weight priority vector is obtained. The resulting vector is called the alternatives' score priority vector. Again, there will be $\mathrm{M}$ amount of score priority vectors $\left(\mathrm{s}^{(1)}, \mathrm{s}^{(1)}, \mathrm{s}^{(1)} \ldots \mathrm{s}^{(\mathrm{M})}\right)$ as shown bordered in light blue in Figure 45.

\begin{tabular}{|l|l|l|l|l|l|}
\hline $\mathbf{C}_{\mathbf{1}}$ & $\mathrm{A}_{1}$ & $\mathrm{~A}_{2}$ & $\mathrm{~A}_{3}$ & $\mathrm{~A}_{\mathrm{N}}$ & $\mathbf{s}^{\mathbf{( 1 )}}$ \\
\hline $\mathrm{A}_{1}$ & & & & & \\
\hline $\mathrm{A}_{2}$ & & & & & \\
\hline $\mathrm{A}_{3}$ & & & & & \\
\hline $\mathrm{A}_{\mathrm{N}}$ & & & & & \\
\hline
\end{tabular}

\begin{tabular}{|l|l|l|l|l|l}
\hline $\mathbf{C}_{2}$ & $\mathrm{~A}_{1}$ & $\mathrm{~A}_{2}$ & $\mathrm{~A}_{3}$ & $\mathrm{~A}_{\mathrm{N}}$ & $\mathbf{s}^{(2)}$ \\
\hline $\mathrm{A}_{1}$ & & & & & \\
\hline $\mathrm{A}_{2}$ & & & & & \\
\hline $\mathrm{A}_{3}$ & & & & & \\
\hline $\mathrm{A}_{\mathrm{N}}$ & & & & & \\
\hline
\end{tabular}

\begin{tabular}{|l|l|l|l|l|l|}
\hline $\mathbf{C}_{3}$ & $\mathrm{~A}_{1}$ & $\mathrm{~A}_{2}$ & $\mathrm{~A}_{3}$ & $\mathrm{~A}_{\mathrm{N}}$ & $\mathbf{s}^{(\mathbf{3})}$ \\
\hline $\mathrm{A}_{1}$ & & & & & \\
\hline $\mathrm{A}_{2}$ & & & & & \\
\hline $\mathrm{A}_{3}$ & & & & & \\
\hline $\mathrm{A}_{\mathrm{N}}$ & & & & & \\
\hline
\end{tabular}

\begin{tabular}{|c|l|l|l|l|l|}
\hline $\mathbf{C}_{\mathbf{M}}$ & $\mathrm{A}_{1}$ & $\mathrm{~A}_{2}$ & $\mathrm{~A}_{3}$ & $\mathrm{~A}_{\mathrm{N}}$ & $\mathbf{s}^{(\mathbf{M})}$ \\
\hline $\mathrm{A}_{1}$ & & & & & \\
\hline $\mathrm{A}_{2}$ & & & & & \\
\hline $\mathrm{A}_{3}$ & & & & & \\
\hline $\mathrm{A}_{\mathrm{N}}$ & & & & & \\
\hline
\end{tabular}

Figure 45. AHP alternative judgement matrices ${ }^{19}$

When making pairwise comparisons to obtain the criteria and alternative judgement matrix, inconsistencies typically arise. As an example, let us assume that there are three criteria to be considered in a particular decision problem. An inconsistency would be if the decision maker decides that criteria 1 is more important than criteria 2 , criteria 2 is more important than criteria 3 , but criteria 3 is more important that criteria 1 . The AHP incorporates a technique for checking the consistency of the pairwise comparisons made by the decision maker. The technique computes a Consistency Index (CI) that is obtained by Equation 9, where $\mathrm{M}$ is the number of criteria being considered in the decision, and $\lambda_{\max }$ is obtained by "adding the columns in the judgement matrix and multiplying the resulting vector by the priority vector". ${ }^{20}$

$$
C I=\frac{\lambda_{\max }-M}{M-1}
$$

A decision maker that is perfectly consistent should always make pairwise comparisons that result in $\mathrm{CI}=0$, but small values of $\mathrm{CI}$ are acceptable. A CI value is 
considered adequately small if the corresponding Consistency Ratio (CR) is less than $10 \%$, where CR is defined by Equation 10.

$$
C R=\frac{C I}{R I}<0.10
$$

RCI is the Random Consistency Index, which is given in Table 21.

Table 21. RI values for different values of $N$ (number of alternatives $)^{19}$

\begin{tabular}{|c|c|c|c|c|c|c|c|c|c|c|}
\hline $\mathrm{n}$ & 1 & 2 & 3 & 4 & 5 & 6 & 7 & 8 & 9 & 10 \\
\hline $\mathbf{R I}$ & 0 & 0 & 0.58 & 0.90 & 1.12 & 1.24 & 1.32 & 1.41 & 1.45 & 1.51 \\
\hline
\end{tabular}

When the judgement matrix and alternative score's matrices do not satisfy Equation 10, the decision maker should reevaluate the pairwise comparisons until Equation 10 is satisfied in order to ensure consistency in the results.

Step 5: Rank the options ${ }^{19}$

At this point, the criteria weight priority vector and the alternatives' scores priority vectors have been calculated. The next step is to put the alternatives' scores priority vectors that were obtained in Step 2 into a common matrix called the Score Matrix (S) as shown in Equation 11. Equation 12 represents the criteria weight priority vector obtained in Step 3.

$$
\begin{aligned}
S_{N x M} & =\left[\begin{array}{llll}
S^{(1)} S^{(2)} s^{(3)} \ldots s^{(M)}
\end{array}\right] \\
w_{M x 1} & =\left[\begin{array}{lllll}
w_{1} & w_{2} & w_{3} & \ldots & w_{M}
\end{array}\right]^{T}
\end{aligned}
$$

Once the weight vector $\mathrm{w}$ and the score matrix $\mathrm{S}$ have been computed, the AHP obtains a vector of the final alternative priorities, $v$, by taking the dot product of $S$ and w as shown in Equation 13. The $i^{\text {th }}$ entry $v_{i}$ of $v$ represents the global score assigned by the AHP to the $i^{\text {th }}$ alternative. Figure 46 displays a chart that can be used to display that final results. The AHP final priority vector is composed of ratios that add up to 1 (just like the criteria weights priority vector). What this means is that the ranking is based on relative performance of the alternatives in the set. The disadvantage to this is that if more alternatives were introduced to the study, then the scores of the alternatives will change since they are relative to the set of alternatives, thus the ranking will change. Therefore, the final priority vector can only be used to make conclusions based on the relative performance of the alternatives and not on the values of the customer as you can with the criteria weights.

$$
v=S \cdot \mathrm{w}
$$




\begin{tabular}{|c|c|c|c|c|c|}
\hline & $\begin{array}{l}\mathbf{C}_{1} \\
\mathrm{w}_{1}\end{array}$ & $\begin{array}{l}\mathbf{C}_{2} \\
\mathrm{w}_{2}\end{array}$ & $\begin{array}{l}\mathbf{C}_{3} \\
\mathrm{w}_{3}\end{array}$ & $\begin{array}{l}\mathbf{C}_{M} \\
w_{M}\end{array}$ & $\begin{array}{c}\text { Final } \\
\text { Priority }\end{array}$ \\
\hline $\begin{array}{l}\mathbf{A}_{1} \\
\mathbf{A}_{2} \\
\mathbf{A}_{3} \\
\mathbf{A}_{\mathbf{N}}\end{array}$ & $S^{(1)}$ & $\mathbf{s}^{(2)}$ & $\mathbf{s}^{(3)}$ & $s^{(\mathrm{M})}$ & $\mathrm{V}$ \\
\hline
\end{tabular}

Figure 46. Image of the table used to display the final priority of alternatives ${ }^{16}$

\section{AHP Numerical Example}

The following is a numerical example to illustrate the mathematical AHP process. In this example, there are four criteria $\left(\mathrm{C}_{1}, \mathrm{C}_{2}, \mathrm{C}_{3}\right.$, and $\left.\mathrm{C}_{4}\right)$ that the decision maker values that are used to prioritize three alternatives $\left(\mathrm{A}_{1}, \mathrm{~A}_{2}\right.$, and $\left.\mathrm{A}_{3}\right)$. Starting with Step 3 , the criteria judgement matrix was populated using the scales from Table 20. The criteria weights were calculated using the geometric mean method. Figure 47 shows what would result after applying Step 3.

\begin{tabular}{|c|c|c|c|c|c|}
\hline $\begin{array}{c}\text { The } \\
\text { four } \\
\text { Criteria }\end{array}$ & $\mathrm{C}_{1}$ & $\mathrm{C}_{2}$ & $\mathrm{C}_{3}$ & $\mathrm{C}_{4}$ & $\begin{array}{c}\text { Criteria } \\
\text { Weights } \\
\text { (w) }\end{array}$ \\
\hline $\mathrm{C}_{1}$ & 1 & 5 & 3 & 7 & 0.553 \\
\hline $\mathrm{C}_{2}$ & $1 / 5$ & 1 & $1 / 3$ & 5 & 0.131 \\
\hline $\mathrm{C}_{3}$ & $1 / 3$ & 3 & 1 & 66 & 0.271 \\
\hline $\mathrm{C}_{4}$ & $1 / 7$ & $1 / 5$ & $1 / 6$ & 1 & 0.045 \\
\hline
\end{tabular}

Figure 47. AHP numerical example of criteria judgement matrix ${ }^{20}$

The next step, Step 4, is to determine the alternative judgement matrices using the same scales from Table 20 to populate the alternative judgement matrix and the geometric mean to calculate the alternatives' scores priority vectors. Since there are four criteria, there will be four scores priority vectors as seen in Figure 48. 


\begin{tabular}{|c|c|c|c|c|}
\hline $\mathbf{C}_{\mathbf{1}}$ & $\mathrm{A}_{1}$ & $\mathrm{~A}_{2}$ & $\mathrm{~A}_{3}$ & $\mathbf{s}^{\mathbf{( 1 )}}$ \\
\hline $\mathrm{A}_{1}$ & 1 & 6 & 8 & $\mathbf{0 . 7 5 4}$ \\
\hline $\mathrm{A}_{2}$ & $1 / 6$ & 1 & 4 & $\mathbf{0 . 1 8 1}$ \\
\hline $\mathrm{A}_{3}$ & $1 / 8$ & $1 / 4$ & 1 & $\mathbf{0 . 0 6 5}$ \\
\hline
\end{tabular}

\begin{tabular}{|c|c|c|c|c|}
\hline $\mathbf{C}_{2}$ & $\mathrm{~A}_{1}$ & $\mathrm{~A}_{2}$ & $\mathrm{~A}_{3}$ & $\mathbf{s}^{(\mathbf{2})}$ \\
\hline $\mathrm{A}_{1}$ & 1 & 7 & $1 / 5$ & $\mathbf{0 . 2 3 3}$ \\
\hline $\mathrm{A}_{2}$ & $1 / 7$ & 1 & $1 / 8$ & $\mathbf{0 . 0 5 5}$ \\
\hline $\mathrm{A}_{3}$ & 5 & 8 & 1 & $\mathbf{0 . 7 1 3}$ \\
\hline
\end{tabular}

\begin{tabular}{|c|c|c|c|c|}
\hline $\mathbf{C}_{3}$ & $\mathrm{~A}_{1}$ & $\mathrm{~A}_{2}$ & $\mathrm{~A}_{3}$ & $\mathbf{s}^{\mathbf{( 3 )}}$ \\
\hline $\mathrm{A}_{1}$ & 1 & 8 & 6 & $\mathbf{0 . 7 5 4}$ \\
\hline $\mathrm{A}_{2}$ & $1 / 8$ & 1 & $1 / 4$ & $\mathbf{0 . 0 6 5}$ \\
\hline $\mathrm{A}_{3}$ & $1 / 6$ & 4 & 1 & $\mathbf{0 . 1 8 1}$ \\
\hline
\end{tabular}

\begin{tabular}{|c|c|c|c|c|}
\hline $\mathbf{C}_{4}$ & $\mathrm{~A}_{1}$ & $\mathrm{~A}_{2}$ & $\mathrm{~A}_{3}$ & $\mathbf{s}^{(\mathbf{4})}$ \\
\hline $\mathrm{A}_{1}$ & 1 & 5 & 4 & $\mathbf{0 . 6 7 4}$ \\
\hline $\mathrm{A}_{2}$ & $1 / 5$ & 1 & $1 / 3$ & $\mathbf{0 . 1 0 1}$ \\
\hline $\mathrm{A}_{3}$ & $1 / 4$ & 3 & 1 & $\mathbf{0 . 2 2 6}$ \\
\hline
\end{tabular}

Figure 48. AHP Numerical example of alternatives' score matrices ${ }^{20}$

After the criteria weight priority vector and the alternatives' scores priority vector for each criteria have been calculated, the next step, Step 5, is to rank the alternatives. The first thing to do is put the alternatives' priority score vectors into the score matrix, S. The final priority vector is calculated using Equation 13. Figure 49 shows the final priority vector for the numerical example. In this example, Alternative 1 is prioritized with a score of 0.680, Alternative 3 is the second to be prioritized with a score of 0.190, and Alternative 3 is the last to be prioritized with a score of 0.130 . Figure 49 displays the final results chart.

$$
\begin{aligned}
& S=\left[s^{(1)} s^{(2)} s^{(3)} s^{(4)}\right]=\left[\begin{array}{llll}
0.754 & 0.233 & 0.745 & 0.674 \\
0.181 & 0.055 & 0.065 & 0.101 \\
0.065 & 0.713 & 0.181 & 0.226
\end{array}\right] \\
& w=\left[\begin{array}{llll}
0.553 & 0.131 & 0.271 & 0.045
\end{array}\right]^{T} \\
& v=S \cdot \mathrm{w}=\left[\begin{array}{l}
0.680 \\
0.130 \\
0.190
\end{array}\right]
\end{aligned}
$$

\begin{tabular}{|lcccc|c|}
\hline & $\mathbf{C}_{\mathbf{1}}$ & $\mathbf{C}_{\mathbf{2}}$ & $\mathbf{C}_{\mathbf{3}}$ & $\mathbf{C}_{\mathbf{4}}$ & Final \\
$\mathbf{w}$ & 0.533 & 0.131 & 0.271 & 0.045 & Priority \\
\hline $\mathbf{A}_{1}$ & 0.754 & 0.233 & 0.745 & 0.674 & $\mathbf{0 . 6 8 0}$ \\
$\mathbf{A}_{\mathbf{2}}$ & 0.181 & 0.055 & 0.065 & 0.101 & $\mathbf{0 . 1 3 0}$ \\
$\mathbf{A}_{3}$ & 0.065 & 0.713 & 0.181 & 0.226 & $\mathbf{0 . 1 9 0}$ \\
\hline
\end{tabular}

Figure 49. AHP final prioritization chart $^{20}$ 


\section{Appendix C: TOPSIS Methodology and Example}

TOPSIS typically relies on other MCDM techniques to qualitatively assess inputs like the evaluation criteria and the alternatives to be evaluated. TOPSIS is commonly applied with AHP, where AHP is used to develop the criteria weights and sometimes the alternatives' scores. If scores are not found with AHP, TOPSOS determines scores using qualitative measures (e.g., Good, Very Good, and Extremely Good) that are then quantified to a scale (e.g., 5, 7, and 9). TOPSIS is merely a mathematical algorithm that prioritizes scores subject to multiple criteria by comparing them to a Positive Ideal Solution, (PIS) and a Negative Ideal Solution (NIS). The best alternative is the one closest to the PIS and furthest away from the NIS. ${ }^{21}$

Steps for TOPSIS are: ${ }^{21}$

\section{Step 1: Form a decision matrix}

Assuming there are $\mathrm{M}$ criterion and $\mathrm{N}$ alternatives, the decision matrix (D) is of the form shown in Figure 50. The TOPSIS decision matrix is similar to the AHP final prioritization chart shown in Figure 49.

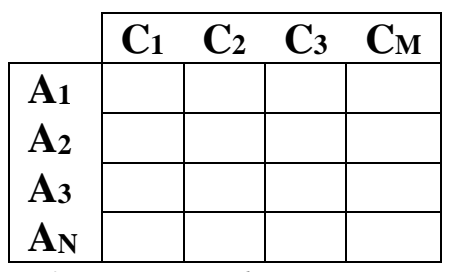

Figure 50. TOPSIS decision matrix (D)

The TOPSIS decision matrix is either populated using other MCDM techniques like AHP, or populated from scores that are obtained from a user-determined scale derived from qualitative measures. For example, qualitative score measures can be in the form of "Good, Very Good, and Extremely Good", with a respective scale of 5, 7, and 9. In the case that AHP is used, the alternatives' scores priority vectors are used to populate the TOPSIS decision matrix.

\section{Step 2: Normalize the decision matrix}

The next step is to normalize the decision matrix using Equation 14. The normalized decision matrix is defined by the variable $r$, where $i$ is the decision matrix row index and $j$ is the decision matrix column index.

$$
r_{i j}=\frac{x_{i j}}{\sqrt{\sum_{i=1}^{N}\left(x_{i j}\right)^{2}}}
$$




\section{Step 3: Construct weighted normalized decision matrix}

The next step is to multiply the criteria weights attained by other MCDM techniques using Equation 15, like AHP, to the normalized decision matrix to attain the weighted normalized decision matrix.

$$
v_{i j}=w_{i j} r_{i j}
$$

Step 4: Determine positive ideal solution and negative ideal solution

Now that we have a weighted normalized decision matrix, we can now determine what the positive ideal solution $\left(\mathrm{I}^{+}\right)$and the negative ideal solution is $\left(\mathrm{I}^{-}\right)$using Equation 16 and 17 , respectively.

$$
I^{+}=\left\{\left(\max v_{i j} \mid j \in J\right),\left(\min v_{i j} \mid j \in J^{\prime}\right)\right\}
$$

where $\mathrm{J}=1,2,3, \ldots, \mathrm{M}$ and is associated with the benefit criteria

$$
I^{-}=\left\{\left(\min v_{i j} \mid j \in J\right),\left(\max v_{i j} \mid j \in J^{\prime}\right)\right\}
$$

where $\mathrm{J}^{\prime}=1,2,3, \ldots, \mathrm{M}$ and is associated with the cost criteria

Equation 16 is simply stating that the positive ideal solution is composed of the highest weighted normalized values for each criterion (columns in the weighted normalized decision matrix), unless it is cost criterion, which the lowest weighted normalized value is selected. This is intuitive because an ideal solution maximizes benefit/performance and minimizes cost. For the negative ideal solution, the opposite is true. Equation 17 states that the negative ideal solution is compose of the lowest weighted normalized values for each criterion, unless it is cost criterion, which the highest weighted normalized value is selected. This is intuitive because the worst solution minimizes benefit/performance and maximizes cost.

\section{Step 5: Calculate the separation measure}

After the positive ideal and negative ideal solutions have been determined, the next step is to calculate how far each alternative is from the positive and negative ideal solutions. This is determined by calculating the positive separation measure and the negative separation measure using Equation 18 and 19.

$$
\begin{aligned}
& S_{i}^{+}=\sqrt{\sum_{j=1}^{n}\left(v_{i j}-v_{i j}^{+}\right)^{2}} \\
& S_{i}^{-}=\sqrt{\sum_{j=1}^{n}\left(v_{i j}-v_{i j}^{-}\right)^{2}}
\end{aligned}
$$

where $i=1,2,3, \ldots, \mathrm{N}$ 
Step 6: Calculate the relative closeness to the positive ideal solution

Once the positive and negative separation measures for each alternative have been calculated, the next step is calculate the relative closeness of each alternative to the positive ideal solution. The relative closeness of $\mathrm{A}_{\mathrm{i}}$ with respect to $\mathrm{I}^{+}$is defined by Equation 20 .

$$
C_{i}^{+}=\frac{S_{i}^{-}}{\left(S_{i}^{+}+S_{i}^{-}\right)}, \quad 0 \leq C_{i}^{+} \leq 1
$$

where $i=1,2,3, \ldots, \mathrm{N}$

\section{Step 7: Rank the preference order}

An alternative with a $\mathrm{C}_{\mathrm{i}}^{+}$value of 1 would be exactly the positive ideal solution and an alternative with a $\mathrm{C}_{\mathrm{i}}^{+}$value of 0 would be exactly the negative ideal solution. Therefore, alternatives are ranked by how close their $\mathrm{C}_{\mathrm{i}}^{+}$value is to 1 . For example, let's say there are three alternatives to be ranked $\left(\mathrm{A}_{1}, \mathrm{~A}_{2}\right.$, and $\left.\mathrm{A}_{3}\right)$ and $\mathrm{A}_{1}$ has a $\mathrm{C}_{\mathrm{i}}^{+}$value of $0.90, \mathrm{~A}_{2}$ has a $\mathrm{C}_{\mathrm{i}}^{+}$ value of 0.70 , and $\mathrm{A}_{3}$ has a $\mathrm{C}_{\mathrm{i}}^{+}$value of 0.80 . The ranking would go $\mathrm{A}_{1}, \mathrm{~A}_{3}$, and $\mathrm{A}_{2}$ from top ranked to lowest ranked.

\section{TOPSIS Numerical Example}

For the purposes of a numerical example of TOPSIS, let's assume that AHP was used to determine the decision matrix. The weight vector and scores matrices from the AHP numerical example in this report will be used. The decision matrix is as shown in Figure 51 (Step 1).

\begin{tabular}{|lllll|}
\hline & $\mathbf{C}_{1}$ & $\mathbf{C}_{2}$ & $\mathbf{C}_{3}$ & $\mathbf{C}_{4}$ \\
$\mathbf{w}$ & 0.533 & 0.131 & 0.271 & 0.045 \\
\hline $\mathbf{A}_{1}$ & 0.754 & 0.233 & 0.745 & 0.674 \\
$\mathbf{A}_{2}$ & 0.181 & 0.055 & 0.065 & 0.101 \\
$\mathbf{A}_{3}$ & 0.065 & 0.713 & 0.181 & 0.226 \\
\hline
\end{tabular}

Figure 51. Decision matrix for TOPSIS numerical example

Step 2 is now to normalize the decision matrix using Equation 14. The resulting normalized decision matrix is shown in Figure 52.

\begin{tabular}{|l|l|l|l|l|}
\cline { 2 - 5 } \multicolumn{1}{c|}{} & \multicolumn{1}{l}{$\mathbf{C}_{1}$} & \multicolumn{1}{c|}{$\mathbf{C}_{2}$} & \multicolumn{1}{c|}{$\mathbf{C}_{3}$} & $\mathbf{C}_{4}$ \\
\hline $\mathbf{A}_{1}$ & 0.9690 & 0.3098 & 0.9683 & 0.9387 \\
\cline { 2 - 5 } $\mathbf{A}_{2}$ & 0.2326 & 0.0731 & 0.0845 & 0.1407 \\
\cline { 2 - 5 } $\mathbf{A}_{3}$ & 0.0835 & 0.9480 & 0.2352 & 0.3148 \\
\hline
\end{tabular}

Figure 52. Normalized decision matrix for TOPSIS numerical example

Step 3 is now to multiply the weights from AHP to the normalized decision matrix using Equation 15. The resulting weighted normalized decision matrix is show in Figure 53.

\begin{tabular}{|l|l|l|l|l|}
\cline { 2 - 5 } \multicolumn{1}{c|}{} & \multicolumn{1}{l}{$\mathbf{C}_{1}$} & $\mathbf{C}_{2}$ & \multicolumn{1}{l|}{$\mathbf{C}_{3}$} & $\mathbf{C}_{4}$ \\
\hline $\mathbf{A}_{1}$ & 0.5165 & 0.0406 & 0.2624 & 0.0422 \\
\cline { 2 - 5 }
\end{tabular}




$$
\begin{array}{|l|l|l|l|l|}
\cline { 2 - 5 } \text { A2 } & 0.1240 & 0.0096 & 0.0229 & 0.0063 \\
\cline { 2 - 5 } \mathbf{A}_{3} & 0.0445 & 0.1242 & 0.0638 & 0.0142 \\
\hline
\end{array}
$$

Figure 53. Weighted normalized decision matrix for TOPSIS numerical example

Step 4 is now to determine the positive ideal and negative ideal solutions using Equations 16 and 17. The resulting positive ideal and negative ideal solutions are shown in Figure 54.

\begin{tabular}{|l|l|l|l|l|}
\cline { 2 - 5 } \multicolumn{1}{c|}{} & \multicolumn{1}{|c}{$\mathbf{C}_{\mathbf{1}}$} & $\mathbf{C}_{\mathbf{2}}$ & $\mathbf{C}_{\mathbf{3}}$ & $\mathbf{C}_{\mathbf{4}}$ \\
\hline $\mathbf{I}^{+}$ & 0.5165 & 0.1242 & 0.2624 & 0.0422 \\
\cline { 2 - 6 } $\mathbf{I}^{-}$ & 0.0445 & 0.0096 & 0.0229 & 0.0063 \\
\hline
\end{tabular}

Figure 54. Positive and negative ideal solutions for TOPSIS numerical example

Step 5 is now to calculate the positive and negative separation measure, which again are the measures of how far away each alternative is to the positive ideal solution and negative ideal solution. The separation measures are found using Equations 16 and 17 and the results are shown in Figure 55.

\begin{tabular}{|l|l|l|}
\cline { 2 - 3 } \multicolumn{1}{c|}{} & $\mathbf{S i}_{\mathbf{i}}{ }^{+}$ & $\mathbf{S i}_{\mathbf{i}}{ }^{-}$ \\
\hline $\mathbf{A}_{\mathbf{1}}$ & 0.0836 & 0.5314 \\
\hline $\mathbf{A}_{2}$ & 0.4752 & 0.0795 \\
\hline $\mathbf{A}_{3}$ & 0.5128 & 0.1219 \\
\hline
\end{tabular}

Figure 55. Separation measures for TOPSIS numerical example

Step 6 is now to calculate the relative closeness of each alternative to the positive ideal solution using Equation 20. Results are shown in Figure 56.

\begin{tabular}{|l|l|}
\cline { 2 - 2 } \multicolumn{1}{l|}{} & $\mathbf{C}_{\mathbf{i}}{ }^{+}$ \\
\hline $\mathbf{A}_{1}$ & 0.8641 \\
\hline $\mathbf{A} \mathbf{2}$ & 0.1432 \\
\hline $\mathbf{A 3}$ & 0.1921 \\
\hline
\end{tabular}

Figure 56. Relative closeness of alternatives for TOPSIS numerical example

Alternatives are now ranked using the relative closeness measure for each alternative in Step 7 shown in Figure 57. The alternatives with the higher values are the better performing. The figure below displays the final ranking table. Notice that the ranking for the TOPSIS numerical example is the same as the ranking for the AHP numerical example, except with different final scores $\left(\mathrm{C}_{\mathrm{i}}^{+}\right.$vs final priority vector)

\begin{tabular}{|l|l|l|l|c|}
\cline { 2 - 6 } \multicolumn{1}{c|}{} & $\mathbf{S}_{\mathbf{i}}{ }^{+}$ & $\mathbf{S}_{\mathbf{i}}{ }^{-}$ & $\mathbf{C}_{\mathbf{i}}{ }^{+}$ & Rank \\
\hline $\mathbf{A}_{1}$ & 0.0836 & 0.5314 & 0.8641 & 1 \\
$\mathbf{A}_{2}$ & 0.4752 & 0.0795 & 0.1432 & 3 \\
$\mathbf{A}_{3}$ & 0.5128 & 0.1219 & 0.1921 & 2 \\
\hline
\end{tabular}

Figure 57. Final priority vector for TOPSIS numerical example

Since TOPSIS is a MCDM technique, the discussion of why AHP falls short of MODA also applies to TOPSIS. The things that differentiate TOPSIS from AHP is that TOPSIS makes it relatively easy to compare a higher number of alternatives, a high number 
of criterion, or both since it does not use pairwise comparisons (unless used in conjunction with AHP). TOPSIS also compares alternatives to the best possible solution in the set, so the user can make conclusions on how alternatives can be improved and by how much (in terms of percentage if ideal solution is $100 \%$ ) in order to better perform in the set criteria. 


\section{Appendix D: Interviews}

The following are best practices for interviewing stakeholders as seen in Decision Making in Systems Engineering and Management ${ }^{3}$ :

\section{Before the Interview ${ }^{3}$}

For interviews with senior leaders and key stakeholder representatives, it is important to prepare a questionnaire to guide the interview discussion. The following are the best practices for interview preparation:

- Unless the team has significant problem domain experience, research may be essential to understand the problem domain and the key terminology.

- Develop as broad a list of interviewees as possible. Identify one or more interviewees for each stakeholder group. Review the interview list with the project client to insure that all key stakeholders are on the list of potential interviewees.

- Begin the questionnaire with a short explanatory statement that describes the reason for the interview, the preliminary statement of the problem, and the stakeholders being interviewed.

- It is usually useful to begin the interview with an unfreezing question that encourages the interviewee to think about the future and how that will impact the problem you are interviewing about.

- Tailor the questionnaire to help you define the problem and obtain information that will be needed in the future.

- Tailor the questionnaire to each category of interviewee. Make the questions as simple as possible.

- Do not use leading questions that imply you know the answer and want the interviewee to agree with your answer.

- Do not ask a senior leader a detailed question the answer to which can be looked up on the Internet or obtained by research.

- End the questionnaire with a closing question, for example, "Is there any other question we should have asked you?"

- Arrange to have an experienced interviewer and a recorder for each interview.

- Decide if the interview will be for attribution or not for attribution. Usually, the interviews will be for no attribution.

\section{$\underline{\text { Schedule/Reschedule }^{3}}$}

Interviews with senior leaders require scheduling and, frequently, rescheduling. The following are best practices for interview scheduling:

- It is usually best to conduct interviews individually to obtain each interviewee's thoughts and ideas on the problem and the potential solutions. Additional attendees change the interview dynamic. The senior leader may be reluctant to express ideas in front of a large audience or may defer to staffers to let them participate. 
- Provide the brief problem statement to the interviewees when the interview is scheduled.

- If possible, do not provide the interview questionnaire to the interviewees. When the questionnaire is provided, the interviewee's staff may provide the answers to the questions instead of the principal being interviewed. This can result in the interviewee reading "staff answers". If we want staff answers we should consider a focus group for staff members.

- Many times it is best to have the stakeholder representatives assigned to your team schedule the interview since they may have better access.

- Depending on the importance of the problem and the difficulty of scheduling, we usually request 30-60 minutes for the interview.

- The interviews can be done in person or over the phone. In-person interviews are the most effective since interaction is easier, but sometimes they are not possible and the only practical choice is a phone interview.

- The more senior the leader, the more likely scheduling will be a challenge.

During the Interview ${ }^{3}$

The interview teams' execution of the interview creates an important first impression with the senior leader about the team that will develop a solution to the problem. The goal of the interview is to obtain the stakeholder insights in a way that is interesting to the interviewee. Some thoughts for conducting interviews are as follows:

- The best number of people to conduct the interview is one interviewer and one notetaker. An alternative to the notetaker is a recorder. Some interviewees may be reluctant to be recorded. If you are considering using a tape recorder, request permission first.

- Conduct the interview as a conversation with the interview. Use the interview questionnaire as a guideline. Take the questions in the order the interviewee wants to discuss them.

- Make the interview interesting to the interviewee.

- Use and unfreezing question for the first question. An unfreezing question helps the interviewer focus on the problem in the future.

- Be flexible, follow up on an interesting observation even if it was not on your questionnaire. Many times an interviewee will make only one important observation. It is critical to make sure you understand the observation and the implications.

- Ask simple open-ended questions that require the interviewee to think and respond. Avoid complex, convoluted questions that confuse the interviewee.

- Respect the interviewee's time. Stay within the interview time limit unless the interviewee wants to extend the interview period. 
- When the interviewee's body language signals that they have finished the interview (e.g., fold up paper, look at their watch), go quickly to your closing question, and end the interview.

\section{After the Interview ${ }^{3}$}

Documentation of the interview is the key to providing the results of the interview to the problem definition team. The best practice for documenting the interview is the following:

- As soon as possible after the interview, the recorder should type the interview notes.

- The questions and the answers should be aligned to provide proper context for the answers.

- It is best to record direct quotes as much as possible.

- The interviewer should review the recorder's typed notes and make revisions as required.

- Once the interview notes are complete, they should be provided to the interview team.

- The documentation should be consistent with the decision to use the notes with or without attribution.

\section{Analysis of the Interview Notes ${ }^{3}$}

The interview notes are a great source of data for the entire decision analysis team. They key to interview analysis is binning (i.e., categorizing) the comments, summarizing observations, and identifying unique "nuggets" of information that only one or two interviewees provide. The best practice for analysis of interview notes is the following:

- The most common analysis approach is to bin the interviewee responses by the questions.

- The most challenging task is to identify unique "nuggets" of information that only one or two interviewees provide.

- The best way to summarize interviews is by findings, conclusions, and recommendations. Findings are facts stated by the stakeholders. Conclusions are a summary of several findings. Recommendations are what we recommend we do about the conclusion.

- It is important to integrate research findings with interview findings. Many times an interviewee will identify an issue that we must research to complete our data collection.

- Identifying the findings for a large number of interviews is challenging. One approach is the preliminary findings approach. Here is one way to do the approach:

- Read several of the interview notes.

$\circ$ Form preliminary findings. 
- Bin quotes for the interviews that relate to the preliminary findings.

- Add research information to the quotes.

$\circ$ Revise the preliminary findings to findings that are fully supported by the interview and research data.

As the findings are being identified, it is important not to get distracted by focusing on potential findings that are interesting but unrelated to the purpose of the stakeholder analysis. If appropriate, these findings should be presented separately to the decision makers.

Follow up with Interviewees ${ }^{3}$

Many times the interviewee will request follow-up information. The following are examples of the appropriate follow-up:

- Thank you note or e-mail to the interviewee and/or stakeholder representative that scheduled the meeting.

- A revised statement of the problem after the problem definition is complete.

- A copy of the findings, conclusions, and recommendations from the interviews.

- A briefing or copy of the report at the end of the project. 


\section{Appendix E: Focus Groups}

The following are best practices for focus group interviews as seen in Decision Making in Systems Engineering and Management ${ }^{3}$ :

\section{Preparing for the Focus Group Session ${ }^{3}$}

As with any stakeholder analysis technique, developing the goals and objectives of the focus group session is critical to success. A few best practices for preparing for a focus group session include the following:

- Develop a clear statement of purpose of the focus group and what you hope to achieve from the session. This should be coordinated with the project client and provided to the focus group participants.

- Develop a profile of the type of participant that should be part of the session and communicate that to the project client.

- Select a participant pool with the project client.

- Select and prepare moderators that can facilitate a discussion without imposing their own biases on the group. If resourced permit, hire a professional moderator.

- Schedule a time and location during which this group can provide 60-90 minutes of uninterrupted discussion.

- Develop a set of questions that are open-ended and will generate discussion. Do not use "Yes/No" questions that will yield little discussion. The most important information may come out of discussion about an issue ancillary to a question posed to the group.

\section{Executing the Focus Group Session ${ }^{3}$}

The most important components of executing the session are the moderator and the recording plan. Here are some thoughts for the execution of a focus group session:

- The moderator should review the session goals and objectives, provide an agenda, and discuss the plan for the recording session.

- Ask a question and allow participants a few minutes to discuss their ideas. The moderator should ensure even participation from the group to prevent a few individuals from dominating the group.

- A good technology solution for facilitating focus groups is the GroupSystems software. This technology facilitates groups in brainstorming activities and generating ideas. It helps mitigate the impact from individuals who tend to dominate discussions because participants type their ideas on a computer in response to questions generated by the moderator. It also significantly helps the team in recording the information from the session and sets them up for analysis of the data.

- Do a video and audio recording of the session if possible. If not, use multiple notetakers. 
- The moderator may steer the discussion to follow a particular issue brought up that impacts the problem being studied.

- On closing, tell the participants they will receive a record of the session to verify their statements and ideas.

- Follow up the session with an individual thank you note for each participant.

Analyzing the information ${ }^{3}$

Focus groups can provide a great source of qualitative systems analysis team to analyze and create useful information. The recorders should first verify the raw that was generated during the session. This data should then be processed into findings, conclusions, and recommendations using the methods discussed in the interview section. If you run more than one focus group, realize that you cannot necessarily correlate the data between the groups since they represent different subgroups of the stakeholders. 


\section{Appendix F: Surveys}

The following are best practices for conducting surveys as seen in Decision Making in Systems Engineering and Management: ${ }^{3}$

The following steps can be followed to plan, execute, and analyze surveys:

- Establish the goals of the survey.

- Determine who and how many people you will ask to complete the survey, that is, determine the sample of stakeholders you will target with the survey.

- Determine how you will distribute the survey and collect the survey data.

- Develop the survey questions.

- Test the survey.

- Distribute the survey to the stakeholders and collect data from them.

- Analyze the survey data.

\section{Preparing an Effective Survey ${ }^{3}$}

Determine the goals of the survey, the survey participants, and the means by which the survey will be distributed. The sample size of participants needs to be determined in order to make valid statistical conclusions from the survey. Sample size calculations are discussed in basic statistics books or can be calculated using online tools. Before the survey is designed, the method for implementing the survey needs to be selected. Table 22 provides a listing of some of the advantages and disadvantages of some common survey methods.

Table 22. Advantages and Disadvantages of Common Survey Methods ${ }^{3}$

\begin{tabular}{|c|c|c|}
\hline Survey Method & Advantages & Disadvantages \\
\hline Mail & $\begin{array}{l}\text { - Can include extensive } \\
\text { supporting graphics } \\
\text { - Respondents have } \\
\text { flexibility in completing } \\
\text { the survey }\end{array}$ & $\begin{array}{l}\text { - Takes a great deal of } \\
\text { time } \\
\text { - Hard to check } \\
\text { compliance and conduct } \\
\text { follow-up with } \\
\text { respondents } \\
\text { - Response data will have } \\
\text { to be transformed by } \\
\text { the analysis team into a } \\
\text { format for analysis }\end{array}$ \\
\hline E-mail & 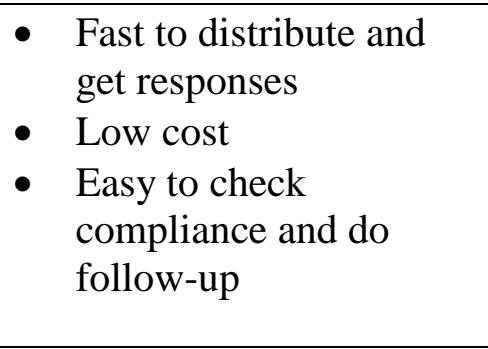 & $\begin{array}{l}\text { - Need to obtain e-mail } \\
\text { address for the survey } \\
\text { sample } \\
\text { Cannot program } \\
\text { automatic logic into the } \\
\text { survey (e/g/, "skip over } \\
\text { the next set of questions }\end{array}$ \\
\hline
\end{tabular}




\begin{tabular}{|l|l|l|}
\hline & & $\begin{array}{l}\text { if your answer is No to } \\
\text { this question") } \\
\text { Respondent e-mail } \\
\text { programs may limit the } \\
\text { type of information that } \\
\text { can be sent in the } \\
\text { survey } \\
\text { Response data will have } \\
\text { to be transformed by } \\
\text { the analysis team into a } \\
\text { format for analysis }\end{array}$ \\
\hline$\bullet \begin{array}{l}\text { Extremely fast } \\
\text { Can include special } \\
\text { graphics and formatting } \\
\text { Can collect responses in } \\
\text { a database to facilitate } \\
\text { analysis }\end{array}$ & $\begin{array}{l}\text { May be hard to control } \\
\text { who responds to the } \\
\text { survey due to Internet } \\
\text { access } \\
\text { Respondents can easily } \\
\text { provide only a partial } \\
\text { response to the survey }\end{array}$ \\
\hline
\end{tabular}

\section{Executing a Survey Instrument ${ }^{3}$}

Developing the survey questions, testing, and distributing the survey. Surveys should be designed to obtain the information that will help the stakeholder analysis team meet the goals of the survey. To maximize response, the survey should be short with clearly worded questions that are not ambiguous from the respondent's perspective. Start the survey with an overview of the purpose of the survey and the goals that the team hopes to achieve from the information provided by the respondents. Here are some general principles that can be followed in developing effective survey questions:

- Ask survey respondents about their first-hand experiences, that is, about what they have done and their current environment so that they can provide informed answers. Respondents should not be asked hypothetical questions, nor should they be asked to comment on things outside their working environment.

- Ask only one question at a time.

- In wording questions make sure that respondents answer the same question. If the question includes terms that could be interpreted differently by respondents, provide a list of definitions to clarify any possible ambiguities. This list of definitions should precede the questions.

- Articulate to respondents the kind of acceptable answers to a questions. For objective questions, the answer scales can be set up as multiple choice answers from a rating scale or level-of-agreement scale. For certain questions and stakeholders, it may be appropriate to provide benchmark statement like "full time effort equates to 40 hours of work per week." For open-ended text response questions, the question should be worded so that respondents provide information germane to the 
question. Close the survey with a statement allowing respondents to provide any additional information they believe is pertinent to the goal of the survey.

- Format the survey so that it is easy for respondents to read the questions, follow instructions, and provide their answers. For example, answer scales should follow a similar pattern in terms of the order in which they are presented (e.g., the least desirable answer is the first choice ascending to the most desirable answer).

- Orient the respondents to the survey in a consistent way. This can be accomplished with a set of instructions that describe the goals of the survey, the method for completing their responses, and the means for submitting the completed survey.

Once the survey questions are written, test the survey instrument with a few individuals outside the team. Ask them to complete the survey using the same medium that respondents will use (e.g., by e-mail, mail, or on the internet) Ask for input from the test sample regarding the instructions and wording of the questions and answer scales. If an internet survey is used, test the method for collecting responses, for example, in a database. Use the input from the test sample to improve the survey. Once improvements are made, distribute the survey to respondents using the method chosen. Develop a plan for monitoring the response rate and establish when reminders will be sent to respondents who have not completed the survey. The team should also have a standard way to think respondents for their time and efforts, for example, a thank you note or e-mail.

\section{Analyzing Survey Data ${ }^{3}$}

A key part of the analysis effort will be in formatting the survey data that is received. If a web survey is used, the team can program the survey instrument to put responses directly into a database file. This will allow the team to perform statistical analysis on object-type questions relatively quickly. For text answer questions, a database file provides a means to bin the responses quickly. The goals of the analysis are the same as for interviews and focus group sessions. Similar to the process discussed earlier in this section, the team should bin the responses by survey question and analyze these responses to develop findings. These findings will lead to forming conclusions, which then will lead the team to form recommendations. 


\section{Appendix G: Duncker Diagram Example}

To clarify the Duncker Diagram, let's consider the following example. ${ }^{9}$ Most laundry detergents are toxic to humans when consumed. Small children are more likely to consume these detergents, resulting in the perceived problem: Find a way to prevent children from being able to get to the detergent in the bottle. Some possible ways of solving this is to print a note on the bottle for adults to read, instructing them to keep the bottle away from children. This is not a good solution because it relies on the adults reading the note, which may or may not happen. Another solution is to child-proof the caps on the bottles. However, there is a chance that adults may not seal the caps properly. Also, if the adult has trouble opening the bottle, they may leave the cap only partially closed for convenience. Figure 58 shows how the Duncker Diagram is used to create a new problem statement.

Prevent children from
getting to the chemicals

\section{Figure 58. Duncker Diagram of detergent example ${ }^{9}$}

The solution that one company (Macfarlan Smith Ltd.) arrived at was to add chemicals that are harmless to ingest and to add a bitter taste to it so that children will not want to drink it after tasting it. After considering both sides of the Duncker Diagram, a new problem statement was written: Determine the exact amount of the bitter-tasting chemical to be added to the cleaning solution. 


\section{Appendix H: Statement-Restatement Example}

In order to illustrate the Statement-Restatement technique ${ }^{9}$ let's consider the following problem statement: Cereal is clearly not getting to market fast enough to maintain freshness. ${ }^{9}$

- $\quad$ Trigger 1:

- Cereal not getting to market fast enough to maintain freshness.

(Do other products we have get there faster?)

- Cereal not getting to market fast enough to maintain freshness.

(Can we make the distance/time shorter?)

- Cereal not getting to market fast enough to maintain freshness.

(Can we distribute it from a centralized location?)

- Cereal not getting to market fast enough to maintain freshness.

(How can we keep cereal fresher, longer?)

- Trigger 2:

$\circ$ Breakfast food that comes in a box is not getting to the place where it is sold fast enough to keep it from getting stale.

(This restatement makes us think about the box and staleness. How might we change the box to prevent staleness?)

- Trigger 3:

o How can we find a way to get the cereal to market so slowly that it will never be fresh?

(This restatement makes us think about how long we have to maintain freshness and what controls it)

- Trigger 4:

- Cereal is not getting to market fast enough to always maintain freshness.

(This change opens up new avenues of thought. Why isn't our cereal always fresh?)

- Trigger 5:

○ The word "clearly" in the problem statement implies that if we could speed up delivery freshness would be maintained. Maybe not! Maybe the store holds the cereal too long. Maybe the cereal is stale before it reaches the store.

(This trigger helps us challenge the implicit assumptions made in the problem statement.)

- $\quad$ Trigger 6:

○ Freshness is inversely proportional to the time since the cereal was baked:

$$
(\text { Freshness })=\frac{k}{(\text { Times since cereal baked })}
$$


This restatement makes us think about to attack the freshness problem. For example, what does the proportionality constant, $k$, depend on?

The storage conditions, packaging, type of cereal, and other factors are logical variables to examine. How can we change the value of $k$ ?

After applying the Statement-Restatement technique, the new problem statement is: Find how to best improve packaging to keep the cereal fresher longer. 


\section{Appendix I: Mental Blocks}

The following the common conceptual mental blocks as seen in Strategies for Creative Problem Solving: ${ }^{9}$

\section{$\underline{\text { Perceptual Blocks }}{ }^{9}$}

A perceptual block is one that "prevents the problem solver from clearly perceiving either the problem itself or the information needed to solve it." Fogler and Leblanc named a few types as described below: ${ }^{9}$

\section{- Stereotyping $^{9}$}

Stereotyping is when the problem solver assumes the functionality or application of a possible solution is only what that possible solution is known to do. For example, let's say you were stranded in an island and you only had a flashlight in your tool kit. Stereotyping the flashlight would be assuming that the only functions and applications of the flashlight would be to find things in the dark or signaling. However, if the problem solver were to think creatively and break from the stereotypical perceptual block, they would find that the batteries of the flashlight could be used to start a fire, the casing could be converted into a drinking vessel, or the silver casing reflector could be used as a signaling mirror in the daylight. If one can break away from this block, there are many more functions and applications that can be discovered. Even for a simple object like a flashlight.

\section{- $\quad$ Limiting the Problem Unnecessarily ${ }^{9}$}

Limiting the problem unnecessarily is when the problem solver assumes that there is a limited way of solving a problem. A classic example of this is the nine-dot problem as can be seen in Figure 59. The rules to this puzzle is to draw four or fewer lines that will pass through all nine dots (without lifting the pencil from the paper). What makes this a difficult puzzle to solve is that most people create an imaginary boundary with the eight outer dots. Another assumption that people make is that the lines must cross through the center of the dots, which is not part of the problem statement. Figures 60 and 61 show possible solutions that are literally "outside the box" that people constrain themselves within. 


\section{:
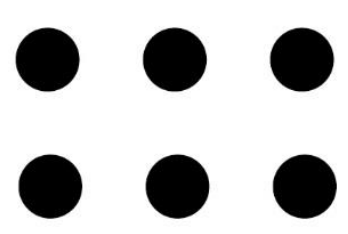

Figure 59. The Nine-Dot Problem ${ }^{9}$

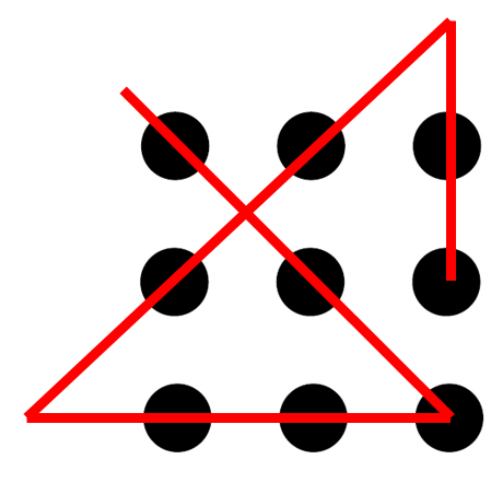

Figure 60. Nine-Dot Problem: four-line solution ${ }^{9}$

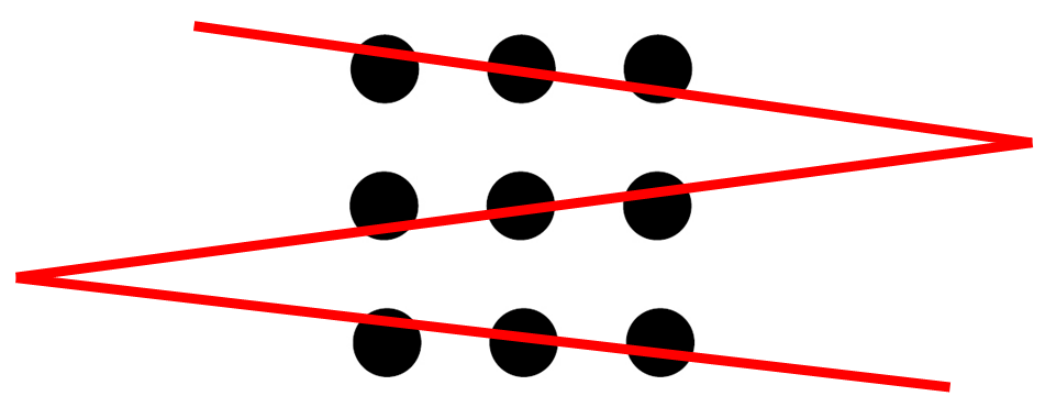

Figure 61. Nine-Dot Problem: three-line solution ${ }^{9}$

The purpose of this exercise is to show that putting too many constraints (either consciously or subconsciously) on the problem statement narrows the range of possible solutions (i.e., Alternative-Focused Thinking). "You must explore and challenge the boundaries of the problem if you hope to find the best solution." 9

\section{- $\quad$ Saturation or Information Overload ${ }^{9}$}

Too much information can be nearly as big a problem as not enough information. You can become overloaded with minute details and be unable to sort out the critical aspects of the problem. Air traffic controllers have learned to overcome this kind of perceptual block. They face information overload regularly in the course of their jobs, particularly during bad 
weather. They are skilled in sorting out the essential information to ensure safe landings and takeoffs for thousands of aircraft daily.

\section{Emotional Blocks 9}

Emotional blocks interfere with your ability to solve problems in many ways. They decrease the amount of freedom with which you explore and manipulate ideas, and they interfere with your ability to conceptualize fluently and flexibly. Emotional blocks also prevent you from communicating your ideas to others in a manner that will gain their approval. The following are some common emotional blocks as described in Fogler and LeBlanc: ${ }^{9}$

\section{- Fear of Risk Taking ${ }^{9}$}

This block usually stems from childhood. Many people grow up being rewarded for solving problems correctly and punished for solving problems incorrectly. Implementing a creative idea is like taking a risk. You take a risk of making a mistake, looking foolish, losing your job, or (in a student's case) getting an unacceptable grade.

\section{- Lack of Appetite for Chaos ${ }^{9}$}

Problems solvers must learn to live with confusion. For example, the criteria for the best solution may seem contradictory. You have to be willing to deal with the chaos of not knowing an answer and sorting through the details in order to solve a new problem.

\section{- $\quad$ Judging While Generating Ideas ${ }^{9}$}

Judging ideas too quickly can discourage even the most creative problem solvers. It is important that a positive creative environment is maintained throughout the brainstorming process so all members are able to participate fully. Wild ideas, although often impractical, can sometimes trigger feasible ideas that lead to innovative solutions; however, these wild ideas are often the ones individuals are discouraged from sharing when ideas are being judged. This block can be avoided by complementing ideas that are truly unique, even if they aren't the perfect solution.

\section{- $\quad$ Lack of Challenge ${ }^{9}$}

Sometimes problem solvers don't want to get started because they perceive the problem as being too trivial and easily solved. They believe that the problem is not worthy of their efforts.

\section{- $\quad$ Thinking All or Some Part of the Problem Cannot Be Solved ${ }^{9}$}

Many times this block is related to a lack of energy, or it is used as an excuse to not do work on the problem because "you will never" solve that part of the problem. 
- Inability to Incubate $^{9}$

Rushing to solve the problem just to get it off your mind can create mental blocks.

\section{Cultural Blocks 9}

Cultural blocks are acquired by exposure to a given set of cultural patterns, whereas environmental blocks are imposed by our immediate social and physical environment. One type of cultural block is the failure to consider an act that causes displeasure or disgust to certain members of society.

\section{Environmental Blocks 9}

Environmental blocks are distractions (phones, interruptions) that inhibit deep, prolonged concentration. Working in an atmosphere that is pleasant and supportive most often increases the productivity of the problem solver. Conversely, working under conditions where there is a lack of emotional, physical, economical, or organizational support to bring ideas into action usually has a negative effect on the problem solver and decreases the level of productivity.

\section{Intellectual Blocks ${ }^{9}$}

Intellectual blocks can occur as a result of inflexible or inadequate uses of problemsolving strategies. A lack of the intellectual skills necessary to solve a problem can certainly be a block, as can a lack of the information necessary to solve the problem. For example, attempting to solve complicated satellite communications problems without sufficient background in the area would soon result in blocked progress. Additional background, training, or resources may be necessary to solve a problem.

\section{Expressive Blocks ${ }^{9}$}

Expressive blocks is the inability to communicate ideas to others, in either verbal or written form. Anyone who has played the games of charades or Pictionary can certainly relate to the difficulties that this type of block can cause. 


\section{Appendix J: 77 Design Heuristic Cards}

Table 23 displays the 77 Design Heuristic Cards as seen in Design Heuristics as a Tool to Improve Innovation: ${ }^{28}$

Table 23. Complied list of Design Heuristics ${ }^{28}$

\begin{tabular}{|c|c|c|c|}
\hline 1 & Add levels & 40 & Incorporate user input \\
\hline 2 & Add motion & 41 & Layer \\
\hline 3 & Add natural features & 42 & $\begin{array}{l}\text { Make components } \\
\text { attachable/detachable }\end{array}$ \\
\hline 4 & Add to existing product & 43 & Make multifunctional \\
\hline 5 & Adjust function through movement & 44 & Make product recyclable \\
\hline 6 & Adjust function for specific users & 45 & Merge surfaces \\
\hline 7 & Align components around center & 46 & Mimic natural mechanisms \\
\hline 8 & Allow user to assemble & 47 & Mirror or array \\
\hline 9 & Allow user to customize & 48 & Nest \\
\hline 10 & Allow user to rearrange & 49 & Offer optional components \\
\hline 11 & Allow user to reorient & 50 & Provide sensory feedback \\
\hline 12 & Animate & 51 & Reconfigure \\
\hline 13 & Apply existing mechanism in new way & 52 & Redefine joints \\
\hline 14 & $\begin{array}{l}\text { Attach independent functional } \\
\text { components }\end{array}$ & 53 & Reduce material \\
\hline 15 & Attach product to user & 54 & Repeat \\
\hline 16 & Bend & 55 & Repurpose packaging \\
\hline 17 & Build user community & 56 & Roll \\
\hline 18 & Change direction of access & 57 & Rotate \\
\hline 19 & Change flexibility & 58 & Scale up or down \\
\hline 20 & Change geometry & 59 & Separate functions \\
\hline 21 & Change product lifetime & 60 & Simplify \\
\hline 22 & Change surface properties & 61 & Slide \\
\hline 23 & Compartmentalize & 62 & Stack \\
\hline 24 & Contextualize & 63 & Substitute way of achieving function \\
\hline 25 & $\begin{array}{l}\text { Convert 2-D material into 3-D } \\
\text { object }\end{array}$ & 64 & Synthesize function \\
\hline 26 & Convert for second function & 65 & Telescope \\
\hline 27 & Cover or wrap & 66 & Twist \\
\hline 28 & Create service & 67 & Unify \\
\hline 29 & Create system & 68 & Use common base to hold components \\
\hline 30 & Divide continuous surface & 69 & Use continuous material \\
\hline 31 & Elevate or lower & 70 & Use different energy source \\
\hline 32 & Expand or collapse & 71 & Use human-generated power \\
\hline 33 & Expose interior & 72 & $\begin{array}{l}\text { Use multiple components for one } \\
\text { function }\end{array}$ \\
\hline 34 & Extend surface & 73 & Use packaging as functional component \\
\hline 35 & Flatten & 74 & Use repurposed or recycled materials \\
\hline 36 & Fold & 75 & Utilize inner space \\
\hline
\end{tabular}




\begin{tabular}{|l|l|l|l|}
\hline 37 & Hollow out & 76 & Utilize opposite surface \\
\hline 38 & Impose hierarchy on functions & 77 & Visually distinguish functions \\
\hline 39 & Incorporate environment & \multicolumn{2}{|c|}{} \\
\cline { 1 - 2 }
\end{tabular}




\section{Appendix K: TRIZ Tables and Example}

The following are tables used in the TRIZ and an example ${ }^{9}$ to illustrate the process as seen in Strategies for Creative Problem Solving. ${ }^{9}$

Altshuller identified 39 features that would either improve or worsen solutions from his research on patents and created the following list shown in Table 24:

Table 24. 39 TRIZ Features ${ }^{9}$

\begin{tabular}{|l|l|l|l|}
\hline 1 & Weight of moving object & 21 & Power \\
\hline 2 & Weight of stationary object & 22 & Loss of energy \\
\hline 3 & Length of moving object & 23 & Loss of substance \\
\hline 4 & Length of stationary object & 24 & Loss of information \\
\hline 5 & Area of moving object & 25 & Loss of time \\
\hline 6 & Area of stationary object & 26 & Quantity of substance \\
\hline 7 & Volume of moving object & 27 & Reliability \\
\hline 8 & Volume of stationary object & 28 & Measurement accuracy \\
\hline 9 & Speed for object & 29 & Manufacturing precision \\
\hline 10 & Force (intensity) & 30 & Object-affected harmful \\
\hline 11 & Stress of pressure & 31 & Object-generated harmful \\
\hline 12 & Shape & 32 & Ease of manufacture \\
\hline 13 & Stability of the object & 33 & Ease of operation \\
\hline 14 & Strength & 34 & Ease of repair \\
\hline 15 & Durability of moving object & 35 & Adaptability or versatility \\
\hline 16 & Durability of nonmoving object & 36 & Device complexity \\
\hline 17 & Temperature & 37 & Difficulty of detecting \\
\hline 18 & Illumination intensity & 38 & Extent of automation \\
\hline 19 & Use of energy by moving object & 39 & Productivity \\
\hline 20 & Use of energy by stationary object & & \multicolumn{2}{|l|}{} \\
\cline { 1 - 2 } & \multicolumn{2}{|l|}{} \\
\hline
\end{tabular}

This list is used to generate a $39 \times 39$ contradiction matrix that is composed by listing each of the features along the rows as well as the columns. The features labeling the columns are those that worsen the product or worsen the situation, while the features labeling the rows are those that improve the product or situation.

Once contradictions are identified, the contradiction matrix is used to suggest which of Altshuller's 40 principles might help solve the problem by resolving the contradictions as listed in Table 25:

Table 25. Altshuller's 40 Principles of TRIZ ${ }^{9}$

\begin{tabular}{|l|l|l|l|}
\hline 1 & Segmentation & 21 & Skipping \\
\hline 2 & Taking out & 22 & "Blessing in disguise" \\
\hline 3 & Local quality & 23 & Feedback \\
\hline 4 & Asymmetry & 24 & "Intermediary" \\
\hline 5 & Merging & 25 & Self-service \\
\hline
\end{tabular}




\begin{tabular}{|l|l|l|l|}
\hline 6 & Universality & 26 & Copying \\
\hline 7 & "Nested doll" & 27 & Cheap short-living \\
\hline 8 & Anti-weight & 28 & Mechanics substitution \\
\hline 9 & Preliminary anti-action & 29 & Pneumatics and hydraulics \\
\hline 10 & Preliminary action & 30 & Flexible shells and thin films \\
\hline 11 & Beforehand cushioning & 31 & Porous materials \\
\hline 12 & Equipotentiality & 32 & Color changes \\
\hline 13 & The other way around & 33 & Homogeneity \\
\hline 14 & Spheroidality & 34 & Discarding and recovering \\
\hline 15 & Dynamics & 35 & Parameter changes \\
\hline 16 & Partial or excessive actions & 36 & Phase transitions \\
\hline 17 & Another dimension & 37 & Thermal expansion \\
\hline 18 & Mechanical vibration & 38 & Strong oxidants \\
\hline 19 & Periodic action & 39 & Inert atmosphere \\
\hline 20 & Continuity of useful action & 40 & Composite material films \\
\hline
\end{tabular}

Altshuller developed this list of principles that represent solution techniques that have been applied to other problems. Explanations of each principle are available on the TRIZ40 website.

In order to learn TRIZ, let's apply it to the following problem. Boeing Aircraft Company wants to increase the number of passengers from 100 to 140 from their successful aircraft, the Boeing 737-100 and 737-200 series. This increase in passengers means that the length of the fuselage needs to be extended by 10 feet, however, this increase in length requires a larger-sized engine due to the increase in weight. When initial research on larger engines was conducted, it was found that if any of the larger engines were placed on the wings of the new design, the clearance from the bottom of the engines to the ground is not enough to meet safety regulations. Unfortunately, neither the wing nor the engine can be raised without a major redesign of the aircraft. Let's apply TRIZ to solve this problem and suggest a solution by first identifying contradiction(s) and using them to fill the contradiction matrix. The contradiction is identified to be that a larger engine (good) decreases the clearance to an unsafe length (bad). The next step is to look at the list of features and to identify those that are important to our contradiction. Since the aircraft engine is a moving object and the increase in size of engine can be seen as an increase in volume, the first TRIZ feature of importance is the volume of moving object. Since the larger engine decreases the length of clearance, the second TRIZ feature of importance is the length of the moving object. Now that we know the two important features, we need to identify which one is improving and which one is worsening. Since we need a larger engine, the improving feature is volume of the moving object. Since this results in a smaller clearance length (unsafe), length of the moving object, is the worsening feature. The next step is to find the intersection of these two features to identify the principles needed to solve the problem. After reading the principles from the TRIZ website (www.triz40.com), we can identify the following principles? 
1) Segmentation

- Divide an object into independent parts

- Make an object easy to disassemble (replace worn or damaged parts)

- Increase the degree of fragmentation or segmentation

4) Asymmetry

- Change the shape of an object from symmetrical to asymmetrical

- If an object is asymmetrical, increase its degree of asymmetry

7) "Nested doll"

- Nesting by placing one object inside another; place and object, in turn, inside the other

- Make one part pass through a cavity in the other

35) Parameter changes

- Change an object's physical state (e.g. to a gas, liquid, or solid)

- Change the concentration or consistency

- Change the degree of flexibility

- Change the temperature

Now that we have four principles, we can brainstorm to see how we can apply them to develop a solution. Segmentation may not be applicable since the spinning blades inside the engine require a circular intake area. Asymmetry is a possible solution since the cowl doesn't need to be symmetric, only the intake area does. "Nested doll" could potentially be applicable. We can ask "Could the symmetrical spinning blade are be "nested" inside an asymmetrical casing? Could the bottom of the cowl be flattened and this leave a greater clearance?"9 "Parameter changes" is not applicable to this problem. The solution that was actually implemented by Boeing engineers was to nest the symmetrical intake inside an asymmetrical cowl casing that is flat at the bottom. This example illustrated that by identifying contradictions, we could use the TRIZ process to arrive to solutions. In this example, the TRIZ principles that were identified allowed for the same conclusion to be reached as the Boeing engineers did. Two solutions were combined to arrive to the final solution. The contradiction matrix for this example is shown in Table 26.

Table 26. TRIZ contradiction matrix - Boeing example ${ }^{9}$

\begin{tabular}{|c|c|c|c|c|c|c|}
\hline & \multicolumn{6}{|c|}{ Worsening Feature } \\
\hline$\stackrel{00}{\stackrel{0}{\Omega}}$ & & $\begin{array}{l}\text { Weight of } \\
\text { moving } \\
\text { object }\end{array}$ & $\begin{array}{l}\text { Weight of } \\
\text { stationary } \\
\text { object }\end{array}$ & $\begin{array}{l}\text { Length of } \\
\text { moving } \\
\text { object }\end{array}$ & $\begin{array}{l}\text { Length of } \\
\text { stationary } \\
\text { object }\end{array}$ & $\begin{array}{l}\text { Area of } \\
\text { moving } \\
\text { object }\end{array}$ \\
\hline 音 & $\begin{array}{l}\text { Weight of } \\
\text { moving } \\
\text { object }\end{array}$ & $*$ & 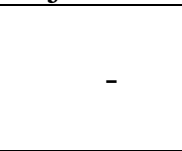 & $\begin{array}{c}15,8 \\
29,34\end{array}$ & 5 & $\begin{array}{l}29,17 \\
38,34\end{array}$ \\
\hline
\end{tabular}




\begin{tabular}{|c|c|c|c|c|c|}
\hline $\begin{array}{l}\text { Weight of } \\
\text { stationary } \\
\text { object }\end{array}$ & - & $*$ & - & $\begin{array}{c}10,1 \\
29,35\end{array}$ & - \\
\hline $\begin{array}{l}\text { Length of } \\
\text { moving } \\
\text { object }\end{array}$ & $\begin{array}{c}8,15 \\
29,34\end{array}$ & - & $*$ & - & $\begin{array}{c}15,17 \\
4\end{array}$ \\
\hline $\begin{array}{l}\text { Length of } \\
\text { stationary } \\
\text { object }\end{array}$ & - & $\begin{array}{l}35,28 \\
40,29\end{array}$ & - & $*$ & - \\
\hline $\begin{array}{l}\text { Area of } \\
\text { moving } \\
\text { object }\end{array}$ & $\begin{array}{l}2,17 \\
29,4\end{array}$ & - & $\begin{array}{c}14,15 \\
18,4\end{array}$ & - & $*$ \\
\hline $\begin{array}{l}\text { Area of } \\
\text { stationary } \\
\text { object }\end{array}$ & - & $\begin{array}{c}30,2 \\
14,18\end{array}$ & - & $\begin{array}{l}26,7 \\
9,39\end{array}$ & - \\
\hline $\begin{array}{l}\text { Volume of } \\
\text { moving } \\
\text { object }\end{array}$ & $\begin{array}{c}2,26 \\
29,40\end{array}$ & - & $\begin{array}{c}1,7 \\
4,35\end{array}$ & - & $\begin{array}{c}1,7 \\
4,17\end{array}$ \\
\hline
\end{tabular}




\section{Appendix L: Fish Diagram Example}

To apply the fishbone diagram, let's apply it again to the children's playground design problem, ${ }^{9}$ where the following is the list of potential uses of the old car:

\section{Painting}

- Let the kids paint graffiti on the cars

- Paint targets and let the kids throw balls at them

- Paint the car as a covered wagon and let the kids pretend to be cowboys

\section{Whole Car}

- Turn the car into a teeter-totter (upside down)

- Turn the car into a go-cart

- Crush the car and make blocks from it

- Let the kids drive the car as is

- Open the car's doors and use them as goals for field hockey

$\underline{\text { Parts }}$

- Use the seats as swings

- Use the roof and doors as part of the fort

- Use the tires' inner tubes as part of an obstacle course (to jump on)

- Use the car's hood as a toboggan

- Use the car's springs for a wobble ride

The next step is to select the best ideas for each category, and if possible, select the best idea from all categories: ${ }^{9}$

$\underline{\text { Painting }} \rightarrow$ Graffiti

$\underline{\text { Parts }} \rightarrow$ Tire Inner Tubes

$\underline{\text { Whole Car }} \rightarrow$ As is

Figure 62 shows an example ${ }^{9}$ of the fishbone diagram for the children's playground design problem. 


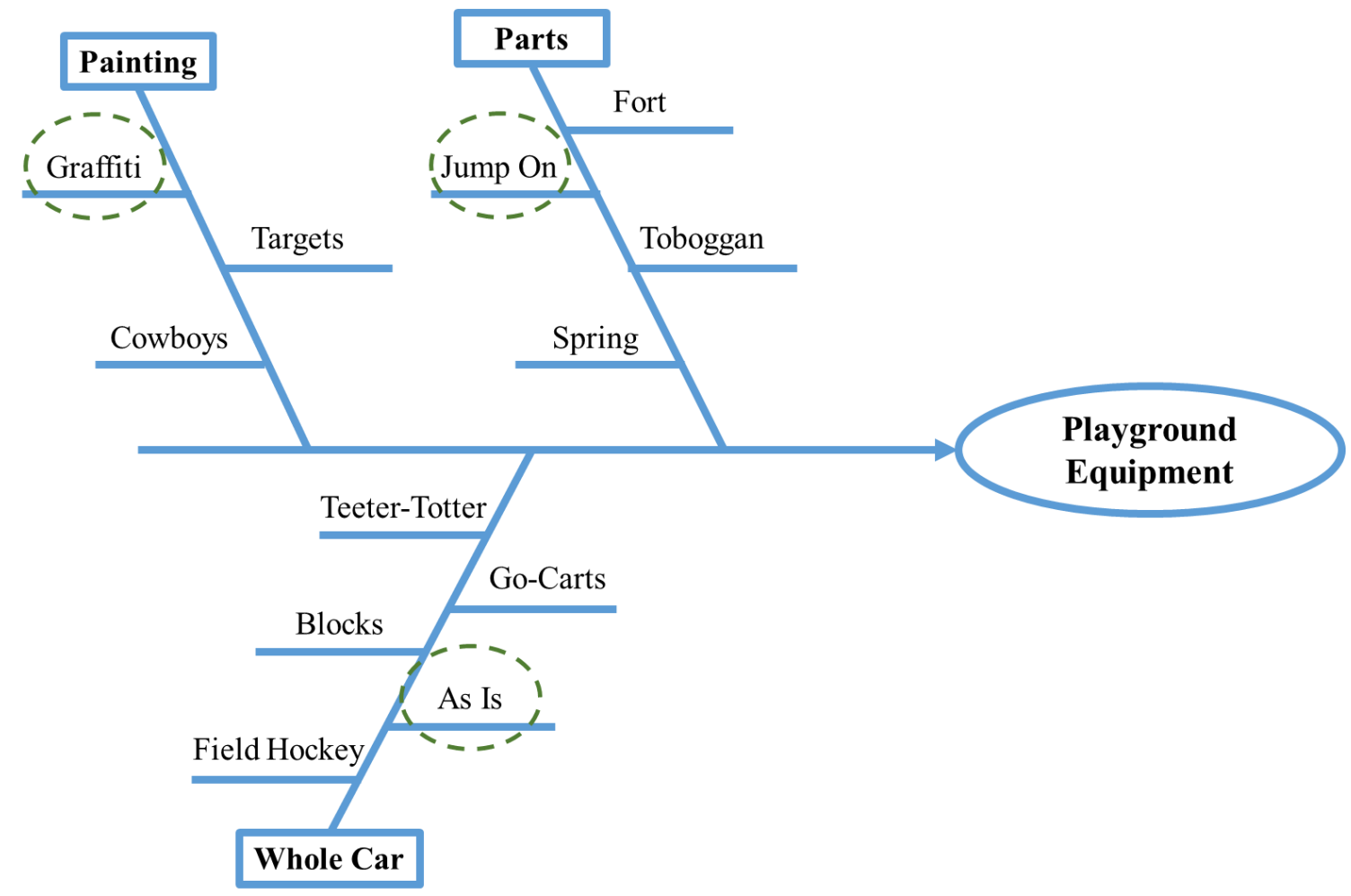

Figure 62. Playground Equipment Fishbone Diagram ${ }^{9}$ 


\section{Appendix M: GMA Example}

To illustrate GMA, let's assume that we need to generate alternatives for a rocket design $^{3}$ that includes the following design parameters: fins, thrust, seeker, and guidance system. Four possible configurations for each design parameter were generated using the idea generation techniques in the previous step. Therefore, the resulting morphological box is of size $5 \times 4$ as seen on the left in Figure 63. This matrix produced 20 possible solutions. Those that were logically, empirically, and/or normatively inconsistent were eliminated. The remaining five alternatives are as shown in the table on the right in Figure 63. These alternatives are then ready to be enhanced via feasibility screening in the Alternative Enhancement step.

\begin{tabular}{|c|c|c|c|}
\hline \multicolumn{4}{|c|}{ Solution Design Parameters } \\
\hline Fins & Thrust & Seeker & Guidance \\
\hline 2 & 1000 & $\begin{array}{c}\text { Forward } \\
\text { looking } \\
\text { infrared }\end{array}$ & Inertial \\
\hline 3 & 1667 & Laser & $\begin{array}{c}\text { Global } \\
\text { Positioning } \\
\text { System }\end{array}$ \\
\hline 4 & 2334 & Audio & Wire \\
\hline 5 & 3000 & None & Optical \\
\hline
\end{tabular}

Morphological Box

\begin{tabular}{|c|c|c|c|c|}
\hline \multicolumn{5}{|c|}{ Solution Design Parameters } \\
\hline Strategy & Fins & Thrust & Seeker & Guidance \\
\hline $\begin{array}{c}\text { Global } \\
\text { Lightning }\end{array}$ & 5 & 2334 & Laser & $\begin{array}{c}\text { Global } \\
\text { Positioning } \\
\text { System }\end{array}$ \\
\hline $\begin{array}{c}\text { Hot } \\
\text { Wired }\end{array}$ & 4 & 3000 & None & Wire \\
\hline $\begin{array}{c}\text { Sight and } \\
\text { Sound }\end{array}$ & 2 & 3000 & Audio & Optical \\
\hline $\begin{array}{l}\text { Slow } \\
\text { Poke }\end{array}$ & 3 & 1000 & $\begin{array}{c}\text { Forward } \\
\text { looking } \\
\text { Infrared }\end{array}$ & Inertial \\
\hline $\begin{array}{c}\text { Star } \\
\text { Cluster }\end{array}$ & 3 & 1667 & $\begin{array}{c}\text { Forward } \\
\text { looking } \\
\text { Infrared }\end{array}$ & $\begin{array}{c}\text { Global } \\
\text { Positioning } \\
\text { System }\end{array}$ \\
\hline
\end{tabular}

Alternative Generation Table

Figure 63. Morphological box and alternative generation table for rocket example ${ }^{3}$ 


\section{Appendix N: Exponential Constant Methodology}

The following is Kirkwood's explanation on how to find the exponential constant as found in Strategic Decision Making: Multi-Objective Decision Analysis with Spreadsheets ${ }^{5}$ :

The procedure to determine the value of $\rho$ for a specific exponential single dimensional value function depends on the concept of the midvalue for the range of evaluation measure scores that is of interest. The midvalue of a range is defined to be the score such that the difference in value between the lowest score in the range and the midvalue is the same as the difference in value between the midvalue and the highest score.

The single dimensional value for one end of the range of scores being considered is zero, while the single dimensional vale for the other end is 1 . Thus, if the value differences between the midvalue and either end of the range are the same, it must be true that the single dimensional value for the midvalue is 0.5. Why is this? Because the increment in values between the least preferred score in the range and the midvalue must be equal to the increment in value between the midvalue and the most preferred score in the range. We know that the sum of the value increments must be 1 . Hence, since the two value increments must be equal, they must each be 0.5 , and thus the single dimensional value for the midvalue is 0.5 .

If the two endpoints for a range are known, along with the midvalue, then either Equation 2 or 3 can be solved to determine the exponential constant. This is done by setting $\mathrm{v}\left(\mathrm{x}_{\mathrm{m}}\right)=0.5$ for the appropriate equation, where $\mathrm{v}(\mathrm{x})$ is the appropriate one of Equation 2 or 3 and $x_{m}$ is the midvalue. Since everything will be known in the equation except $\rho$, the equation can be solved for $\rho$.

Unfortunately, there is no closed form solution to the resulting equation, and hence it must be solved numerically. However, it is generally quicker to use the procedure presented below based on Table 27. This table presents the exponential constants that correspond to various possible midvalues. Since there are an infinite number of different Low and High levels in Equations 2 or 3, a table that include Low and High would be very large. To keep the table to a reasonable size, a user is required to do some conversions on the midvalue and exponential constant.

1) If the midvalue is equal to the average of the highest and lowest possible scores of the evaluation measure, then the value function is a straight line.

2) For the situation where higher scores are more preferred, if the midvalue is less that the average of the highest and lowest score in the range, then $\rho$ will be greater than zero. If the midvalue is greater than the average of the highest and lowest score in the range, then $\rho$ will be less than zero. This result holds in general for situations where higher scores are more preferred.

3) For situations where higher scores are less preferred, if the midvalue is greater than the average of the highest and lowest scores in the range, then $\rho$ will be greater than zero. If 
the midvalue is less than the average of the highest and lowest scores in the range, then $\rho$ will be less than zero. This result holds in general for situations where higher scores are less preferred.

Once the midvalue has been determined for some range of an evaluation measure, the value of the exponential constant $\rho$ can be found using Table 27 as follows:

1) Calculate the normalized midvalue ( $\mathrm{z}_{0.5}$ ) by taking the difference between the midvalue and the less preferred of the two ends of the range of interest and dividing this by the difference between the highest and lowest scores in the range. When doing this, take each of the two differences so that the result has a positive sign.

2) Look up the normalized midvalue in Table 27 under the column marked $z_{0.5}$, and find the normalized exponential constant $(\mathrm{R})$ that corresponds to this.

3) The value of the exponential constant $\rho$ that corresponds to this value of $R$ is found by multiplying $\mathrm{R}$ by the distance between the highest and lowest scores in the range.

This table presents pairs of numbers $\mathrm{z}_{0.5}$ and $\mathrm{R}$ that solve Equation $21:^{5}$

$$
0.5=\frac{1-\exp \left(-z_{0.5} / R\right)}{1-\exp (-1 / R)}
$$

Table 27. Calculating the exponential constant ${ }^{5}$

\begin{tabular}{|cc|cc|cc|cc|}
\hline $\mathbf{z 0 . 5}$ & $\mathbf{R}$ & $\mathbf{z 0 . 5}$ & $\mathbf{R}$ & $\mathbf{z 0 . 5}$ & $\mathbf{R}$ & $\mathbf{z 0 . 5}$ & $\mathbf{R}$ \\
\hline 0.00 & --- & 0.25 & 0.410 & 0.50 & Infinity & 0.75 & -0.410 \\
0.01 & 0.014 & 0.26 & 0.435 & 0.51 & -12.497 & 0.76 & -0.387 \\
0.02 & 0.029 & 0.27 & 0.462 & 0.52 & -6.243 & 0.77 & -0.365 \\
0.03 & 0.043 & 0.28 & 0.491 & 0.53 & -4.157 & 0.78 & -0.344 \\
0.04 & 0.058 & 0.29 & 0.522 & 0.54 & -3.112 & 0.79 & -0.324 \\
0.05 & 0.072 & 0.30 & 0.555 & 0.55 & -2.483 & 0.80 & -0.305 \\
0.06 & 0.087 & 0.31 & 0.592 & 0.56 & -2.063 & 0.81 & -0.287 \\
0.07 & 0.101 & 0.32 & 0.632 & 0.57 & -1.762 & 0.82 & -0.269 \\
0.08 & 0.115 & 0.33 & 0.677 & 0.58 & -1.536 & 0.83 & -0.252 \\
0.09 & 0.130 & 0.34 & 0.726 & 0.59 & -1.359 & 0.84 & -0.236 \\
0.10 & 0.144 & 0.35 & 0.782 & 0.60 & -1.216 & 0.85 & -0.220 \\
0.11 & 0.159 & 0.36 & 0.845 & 0.61 & -1.099 & 0.86 & -0.204 \\
0.12 & 0.174 & 0.37 & 0.917 & 0.62 & -1.001 & 0.87 & -0.189 \\
0.13 & 0.189 & 0.38 & 1.001 & 0.63 & -0.917 & 0.88 & -0.174 \\
0.14 & 0.204 & 0.39 & 1.099 & 0.64 & -0.845 & 0.89 & -0.159 \\
0.15 & 0.220 & 0.40 & 1.216 & 0.65 & -0.782 & 0.90 & -0.144 \\
0.16 & 0.236 & 0.41 & 1.359 & 0.66 & -0.726 & 0.91 & -0.130 \\
0.17 & 0.252 & 0.42 & 1.536 & 0.67 & -0.677 & 0.92 & -0.115 \\
0.18 & 0.269 & 0.43 & 1.762 & 0.68 & -0.632 & 0.93 & -0.101 \\
0.19 & 0.287 & 0.44 & 2.063 & 0.69 & -0.592 & 0.94 & -0.087
\end{tabular}




\begin{tabular}{|cc|cc|cc|cc|}
0.20 & 0.305 & 0.45 & 2.483 & 0.70 & 0.555 & 0.95 & -0.072 \\
0.21 & 0.324 & 0.46 & 3.112 & 0.71 & -0.522 & 0.96 & -0.058 \\
0.22 & 0.344 & 0.47 & 4.157 & 0.72 & -0.491 & 0.97 & -0.043 \\
0.23 & 0.365 & 0.48 & 6.243 & 0.73 & -0.462 & 0.98 & -0.029 \\
0.24 & 0.387 & 0.49 & 12.497 & 0.74 & -0.435 & 0.99 & -0.014
\end{tabular} \mid




\section{Appendix O: Swing Weights Method}

The following are steps for the swing weight matrix method as seen in Chapter 19: Value-Focused Thinking: ${ }^{14}$

\section{Step 1: Define the importance and variance dimensions ${ }^{14}$}

For installation military value, the relative importance of an attribute depends on the Army's ability to change an installation's attribute level. For example, an installation can't simply expand its acreage, but it can expand administrative space by building more facilities. Columns in Figure 64 represent the ability to change; the second criterion, the attribute's variability of range, is in the rows.

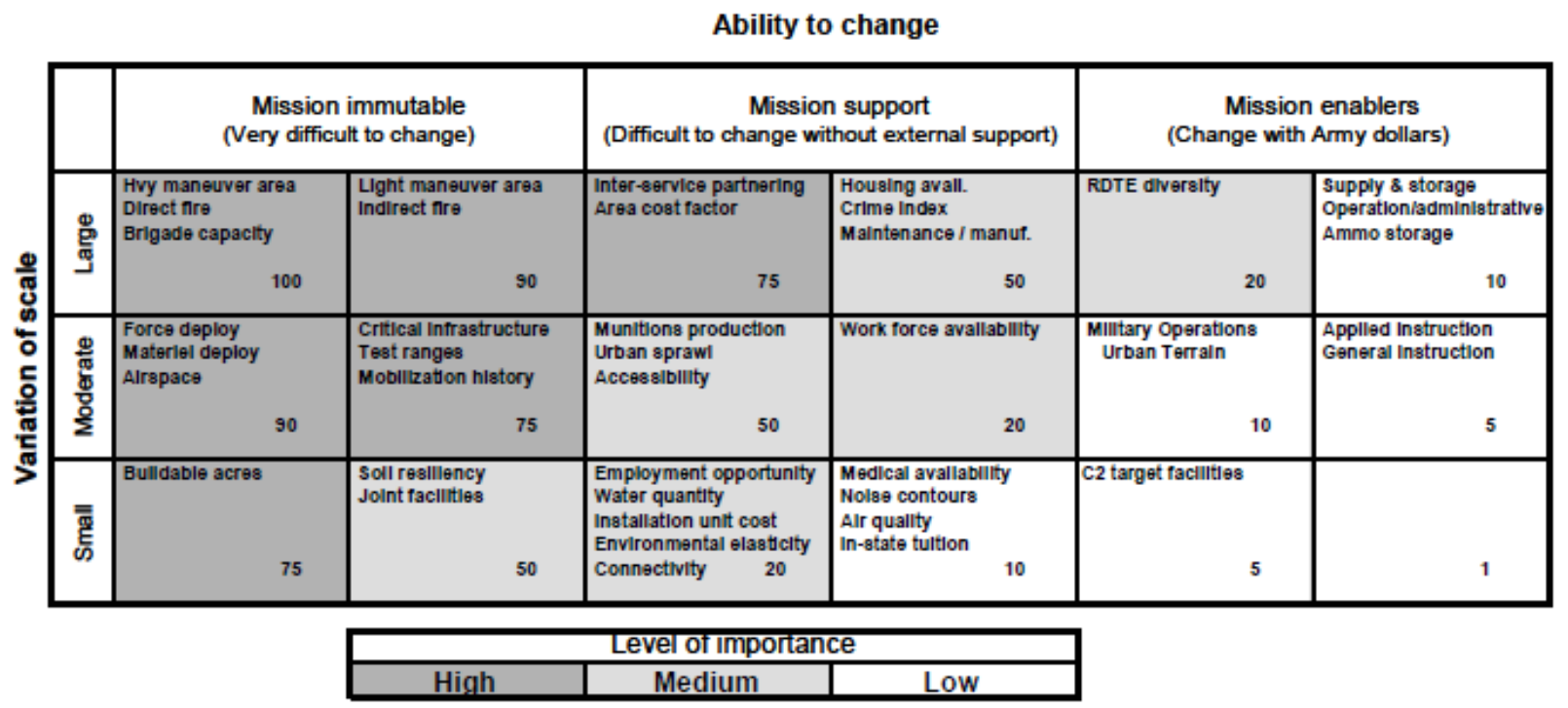

Figure 64. Swing Weight Matrix ${ }^{14}$

Step 2: Place the value measures in the matrix ${ }^{14}$

With the matrix defined, we add attributes to it. As an example, the heavymaneuver area attribute is in the upper left corner of the matrix. This heavy maneuver (such as heavier armored vehicles) area usually is impossible to obtain. Some installations (in urban areas, for example) have no heavy-maneuver area at all, whereas others have extensive areas for heavy-maneuver training. The shading represents an attribute's level of importance. We use it to ease the discussion and gain concurrence on the attribute weights. Determining each measure's relative variance requires some discussion for different types of measures.

\section{Step 3: Assess the swing weights ${ }^{14}$}

After leaders approve the placement of attributes in the matrix, we assign the matrix swing weight, $\mathrm{f}_{\mathrm{jk}}(\mathrm{j}=$ row, $\mathrm{k}=$ column), to all of its cells. As in all weighting methods, it's important to ensure the proper range of weights between the highest and lowest weighted attribute. For our application, we used swing weights from 0 to 100 and placed the highest swing weight, $\mathrm{f} 11=100$, in the upper left corner of the matrix. Because of the large number of attributes in the model, we ensured at least two orders of magnitude between the highest 
and lowest matrix weight. The lowest matrix swing weight, $f_{3,6}=1$, is in the lower right corner of the matrix. The remaining matrix swing weights enter the matrix according to their importance level and variation.

\section{Step 4: Calculate the global weights ${ }^{14}$}

The normalized global weights, $\mathrm{w}_{\mathrm{i}}$, used in the additive value function in equation 1 , are found with the following equation:

$$
w_{i}=\frac{F_{i}}{\sum_{i=1}^{40} F_{i}} \text {, where } F_{i}=\text { matrix swing weight, } f_{j, k} \text {, corresponding to attribute } i \text {. }
$$




\section{Appendix P: Cost Analysis Tasks and LCC Estimation Process}

As listed in the AoA Handbook, ${ }^{2}$ the following tasks should be completed when performing a cost analysis: ${ }^{2}$

- Develop appropriate cost ground rules and assumptions and ensure they are consistent with effectiveness ground rules and assumptions

- Develop the Work Breakdown Structure (WBS) to be used in the cost analysis; the WBS is a hierarchical organization of the items to be costed

- Determine suitability and availability of cost models and data required

- Define the logistics elements necessary for the cost analysis

- Prepare LCC estimates for the baseline system and each alternative

- Document the cost analysis so that a qualified cost analyst can reconstruct the estimate using only the documentation and references provided in the Final Report

- Review the estimates to ensure the methodology and the ground rules and assumptions are consistent and the LCC estimate is complete

- Bound LCC point estimates with uncertainty ranges

- Include programmatic data in the LCC analyses, such as quantities and delivery schedules (when known)

- Identify cost drivers (those elements to which LCC is most sensitive) and perform sensitivity analyses on significant cost drivers

- Provide funding and affordability constraints and specify schedule limitations

- Provide necessary cost data to implement Cost as an Independent Variable (CAIV) strategy to arrive at an affordable balance among cost, performance, and schedule

- Present all costs in base year dollars (BY\$) - normally the year in which the decision will be made - and also in Then Year Dollars (TY\$) if a production schedule is known

- Identify the appropriate inflation indices used (the most current OSD indices are published on the SAF/FMC web page)

- Separately identify sunk costs for each alternative

Table 28 describes each step of the High-Quality Cost Estimating Process ${ }^{19}$ as seen in the GOA Cost Estimating and Assessment Guide: 
Table 28. The Twelve Steps of a High-Quality Cost Estimating Process ${ }^{24}$

\begin{tabular}{|c|c|c|}
\hline Step & Description & Associated task \\
\hline 1 & $\begin{array}{l}\text { Define estimate's } \\
\text { purpose }\end{array}$ & $\begin{array}{l}\text { - Determine estimate's purpose, required level of detail, and } \\
\text { overall scope; } \\
\text { - Determine who will receive the estimate }\end{array}$ \\
\hline 2 & $\begin{array}{l}\text { Develop } \\
\text { estimating plan }\end{array}$ & $\begin{array}{l}\text { - Determine the cost estimating team and develop its master } \\
\text { schedule; } \\
\text { - Determine who will do the independent cost estimate; } \\
\text { - Outline the cost estimating approach; } \\
\text { - Develop the estimate timeline }\end{array}$ \\
\hline 3 & $\begin{array}{l}\text { Define program } \\
\text { characteristics }\end{array}$ & $\begin{array}{l}\text { - In a technical baseline description document, identify } \\
\text { the program's purpose and its system and performance } \\
\text { characteristics and all system configurations; } \\
\text { - Any technology implications; } \\
\text { - Its program acquisition schedule and acquisition strategy; } \\
\text { - Its relationship to other existing systems, including predecessor } \\
\text { or similar legacy systems; } \\
\text { - Support (manpower, training, etc.) and security needs and risk } \\
\text { items; } \\
\text { - System quantities for development, test, and production; } \\
\text { - Deployment and maintenance plans }\end{array}$ \\
\hline 4 & $\begin{array}{l}\text { Determine } \\
\text { estimating } \\
\text { structure }\end{array}$ & $\begin{array}{l}\text { - Define a work breakdown structure (WBS) and describe each } \\
\text { element in a WBS dictionary (a major automated information } \\
\text { system may have only a cost element structure); } \\
\text { - Choose the best estimating method for each WBS element; } \\
\text { - Identify potential cross-checks for likely cost and schedule } \\
\text { drivers; } \\
\text { - Develop a cost estimating checklist }\end{array}$ \\
\hline 5 & $\begin{array}{l}\text { Identify ground } \\
\text { rules and } \\
\text { assumptions }\end{array}$ & $\begin{array}{l}\text { - Clearly define what the estimate includes and excludes; } \\
\text { - Identify global and program-specific assumptions, such as } \\
\text { the estimate's base year, including time-phasing and life cycle; } \\
\text { - Identify program schedule information by phase and program } \\
\text { acquisition strategy; } \\
\text { - Identify any schedule or budget constraints, inflation } \\
\text { assumptions, and travel costs; } \\
\text { - Specify equipment the government is to furnish as well as the } \\
\text { use of existing facilities or new modification or development; } \\
\text { - Identify prime contractor and major subcontractors; } \\
\text { - Determine technology refresh cycles, technology assumptions, } \\
\text { and new technology to be developed; } \\
\text { - Define commonality with legacy systems and assumed heritage } \\
\text { - savings; }\end{array}$ \\
\hline
\end{tabular}




\begin{tabular}{|c|c|c|}
\hline Step & Description & Associated task \\
\hline 6 & Obtain data & $\begin{array}{l}\text { - Create a data collection plan with emphasis on collecting current } \\
\text { and relevant technical, programmatic, cost, and risk data; } \\
\text { - Investigate possible data sources; } \\
\text { - Collect data and normalize them for cost accounting, inflation, } \\
\text { learning, and quantity adjustments; } \\
\text { - Analyze the data for cost drivers, trends, and outliers and } \\
\text { compare results against rules of thumb and standard factors } \\
\text { derived from historical data; } \\
\text { - Interview data sources and document all pertinent information, } \\
\text { including an assessment of data reliability and accuracy; } \\
\text { - Store data for future estimates }\end{array}$ \\
\hline 7 & $\begin{array}{l}\text { Develop point } \\
\text { estimate and } \\
\text { compare it to an } \\
\text { independent cost } \\
\text { estimate }\end{array}$ & $\begin{array}{l}\text { - Develop the cost model, estimating each WBS element, using } \\
\text { the best methodology from the data collected, }{ }^{a} \text { and including al } \\
\text { estimating assumptions; } \\
\text { - Express costs in constant year dollars; } \\
\text { - Time-phase the results by spreading costs in the years they are } \\
\text { expected to occur, based on the program schedule; } \\
\text { - Sum the WBS elements to develop the overall point estimate; } \\
\text { - Validate the estimate by looking for errors like double counting } \\
\text { and omitted costs; } \\
\text { - Compare estimate against the independent cost estimate and } \\
\text { examine where and why there are differences; } \\
\text { - Perform cross-checks on cost drivers to see if results are similar; } \\
\text { - Update the model as more data become available or as changes } \\
\text { occur and compare results against previous estimates }\end{array}$ \\
\hline 8 & $\begin{array}{l}\text { Conduct sensitivity } \\
\text { analysis }\end{array}$ & $\begin{array}{l}\text { - Test the sensitivity of cost elements to changes in estimating } \\
\text { input values and key assumptions; } \\
\text { - Identify effects on the overall estimate of changing the program } \\
\text { schedule or quantities; } \\
\text { - Determine which assumptions are key cost drivers and which } \\
\text { cost elements are affected most by changes }\end{array}$ \\
\hline 9 & $\begin{array}{l}\text { Conduct risk } \\
\text { and uncertainty } \\
\text { analysis }\end{array}$ & $\begin{array}{l}\text { - Determine and discuss with technical experts the level of cost, } \\
\text { schedule, and technical risk associated with each WBS element; } \\
\text { - Analyze each risk for its severity and probability; } \\
\text { - Develop minimum, most likely, and maximum ranges for each } \\
\text { risk element; } \\
\text { - Determine type of risk distributions and reason for their use; } \\
\text { - Ensure that risks are correlated; } \\
\text { - Use an acceptable statistical analysis method (e.g., Monte Carlo } \\
\text { simulation) to develop a confidence interval around the point } \\
\text { estimate; } \\
\text { - Identify the confidence level of the point estimate; } \\
\text { - Identify the amount of contingency funding and add this to the } \\
\text { point estimate to determine the risk-adjusted cost estimate; } \\
\text { - Recommend that the project or program office develop a risk } \\
\text { management plan to track and mitigate risks }\end{array}$ \\
\hline
\end{tabular}




\begin{tabular}{|c|c|c|}
\hline Step & Description & Associated task \\
\hline 10 & $\begin{array}{l}\text { Document the } \\
\text { estimate }\end{array}$ & $\begin{array}{l}\text { - Document all steps used to develop the estimate so that a cost } \\
\text { analyst unfamiliar with the program can recreate it quickly and } \\
\text { produce the same result; } \\
\text { - Document the purpose of the estimate, the team that prepared } \\
\text { it, and who approved the estimate and on what date; } \\
\text { - Describe the program, its schedule, and the technical baseline } \\
\text { used to create the estimate; } \\
\text { - Present the program's time-phased life-cycle cost; } \\
\text { - Discuss all ground rules and assumptions; } \\
\text { - Include auditable and traceable data sources for each cost } \\
\text { element and document for all data sources how the data were } \\
\text { normalized; } \\
\text { - Describe in detail the estimating methodology and rationale } \\
\text { used to derive each WBS element's cost (prefer more detail over } \\
\text { less); } \\
\text { - Describe the results of the risk, uncertainty, and sensitivity } \\
\text { analyses and whether any contingency funds were identified; } \\
\text { - Document how the estimate compares to the funding profile; } \\
\text { - Track how this estimate compares to any previous estimates }\end{array}$ \\
\hline 11 & $\begin{array}{l}\text { Present estimate to } \\
\text { management for } \\
\text { approval }\end{array}$ & $\begin{array}{l}\text { - Develop a briefing that presents the documented life-cycle cost } \\
\text { estimate; } \\
\text { - Include an explanation of the technical and programmatic } \\
\text { baseline and any uncertainties; } \\
\text { - Compare the estimate to an independent cost estimate (ICE) and } \\
\text { explain any differences; } \\
\text { - Compare the estimate (life-cycle cost estimate (LCCE)) or } \\
\text { independent cost estimate to the budget with enough detail } \\
\text { to easily defend it by showing how it is accurate, complete, and } \\
\text { high in quality; } \\
\text { - Focus in a logical manner on the largest cost elements and cost } \\
\text { drivers; } \\
\text { - Make the content clear and complete so that those who are } \\
\text { unfamiliar with it can easily comprehend the competence that } \\
\text { underlies the estimate results; } \\
\text { - Make backup slides available for more probing questions; } \\
\text { - Act on and document feedback from management; } \\
\text { - Request acceptance of the estimate }\end{array}$ \\
\hline 12 & $\begin{array}{l}\text { Update the } \\
\text { estimate to reflect } \\
\text { actual costs and } \\
\text { changes }\end{array}$ & $\begin{array}{l}\text { - Update the estimate to reflect changes in technical or program } \\
\text { assumptions or keep it current as the program passes through } \\
\text { new phases or milestones; } \\
\text { - Replace estimates with EVM EAC and independent estimate at } \\
\text { completion (EAC) from the integrated EVM system; } \\
\text { - Report progress on meeting cost and schedule estimates; } \\
\text { - Perform a post mortem and document lessons learned for } \\
\text { elements whose actual costs or schedules differ from the } \\
\text { estimate; } \\
\text { - Document all changes to the program and how they affect the } \\
\text { cost estimate }\end{array}$ \\
\hline
\end{tabular}




\section{Appendix Q: FMECA Methodology}

The following are steps to conduct FMECA as seen in Systems Engineering and Analysis ${ }^{6}$ :

\section{$\underline{\text { Step 1: Define system (product or process) requirements }}{ }^{6}$}

Describe the system in question, the expected outcomes, and the relevant technical performance measures (TPMs).

\section{Step 2: Accomplish functional analysis ${ }^{6}$}

This involves defining the system in functional terms. A system may be broken down into functional entities early in the life cycle and subsequently into a physical packaging scheme.

Step 3: Accomplish requirements allocation ${ }^{6}$

This is a top-down breakdown of system-level requirements.

Step 4: Identify failure modes ${ }^{6}$

A "failure mode" is the manner in which a system element fails to accomplish its function. For example, a switch may fail in an "open" position; a pipe may "rupture"; a given material may "shear" because of stress; a document may fail to be delivered on time; and so on.

\section{Step 5: Determine causes of failure ${ }^{6}$}

This involves analyzing the process or product to determine the actual cause(s) responsible for the occurrence of failure. Typical causes might include abnormal equipment stresses during operation, aging and wearout, a software coding error, poor workmanship, defective materials, damage because of transportation and handling, or operator- and maintenance-induced faults. Although experience with similar systems, or the availability of good data from the field, is preferred, using an Ishikawa "cause-andeffect" diagram can prove to be highly effective in delineating potential failure causes.

Step 6: Determine the effects of failure

Failure impact, often in multiple ways, the performance and effectiveness of not only the associated functional element but the overall system. It is important to consider the effects of failure on other elements at the same level in the system hierarchical structure, at the next higher level, and on the overall system.

\section{Step 7: Identify failure detection means ${ }^{6}$}

For a process-oriented FMECA, this refers to the current process controls which may detect the occurrence of failures or defects. However, when the FMECA has a design focus, this refers to the existence of any design features, aids, gauges, readout devices, condition monitoring provisions, or evaluation procedures that will result in the detection of potential failures. 
Step 8: Rate failure mode severity ${ }^{6}$

This refers to the seriousness of the effect or impact of a particular failure. If a failure occurs, will this cause the death of the operator and the system to be destroyed, or will it cause only slight degradation in performance? For the purpose of illustration, the degree of severity may be expressed quantitatively on a scale of 1 to 10 with minor effects being 1 , low being 2 to 3 , moderate being 4 to 6 , high being 7 to 8 , and very high being 9 and 10 .

Step 9: Rate failure mode frequency ${ }^{6}$

Given that a function or physical component within the system may fail in a variety of ways, this step addresses the frequency of occurrence of each individual failure mode. The sum of all modal failure frequencies for a system element must equal its failure rate. For the purposes of quantification, the same type of scale as Step 8 can be used.

$\underline{\text { Step 10: Rate failure mode detection probability }}{ }^{6}$

This pertains to the probability that process controls, design feature/aids, verification procedures, and so on, will detect potential failures in time to prevent a major system catastrophe. For the purposes of quantification, the same type of scale as Step 8 can be used.

Step 11: Analyze failure mode criticality ${ }^{6}$

The objective is to consolidate the preceding information in an effort to delineate the more critical aspects of a system design. Criticality, in this context, is a function of severity, frequency, and probability of detection, and may be expressed in terms of a risk priority number (RPN).

$(\mathrm{RPN})=($ severity rating $)($ frequency rating $)($ probability of detection rating $)$

The RPN reflects failure mode criticality. On inspection, one can see that a failure mode that has a high frequency of occurrence, has significant impact on system performance, and is difficult to detect is likely to have a very high RPN.

$\underline{\text { Step 12: Initiate recommendations for product/process improvement }}{ }^{6}$

This pertains to the iterative process of identifying areas with high RPNs and evaluating the causes, and the subsequent initiation of recommendations for product/process improvement. A Pareto analysis can be accomplished to make visible the high-priority items that need to be addressed. 


\section{Appendix R: AoA Report Template}

the AoA. ${ }^{2}$

This appendix contains the AoA Study Plan and Final Report template required for

Refer to these sources for more information:

1. Department of Defense Directive (DODD) 5230.24, - Distribution Statements on Technical Documents\|

2. Air Force Pamphlet (AFP) 80-30, -Marking Documents with Export-Control and Distribution-Limitation Statements\| (to be reissued as Air Force Instruction (AFI) 61-204) Ask your Scientific \& Technical Information (STINFO) Officer for help in choosing which of the available statements best fits your AoA REMEMBER -- AoA information may be PROPRIETARY, SOURCE SELECTION SENSITIVE, OR CLASSIFIED

Executive Summary

$<$ Name of Project Here $>$

Analysis of Alternatives (AoA)

Study Plan/Final Report

$<$ Lead MAJCOM $>$

$<$ Date $>$

1. Introduction

1.1. Background

1.2. Purpose

1.3. Scope

\section{Acquisition Issues}

2.1. Capability Gaps

2.2. Scenarios

2.3. Threats

2.4. Environment

2.5. Constraints and Assumptions

\section{Alternatives}

\section{Table of Contents}

3.1. Description of Alternatives

3.2. Nonviable Alternatives

3.3. Operations Concepts

4. Determination of Effectiveness Measures

4.1. Mission Tasks

4.2. Measures of Effectiveness

4.3. Measures of Performance

5. Effectiveness Analysis

5.1. Effectiveness Methodology

5.2. Analysis Tools, and Data

5.3. Effectiveness Sensitivity Analysis 
5.4. Effectiveness Results

6. Cost Analysis

6.1. Life Cycle Cost Methodology

6.2. Cost Tools and Data

6.3. Cost Risk Methodology

6.4. Life Cycle Cost Results

7. Risk Assessment

7.1. Risk Assessment Methodology

7.2. Risk Assessment Tools

7.3. Risk Analysis Results

8. Alternative Comparisons

8.1. Alternative Comparison Methodology and Presentations

8.2. Criteria for Final Screening of Alternatives

8.3. Alternative Comparison Results

8.4. AoA Conclusions and Recommendations

9. Organization and Management

9.1. Study Team/Organization

9.2. AoA Review Process

9.3. Schedule

Appendices

A. Acronyms

B. References

C. Lessons Learned

D. Technical Description Document

E. Accreditation Plan/Final Report

F. Other appendices as necessary

Note: Additional sections highlighted/underlined in red above to be added to the Final Report (Executive Summary, 5.4, 6.4, 7.3, 8.3, 8.4).

Executive Summary

- Describe the purpose of the study

- Identify key organizations associated with the study

- Summarize the results of the study

\section{Introduction}

\subsection{Background}

- Describe the history of developments that provide the necessity for the AoA

- Summarize relevant analyses that precede this study

- Paraphrase, quote, and refer to Initial Capabilities Document (ICD), Acquisition Decision Memorandum (ADM), and Program Management Directive (PMD) that required the AoA

- Identifies intended results in general terms

- Identifies any applicable Joint Concept Technology Demonstrations (JCTDs) or Advanced Concept Technology Demonstrations (ACTDs) 


\subsection{Purpose}

- Identifies major acquisition issues to be studied

1.3. Scope

- Identifies the Milestone to be supported

- Identifies the level (engineering, one-on-one, few-on-few, mission, or campaign)

and scope of the analysis planned

- Identifies the - tailoring and - streamlining used to focus the study

- Describe broadly the nature of possible alternative solutions to be considered

\section{Acquisition Issues}

\subsection{Capability Gaps}

- Describe deficiency in system capabilities and refer to ICD or CDD as appropriate

- Identify the timeframe for the mission need

- Describe any applicable ACTDs

\subsection{Scenarios}

- Describe scenarios and rationale for selection

- Discuss how alternatives are evaluated and compared using scenarios

- Discuss how scenarios are traceable back to DPG/IPS (Defense Planning Guidance/

2.3. Threats Integrated Program Summary)

- Describe briefly enemy tactics (include potential countermeasures)

- Paraphrase, quote, and reference the System Threat Assessment Report (STAR) or System

- Threat Assessment (STA), if it exists

- Identifies other sources of projections

- Plan to approve or validate the threat through the Defense Intelligence Agency (DIA)

- Identifies areas of uncertainty, if possible

\subsection{Environment}

- Describe expected operating environment, including terrain, weather, location, and altitude

- Paraphrase, quote, and reference applicable sections in the ICD, CDD or AoA guidance documentation

- Consider the environmental impacts of alternative solutions with the environment

\subsection{Constraints \& Assumptions for the AoA}

- Describe AoA constraints and assumptions, including Initial Operating Capability, Full Operating Capability, and Life Cycle Cost

- Describe the implications of the constraints and assumptions

- Reference applicable sections in the ICD, CDD or AoA guidance

- Identifies the AoA resources available (people, funds and time) and how they affect

\section{Alternatives} the scope of the AoA

\subsection{Description of Alternatives}

- Identify the baseline case (this is usually the system in use today)

- Categorize alternatives based on technology, delivery platform, kill mechanism, etc., if productive

- Summarize each alternative 
- Use figures to show system functions or interfaces

- Discuss operational concepts variations for individual alternatives

- Describe how alternatives perform their function

- Describe the steps taken to ensure an adequate range of alternatives

- Consider whether the alternative systems are reasonable and feasible

- Discuss the availability of the alternatives within the assumed timeframe

- Describe the economic operating life of each alternative, both expected and required

\subsection{Nonviable Alternatives}

- Delineate major alternatives that were not included in this analysis

- Describe the rationale for non-selection

- If nonviable alternatives have not yet been identified state so

\subsection{Operations Concepts}

- Identify organizational functions and operations performed during mission

- Reference applicable sections in ICD or CDD

- Describe how maintenance will be accomplished

- Discuss specific tactics and doctrine used

- Discuss deployment issues

- Discuss interfaces with other systems

- Address needs for inter-operation of the services

- Identifies - day-to-dayll and - contingencyll operation implications

- Consider any recent field or test experiences that might be relevant

- Describe how the Concepts of Operations and Concepts of Employment fit each alternative

\section{Determination of Effectiveness Measures}

\subsection{Mission Tasks (MTs)}

- Identifies what task or tasks need to be achieved to satisfy the ICD

- Endeavor to keep MTs independent of one another

- Try to avoid MTs that use words such as "minimize", "maximize", and "optimize"

\subsection{Measures of Effectiveness (MoEs)}

- Derives MoEs from MTs

- Make military worth a prime consideration in the selection of MoEs

- Strive to form MoEs that measure and compare the most meaningful quantities that affect performance of MTs

- Support each MT with at least one MoE

- Consider that a MoE may support more than one MT, and may even support other MoEs

- Form "unbiased" MoEs that are comparable across all alternatives

- Give preference to quantitative versus qualitative MoEs

\subsection{Measures of Performance (MoPs)}

- Derives MoPs from MoEs

- Support each MoE with at least one MoP

- Consider that a MoP may support more than one MoE, and may even support other MoPs

- Make sure MoPs are — knowable\|l either analytically or through testing

- Defines MoPs by system performance characteristics, if possible

\section{Effectiveness Analysis}




\subsection{Methodology}

- Outline the approach and scope of the analysis, including the proper level of modeling military operations (e.g. campaign, mission, engineering, etc.)

- Plan to carry the baseline alternative through the final effectiveness analysis

- Plan to use MT and, as appropriate, MoE values in the cost-effectiveness analysis

- Consider the influence of threshold performance criteria, if any, in the methodology

- Describe the methodology, including models and simulations to be used

- Assign organizational responsibility for each step

- Describe the mechanisms to be used to obtain the buy-in to the methodology by the appropriate communities

- Plan to perform sensitivity tradeoff analysis, as appropriate

- Discuss how measures used in the AoA are measurable (or testable) and will

support the development of the post-AoA documents (e.g., CDD, CPD, TES, TEMP)

- Add details as the plan matures

\subsection{Effectiveness Analysis Tool Selection and Data}

- Describe briefly the analysis tools and processes that are planned, and the reasons for selection, the input data to be used, and the corresponding sources of the input data

- Give evidence that data for the scenarios, threats, and each of the alternatives will be current, accurate, and unbiased (technically sound and doctrinally correct)

- Describe how models interface and how they are used to calculate MoEs and MoPs (use figures for clarity)

- If $M \& S$ are to be used:

- Discuss who will be running the models

- Discuss any potential model biases, such as -man-in-the-loop\| biases

- Describe the planned Accreditation process to be used for the models

\subsection{Effectiveness Sensitivity Analysis}

- Discuss planned methodologies

\subsection{Effectiveness Results}

- Describe the results of the effectiveness analysis

\section{Cost Analysis}

\subsection{Life Cycle Cost Estimating Methodology}

- Outline the approach and scope of the analysis

- Plan to carry the baseline alternative through the final cost analysis

- Consider the influence of threshold performance criteria, if any, in the methodology

- Use the same operational concepts for cost and effectiveness analyses

- Describe the methodology, including the models used

- Assign organizational responsibility for each step

- Describe the mechanisms to be used to obtain the buy-in to the methodology by the appropriate communities

- Plan to perform risk and sensitivity tradeoff analysis, as appropriate

- Identifies the economic operating life of the alternatives (i.e., $10 \mathrm{yr}$., $20 \mathrm{yr}$., $25 \mathrm{yr}$. sustained Operations and Support cost)

- Discuss the methodology for costing Research, Development, Testing, and Evaluation 
(RDT\&E), Investment, Operations and Support (O\&S), Disposal, and Total LCC for each alternative

- Identifies - sunk costs\| for information purposes only

- Discuss the application of Cost as an Independent Variable to LCC

- Add details as the plan matures

\subsection{Cost Analysis Tools and Data}

- Describe briefly the models used, their reason for selection, the input data to be used, and the corresponding sources of the input data

- Discuss any potential model shortfalls

- Request sufficiency review from AFCAA

\subsection{Cost Risk Sensitivity Analysis}

- Plan to identify cost drivers (usually not the most expensive items - see handbook)

- Describe the methodology for determining the level of uncertainty for each element of LCC, as applicable

6.4. Life Cycle Cost Results

- Describe the results of the cost analysis

\section{Risk Assessment}

\subsection{Methodology}

- Describe the planned methodology for conducting risk analysis and who will be responsible for conducting the analysis

\subsection{Risk Assessment Tools}

- Discuss risk assessment tools or models which may be used in the analysis

\subsection{Risk Analysis Results}

- Describe the results of the Risk analysis

\section{Alternative Comparisons}

\subsection{Methodology}

- Outline the approach and scope of the analysis, including the proper level of analyzing military operations (e.g., campaign, mission, engineering, etc.)

- Consider cost, effectiveness and risk as equal players in the analysis

- Plan to carry the baseline alternative through to the final analysis

- Plan to combine the cost, effectiveness and risk analyses

- Describe the comparison rank ordering methodology

- Describe the methodology, including the analysis tools used

- Assign which organization is responsible for each step

- Describe the mechanisms to be used to obtain the buy-in to the methodology by the appropriate communities

- Plan to perform sensitivity tradeoff analysis, as appropriate

- Plan to use figures and graphics for clarity

\subsection{Alternative Comparison Presentation Methodology}

\subsubsection{Ranking and Decision Criteria}

- Discuss criteria for selecting among alternatives

- Describe possible cost and performance thresholds

\subsection{Alternative Comparison Results}

- Compare the alternatives using effectiveness, cost and risk

\subsection{AoA Conclusions and Recommendations}

- Provide conclusions and recommendations based on the analysis

\section{Organizational Responsibilities}




\subsection{Study Team/Organization}

- Identify who is doing what

- Include a phone number list for all organization points-of-contact

- Study Advisory Group (SAG) (if used)

- Technical Review Group (if used)

9.2. AoA Review Process

- Describe the review process for this particular AoA (use pictorial if appropriate)

- Working Level Integrated Product Team

- Overarching Integrated Process Team

- Milestone Decision Authority

\subsection{Schedule}

- Study Plan Preparation 1-4 Months

- Oversight: Review of Study Plan 1-2 Months

- Analysis 3-5 Months

- Oversight: Mid-term Review of Results 1-2 Months

- Any Further Analysis 3-5 Months

- Evaluate Results 1-2 Months

- Study Report Preparation 1-2 Months

- Oversight: Review of Study Report 1-2 Months

- Total 13-24 Months

\section{Appendices}

Appendix A: Acronyms

Appendix B: References

Appendix C: Lessons Learned

Appendix D: Technical Description Document (TDD)

Appendix E: Accreditation Plan/Final Report

Appendix F: Other Appendices as Necessary 